III) Nordic Council of Ministers
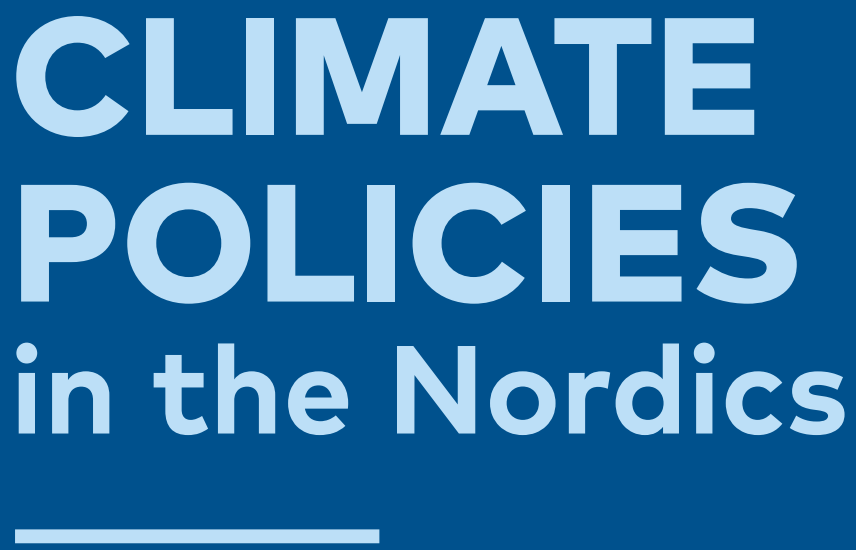

Nordic Economic Policy Review 2019 


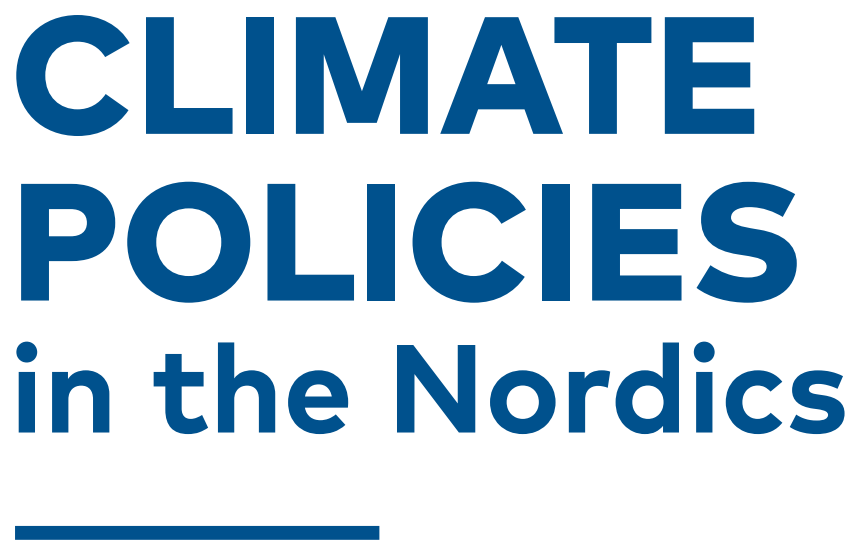

\section{Nordic Economic Policy Review 2019}


Climate Policies in the Nordics

- Nordic Economic Policy Review 2019

Lars Calmfors, John Hassler, Naghmeh Nasiritousi, Karin Bäckstrand, Frederik Silbye, Peter Birch Sørensen, Björn Carlén, Bengt Kriström,

Mads Greaker, Rolf Golombek, Michael Hoel, Katinka Holtsmark

Nord 2019:012

ISBN 978-92-893-6088-3 (PRINT)

ISBN 978-92-893-6089-0 (PDF)

ISBN 978-92-893-6090-6 (EPUB)

ISSN 1904-4526 (PRINT)

ISSN 1904-8092 (PDF)

http://dx.doi.org/10.6027/Nord2019-012

() Nordic Council of Ministers 2019

Layout: Louise Jeppesen, Gitte Wejnold

Print: Rosendahls

Printed in Denmark

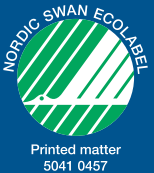

\section{Nordic co-operation}

Nordic co-operation is one of the world's most extensive forms of regional collaboration, involving Denmark, Finland, Iceland, Norway, Sweden, the Faroe Islands, Greenland, and Åland.

Nordic co-operation has firm traditions in politics, the economy, and culture. It plays an important role in European and international collaboration, and aims at creating a strong Nordic community in a strong Europe.

Nordic co-operation seeks to safeguard Nordic and regional interests and principles in the global community. Shared Nordic values help the region solidify its position as one of the world's most innovative and competitive.

Nordic Council of Ministers

Nordens Hus

Ved Stranden 18

DK-1061 Copenhagen

www.norden.org

Download Nordic publications from www.norden.org/nordpub 


\section{Contents}

Climate Policies in the Nordics

Lars Calmfors and John Hassler

International Climate Policy in the Post-Paris Era

Naghmeh Nasiritousi and Karin Bäckstrand

Comment by Torben Mideksa

Comment by Åsa Romson

National Climate Policies and the European Emissions Trading System

Frederik Silbye and Peter Birch Sørensen

Comment by Svante Mandell

Comment by Saara Tamminen

Are Climate Policies in the Nordic Countries Cost-Effective?

Björn Carlén and Bengt Kriström

Comment by Peter K. Kruse-Andersen

Comment by Åsa Löfgren

Global Impact of National Climate Policy in the Nordic Countries

Mads Greaker, Rolf Golombek and Michael Hoel

Comment by Mark Sanctuary

Supply-Side Climate Policy in Norway

Katinka Holtsmark

Comment by Thorvaldur Gylfason

Comment by Klaus Mohn 


\section{Climate Policies in the Nordics}

\section{Lars Calmfors ${ }^{1}$}

John Hassler ${ }^{2}$

${ }^{1}$ Research Institute of Industrial Economics and Institute for International Economics, Stockholm University. Email: lars.calmfors@iies.su.se.

${ }^{2}$ Institute for International Economics, Stockholm University and Department of

Economics, University of Gothenburg. Email: john.hassler@iies.su.se. 


\section{Introduction}

Climate change has become a key concern for policy makers, business leaders and individuals all over the world. There exists a broad scientific consensus that the emissions of greenhouse gases, mainly carbon dioxide $\left(\mathrm{CO}_{2}\right)$, is responsible for global warming that, if not halted, could have unacceptable consequences, including catastrophic ones, in at least parts of the world.

When carbon dioxide is emitted to the atmosphere, it mixes quickly and affects the global energy balance - the difference between the energy flowing in to earth in the form of sunlight and the outflow largely in the form of lower frequency heat radiation. This balance is affected since $\mathrm{CO}_{2}$ and other greenhouse gases easier let the sunlight (the inflow) pass than low-frequency heat radiation (the outflow).

The main argument used by economists to motivate policy intervention against climate change is that emissions of greenhouse gases that drive global warming are an externality. The benefits of using fossil fuel accrue to the user, whereas the largely negative side effects are born by individuals spread over the globe and over very long time horizons. Since the externality extends across borders, a global collective-action problem arises with incentives for individual countries to free-ride on the climate policies by others.

The effect on the global energy balance of higher $\mathrm{CO}_{2}$ atmospheric concentration and the resulting global warming was quantified more than a century ago (Arrhenius 1896). The policy prescription, to tax the emitter to an amount that makes her internalize the costs imposed on others, has been known almost as long (since Pigou 1920). Nevertheless, dealing with climate change has been called the largest challenge to our policy makers. There are a number of reasons for this. First, the natural system that produces climate change is extremely complicated and diverse. Therefore, we do not know with certainty by how much human emissions will affect the climate. Second, although it is often represented by just a single number, the increase in the global mean atmospheric temperature, climate change is immensely multifaceted across the globe. Third, the consequences for human welfare of changes in the climate are very difficult to estimate. This is due to the diversity of climate change 
as well as to the fact that we need to judge its consequences over hundreds of years. The calculation of the cost of a unit of emissions requires aggregation across space and time of all possible damages. This cannot be done without taking a normative position on the relative value of damages to individuals living in different countries and time periods. Therefore, it is difficult to agree on a single number for the externality and thus the tax that emitters should bear.

Within states, institutions that can deal with coordination problems arising from externalities have been established. But climate change has no national borders. Therefore, international cooperation is required to negotiate climate polices. It goes without saying that this is extremely complicated in a world consisting today (March 2019) of 195 sovereign countries with different political systems, at different stages of economic development, which have different impacts on global warming and which are differently impacted by it.

International coordination is also key since measures against climate change in one country are likely to affect emissions in other countries through several mechanisms. If one country reduces the use of, for example, oil, the world market price falls. This raises oil consumption elsewhere. Similarly, an oil-and-gas-producing country like Norway can reduce its supply to the world market, but this raises the price of fossil fuel and thus creates an incentive for other producers to increase their supply. The spillovers also work through politically constructed mechanisms like the EU Emissions Trading System where emission rights are traded across the borders of the member states. Moreover, technological developments in energy production in one country will be diffused to others and this way affect emissions there. Finally, the mere observation that a country chooses an ambitious climate policy may affect political processes in other countries through a demonstration and policy diffusion effect.

Since there is no world government, climate policy must be determined by national governments who may feel more or less committed to international agreements. These may be global like the Kyoto Protocol from 1997 and the Paris Agreement from 2015 or regional as the EU's climate and energy policies. To devise policies that really affect the global climate at a reasonable level of cost effectiveness, policy makers must understand the spillovers discussed above. These 
issues, seen from a Nordic perspective, form the theme of this volume. It addresses a number of pertinent questions:

- What are the prospects for effective global coordination of national climate policies?

- How does the EU Emissions Trading System affect the effectiveness of different national polices?

- How cost-effective are climate policies in the Nordic countries?

- Is it futile to hope that small countries like the Nordic ones can affect the global climate?

- Is the current Norwegian policy of exporting oil and gas, while at the same time subsidizing domestic reductions of fossil fuel use, a cost-effective climate policy?

\section{The articles in the volume}

The volume contains five papers with associated comments which were originally presented at a conference in Stockholm on 24 October 2018.

\subsection{International climate politics in the post-Paris era}

Naghmeh Nasiritousi and Karin Bäckstrand assess how the Paris Agreement has changed global climate policy coordination and to what extent this is for the better. They discuss why it is so difficult to reach binding international agreements on emission reductions. It is stressed that this is a particularly difficult collective-action problem because of the large number of heterogeneous actors involved and conflicts about what constitutes fair burden-sharing between economically more developed countries (which have in the past been responsible for large emissions of greenhouse gases) and developing countries (which may find it natural and right to follow the economic development paths of the advanced countries). The authors also provide a history of international climate policy coordination from the 1992 Rio conference, via the 2009 Copenhagen summit to the 2015 Paris Agreement.

Nasiritousi and Bäckstrand argue that the Paris Agreement and the rulebook adopted in Katowice in December 2018 are gamechangers, as they provide a framework for scaling up state, sub-state and non-state commitments over time. A key difference between 
the Paris Agreement and the previous Kyoto Protocol is the focus on voluntary national commitments. In the words of the authors, 'the Paris Agreement marks a shift in global climate policy from a topdown, centralized legally binding response of target and timetables of greenhouse gas emissions to a bottom-up decentralized and voluntary pledge and review system of reduction targets by states'. On the one hand, this set-up has the advantage that the barriers for participation become much lower. On the other hand, the voluntary commitments are far from sufficient for meeting the Paris Agreement's temperature goal of $2^{\circ} \mathrm{C}$ and even less so for the $1.5^{\circ} \mathrm{C}$ goal.

The biggest challenge for the Paris Agreement is how to ratchet up ambitious climate action. Here, Naisritousi and Bäckstrand offer a mixed judgement on the prospects for the Paris Agreement to deliver on its goals. They emphasize how the agreement allocates an increasingly important role to non-state actors such as business, regions, cities and civil society. For example, the observer groups present at the annual COPs (Conferences of Parties under the United Nations Framework Convention on Climate Change) are now invited to play a larger role in accelerating global climate action. According to the authors, the Paris Agreement provides a framework through which non-state actors can mobilize voluntary action and increase political pressure on states (naming and shaming) to gradually raise their climate policy ambitions.

At the same time, Nasiritousi and Bäckstrand recognize that the Paris Agreement needs to be complemented with many other initiatives. A rapid decarbonization of the global economy requires both technological and socio-political innovations. One promising proposal discussed is the creation of climate clubs. An initially small group of like-minded enthusiastic countries may commit to ambitious climate policies. Within the club, a range of economic instruments, including but not necessarily limited to emissions trading systems or common emission taxes, can ensure efficient mitigation efforts. The club could also devise benefits which accrue only to members and which could therefore entice other countries to join. One such incentive might be a carbon border adjustment tax that applies to non-members. Possibly, such carbon club characteristics could be introduced in the climate policy of the EU. The authors argue that the Nordic countries, with their ambitious climate policy objectives, might have an important role to play in such a context. 


\subsection{National climate policies and the European Emissions Trading System}

Frederik Silbye and Peter Birch Sørensen analyze the EU Emissions Trading System (EU ETS). This arrangement requires large emitters in the EU - energy-intensive industries and energy producers - to surrender an emission right (allowance) for each ton of $\mathrm{CO}_{2}$ emitted. The system covers around half of all emissions within the EU. Since 2008, emission rights can be saved for later use and a large stock of such saved emission rights has been built up. The stock is at a level roughly corresponding to one year of emissions in the system. The build-up of an allowance surplus took place at the same time as the price of allowances fell to very low levels, almost certainly below the social cost of emissions.

As a response to the large allowance surplus and the low and volatile allowance price, the EU ETS was reformed in 2018. A Market Stability Reserve to absorb part of the allowance surplus was established. A key feature of the reformed system is that the yearly supply of emission allowances, some of which are allocated freely and some auctioned, will depend on the size of the stock of previously issued, but not used, allowances. The mechanism is that a fraction of the total allowance surplus in the market will be withheld from the yearly auctions and transferred to the Market Stability Reserve if the surplus exceeds a certain level (corresponding to about half the current surplus). From 2023 there will be a cap on the amount of allowances that can be held in the Market Stability Reserve. Allowances above the cap will be automatically and permanently annulled. Although this cap starts to bind first in the future, the reform immediately caused the price of emission allowances to rise substantially. The interpretation is that the market anticipated the reform to significantly increase the scarcity of emission rights in the future. The value of emission rights that can be saved for future use thus increased already today.

To model the current and future demand for emission rights, Silbye and Sørensen construct a model of emitter demand for allowances which they interact with the supply as dictated by both the old and the new rules for the EU ETS. The finding is that the change in rules will have large effects. The model predicts that accumulated

emissions over the coming four decades will be reduced by around 5000 Megaton $\mathrm{CO}_{2}$ due to the automatic annulment mechanism. 
This reduction is about a hundred times larger than the current yearly Swedish emissions.

Before the reform, the supply of emission rights was predetermined and independent of national policies. Then, if a national government would buy and annul emission rights (a reduction in their supply), the accumulated emissions in the system would be reduced one for one in the long run. On the other hand, national policies to reduce emissions within the ETS, for example through subsidies to renewable energy or a $\mathrm{CO}_{2}$ tax (a reduction in the demand for emission rights) would only lead to other emitters increasing their emissions one for one in the long term. The analysis by Silbye and Sørensen implies that the reform flips the effectiveness of these two national policies to reduce emissions within the ETS. National measures to reduce emissions will increase the stock of saved emission rights and this will trigger less issuance of new emission rights in the future. Such policies will therefore be effective. By contrast, buying and immediately annulling emission rights at the national level will be largely offset by fewer annulments of allowances held in the Market Stability Reserve, as the initial drop in the allowance surplus will cause fewer transfers of allowances to it. ${ }^{3}$ The consequence is a larger issuance of rights in the future, making the national policy ineffective.

Finally, the authors propose further reforms of the EU ETS. Specifically, they propose that the effectiveness of the system could be taken one step further by including explicit floor and ceiling prices when emission allowances are auctioned. Such a system would have similar beneficial effects as the recently introduced annulment mechanism but be much simpler and transparent.

\subsection{Are climate policies in the Nordic countries cost-effective?}

Björn Carlén and Bengt Kriström demonstrate that in a stylized model, without any other externalities than from emissions, a costeffective climate policy requires that the marginal cost of abatement is the same for all emitters. The logic is straightforward: if two emitters have different marginal abatement costs, abatement

\footnotetext{
${ }^{3}$ Buying and hoarding emission allowances for a long time before annulling them could reduce emissions. The effectiveness of such a policy depends on how the demand for emission allowances evolves in the long run and whether further EU ETS reforms are undertaken.
} 
efforts should be reallocated towards the one with a lower marginal cost. The cost reductions of the agent with a higher marginal cost are then larger than the cost increases of the other agent. Thus total abatement costs fall.

The authors discuss a number of complications that could potentially overturn the result that marginal abatement costs should be equalized. Among them are distributional issues, carbon leakage and technology spillovers. However, the conclusion is that in the Nordic case, these complications are unlikely to lead to another result than that marginal costs should be equalized.

Carlén and Kriström document the extent to which abatement costs are different across emitters. In particular, they argue that overlapping polices - for example various investment support schemes like the Swedish program Klimatklivet (a support scheme for investments deemed to reduce greenhouse gas emissions) - cause large divergences in the marginal costs of mitigation faced by different emitters in the Nordics. When it comes to the transportation sector, the tax rates on emissions are relatively well harmonized within and between the Nordic countries. The tax rates are also close to the mean rates in the EU. However, the Nordic countries have employed a number of other instruments, e.g. $\mathrm{CO}_{2}$-differentiated vehicle taxation and programs supporting climate investments. These policies are far from uniform across the Nordic countries. Furthermore, the Nordic countries have more ambitious policies for emission reductions in the transportation sector than other EU countries. Therefore, taxes will need to become much higher than in the rest of the EU. In a benchmark calculation, fulfilling Swedish emission targets would require a tax per liter of gasoline that is 0.44 euros higher than the EU median in 2030.

A key point in the Carlén-Kriström paper concerns emission reductions in the non-ETS sector (the sector which is not part of the EU Emissions Trading System), which includes non-energy-intensive industries, households and services, and domestic transportation. For this sector, all the Nordic countries have very ambitious emission reduction obligations according to EU rules (the Effort Sharing Regulation). At the same time, there are significant marginal cost disparities in the non-ETS sectors between the Nordic 
countries and several (other) EU-countries. The authors argue that the existing flexibility mechanisms in the $\mathrm{EU}$ regulation should be used to arrange non-ETS trades between the Nordic countries and (other) EU countries. This would in effect imply intergovernmental emissions trading on behalf of the actors in the part of the economy not covered by the existing trading system. This can be highly cost-effective. For any given amount of resources expended, such trade will imply larger emission reductions than would otherwise be the case. Alternatively, any given reduction target can be reached at a lower cost. But it does require an acceptance of the idea that the priority is to reduce global emissions independently of where the emission reductions take place.

\subsection{Global impact of national climate policy in the Nordic countries}

Mads Greaker, Rolf Golombek and Michael Hoel analyze both the rationales for and the effectiveness of the more ambitious climate policies in the Nordics than elsewhere. The authors first document that the Nordic countries do more than what is implied by the necessary obligations according to international agreements and EU regulations when it comes to spending resources on climate policy. It is also shown that the Nordic climate polices are not well aligned.

A key question is why the small Nordic countries have chosen to pursue so ambitious climate policies even though their direct effects on global emissions are very modest and the indirect effects may be adverse as domestic emission reductions could weaken the incentives for others to act.

Golombek et al. provide a classification of possible rationales for the Nordic policies. The reasons are divided into two groups: those that rest on national self-interest only (but take account of the repercussions on other countries' behavior and how they in turn affect the welfare of the own citizens) and those that reflect concerns also for the welfare of the citizens of other countries. The first category includes strategic motives like promoting green business, developing new technology (which can also be used by others) and demonstrating that abatement costs may be lower than expected. The second category includes direct altruism as well as arguments based on moral obligations. 
The classification provides a basis for analyzing different elements of the Nordic climate policies. In particular, it is argued that promoting the development of clean technologies is likely to be the most effective way of reducing global emissions. Here, the authors stress that two ways forward are possible. The first is to focus on clean technologies that have a potential for cost reductions from learning by doing. The Nordic countries are, however, too small to be able to do this effectively in isolation. Instead, coordination within EU and with other large countries is required.

The other way is to focus on areas where Nordic countries have special expertise to make innovations that can have a global impact. An example of such an area could, according to the authors, be Danish wind power, perhaps in combination with Norwegian offshore technologies. Also, Nordic cooperation to promote the development of technologies for carbon capture and storage has a large unexploited potential and could become important on a global scale. However, there are also bad examples where Nordic governments have subsidized technological innovations in green technologies that have been kept secret and thus not possible to use in the rest of the world.

Golombek et al. also argue that the Nordic countries have too much of a country focus. Subsidizing technological developments that only serve as a means to achieve national emission targets seems to be a bad climate policy.

An important recommendation is that the Nordic countries should coordinate their climate policies better to achieve maximum global impact. Doing this is likely both to affect technological developments more and to enhance the demonstration effect of Nordic policies on other countries.

\subsection{Supply-side climate policies in Norway}

Norway has implemented an ambitious climate policy with fairly expensive measures to reduce emissions within its borders. At the same time, an important share of Norway's national income is derived from the sale of fossil fuel to other countries. Katinka Holtsmark discusses this apparent contradiction. She asks whether a policy shift from reductions in Norwegian demand for fossil fuels to reductions in the Norwegian supply of oil and gas would be desirable. 
The paper begins by noting that the effect of changes in supply and demand in one country on total world consumption depends on the sensitivity of world market demand and supply to price changes. Suppose Norway reduces its demand for fossil fuel by, for example, subsidizing electric cars. The reduced demand reduces the world market price of oil. If the global supply of oil is inelastic (that is it does not respond much to the price change) while demand is elastic, then Norwegian reduction of fossil fuel use leads to much increased consumption elsewhere in the world. If instead Norway reduces its supply, the world market price increases, but under the assumption of inelastic world market supply the latter does not change much. Thus under these assumptions, reductions in Norwegian oil sales is an effective climate policy, whereas reductions in Norwegian demand for fossil fuel is not. Carbon leakage through compensating changes in fossil fuel use in other countries is then small for supply policy in Norway, but large for demand policy.

Now, make the opposite assumption that world market supply is elastic but world market demand inelastic. Then the conclusions are reversed. A demand reduction in Norway reduces the world market price, which causes large reductions in the world supply of oil. A Norwegian reduction in supply will then mainly lead to increased production elsewhere. Leakage is then large for supply policy in Norway but not for demand policy.

Holtsmark's conclusion is that carbon leakage is larger on the supply side than on the demand side. One has, however, also to take the marginal abatement costs in Norway into account. As they are judged to be much smaller on the supply side than on the demand side, the upshot is that reductions of oil and gas extraction should play a considerably larger role in an optimal Norwegian climate policy (maximizing global emission reductions for given costs or minimizing costs for given reductions). Thus, the current focus on demand reductions in Norway is likely to be highly inefficient.

One obvious way of shifting climate policy in Norway from the demand to the supply side would be to leave reserves in the Artic and in the Northern areas of the Norwegian continental shelf unopened. This would also have the advantage that less resources are put into the development of new technology for oil and gas extraction under 
extreme conditions that could be used by other producers as well (the opposite of contributing to the development of clean technologies as discussed in Section 2.4). In addition, there might be positive local environmental effects of abstaining from oil and gas extraction in sensitive environments. But a complete assessment must also take distributional effects (both within Norway and between countries) as well as moral demonstration effects into account. It is not, however, obvious in what direction such considerations would change the conclusions.

\section{The most important policy conclusions}

In our view, the most important policy conclusions for the Nordic countries from the articles in this volume are the following:

- The success of the Paris Agreement builds in effect on whether sufficiently strong international norms requiring both governments and other actors to do more to halt climate change can be established. The Nordic countries should together with other ambitious states strengthen their cooperation to achieve this. This could, for example, involve granting special benefits to countries meeting high climate policy standards.

- An earlier feature of the EU Emissions Trading System was that larger reductions of emissions encompassed by the system in one country (through national tax incentives or subsidies to green energy) would not affect total emissions, since these were determined by the overall number of emission allowances. This is no longer so. The emissions trading system has been reformed in such a way that national measures to reduce emissions will increase the stock of saved emission allowances and this way trigger less issuance of new allowances in the future. Furthermore, buying and immediately cancelling emission allowances and annulling them, is no longer an efficient national climate policy since it will lead to more issuance within the system in the future.

- The very ambitious emission reduction obligations for the Nordic countries in the sector of the economy that is not encompassed by the EU Emissions Trading System implies that marginal abatement costs there are substantially higher than 
in some (other) countries in the EU. Hence it would be cost-efficient for the Nordics to achieve part of their obligations by paying for emission reductions elsewhere. This is possible according to EU rules.

- Promoting clean technologies may be the most efficient way through which the Nordic countries can contribute to policies against climate change. The focus should then not be on technology that only serves as a means to achieve national emission targets, but instead on technology that can get widespread use globally and where the Nordic countries have special expertise. More Nordic cooperation in developing new technology of this type is likely to enhance the impact.

- Norway represents a special case for climate policy. On the one hand, policy in Norway, like in the other Nordic countries, tries to achieve ambitious national emission reductions. But on the other hand, Norway is a large exporter of oil and gas. A shift in focus from reductions in domestic demand for fossil fuel to reductions in supply would increase cost effectiveness. Such a policy change would contribute to larger global emission reductions at a given cost or lower costs for given global emission reductions. Abstaining from extracting oil and gas in the Artic and in the Northern areas of the Norwegian continental shelf is one way of implementing such a policy shift.

\section{References}

Arrhenius, S. (1896), On the Influence of Carbonic Acid in the Air on the Temperature on the Ground, Philosophical Magazine and Journal of Science, 41, 237-276.

Pigou, A. C. (1920), The Economics of Welfare, London: Macmillan. 


\section{'COP21 was a success, but that was the easy part'}

Christina Figueres, Executive Secretary United Nations Framework Convention on Climate Change (2010-16) 


\title{
International Climate Politics in the Post-Paris Era
}

\author{
Naghmeh Nasiritousi ${ }^{1}$
}

Karin Bäckstrand ${ }^{2}$

\section{Abstract}

The aim of this article is to assess the efficacy of the Paris Agreement to generate policies and incentivize actions that can contribute to halt climate change significantly. The article shows that the agreement in many ways represents a significant shift in global climate politics. By making domestically driven climate policy central to the treaty, the Paris Agreement avoids some of the reasons for multilateral gridlock that permeated global climate policy for decades. The biggest challenge for state and non-state actors is to increase ambition in climate commitments. The article concludes with recommendations on how to accelerate climate action.

Keywords: Climate change, international cooperation, UNFCCC, de-carbonization.

JEL codes: F53, F55, Q54.

\footnotetext{
${ }^{1}$ Department of Political Science, Stockholm University. Email: naghmeh.nasiritousi@statsvet.su.se.

${ }^{2}$ Department of Political Science, Stockholm University. Email: karin.backstrand@statsvet.su.se.
} 


\section{Introduction}

On the $12^{\text {th }}$ of December 2015, over twenty years of international climate change diplomacy culminated in the Paris Agreement, succeeding the Kyoto Protocol as a universal and binding agreement to curb greenhouse gas emissions beyond 2020. Its central objective is to keep the global average temperature rise 'well below $2^{\circ} \mathrm{C}$ above pre-industrial levels and pursuing efforts to limit the temperature increase to $1.5^{\circ} \mathrm{C}$ above pre-industrial levels' (UNFCCC 2015, Article 2(a)). The Paris Agreement was concluded on overtime and signed by over 190 countries of the United Nations Framework Convention on Climate Change (UNFCCC) at the $21^{\text {st }}$ Conference of Parties (COP).

Yet, while the road to get to this agreement had been long and bumpy, the Executive Secretary of the UNFCCC declared that the hard part was now set to begin. The Paris Agreement offers a political framework for implementing the goals in the agreement through voluntary national climate plans - national determined contribution (NDCs) - submitted by the states. The details on how to enhance ambition of NDCs and review commitments is however subject to continued political contestation. In other words, after more than 20 years of contentious international negotiations on climate change, the Paris Agreement is not the final destination, but merely the start of a long process for the world to address climate change.

The recent release of the Intergovernmental Panel on Climate Change's special report on the impacts of global warming of $1.5^{\circ} \mathrm{C}$ (IPCC 2018) illustrates the gap between scientific findings and an effective policy response: the predicted temperature rise is closer to $3^{\circ} \mathrm{C}$ based on current pledges by states under the Paris Agreement. Pertinent questions are: Why has international cooperation to address climate change been so difficult? What are the innovative features of the Paris Agreement? What is the outlook and prospects for effective climate change governance in the post-Paris era?

Our aim is to provide an assessment of the efficacy of the Paris Agreement to generate policies and incentivize actions that can contribute to halt climate change significantly. To do so, we outline the history of international climate change politics and examine to what extent the Paris Agreement can be seen as a successful 
multilateral agreement in curbing global climate change and decarbonising the global economy. Moreover, the article outlines the nature, strengths and limitations of the Paris Agreement and analyses the prospects for effective action on climate change.

The article shows that the Paris Agreement in many ways represents a significant shift in global climate politics. First, as a global universal comprehensive treaty it eroded the Kyoto Protocol's 'firewall' between developed and developing countries where the latter were exempt from mandatory obligations to reduce emissions. Second, the Paris Agreement has replaced the Kyoto Protocol's top down 'targets and timetables' with a bottom-up 'pledge and review' process, thereby making domestic climate action central in multilateral climate policy. Third, the Paris Agreement has enacted a new model of 'hybrid multilateralism' whereby the function of a climate agreement is to direct, orchestrate, harness and mobilize climate action by sub-state and non-state actors such as cities, business, investors, regions and civil society (Andonova 2018, Bäckstrand et al. 2017). While the Paris Agreement in itself will not have a significant impact on halting climate change, it can be successful if it contributes to changing behaviour among states and non-state actors by providing an infrastructure, signal and a direction for ramping up climate action and political commitments to decarbonisation. As Christoff (2016) observes, the Paris Agreement is a promissory note where we cannot yet ascertain progress.

The article proceeds as follows. The next section outlines some structural features of climate change as a collective action problem that generates challenges of enforcement and thereby insufficient policy response to prevent global warming. This is followed by a history of international climate diplomacy from the 1992 Rio conference to the 2015 Paris climate summit, with an emphasis on the 2009 Copenhagen summit that laid the foundation for the Paris Agreement. Thereafter, we assess the potential and limitations of the Paris Agreement to reduce greenhouse gas emissions before offering an analysis of what this agreement means for future international cooperation and effective policy response to climate change. We conclude by examining the prospect for global de-carbonization and offer policy recommendations. 


\section{Features of climate change governance}

What are the reasons for the protracted lack of effective policy response to global climate change? Despite alarming reports from the Intergovernmental Panel on Climate Change (IPCC) every fifth year or so, the world is not on track for meeting the $2^{\circ} \mathrm{C}$ temperature target. We discuss below four features of climate change governance - the collective action problem, burden sharing, the enforcement problem, and the rise of non-state and sub-state actors.

First, climate change as an international problem stems from the nature of the climate issue as a 'public bad', where countries will suffer depending on national capacity, vulnerability, geographical location and stages of economic development. Climate change is essentially a global collective action problem as greenhouse gases that give rise to climate change mix in the atmosphere globally, while the primary costs of policies to reduce emissions are borne within national jurisdictions (Victor 2011). Thus, while the benefits of reducing greenhouse gas emissions are shared globally (although there could be additional benefits enjoyed locally, for example reduced air pollution), the costs are borne by the entity reducing emissions and decarbonising. Climate change thus constitutes a collective action dilemma as each country has an incentive to free-ride on the climate abatement efforts of others rather than to engage in cooperation (Barrett 2003). Thus, international cooperation is required to address climate change, but the form and function of this cooperation is subject to contestation.

Second, the issue of burden-sharing - what constitutes a fair distribution of costs and benefits of climate regulation - has plagued climate diplomacy for 25 years. The time lag between costly measures to reduce carbon emissions and future benefits in terms of discernible and improved climate impacts can span over several decades. Moreover, competing principles for assessing equity and fairness (total emission, per capita emissions, historical emissions, vulnerability, wealth etc.) and different perceptions of fairness among states or negotiation blocs, hamper progress on both short-term and long-term actions to mitigate climate change.

Third, the decentralized nature of world politics and lack of hierarchy and sanctions makes enforcement of a global climate agreement 
difficult. International politics in general, and arguably international climate change politics in particular, is characterized by a heterogeneous set of state and non-state actors that seek to advance their particular interests in multilateral fora. The international political system is made up of almost 200 states that differ widely in terms of population, economic development, political system, greenhouse gas emissions, vulnerability to climate change, economic dependence on the sale or use of fossil fuels, views about the importance of environmental protection and multilateral cooperation, etc. (Underdal 2017). As there is no supreme global authority that can impose cooperation on these states, countries must negotiate to find common ground. As previously discussed, for a public good such as reduced climate change, countries have an incentive to free-ride on other countries' efforts to reduce greenhouse gas emissions to evade own costly changes (Keohane and Victor 2016). Self-enforcement will therefore need to rely on reciprocity between states, soft sanctioning mechanism such as 'naming and shaming' by transnational advocacy networks, and mobilization of domestic interest groups and democratic publics in different countries (Keohane and Oppenheimer 2016).

Fourth, the problem structure of climate change resembles a 'wicked problem' with no quick-fix solutions to decarbonize the world's energy, industrial and transport systems, and cooperation needs to take place on multiple political and geographic levels across many sectors because of the complex nature of the problem (Victor 2009). The magnitude of the global climate threat is augmented by the fact that the major drivers of climate change are fossil fuel combustion and land-use change and therefore involve virtually all human activity across the spheres and actions of citizens, civil society, market and government. Climate change thus challenges the development path that the world has undertaken since the Industrial Revolution. Climate policies therefore need to address a range of difficult issues involving a large number of actors, from establishing fossil fuel-free energy, food and transport systems, to reducing deforestation and emissions from industrial and waste processes (Falkner 2016a).

This is why the world has seen the emergence of non-state, substate and regional initiatives and an 'all-hands-on-deck' approach to combat climate change (Hale 2016). Compared to other policy 
areas, global climate governance has seen an unprecedented participation by non-state actors over the past 25 years in different roles such as agenda-setting, policy formulation, implementation, monitoring, lobbying, protesting and taking on voluntary reduction targets. The number of accredited non-state actors from the UNFCCC 'constituencies' - environmental NGOs, business and industry groups, trade unions, local authorities, women and gender groups, indigenous peoples' organizations, farmers' organizations, research organizations, and youth groups - have grown from 163 in 1995 to 2133 in 2017 (Bäckstrand et al. 2017). The involvement of such diverse non-state actors complicates climate change governance, but could contribute to increasing the legitimacy and effectiveness of climate change policies if managed properly by states and international organisations (Nasiritousi 2016).

The Paris Agreement has consolidated a form of 'hybrid multilateralism' by paving the way for an enhanced role for non-state actors in the effort to reduce greenhouse gas emissions and accelerate societal de-carbonization (Bäckstrand et al. 2017). The UNFCCC secretariat has taken on a role as coordinator and orchestrator of transnational climate action. The decision accompanying the Paris Agreement calls on non-state actors such as investors, regions and cities to 'scale up their climate actions' and to register them as voluntary commitments. Furthermore, non-state actors are seen as contributors to the Paris agreement in overseeing and implementing countries' NDCs and in participating in intergovernmental processes aimed at enhancing ambition such as the global stocktake and facilitative dialogue (see Sections 4 and 5).

In sum, various factors contribute to the persistent multilateral gridlock on climate change. However, we will argue that the Paris Agreement, with its recently adopted rulebook adopted at the climate conference in Katowice in December 2018, can break the impasse as the UNFCCC emerges as a broker for aligning and scaling up nonstate and state commitments.

\section{Milestones in international climate policy}

The international climate negotiations have been described as 'probably the most complex environmental diplomacy ever under- 
taken by the global political community' (Okereke 2010, p. 45). A look at the history of climate change negotiations explains why. The warming potential of greenhouse gas emissions has been known for over a hundred years, but it was not until the 1980s that climate change started to be dealt with as a major political issue. A meeting organized by the World Meteorological Organization (WMO) and the United Nations Environment Program (UNEP) in 1985 in Villach, Austria, concluded that states should consider developing an international climate convention (Bodansky 2001). Such a convention was opened up for signature during the Earth Summit in Rio de Janeiro in 1992. This convention, known as the United Nations Framework Convention on Climate Change, came into force in 1994 with the overarching objective to achieve 'stabilization of greenhouse gas concentrations in the atmosphere at a level that would prevent dangerous anthropogenic interference with the climate system' (UNFCCC 1992, Article 2).

The UNFCCC has since then organized annual conferences where nearly 200 countries negotiate and take decisions on climate change. The decision-making is based on consensus, which often results in least-common-denominator outcomes. This means that politically controversial decisions can be blocked by veto players, delayed, or omitted completely from the negotiations. On the other hand, decisions that are made gain legitimacy because they have been taken by consensus.

The political battles fought to agree on the Convention provide a summary of what makes international climate diplomacy so complex. The key issue of contention has from the outset concerned the responsibility for the causes of climate change, as well as for the efforts to deal with its consequences, i.e. burden sharing. With industrialized countries historically being responsible for the bulk of greenhouse gas emissions, developing countries maintained that it would only be fair if the former countries also took the main responsibility for the costs of mitigating climate change. In this perspective, industrialized countries' call for shared responsibility could be seen as a distraction from developing countries' immediate and pressing problems of poverty alleviation and economic development. Industrialized countries however maintained that rapid industrialization and population growth in developing countries meant that they would soon be the largest emitters of greenhouse gases and 
therefore argued for efforts to address climate change from all countries. The political compromise that underpinned agreement in Rio was the principle of 'common but differentiated responsibility', meaning that all countries have a responsibility to address climate change but that this responsibility is dependent on states' national circumstances. Differences in opinion between countries over how this principle should be applied has been a key issue of contention in the different negotiation rounds since the signing of the Convention (Okereke 2010).

While different interests between developed and developing countries explain much of the multilateral gridlock at the heart of the climate change negotiations in the past twenty years, the picture is further complicated by divisions within the developed and developing country blocs. This was already evident when states were negotiating the nature of the agreement prior to the Rio summit. While several European countries argued for the need to have an agreement with specific targets and time-tables, the US instead wanted a framework convention that allowed for a gradual development of tools to address climate change. The European countries were backed by small island states who are some of the most vulnerable countries to climate change. The position of the US was favoured by many oil-producing countries, who saw a targets and time-table approach as a threat to their main source of income. The European countries eventually agreed to the US position, not least since they wanted to secure US participation in the climate regime. That is why the UNFCCC signed in Rio is a broad and general framework convention without binding emissions targets (Okereke 2010).

The EU, however, found allies in many developing countries for their targets and time-table approach on the condition that the targets would apply only to industrialized countries (Bäckstrand and Elgström 2013). Negotiations on such an agreement began in earnest when the UNFCCC entered into force and resulted in the signing of the Kyoto Protocol in December 1997. The Kyoto Protocol set out legally binding emission reduction targets for 38 industrialized countries and economies in transition (mostly former countries of the Soviet Union) for the first commitment period 2008-2012. The emission reduction targets for industrialized countries varied between different states but amounted to a modest average of a $5 \%$ reduction from 1990 levels. It also allowed for cost-effective 
emission reduction through the Kyoto Protocol's flexible mechanisms, including emissions trading, Joint Implementation and the Clean Development Mechanism (CDM). ${ }^{3}$ These mechanisms were designed to help developed countries fulfil their commitments by allowing the purchase of emission reduction credits through financial transactions between countries, for example by investing in emission reduction projects in developing countries (Bodansky 2001).

The Kyoto Protocol was historic as it set out the first mandatory emission reduction targets. However, while the emission reductions of the Kyoto Protocol were achieved, the aggregate reduction in emissions was largely attributed to the economic restructuring that took place in the economies in transition countries (Chan, Stavins et al. 2018, Shishlov et al. 2016). There are several factors that hampered the Kyoto Protocol's environmental effectiveness. First, while the US was a key actor shaping the provisions of the Kyoto Protocol, this country never ratified the agreement on the basis that developing countries including large emitters, such as China, were exempt from greenhouse gas emission reduction targets. Second, political compromises made to reach agreement led to loose targets particularly for the economies in transition, which were credited for emission reductions that happened as a result of economic restructuring after the fall of the Soviet Union rather than as a result of the Kyoto Protocol (Chan et al. 2018).

The Kyoto Protocol has been criticized for not offering a viable way forward in designing further agreements based on the targets and time-table approach (Keohane and Oppenheimer 2016, Victor 2011). This is because countries that had struggled or failed to meet their targets (illustrated by Canada's withdrawal from the Protocol in December 2011) were reluctant to sign up to a second commitment period of the Kyoto Protocol (Canada, US, Russia, Japan and New Zealand decided not to participate in a second commitment period). Furthermore, there was no plan for how to distribute emission reduction responsibilities also among developing countries over time. The focus on legally binding targets had turned the negotiations into a conflict over how to distribute the mitigation burden between countries (Falkner 2016a). While developed countries' share of glob-

\footnotetext{
${ }^{3}$ A description of the flexible mechanisms can be found at https://unfccc.int/process/ the-kyoto-protocol/mechanisms.
} 
al greenhouse gas emissions had declined significantly from around $56 \%$ of global emissions in 1990 to around $39 \%$ in 2010 , global emissions had risen by around $31 \%$ in the same time period, with most of the rise being associated with rapid growth in the emerging economies (Chan, Stavins et al. 2018). Thus while developed countries urged developing countries to take on emission reduction targets, developing countries resisted and argued that developed countries had done little to take the lead in reducing emissions.

These were the circumstances that negotiators found themselves in when they met for the Copenhagen climate conference in 2009 intended to create a successor agreement to the Kyoto Protocol. There was strong pressure on negotiators to reach agreement on the Kyoto Protocol's second commitment period and a long-term cooperative action framework with the aim to encompass all countries. Despite two weeks of intensive negotiations, however, the conference did not reach agreement on the outstanding issues. Instead, a small group of heads of 28 states negotiated what became the Copenhagen Accord - a political compromise that offered a new approach to the climate negotiations. Instead of targets and time-tables, all countries were to offer voluntary domestic pledges as a basis for climate action. The Copenhagen Accord thus blurred the distinction between developed and developing countries in terms of responsibility for reducing emissions. The agreement also included the promise of substantial climate finance by developed countries to support mitigation and adaptation in developing countries.

While the conference did not produce any new binding agreements and was seen as a great disappointment at the time, it paved the way for the pledge-and-review system institutionalized in the Paris Agreement in 2015 (Falkner 2016a). In response to the perceived failure of the Copenhagen summit, the 2011 Durban climate conference adopted the mandate to 'develop a protocol, another legal instruments or an agreed outcome with legal force under the Convention applicable to all Parties' (UNFCCC 2011, Decision 1/CP.17, Article 2). 187 voluntary intended nationally determined contributions (INDCs) were submitted by states in advance of the Paris climate summit covering $95 \%$ of global emissions. However, the ambition level of the collective INDCs was not sufficient to keep the temperature goal below $2^{\circ} \mathrm{C}$ (Rogelj et al. 2016). 


\section{The Paris Agreement, nationally determined contributions and global climate action}

The Paris Agreement signals a new phase of international climate diplomacy and a major break with the Kyoto-Protocol approach of quantified legally binding targets for industrialized countries only. By cementing a domestic logic of international climate politics, the Paris Agreement is more aligned with the realities and changing geopolitical context of climate politics. States' voluntary pledges and domestic action to mitigation - the NDCs - remain the centrepiece of the Paris Agreement for the post-2020 period (Falkner 2016a). The dichotomous distinction between developing and developed countries in the Kyoto Protocol is abandoned, as all countries are obliged to submit national climate plans. However, it leaves much discretion to countries to formulate and implement their NDCs. The Paris Agreement marks a shift in global climate policy from a topdown, centralized legally binding response of target and timetables of greenhouse gas emissions to a bottom-up decentralized and voluntary pledge and review system of reduction targets by states. In essence, the Copenhagen Accord laid the foundation for the pledgeand-review system that was six years later formalized in the Paris Agreement.

The Paris Agreement specifies a clear objective and goals based on the stabilization objective of the UNFCCC. Article 2 of the Paris Agreement contains the overall purpose for the global response to climate change in: (a) the temperature goal of 'holding the increase of the global average temperature to well below $2^{\circ} \mathrm{C}$ above preindustrial levels and pursuing efforts to limit the temperature increase to $1.5^{\circ} \mathrm{C}$ above pre-industrial levels'; (b) facilitating adaptation to the adverse effects of climate change to ensure climate-resilience; as well as (c) 'making finance flows consistent with a pathway towards low greenhouse gas emissions and climate-resilient development' (UNFCCC 2015). It further specifies that global net greenhouse gas emissions should be phased out 'in the second half of this century' in order to achieve the $2^{\circ} \mathrm{C}$ or $1.5^{\circ} \mathrm{C}$ temperature goal (UNFCCC 2015, Article 4.1). This essentially means that the Paris Agreement sets the direction for a global de-carbonization within the next decades.

By making domestically driven climate policy central to the treaty, the Paris Agreement escapes some of the reasons for multilater- 
al gridlock that permeated global climate policy for decades. First, it lowers the barriers for participation of major emitters such as the US, which has been reluctant to take on quantified targets for emission reductions as illustrated by its decision not to ratify the Kyoto Protocol. Second, it dampens distributional conflicts related to negotiations of burden-sharing and distribution of emission reductions that have been at the heart of the international climate negotiations since the Kyoto Protocol. Domestic climate action such as those outlined in the NDCs can catalyse climate action and experimentation toward de-carbonization by a wide array of actors at the subnational (municipal and state/provincial) and non-state levels (Bernstein and Hoffmann 2018). Research has shown that the process of requesting countries to come forward with pledges has already set in motion a wave of national climate change strategies around the world. According to lacobuta et al. (2018, p. 1114), 'economy-wide GHG reduction targets witnessed a strong increase in the build-up to 2015 and are adopted by countries covering $89 \%$ of global GHG emissions (76\% not counting USA) and $90 \%$ of global population ( $86 \%$ not counting USA) in 2017'.

Third, the Paris Agreement puts in place a dynamic ambition mechanism for international review and ratcheting-up of domestic mitigation plans. This includes rules to ensure the transparency of countries' climate action and their accountability, a five-year global stock-take of existing NDCs and an agreement to enhance ambition and build in progression in future of climate plans. The overall purpose of the ambition mechanism is to close the gap between existing NDCs and what would be required to achieve the temperature goal over time.

An innovative feature of the Paris Agreement is the combination of bottom-up domestic pledges with top-down review and comparisons of mitigation action. Another particular feature is that the procedural aspects of submitting NDCs and the transparency framework are legal obligations, whereas the content of the climate plans in terms of mitigation and adaptation measures are not (Bodansky 2016). The transparency mechanism will thus be a central element in holding states accountable as it will be putting pressure on states to update their climate pledges every five years. This periodic global stock-take will take place in 2023 with the goal to ratchet up ambition to reach the long-term temperature goal (Falkner 2016a). 
A limitation is that the Paris Agreement does not mandate reviews of state's individual NDCs, but it is a review of the collective ambition and a synthesis of NDCs. Nevertheless, the global stock-take will create opportunities for civil society to use 'naming and shaming' for laggard countries not delivering on their pledges. While non-state actors do not have any formal role in the periodic reviews under the Paris Agreement, the Climate Action Tracker ${ }^{4}$ and Civil Society Review $^{5}$ are tools for NGOs to monitor and pressure governments toward compliance.

The Paris Agreement with its bottom-up approach to multilateral climate diplomacy paved the way for an enhanced role for non-state actors, such as regions, cities, companies, investors and civil society. The recognition that current NDCs if implemented are not on track to achieving the agreement's objective, has prompted calls for mobilization of non-state and sub-state actors to close the emission gap (Nasiritousi 2016). The COP decision accompanying the Paris Agreement authorized the appointment of two High-Level Champions to mobilize non-state climate action and engage non-state actors for the pre-2020 period (UNFCCC 2015). The French Presidency of COP21 and the Moroccan Presidency of COP22 each nominated a senior diplomat for 2016-18 culminating in the adoption of the Marrakech Partnership for Global Climate Action (UNFCCC 2016). The Marrakech Partnership subsequently coalesced into the Global Climate Action Agenda with the aim to enhance pre-2020 action (Chan, Ellinger et al. 2018).

Moreover, non-state actors play an increasingly important role in shaping climate action at the UNFCCC and beyond (Nasiritousi 2016). At COP Lima in 2014, the Lima-Paris Action Agenda and the Non-State Actor Zone for Climate Action (NAZCA) were launched to 'galvanize the groundswell of actions on climate change mitigation and adaptation from cities, regions, businesses and civil society organizations' (Chan et al. 2015, p. 467). The numbers of participants at the annual COPs have increased over the years, peaking in Paris with more than 28,000 accredited participants, of whom 8000

\footnotetext{
${ }^{4}$ The Climate Action Tracker provides analysis by three research organizations of countries' progress toward meeting the temperature goals of the Paris Agreement. See https://climateactiontracker.org/.

${ }^{5}$ The Civil Society Review provides analysis by a range of civil society actors of countries' climate commitments with a special focus on equity issues.

See http://civilsocietyreview.org/.
} 
were registered as non-state observers (Lövbrand et al. 2017). With the adoption of the Paris Agreement, the observer groups present at the annual COPs are now invited to play a more integrated role in multilateral processes through, for instance, monitoring of national action and experimentation with local, regional and transnational mitigation and adaptation strategies. The Paris Agreement thus provides a framework through which non-state actors can mobilize voluntary action and increase political pressure on states.

The Paris Agreement refers to NAZCA, a platform established and hosted by the UNFCCC that to date has registered more than 19000 individual or cooperative climate commitments by companies, investors, civil society, regions and cities. The function of NAZCA is to mobilize the mitigation potential of transnational climate action and thereby help close the global emissions gap. While the Paris Agreement primarily rests upon NDCs submitted by states, the COP decision formally recognizes that 'non-party stakeholders', i.e. nonstate actors, can contribute to the goal of limiting global warming well below $2^{\circ} \mathrm{C}$. As such, the agreement spells out a new role for the UNFCCC as 'orchestrator' of transnational climate action.

Thus the Paris Agreement has several innovative features that sets it apart from the Kyoto Protocol. It combines mandatory and non-mandatory provisions, mixes top-down and bottom-up features, and involves states and non-state actors. Moreover, it sets ambitious targets and applies to both developed and developing countries. The Paris Agreement thereby sends a signal to actors on the long-term direction of travel for the global economy. The lack of details in the Paris Agreement, however, raises the question of whether this signal is strong enough to lead to significant reduction of greenhouse gas emissions and spur decarbonization (Falkner 2016a).

\section{International climate change cooperation after Paris}

The speedy ratification and the sooner-than-expected entry into force of the Paris Agreement on 4 November 2016, attests to the Agreement's strength in providing a new regulatory approach for catalysing and mobilizing climate change among governments, 
market and civil society actors. Ultimately effectiveness, however, depends on how the Paris Agreement is able to fulfil the objectives of the agreement, where the temperature target provides the clearest measure of success. Recent assessments show that countries' NDCs are not ambitious enough to close the gap (UNEP 2018a). However, the Paris Agreement's review cycle is aimed at assessing collective efforts by countries to implement their NDCs and increase ambition over time. The first important test of this will be if countries indeed offer more ambitious NDCs by 2020.

So far, the Paris Agreement has in its short time frame faced two significant challenges that undermine its effectiveness to mitigate climate change. The first was the announcement of President Trump in June 2017 that the US would withdraw from the agreement (effective November 2020). This announcement raised concerns about the resilience of the agreement, given the important role of the US as the world's second largest greenhouse gas emitter after China (Chan, Stavins et al. 2018). The second is the ongoing contestation over the agreement's implementing guidelines, also known as the 'Paris rulebook'. The most recent climate change negotiations in Katowice in December 2018 resolved some key differences among states on the rules for implementation, but postponed some important decisions for future negotiations.

In regard to the first challenge, the Paris Agreement has thus far shown itself durable in the face of the challenge presented by the US' intention to withdraw from the agreement. While other countries could have followed the example of the US and abandoned the Paris Agreement, the political reactions to President Trump's announcement seem instead to have strengthened the support and legitimacy of the agreement as world leaders have reaffirmed their commitments (Betsill 2017). Moreover, the establishment of a coalition of over 3000 US sub-state and non-state actors under the banner of America's Pledge initiative testifies to the support for the Paris Agreement among a range of important US actors despite lack of federal support. The America's Pledge Initiative was launched by California Governor Jerry Brown and the UN Secretary-General's Special Envoy for Climate Action, Michael Bloomberg, to demonstrate non-state actor leadership on climate change in the absence of federal leadership. A recent report by the Initiative concludes that accelerated action by non-state actors can bring down US 
emissions by around 24\% below 2005 levels by 2025, thereby nearly fulfilling the country's NDC pledge (America's Pledge Initiative on Climate 2018).

Governor Brown also hosted the Global Climate Action Summit in September 2018 which gathered 4000 participants and showcased climate action by a range of actors such as cities, regions, investors and companies. The summit featured several commitments and announcements by non-state actors, such as:

- 'More than 60 state, regional and city governments, and multinational businesses committed to $100 \%$ zero emission vehicles through The Climate Group's ZEV Challenge.

- To unlock inclusive economic growth, 488 companies from 38 countries adopted emission reduction pathways in line with the Paris Agreement on climate change.

- Over 70 cities committed to carbon neutrality by 2050.' (Mead 2018).

Thus, while the US decision to pull out of the Paris Agreement is a set-back for climate action, it has only slowed it down rather than reversed it, as it has galvanized cities, states and companies actors to step up. The Paris Agreement has thus proven itself resilient against this first challenge.

In regard to the second challenge, however, the flaws of the Paris Agreement become more apparent. The Paris Agreement is a carefully negotiated agreement with a range of political compromises that postponed many of the difficult decisions on detail that are necessary for the implementation phase. Negotiators set themselves a deadline for negotiating the rulebook for the Paris Agreement: the climate change conference in Katowice, Poland in December 2018. The task was to agree on rules for implementing the Paris Agreement such as review of climate plans and the transparency mechanism. Even with an extra round of negotiations that took place in Bangkok in September 2018, however, countries were far from agreeing on such a text. One sticking point was the familiar issue of differentiation: China and other developing countries argued that the same rules on NDC reporting and verification should not apply to all countries. The EU and US, however, were not keen on returning to 
a system with different rules for different categories of countries (ENB 2018). Negotiators decided in Katowice that there should be common reporting rules for all countries, but the rulebook provides considerable flexibility to those countries that deem that they do not have the capacity to follow those rules.

A further hurdle in the negotiations on the rulebook for the Paris Agreement was the issue of climate finance to support climate action in developing countries. Developing countries argue that developed countries have fallen short of their promises on providing climate finance and want assurances of predicable financial flows from developed countries (ENB 2018). Thus the Paris Agreement has not overcome the general lack of trust between developed and developing countries that has marked the climate negotiations since the start. It is perhaps here that the US decision to withdraw from the Paris Agreement has its biggest effects, since the dwindling climate finance contributions of the US will be difficult to compensate for by other countries. In Katowice, countries such as Germany and Norway announced increases in climate finance, and it was decided that discussions on a long-term finance goal would be discussed at the climate change conference in 2020.

What negotiators in Katowice could not agree on, however, were common rules for voluntary market mechanisms. The sticking point appears to be how to ensure the environmental integrity of trade in carbon credits so as to avoid double-counting by states. Negotiators will return to this issue at the next round of negotiations. This delay will have implications for CORSIA, which is the trading scheme that will be set up for aviation emissions (Carbon Brief 2018).

On the whole, the Katowice results were stronger than expected given the changing geopolitical forces, populism, and nationalism that have made multilateralism more contentious. The Katowice conference resulted in common rules for reporting and verification that states will need to apply from 2024. It also established rules for the Global Stock take which will review implementation and is aimed at increasing ambition over time. This is important for establishing the credibility of the Paris Agreement, as the regulatory approach of voluntary NDCs requires mechanisms for holding states accountable. Without robust rules for transparency and verification, the upward spiral of trust and learning from best practices envisaged by the 
architects of the Paris Agreement risk turning into a downward spiral of distrust and lack of ambition by countries (Falkner 2016a). The facilitative ('Talanoa') dialogue ${ }^{6}$ in Katowice in 2018 was the first test to the upscaling of ambition to revise NDCs with peer accountability by states. The UN Secretary General's climate change summit in September 2019 will provide an indication of whether the facilitative dialogue has provided countries with inputs to raise the ambition of their climate actions.

The biggest challenge for the Paris Agreement will thus still be how to ratchet up ambitious climate action. The world is not on track to meeting the Paris Agreement's temperature goal of $2^{\circ} \mathrm{C}$ and even less so for the $1.5^{\circ} \mathrm{C}$ goal (UNEP 2018a, IPCC 2018). As for meeting the aspirational goal of keeping temperature rise below $1.5 \mathrm{C}$, as small-island states have pushed for, this would require transformation of energy, transport and food sectors on an unprecedented scale. According to one of the authors of the IPCC's special report on the impacts of global warming of $1.5^{\circ} \mathrm{C}$ above pre-industrial levels, reaching this target is 'technically possible, [but] it's extremely improbable, absent a real sea change in the way we evaluate risk. We are nowhere near that' (Drew Shindell in Milman 2018, September 27).

In sum, the Paris Agreement and the recently agreed-on rulebook provide a foundation for the implementation of climate action by states and non-state actors. The fulfilment of its goals depends on creating a positive cycle of climate action that will raise ambition over time among state and non-state actors. This momentum will need to be reinforced not just by the UNFCCC, but also by other governance arrangements as explained in the next section.

\section{Complementary international institutions outside the UNFCCC}

Breaking the path dependency of the global fossil fuel economy and carbon lock-in is likely to require additional approaches to complement the regulatory approach of pledge and review of the

\footnotetext{
${ }^{6}$ A dialogue mandated by the Paris Agreement to evaluate progress toward the longterm goal and share ideas on how to implement and increase climate commitments. See https:/unfccc.int/topics/2018-talanoa-dialogue-platform.
} 
Paris Agreement. In this regard, the UNFCCC is one of many building blocks of a climate regime that consists of a range of international institutions and processes whose mandate affects climate action. While the UNFCCC has a central role in the climate regime, it interacts with many other intergovernmental and public-private institutions (Hjerpe and Nasiritousi 2015). Such examples include the $\mathrm{G}^{2} \mathrm{O}^{7}$ the Clean Energy Ministerial, ${ }^{8}$ the Climate and Clean Air Coalition, ${ }^{9}$ the Friends of Fossil Fuel Subsidy Reform, ${ }^{10}$ the Carbon Pricing Leadership Coalition ${ }^{11}$ and many others. In other words, climate change can be tackled through cooperative action in a number of sub-fields, such as clean energy development, carbon pricing initiatives, and fossil fuel subsidy reform.

Moreover, Agenda 2030 and the Sustainable Development Goals ${ }^{12}$ can be viewed as complementary institutional frameworks to the NDCs. They have introduced a nexus thinking showing that many goals for sustainable development (where climate change is one of 17 goals) are interlinked. There are considerable synergies between climate action and measures to reach other goals such as health (goal 3), clean energy (goal 7), sustainable cities and communities (goal 11), responsible consumption and production (goal 12) and oceans (goal 14) (IPCC 2018). For example, fulfilling goals on sustainable consumption and production will also work to help address climate change. The latest New Climate Economy report (The Global Commission on the Economy and Climate 2018) shows the positive externalities that climate actions can have, for example when taking into account co-benefits such as health benefits and enhanced

\footnotetext{
${ }^{7} \mathrm{G} 2 \mathrm{O}$ (or the Group of 20) is an international forum for the governments and the central bank governors of 19 leading economies and the European Union. Initially it was set up to discuss international financial issues, but its agenda has expanded to also include, for instance, climate change and energy policies.

See https://www.g20.org/en/.

${ }^{8}$ The Clean Energy Ministerial is a high-level forum comprising 26 major economies with the aim to accelerate a global clean-energy transition.

See https://www.cleanenergyministerial.org/.

${ }^{9}$ The Climate and Clean Air Coalition is a coalition of countries and non-state actors. See http://ccacoalition.org/en

10 The Friends of Fossil Fuel Subsidy Reform is an informal group of nine non-G2O countries that work to promote political consensus on the importance of fossil-fuel subsidy reform. See http://fffsr.org/.

${ }^{11}$ The Carbon Pricing Leadership Coalition is a voluntary partnership of national and sub-national governments, businesses and civil society organizations advocating the expansion of effective carbon pricing policies around the world. See https://www. carbonpricingleadership.org/.

${ }^{12}$ Agenda 2030 is a plan for action for all countries to achieve a more sustainable world by 2030. It includes 17 Sustainable Development Goals and 169 targets set by the UN General Assembly in 2015.

See https://www.un.org/sustainabledevelopment/development-agenda/.
} 
energy security. Greater nexus thinking can thus change the cost-benefit calculations of countries in favour of more ambitious climate action (Sterner et al. 2019).

Furthermore, the building of catalytic linkages between different actors at the international, regional, national and local levels through so-called 'orchestration' efforts could lead to greater ambition (Bernstein and Hoffmann 2018, Chan, Ellinger et al. 2018). In other words, by creating cooperative platforms for climate action, different actors can be induced to work together to arrive at more ambitious climate commitments. One example is the participation of state and non-state actors in global coalitions, such as the Carbon Neutrality Coalition, ${ }^{13}$ which aims to demonstrate leadership and showcase actions to achieve carbon neutrality through the exchange of knowledge and ideas. Another example, from the national level, is the Swedish government's multi-stakeholder platform Fossilfritt Sverige (Fossil Free Sweden). It serves as an example of how national efforts to engage non-state actors can foster learning and lead to shared visions that can facilitate implementation of more ambitious climate action. By inviting non-state actors to discuss how ambitious climate targets should be met, this initiative aims to provide these actors with a sense of shared ownership and responsibility for the implementation of climate targets.

The plethora of international institutions across the public-private divide governing climate change reflects the nature of the climate change problem in that an effective response requires action on multiple political levels, jurisdictions and sectors across spheres of government, market and civil society. Climate change is thus a very different type of problem compared to the stratospheric ozone hole, for example, where the Montreal Protocol has been hailed for effective multilateral action to halt the depletion of the ozone layer. Negotiations led to phasing out and banning production of ozone depleting substances. The solution was readily identified in substitutes for these chemicals. To decarbonise the global economy, however, requires actions on many fronts. The climate change problem, as was discussed in Section 2, is thus not conducive to simple

${ }^{13}$ This is a group of 19 countries and 32 cities that have pledged to 'develop long-term low-greenhouse gases emission climate-resilient development strategies, in line with the agreed long-term temperature increase limit' by 2020 . See https://www.carbonneutrality.global/. 
solutions. Climate change governance is therefore characterized by a multitude of institutions and initiatives with overlapping mandates. The question, which we turn to next, is whether these initiatives add up to provide an effective response and what additional initiatives are necessary to curb climate change.

\section{Outlook and policy recommendations}

Over twenty years of international climate change politics has resulted in a climate regime that consists of important norms, principles, decision-making and institutions. However, at the same time, the Kyoto Protocol proved to be a dead end as it failed to produce an effective response to halting greenhouse gas emissions. The Kyoto Protocol's second commitment period that ends in 2020 only covers $15 \%$ of the world's emissions. As the global climate regime failed to deliver, experimental governance entailing decentralized, multi-level and bottom-up climate action independent of state-centric bargaining processes emerged (Hoffmann 2011, Bernstein and Hoffmann 2018). The Paris Agreement left the binary structure of the Kyoto Protocol behind and provided a new framework for curbing climate change and decarbonising the economy through voluntary commitments by state, non-state and sub-state actors. Hybrid multilateralism captures the changing nature of global climate negotiations where the UNFCCC takes on the role as orchestrator, facilitator and coordinator of NDCs submitted by states and voluntary climate actions by non-state and sub-state actors (Bäckstrand et al. 2017). This brokering role entails 'convincing states and nonstate actors to stay in the agreement, encouraging increasing commitments, and building links with other issue areas across the broad climate governance landscape' (Kuyper et al. 2018, p. 362).

Climate governance thus appears as institutionally complex, experimental and 'polycentric' illustrated by the emergence of a range of public and private institutions, fora and transnational initiatives that also seek to address the climate change challenge beyond the realm of the UNFCCC (Bulkeley et al. 2014, Jordan et al. 2015, 2018). The 'climate regime complex' (Keohane and Victor 2011) as it is currently shaped thus provides benefits in terms of offering a diversity of venues through which climate cooperation can be advanced. It offers space for learning and experimentation. It also provides 
actors with different sets of priorities and capabilities flexibility in how to undertake climate action, thereby reflecting political realities. The drawbacks of this type of climate regime, however, are that the fragmentation and institutional complexity lead to coordination gaps that can undermine the public legitimacy of the climate regime (Bäckstrand et al. 2018, Zelli and van Asselt 2015). If coupled with weak accountability and transparency mechanisms and inadequate coordination, the multitude of institutions and initiatives that seek to address climate change could give rise to an unnecessary duplication of efforts and inefficient policies. The UNFCCC now finds itself with a broader task to navigate in a diverse landscape of climate governance and beyond.

In essence, the flexibility offered by the climate regime will only prove to be an advantage if countries engage in a cooperative manner. If countries instead set their narrowly defined national interests first, this type of climate regime will fail to drive up climate ambition. The challenge to multilateralism coming from some parts of the world today does not bode well for international climate change cooperation. As there are no enforcement mechanisms and sanctions at the international level to force countries to decarbonise their economies, other measures are necessary to change the cost-benefit calculations of countries in order to ratchet up climate ambition.

This ties into research that shows that the world needs green economies to drive a sustainability transformation (Jackson 2017, Alfredsson and Wijkman 2014). Specifically, decarbonisation of the global economy is likely to require new economic instruments to drive a transition away from fossil fuels. For example, a study of the largest oil and gas companies showed that these companies do not see enough political pressure to change their businesses in a fundamental way (Nasiritousi 2017). Presently the large externalities associated with the activities of the fossil fuel industry are not taken into account, with implications for investment decisions into new fossil fuel reserves that scientist warn will be inconsistent with the Paris targets (McGlade and Ekins 2015).

Moreover, a survey conducted at the climate negotiations showed that state and non-state actors agree that to effectively address climate change, the introduction of economic systems valuing 
sustainability is needed (Nasiritousi et al. 2014). One step in that direction are new ways of thinking about economic growth. The Sustainable Development Goals have established that the current focus on GDP provides a poor basis for assessing human well-being and therefore mandate countries to complement GDP with other measures (UNEP 2018b). Recent reports by the World Bank (2018), UNEP (2018b) and the OECD (Stiglitz et al. 2018) argue that GDP is a poor measure of countries' wealth and encourage the use of measurements that take into consideration changes in the underlying asset base of the economy, including environmental indicators.

An additional way to drive the transformation could be through the establishment of a new 'economic framework' being developed by a group of like-minded, ambitious countries. Such a proposal was presented recently by Richard Samans, the managing director of the World Economic Forum. According to him, a coalition of vanguard countries should use economic incentives to drive the decarbonisation of the economy that go beyond simply introducing a carbon tax or a cap-and-trade system. In his words, these countries should make use of a whole range of measures including 'tariffs, procurement, financing, corporate governance, subsidies, technical standards, targeted tax, investor disclosure, or emission trading rules and policies' to increase demand for low-carbon products (Samans 2018). Simply put, this builds on the idea of a group of countries taking the lead through the creation of a climate club where membership comes with the condition of ambitious climate policies with particular benefits accrued to members. By coordinating policy responses among ambitious states and accruing club-benefits on first movers, such ideas are expected to reduce the economic and political barriers to decarbonisation (Pahle et al. 2018).

The scholarship on climate clubs has been growing in recent years as it has become apparent that laggard countries can reduce the pace of international cooperation on climate change as consensus is required at the UNFCCC. This literature argues that it would be promising to start off with a small group of 'enthusiastic' countries that set ambitious targets and then try to entice 'reluctant' countries (Hovi et al. 2016, Victor 2011). According to a literature review on climate clubs by Hovi et al. (2016, p. 2), key factors for making such clubs successful include: 'the club's ability to (1) provide a viable basis for cooperation among enthusiastic countries, (2) attract new 
members and (3) ensure that new and existing members alike contribute with considerable emissions reductions'. To reduce free-riding, a range of member-only benefits have been proposed, such as 'a low-tariff zone for low-emission technologies, international linkage of properly designed emissions trading systems and border tax adjustments to combat leakage' (Hovi et al. 2016, p. 4). Effective climate clubs thus require ambitious targets and a joint vision by members, clearly defined conditions for club members to fulfil, and club benefits for members (Ott et al. 2016). Sanctions against members who shirk responsibility and non-members may also be needed (Falkner 2016b, Nordhaus 2015, van den Bergh 2017). The literature on climate clubs thus proposes several ways in which a group of ambitious countries could lead the way in decarbonisation by showing political leadership and reaping rewards through collaboration (Ott et al. 2016).

In sum, while the Paris Agreement has provided a direction for the global response on climate change, the difficult political compromises underpinning the agreement and the political battles that will need to be settled in upcoming climate negotiations, reflect a world where the incentives for taking ambitious action are still not strong enough. Political leadership by different actors will be key for increasing the momentum on climate action and tip the balance for decarbonisation. All actors with the capacity to embark on rapid decarbonisation must pave the way for a transformation of societies in accordance with science. Setting a clear vision through dialogue with citizens and coordinating actions by a multitude of stakeholders will be key tools for realizing the objectives of the Paris Agreement. For example, there could be transformative coalitions built around objectives such as zero-energy buildings, zero-emissions aviation and other sectors facing a decarbonisation challenge (Höhne et al. 2017). Moreover, rapid transformation of economies will require capacity building and implementation of just transitions to facilitate climate resilience (Rosemberg 2010). While the NDCs have helped expand the capacity of many developing country governments to include climate considerations in their national plans, there is a continuing need for capacity building and support for developing countries. In particular, many of the NDCs of developing countries are partially conditional on support by developed countries. 
For the Nordic countries, this analysis highlights that greater cooperation is important on several fronts. The Nordic countries are in a good position to show leadership and develop pathways towards carbon-neutral societies. While being mindful of the Nordic countries' favourable starting points, they can serve as examples for the innovations - both technological and socio-political - that will be necessary for achieving carbon neutrality. As such, strengthened cooperation around for instance negative emission technologies, circular and green economies, adaptation and resilience will be important. Moreover, through their membership in the Carbon Neutrality Coalition, the Nordic countries could explore ideas for a climate club that go beyond sharing experiences and information to include joint policy tools and specific club benefits.

To conclude, while the Paris Agreement in itself is not a silver bullet for resolving the climate crisis, it provides the institutional foundation for measuring, reviewing, and increasing ambition in emission reduction targets and thereby incentivizes domestic action toward de-carbonization among almost 200 states. In addition, the UNFCCC has emerged as a central node in coordinating tens of thousands of non-state actors - cities, business, regions, investors - to take on voluntary commitments toward a low-carbon transformation of society and economy. The Paris Agreement can in this way be viewed as a foundation ready to be built on by a multitude of actors. How ambitious the final outcome will be is now up to all of us.

\section{References}

Alfredsson, E. and Wijkman, A. (2014), The Inclusive Green Economy Shaping Society to Serve Sustainability - Minor Adjustments or a Paradigm Shift?, Mistra Prestudy, The Swedish Foundation for Strategic Environmental Research.

America's Pledge Initiative on Climate. (2018), Fulfilling America's Pledge: How States, Cities, and Business Are Leading the United States to a Low-Carbon Future, Retrieved January 3, 2019, from https://www.bbhub.io/ dotorg/sites/28/2018/09/Fulfilling-Americas-Pledge-2018.pdf.

Andonova, L. (2018), Governance Entrepreneurs. International Organizations and the Rise of Global Public-Private Partnerships, Cambridge: Cambridge University Press.

Barrett, S. (2003), Environment and Statecraft, Oxford: Oxford University Press. 
Bernstein, S. and Hoffmann, M. (2018), The Politics of Decarbonization and the Catalytic Impact of Subnational Climate Experiments, Policy Sciences, 51(2), 189-2011.

Betsill, M. M. (2017), Trump's Paris Withdrawal and the Reconfiguration of Global Climate Change Governance, Chinese Journal of Population Resources and Environment, 15(3), 189-191.

Bodansky, D. (2016), The Paris Climate Change Agreement: A New Hope? American Journal of International Law, 110(2), 288-319.

Bodansky, D. (2001), The History of the Global Climate Change Regime, in Luterbacher, U. and Sprinz, D. F. (eds.), International Relations and Global Climate Change, Cambridge, MA: MIT Press.

Bäckstrand, K., Zelli, F. and Schleifer, P. (2018), Legitimacy and Accountability in Polycentric Climate Governance, in Jordan, A., Huitema, D., van Asselt, H. and Forster, J. (eds.), Governing Climate Change:

Polycentricity in Action, Cambridge: Cambridge University Press.

Bäckstrand, K., Kuyper, J., Linnér, B-O. and Lövbrand, E. (2017), Non-state Actors in Global Climate Governance: From Copenhagen to Paris and Beyond, Environmental Politics, 26(2), 561-579.

Bäckstrand, K. and Elgström, O. (2013), The EU's Role in Climate Negotiations: From Leader to 'Leadiator'? Journal of European Public Policy, $20(10), 1369-1386$.

Bulkeley, H., Andonova, L. B., Betsill, M. M., Compagnon, D., Hale, T., Hoffmann, M. J., Newell, P., Paterson, M., Roger, C. and van Deveer, S.D. (2014), Transnational Climate Change Governance, Cambridge: Cambridge University Press.

Carbon Brief. (2018), COP 24: Key Outcomes Agreed at the Climate Talks in Katowice, Retrieved January 4, 2019, from https://www.carbonbrief.org/ cop24-key-outcomes-agreed-at-the-un-climate-talks-in-katowice.

Chan, S., Ellinger, P. and Widerberg, O. (2018), Exploring National and Regional Orchestration of Non-state Action for a $<1.5^{\circ} \mathrm{C}$ World, International Environmental Agreements: Politics, Law and Economics, 18(1), 135-152.

Chan, G., Stavins, R. and Ji, Z. (2018), International Climate Change Policy, Annual Review of Resource Economics, 10(1), 335-360.

Chan, S., van Asselt, H., Hale, T., Abbott, K. W., Beisheim, M., Hoffmann, M., Guy, B., Höhne, N., Hsu, A., Pattberg, P., Pauw, P., Ramstein, C. and Widerberg, O. (2015), Reinvigorating International Climate Policy: A Comprehensive Framework for Effective Nonstate Action, Global Policy, 6(4), 466-473.

Christoff, P. (2016), The Promissory Note: COP21 and the Paris Climate Agreement, Environmental Politics 25(2), 765-787. 
ENB (2018), Summary of the Bangkok Climate Change Conference, Earth Negotiations Bulletin, 12(773), 1-15, Retrieved January 4, 2019, from http:// enb.iisd.org/vol12/enb12733e.html.

Hale, T. (2016), 'All Hands on Deck': The Paris Agreement and Non-state Climate Action, Global Environmental Politics, 16(3), 12-21.

Hjerpe, M. and Nasiritousi, N. (2015), Views on Alternative Forums for Effectively Tackling Climate Change, Nature Climate Change 5, 864-867.

Hoffmann, M. J. (2011), Climate Governance at the Crossroads: Experimenting with a Global Response After Kyoto, Oxford: Oxford University Press.

Höhne, N., Kuramochi, T., Warnecke, C., Röser, F., Fekete, H., Hagemann, M., Day, T., Tewari, R., Kurdziel, M., Sterl, S. and Gonzales, S. (2017), The Paris Agreement: Resolving the Inconsistency Between Global Goals and National Contributions, Climate Policy, 17(1), 16-32.

Hovi, J., Sprinz, DF., Sælen, H. and Underdal, A. (2016), Climate Change Mitigation: A Role for Climate Clubs?, Palgrave Communications, 2, 1-9.

Falkner, R. (2016a), The Paris Agreement and the New Logic of International Climate Politics, International Affairs, 92(5), 1107-1125.

Falkner, R. (2016b), A Minilateral Solution for Global Climate Change? On Bargaining Efficiency, Club Benefits, and International Legitimacy, Perspectives on Politics, 14(1), 87-101.

lacobuta, G., Dubash, N. K., Upadhyaya, P., Deribe, M. and Höhne, N. (2018), National Climate Change Mitigation Legislation, Strategy and Targets: A Global Update, Climate Policy, 18(9), 1114-1132.

Intergovernmental Panel on Climate Change (IPCC) (2018), Global Warming of 1.5C, Retrieved January 3, 2019, from https://www.ipcc.ch/ sr15/.

Jackson, T. (2017), Prosperity Without Growth - Foundations for the Economy of Tomorrow, $2^{\text {nd }}$ edition, Routledge: London.

Jordan, A., Huitema, D., Hildén, M., van Asselt, H., Rayner, T. J., Schoenefeld, J. J., Tolsun, J., Forsterm J. and Boasson, E. L. (2015), Emergence of Polycentric Climate Governance and its Future Prospects, Nature Climate Change, 5, 977-982.

Jordan, A., Huitema, D., van Asselt, H. and Forster, J. (2018), Governing Climate Change. Polycentricity in Action, Cambridge: Cambridge University Press.

Keohane, R. O. and Oppenheimer, M. (2016), Paris: Beyond the Climate Dead End through Pledge and Review, Politics and Governance, 4(3), 142-151. 
Keohane, R. O. and Victor, D. G. (2011), The Regime Complex for Climate Change, Perspectives on Politics, 9(1), 7-23.

Keohane, R. O. and Victor, D. G. (2016), Cooperation and Discord in Global Climate Policy, Nature Climate Change, 6, 570-575.

Kuyper, J., Schroeder, H., and Linnér, B-O. (2018), The Evolution of the UNFCCC, Annual Review of Environment and Resources, 43, 343-368.

Lövbrand, E., Hjerpe, M., and Linnér, B-O. (2017), Making Climate Governance Global: How UN Climate Summitry Comes to Matter in a Complex Climate Regime, Environmental Politics, 26(4), 580-599.

McGlade, C. and Ekins, P. (2015), The Geographical Distribution of Fossil Fuels Unused When Limiting Global Warming to $2^{\circ} \mathrm{C}$, Nature, 517(7533), 187-190.

Mead, L. (2018), GCAS Inspires New Climate Commitments, Urges National Governments to Step Up Climate Action by 2020, SDG Knowledge Hub, IISD, 18 September, Retrieved January 4, 2019, from http://sdg.iisd.org/ news/gcas-inspires-new-climate-commitments-urges-national-governments-to-step-up-climate-action-by-2020/.

Milman, O. (2018), World 'Nowhere Near on Track' to Avoid Warming Beyond 1.5C Target, The Guardian, 27 September, Retrieved January 4, 2019, from https://www.theguardian.com/environment/2018/sep/26/globalwarming-climate-change-targets-un-report.

Nasiritousi, N. (2017), Fossil Fuel Emitters and Climate Change: Unpacking the Governance Activities of Large Oil and Gas Companies, Environmental Politics, 26(4), 621-647.

Nasiritousi, N. (2016), Shapers, brokers and doers: the dynamic roles of non-state actors in global climate change governance, Thesis (PhD), Linköping University, Linköping.

Nasiritousi, N., Hjerpe, M. and Buhr, K. (2014), Pluralising Climate Change Solutions? Views Held and Voiced by Participants at the International Climate Change Negotiations, Ecological Economics, 105, 177-184.

Nordhaus, W. (2015), Climate Clubs: Overcoming Free-riding in International Climate Policy, American Economic Review, 105(4), 1339-1370.

Okereke, C. (2010), The Politics of Interstate Climate Negotiations, in Boykoff, M. (ed.), The Politics of Climate Change: A Survey, London: Routledge.

Ott, HE., Baver, S., Brandi, C., Mersmann, F. and Weischer, L. (2016), Climate Alliances après Paris: The Potential of Pioneer Climate Alliances to Contribute to Stronger Mitigation and Transformation, Working Paper, Retrieved January 4, 2019, from https://hermann-e-ott.de/cms/wp-content/ uploads/2016/11/PACA_paper_2016_WI-1.pdf. 
Pahle, M., Burtraw, D., Flachsland, C., Kelsey, N., Biber, E., Meckling, J., Edenhofer, O. and Zysman, J. (2018), Sequencing to Ratchet up Climate Policy Stringency, Nature Climate Change, 8, 861-867.

Rogelj, J., den Elzen, M., Höhne, N., Fransen, T., Fekete, H., Winkler, H., Schaeffer, R., Sha, F., Riahi, K. and Meinhausen, M. (2016), Paris Agreement Climate Proposals Need a Boost to Keep Warming Well Below $2^{\circ} \mathrm{C}$, Nature, 534(7609), 631-639.

Rosemberg, A. (2010), Building a Just Transition: The Linkages Between Climate Change and Employment, International Journal of Labour Research, 2(2), 125-161.

Samans, R. (2018), The Paris Accord Won't Stop Global Warming on Its Own, Foreign Policy Magazine, 26 September, Retrieved January 16, 2019, from https://foreignpolicy.com/2018/09/26/the-paris-accord-wont-stopglobal-warming-on-its-own/.

Shishlov, I., Morel, R. and Bellassen, V. (2016), Compliance of the Parties to the Kyoto Protocol in the First Commitment Period, Climate Policy, 16(6), 768-782.

Sterner, T., E. B. Barbier, I. Bateman, I. van den Bijgaart, A.-S. Crépin, O. Edenhofer, C. Fischer, W. Habla, J. Hassler, O. Johansson-Stenman, A. Lange, S. Polasky, J. Rockström, H. G. Smith, W. Steffen, G. Wagner, J. E. Wilen, F. Alpízar, C. Azar, D. Carless, C. Chávez, J. Coria, G. Engström, S. C. Jagers, G. Köhlin, Å. Löfgren, H. Pleijel and A. Robinson. (2019), Policy Design for the Anthropocene. Nature Sustainability 2(1): 14-21.

Stiglitz, J., Fitoussi, J. and Durand, M. (2018), Beyond GDP: Measuring What Counts for Economic and Social Performance, Paris: OECD Publishing.

The Global Commission on the Economy and Climate (2018), The New Climate Economy Report, Retrieved January 4, 2019, from https:// newclimateeconomy.report/2018/.

Underdal, A. (2017), Climate Change and International Relations (After Kyoto), Annual Review of Political Science, 20, 169-188.

UNEP (2018a), The Emissions Gap Report 2018, Nairobi: UNEP.

UNEP (2018b), Inclusive Wealth Report 2018, Nairobi: UNEP.

UNFCCC (2016), Marrakech Partnership for Global Climate Action, Retrieved January 16, 2019, from https://unfccc.int/sites/default/files/ marrakech_partnership_for_global_climate_action.pdf.

UNFCCC (2015), Paris Agreement, FCCCC/CP/2015/L.9/Rev.1.

UNFCCC (2011), Report of the Conference of the Parties on its seventeenth session, held in Durban from 28 November to 11 December 2011, FCCC/ CP/2011/9/Add.1. 
UNFCCC (1992) United Nations Framework Convention on Climate Change, FCCC/INFORMAL/84.

van den Bergh, J. C. J. M. (2017), Rebound Policy in the Paris Agreement: Instrument Comparison and Climate-club Revenue Offsets, Climate Policy, $17(6), 801-813$.

Victor, D. (2011), Global Warming Gridlock: Creating More Effective Strategies for Protecting the Planet, Cambridge: Cambridge University Press.

Victor, D. (2009), Plan B for Copenhagen, Nature, 461, 342-344.

World Bank. (2018), The Changing Wealth of Nations 2018 - Building a Sustainable Future, Washington, DC: World Bank.

Zelli, F. and van Asselt, H. (2015), Fragmentation, in Bäckstrand, K. and Lövbrand, E. (eds.), Research Handbook on Climate Governance,

Cheltenham: Edward Elgar. 


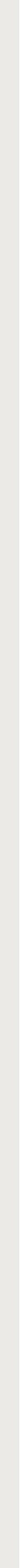




\section{Comment on N. Nasiritousi and K. Bäckstrand: \\ International Climate Politics in the Post-Paris Era}

\section{Torben K. Mideksa'}

Nasiritousi and Bäckstrand provide an insightful assessment of the evolution of the international politics of the climate change problem. They explain why countries find it challenging to cooperate and form an effective international climate agreement. The central hurdles include free-rider incentives, burden-sharing conflicts, and agreement-enforceability problems. The authors take a reader through the history of frustrating climate negotiations and convey the key point that the Paris Agreement, despite its unusual novel institutional features, is just the first step towards solving the conundrum of reducing global emissions. From the paper, one is predisposed to understand that the combinations of mandatory and voluntary provisions, top-down and bottom-up features, and reliance on state and non-state actors are the novel institutional features that the Paris Agreement has introduced in the international politics of mitigating climate change.

The discussion about the prospects of the post-Paris climate governance in light of the US withdrawal from the agreement, the lingering conflict about transparency and reporting between developing and developed countries, and the dwindling contributions to climate finance is spot on and quite relevant to contemporary climate policy. Similarly, the assessment about nexus thinking, catalytic linkages between different actors, and leadership through a climate club hints about the key emerging issues that will become crucial in facilitating the green transformation of the world economy. As I agree with the authors' evaluation and messages, I would like to add the following remarks.

First, there exists a strong tension between the agreement's goal and the ways of achieving the goal. The agreement is committed to a precise goal of keeping the global temperature change below two degrees Celsius. The ways of meeting this goal are decentralized, bottom-up, voluntary, and partially rely on non-state actors.

\footnotetext{
${ }^{1}$ Uppsala University. Email: torben_mideksa@post.harvard.edu.
} 
The agreement's link between the goal and the means of achieving the goal is at best weak. While institutional innovations can be useful, the effect of these institutional innovations on the bottom line of global emissions reduction is not clear. In fact, as Nasiritousi and Bäckstrand note, both the Kyoto Protocol and the Paris Agreement are weak international climate agreements (see also Tulkens 2016 and Weitzman 2016). It is puzzling as to why do countries sign up for environmentally ineffective global agreements that kick the solution to the future. Understanding why ineffective global environmental agreements emerge and how to make such agreements environmentally effective are important challenges to address the problem of climate change. ${ }^{2}$

Second, it is necessary to think about supporting policies that enable countries to get as much abatement as possible through the Paris Agreement. This is because the agreement is the only internationally comprehensive mechanism in place to address the problem. There can be many issues with the agreement, and temporary participation by a decisive country can become a contentious issue. The political realities so far suggest that the US, as a country, will not be a reliable participant in international environmental agreements. The policy challenge in this regard will be: how can the adherents to the agreement accommodate a country that can only deliver temporary and short-term emission reductions?

Since the first-best climate agreement seems to have frequently failed to pass the test of global politics, the ultimate remedy to the sub-optimal $\mathrm{CO}_{2}$ problem involves a combined stick- and-carrot approach by a coalition of powerful countries. One approach to getting more abatement, within the Paris framework, is through incentivizing free-riding countries using a border tax adjustment, or carbon tariff. Carbon tariffs by countries with a strong environmental commitment on the imports from non-participating countries, or countries with weak climate commitment, protect domestic producers who invest in decarbonized technologies. Such tariffs also provide internationally exporting firms elsewhere the right incentives to invest in a less $\mathrm{CO}_{2}$-intensive technology. Whereas a properly designed carbon tariff can be a sensible complementary

\footnotetext{
${ }^{2}$ With the exception of Battaglini and Harstad (2018) and Harstad (2018), I am not aware of research which addresses this puzzle.
} 
policy, the politics of effective border tax adjustment and its interaction with trade wars is not entirely clear (Nordhaus 2015, Sanctuary 2018). More research in this direction would be useful.

Another complementary approach, within the Paris framework, to raise global abatement is the provision of robust incentives for countries to abate more from activities with low economic and high environmental values. This can be done through forest and fossil fuel conservation contracts. The environmental and economic logic of such measures is straight forward (Harstad and Mideksa 2017). In fact, the Nordic countries have been in the forefront of financing and managing contracts to reduce deforestation and enhance biodiversity conservation in countries such as Brazil, Guyana, and Indonesia. While an empirically credible evaluation of such contracts will take time, such incentives have reduced deforestation as stipulated in the contracts. Beyond the reductions in deforestation, however, the experience with these contracts is too limited to let policy makers and researchers understand what does and what does not work. In addition, offering conservation contracts can result in changes in domestic political institutions, which can induce either positive or perverse conservation incentives (Harstad and Mideksa 2016). More research in this direction can be valuable.

Finally, leadership in climate policy is important. Until recently, the economic case for leadership and unilateral strategies to reduce $\mathrm{CO}_{2}$ emissions has been understudied. An emerging body of research has examined the different dimensions through which leadership can contribute towards facilitating reductions of global $\mathrm{CO}_{2}$ emissions (Brandt 2004, Golombek and Hoel 2004, Eskeland 2013, Mideksa 2016, Buchholz and Eichenseer 2017, Leroux and Spiro 2018, Greaker et al. 2019).

Leadership can be useful to signal a country's commitment to reduce emissions or the fact that abatement costs are cheap when they are indeed cheap. Low abatement is a decisive signal that the climate change is not a serious problem. If a country with an experience of addressing other environmental problems commits to small emissions reduction, then countries without the experience infer that abatement could be very costly and refrain from socially useful emissions reduction. A credible way to convey useful information that abatement costs are low is commitment to larger, not 
smaller, emissions reduction. Similarly, leadership entailing investment in R\&D that can reduce abatement cost in other countries can facilitate emissions reduction there (Mideksa 2016).

To sum up, the politics of addressing global climate change is very demanding. Perhaps, the most important point from the Nasiritousi and Bäckstrand paper is that there is a need for constructive ideas that can help countries mobilize resources to generate significant emissions reductions in the near term.

\section{References}

Battaglini, M. and Harstad, B. (2018), The Political Economy of Weak Treaties, Working Paper, Department of Economics, University of Oslo.

Brandt, U. S. (2004), Unilateral Actions, the Case of International Environmental Problems, Resource and Energy Economics, 26(4), 373-391.

Buchholz, W. and Eichenseer, M. (2017), Advantageous Leadership in Public Good Provision: the Case of an Endogenous Contribution Technology, Journal of Economics, 126(1), 1-17.

Eskeland, G. S. (2013), Leadership in Climate Policy: Is there a Case for Early Unilateral Unconditional Emission Reductions?, NHH Dept. of Business and Management Science Discussion Paper No. 2013/6, Norwegian School of Economics.

Golombek, R. and Hoel, M. O. (2004), Unilateral Emission Reductions and Cross-country Technology Spillovers, Advances in Economic Analysis \& Policy, 3(2): 1-25.

Greaker, M., Golombek, R. and Hoel, M. (2019), Global Impact of National Climate Policy in the Nordic Countries, this volume.

Harstad, B. (2018), Pledge-and-Review Bargaining, Working Paper, Department of Economics, University of Oslo.

Harstad, B. and Mideksa, T. K. (2016), Conservation Contracts and Institutional Change, Working Paper, Department of Economics, University of Oslo.

Harstad, B. and Mideksa, T. K. (2017), Conservation Contracts and Political Regimes, Review of Economic Studies, 84(4), 2017, 1708-34.

Leroux, J. and Spiro, D. (2018), Leading the Unwilling: Unilateral Strategies to Prevent Arctic Oil Exploration, Resource and Energy Economics, 54, 125-149. 
Mideksa, T. K. (2016), Leadership and Climate Policy, Working Paper, Department of Economics, University of Oslo.

Nordhaus, W. (2015), Climate Clubs: Overcoming Free-riding in International Climate Policy, American Economic Review, 105(4), 1339-70.

Sanctuary, M. (2018), Border Carbon Adjustments and Unilateral Incentives to Regulate the Climate, Review of International Economics, 26(4), 826-851.

Tulkens, H. (2016), COP 21 and Economic Theory: Taking Stock, CESifo Working Paper 5918, CESifo Group Munich.

Weitzman, M. L. (2016), On a World Climate Assembly and the Social Cost of Carbon, NBER Working Paper Series No. 22813, National Bureau of Economic Research. 


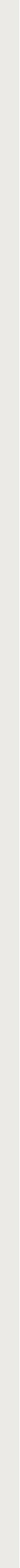




\section{Comment on N. Nasiritousi and K. Bäckstrand: \\ International Climate Politics in the Post-Paris Era}

\section{Åsa Romson ${ }^{1}$}

This comment discusses two of the main findings in the Nasiritousi and Bäckstrand article on the Paris Agreement: the shift of logic from the top-down approach for developed states only to the bottom-up approach for all, and the notable strong support that was given the agreement by non-state actors. The paper highlights how the Paris Agreement makes national climate policies become international law and suggests an implementation of Paris principles on non-state actors. The exposition further suggests that a legal perspective may enrich the understanding of today's climate governance.

As Nasiritousi and Bäckstrand note, the Paris Agreement in many ways represents a significant shift in global climate politics. The replacement of the Kyoto protocol top-down approach for developed states only with a bottom-up pledge-and-review system, accommodating all states, has indeed changed the rules of the game for global climate law and policy. Also, the negotiating context in which the agreement was finally delivered implies significant novelties regarding active participation of non-state actors.

By shifting the logic for participation in the global climate regime, it was possible to agree on a legal framework that included all states. As climate emission impacts are global and fossil fuels are used across all societies, this was a critical achievement (and in itself a reason why the climate meeting in Paris was announced in media as a success). As Nasiritousi and Bäckstrand note, the background for this shift was founded in Copenhagen 2009 at a climate meeting, described as a fiasco at the time.

The new logic in the climate regime also puts national law and policy at the core for the fulfilment of the international agreement. By its requirement of National Determined Contributions (NDCs) - the instrument where each state describes its climate goals and work

${ }^{1}$ IVL Swedish Environmental Research Institute. Email: asa.romson@ivl.se. 
plan for climate mitigation and adaptation - the Paris Agreement balances the need for differentiation of states' commitments with the needs for collective measurable results and tools to incentivise states to more ambitious climate goals. Hereby the policies that states are able to communicate are put into, and thereby building, a framework of international law.

Many have emphasised how the bottom-up approach may result in weak international goals and insufficient climate actions, also questioning the legal standard of the commitments. While some of those arguments are valid, there is more to the picture. The bottom-up approach should be scrutinised concerning the linkage between international objectives and the agreement's power to push national climate law and policy to be more ambitious. Article 4.3 of the Paris Agreement states:

'Each Party's successive nationally determined contribution will represent a progression beyond the Party's then current nationally determined contribution and reflect its highest possible ambition...' (italics by author).

As Rajamani and Brunnée (2017) argue, this principle clearly restricts states' ability to roll back their climate goals (as long as they want to stay in the Paris Agreement). Furthermore, the standard to evaluate each state's NDC, as demonstrated by Voigt (2016), is set to the highest possible climate ambitions regarding the circumstances for the country. This means that everybody has to do what one can to halt climate emissions, no less.

It is not the quantities of climate mitigation expressed by the states in their first NDCs that show if the Paris Agreement will succeed. The real test will be when the NDCs are renewed every five years, after a global stocktaking and evaluation of the actions taken. A true success, and overcoming the collective actions dilemma, would be if the future NDCs together imply more ambitious climate policies for the planet, closing the gap to meet the two degrees objective. 
A legal agreement between states has its limits regarding the degree to which it can affect global climate emissions. Nasiritousi and Bäckstrand suggest that a good outcome of Paris is 'if it contributes to changing behaviour among states and non-state actors by providing an infrastructure, signal and direction for ramping up climate action and political commitments to decarbonisation'. The non-state actors play a double role when implementing the agreement. Some of the actors contribute significantly to climate emissions, but also have access to many of the new techniques and solutions to mitigate and stop the emissions. At the same time, as shown by i.a. Chan et al. (2016), many non-state actors have enrolled themselves in initiatives connected to the Paris Agreement and thereby broaden the political mandate of the agreement.

Nasiritousi and Bäckstrand note with interest after the climate meeting 2018 that 'UNFCCC emerges as a broker for aligning and scaling up [both] non-state and state commitments'. However, so far it is the non-state actors who voluntarily announce their climate responsibility as a part of the Paris Agreement, most clearly with the campaign 'We're still in' from U.S states and companies who stepped in to fill the void left by the withdrawal of the federal government. If such initiatives find a way into the legal framework of reaching the goals of Paris is still to be seen.

At the national level, in the process of climate policies and designing new and more ambitious NDCs, there is much room for bringing new forms of arrangements to strengthen climate actions and distribute climate responsibility. NGO as well as private actor or municipality activities can become part of the NDCs and consequently the Paris Agreement. The NDC tool may then become, at the national level, what Nasiritousi and Bäckstrand suggest for the Paris Agreement: an infrastructure, signal and direction for actions to decarbonise. It also makes good sense to implement the new principles of Paris equally on states and non-states. Those are: not to back on your commitments and always do the most you can to halt climate missions. The broad political mandate for the Paris Agreement could support such implementation. 
To conclude, the Paris Agreement represents a significant shift for global climate governance although its success is too early to judge. This comment is a lawyer's reading of the article by Nasiritousi and Bäckstrand and highlights i.a. how the agreement makes national climate policies become international law and suggests an implementation of Paris principles on non-state actors. My comment further tries to show how a law perspective may enrich the understanding of today's climate governance.

\section{References}

Chan, S., Brandi, C. and Baver, S. (2016), Aligning Transnational Climate Action with International Climate Governance: The Road from Paris, RECIEL, 25(2), 238-247.

Rajamani, L. and Brunnée, J. (2017), The Legality of Downgrading National Determined Contributions under the Paris Agreement: Lessons from U.S. Disengagement, Journal of Environmental Law, 29(3), 537-551.

Voigt, C. (2016),The Paris Agreement: What is the Standard of Conduct for Parties?, Questions of International Law, March 21. 


\section{National Climate Policies and the European Emissions Trading System}

Frederik Silbye ${ }^{1}$

Peter Birch Sørensen²

\section{Abstract}

We set up a model of the European Emissions Trading System (ETS) to evaluate the prospects for the system after the recent reform. Our simulations indicate that the current allowance surplus may not disappear before the 2050s. They also show that the mechanics of the new Market Stability Reserve imply that annulment of allowances by an EU member state may be largely ineffective, whereas national emission reductions can permanently reduce $\mathrm{EU}$-wide $\mathrm{CO}_{2}$ emissions. We suggest that the next ETS reform should include a floor and a ceiling for the price of emission allowances.

Keywords: European Emissions Trading System, Market Stability Reserve, effectiveness of national climate policies.

JEL codes: Q48, Q52, Q58.

\footnotetext{
${ }^{1}$ Secretariat of the Danish Council on Climate Change. E-mail: frederik.silbye@klimaraadet.dk.

${ }^{2}$ Department of Economics, University of Copenhagen. E-mail: pbs@econ.ku.dk.
} 


\section{Introduction}

Economists have long pointed out that the costs of cutting global greenhouse gas emissions may be reduced by allowing international trade in emission rights. The Emissions Trading System (ETS) in the European Union is so far the most important attempt to reap the gains from trade in $\mathrm{CO}_{2}$ emission allowances, accounting for over three quarters of international carbon trading. The ETS covers the energy sector and energy-intensive industrial emitters, representing about 45 percent of total greenhouse gas emissions in the EU (European Commission 2017).

Despite the existence of the ETS, member states of the European Union offer extensive government support for renewable energy, including various investment subsidies as well as feed-in tariffs and feed-in premiums for renewables-based electricity production. Many economists ${ }^{3}$ have been highly critical of the overlapping regulations implied by the combination of national subsidies to renewables and the EU-wide cap-and-trade system for the ETS sector. The critics argue that national subsidies do not benefit the climate since the total emissions from the ETS sector are capped and that they increase the cost of meeting EU climate policy targets by preventing the cross-country equalization of marginal abatement cost that the free trade in emission allowances would otherwise bring about.

On the other hand, many observers have argued that the current large surplus of ETS emission allowances keeps the allowance price below the level needed to spur a quick transition to renewable energy. According to these critics, the allowance surplus implies that member state subsidies to renewables within the ETS sector will in fact reduce total emissions in the short and medium term and may help to pave the way for a reduction in total allowance supply. ${ }^{4}$

Against this background the present paper seeks to answer four questions: (1) Has the ETS fulfilled its mission so far? (2) What are the prospects for the European carbon market after the latest

\footnotetext{
${ }^{3}$ Böhringer et al. (2008), Eichner and Pethig (2009), Böhringer et al. (2009a, 2009b), Boeters and Koornneef (2011) and Heindl et al. (2015) to name but a few.

${ }^{4}$ See, e.g., Sandbag (2016a) and the Danish Council on Climate Change (2017).
} 
reform of the ETS in 2018? (3) Are member state policies aimed at reducing national emissions from the ETS sector ineffective? (4) How can the future performance of the ETS be improved?

Our analysis has three main implications: First, despite the 2018 ETS reform aimed at reducing the surplus of emission allowances and driving up the allowance price, the allowance surplus is likely to persist for several decades in the absence of further reform. Second, because the 2018 reform endogenizes the total supply of emission allowances, national policy measures that reduce the demand for emission allowances can reduce total European emissions permanently and not just temporarily. Third, the welfare cost of cutting total emissions can be reduced by introducing a minimum and a maximum price of ETS emission allowances.

The present paper extends the analysis in Silbye and Sorensen (2017), which was written before the recent agreement on reform of the ETS. Like us, Perino and Willner (2017), Beck and Kruse-Andersen (2018), Carlén et al. (2018) and the National Institute of Economic Research (2018) evaluate the effects of the reform using simple partial equilibrium simulation models of the ETS. We go beyond these studies by taking into account the recent spike in the allowance price, which we interpret as a consequence of increased investor confidence in the ETS.

The paper is organized as follows: Section 2 sketches the history of the ETS and offers a brief evaluation of its performance so far. Section 3 sets up a simple partial equilibrium model of the emissions trading system, and Section 4 uses the model to evaluate the implications of the 2018 ETS reform for the future evolution of the allowance supply, actual emissions and the allowance price. In Section 5 we use the model to estimate the effect on emissions of two alternative national measures to reduce emissions from the ETS sector: cutting domestic emissions in the ETS sector versus annulment (or purchase) of ETS allowances by the domestic government. Section 6 discusses options for further reform of the system, while our main conclusions are summarized in Section 7. 


\section{A brief history of the European Union Emissions Trading System ${ }^{5}$}

Before considering the consequences of the latest ETS reform, it is instructive to highlight the performance of the system so far. This section provides a brief history.

\subsection{The mechanics of the ETS}

The ETS covers about 45 percent of $\mathrm{CO}_{2}$ emissions in the EU. The system applies to $\mathrm{CO}_{2}$ emissions and equivalent amounts of nitrous oxide and perfluorocarbons from installations in energy-intensive industrial sectors. ${ }^{6}$ By April 30 of each year, registered firms in the ETS sector must surrender emission allowances corresponding to their emissions in the previous calendar year. Allowances can be freely traded across the EU, and a significant share of allowance trades is handled by banks and financial institutions using allowances as financial assets.

Phase I of the ETS was a pilot stage covering the period from 2005 until the end of 2007. Emission allowances in this phase were distributed freely and could not be banked for use in subsequent phases. Phase II coincided with the compliance period 2008-2012 under the Kyoto Protocol. Since the beginning of Phase II, allowances can be banked for use in later phases. The system is currently in Phase III covering the period 2013-2020. From the start of Phase III, a significant and growing share of allowances is being auctioned rather than allocated free of charge to emitting companies.

\subsection{The emissions cap versus actual emissions}

Figure 1 shows the aggregate emissions cap along with the actual verified emissions and the cumulative surplus of unused allowances over the period 2008-2017. In addition to the allowances issued by the EU, firms in the ETS sector were allowed to use a total of almost 1.5 billion so-called offset units from the Kyoto Protocol's

\footnotetext{
${ }^{5}$ This section draws on Gronwald and Hintermann (2015), Ellerman et al. (2016), and the Danish Council on Climate Change (2017) who offer more detailed accounts of the history of the ETS.

${ }^{6}$ Since 2012, emissions from intra-EU aviation have been included as well, but this sector has a separate emissions cap.
} 
Figure 1 Allocations, emissions, and allowance surplus in the EU ETS

$\mathrm{Mt} \mathrm{CO}_{2}$

3500

3000

2500

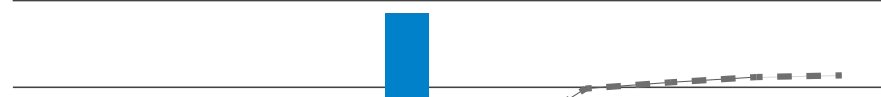

2000
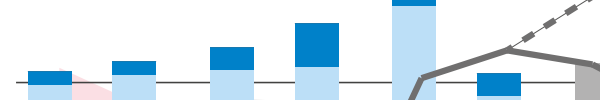

1500

1000

- $-1=$

500

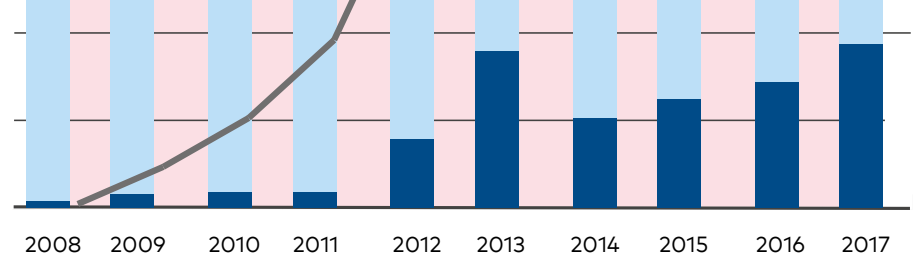

Emissions $\longrightarrow$ Backloading

International offsets

Free allocations

Auctioned allowances

Allowance surplus

- n - . Allowance surplus incl. MSR

Note: Backloading implied that $400 \mathrm{Mt}, 300 \mathrm{Mt}$, and $200 \mathrm{Mt}$ of allowances were held back from the market in 2014, 2015, and 2016, respectively. The backloaded allowances will be placed in the coming Market Stability Reserve (MSR) from 2019. They are included in the allowance surplus shown by the dashed line in the figure.

Source: Carbon Tracker Initiative (2018).

flexible mechanisms during Phase II.7 This has contributed significantly to the cumulative allowance surplus illustrated in the diagram. Another major factor behind the surplus was the fall in energy demand caused by the Great Recession in 2008-09 and the subsequent European sovereign debt crisis. National subsidies to renewable energy have likewise contributed to falling demand for emission allowances. The cumulative allowance surplus fell slightly

\footnotetext{
${ }^{7}$ These offsets are certified emission reductions under the Clean Development Mechanism and emission reduction units from Joint Implementation in Annex B countries.
} 
in 2014 and 2015 as some allowances were withheld from the market through an ad hoc measure labelled as backloading. The current allowance surplus roughly corresponds to one year of emissions.

In the current Phase III the total amount of allowances issued under the ETS is reduced linearly at an annual rate of 1.74 percent of the average emissions cap in Phase II. In Phase IV, which will cover the period 2021-2030, the annual linear reduction of the cap will be 2.2 percent. In addition, the European Council and the European Parliament agreed in the spring of 2018 to establish a so-called Market Stability Reserve (MSR) from 2019 to gradually absorb part of the allowance surplus. ${ }^{8}$ Section 3 describes the detailed mechanics of the MSR which will significantly change the dynamics of the ETS.

\subsection{Evolution of the price of allowances}

Figure 2 illustrates how the spot price of ETS allowances has evolved. The allowance price has been quite volatile. Towards the end of Phase I, the price collapsed to zero as it became clear that the non-bankable allowances issued during this phase would exceed total accumulated emissions. During the first half year of Phase II the allowance price reached its previous peak of around 30 euros per ton, but then the Great Recession quickly drove the price down to around 10-15 euros. As the European sovereign debt crisis deepened in 2011 and 2012, the price was pushed further down to around 5-6 euros.

After rising a bit during 2015, the allowance price came back to 5-6 euros in 2016 and hovered around that level throughout the first half of 2017. However, beginning in late 2017 and continuing during 2018, the price rose sharply and reached a level of around 25 euros in September. Recently, the price has dropped slightly but it still exceeded 20 euros in December 2018.

In an empirical study based on data for the ETS for the period from January 2008 to October 2013, Koch et al. (2014) found that only about 10 percent of the variations in the allowance price could be explained by changes in fundamentals such as fossil fuel prices,

\footnotetext{
${ }^{8}$ The decision to establish the MSR from 2019 was actually made already in 2014, but the recent agreement between the Council and the Parliament includes an important tightening of the rules for the MSR.
} 
Figure 2 The spot price of ETS allowances (monthly averages)

EUR per ton

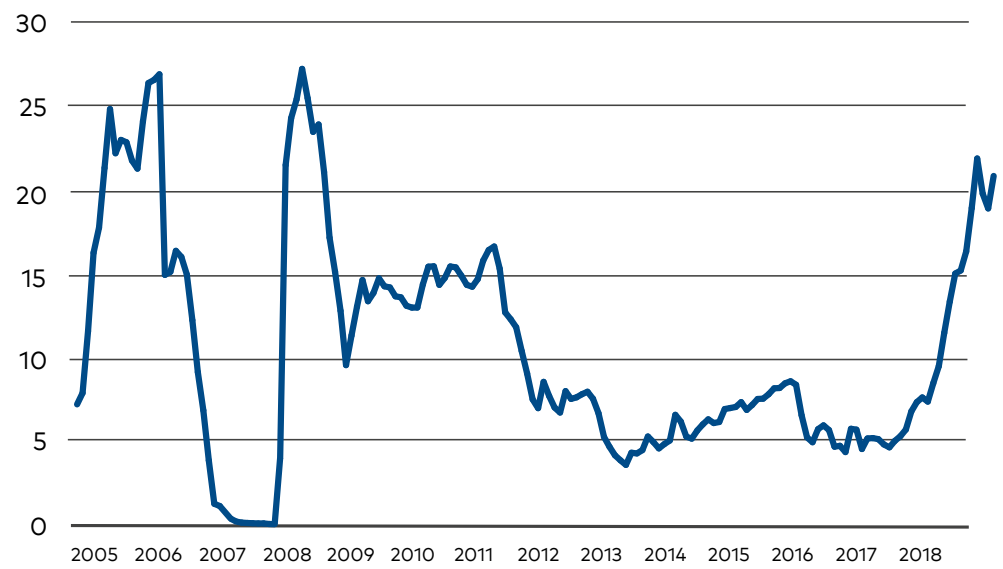

Note: Last price quote retrieved on December 17, 2018.

Source: Market data from European Energy Exchange AG.

expected future economic activity, subsidies to renewables, and additions to the allowance supply from the Kyoto Protocol's flexible mechanisms. The authors suggest that changes in the allowance price may have been driven mainly by shifts in market confidence in the willingness of policy makers to sustain the ETS. We shall return to this possibility below when we discuss the potential reasons for the 2018 price surge.

\subsection{Has the ETS fulfilled its mission so far?}

Critics of the ETS would answer 'No'. They point out that the average level of the allowance price has so far been much lower than expected when the ETS was introduced, so the cap-and-trade system has not provided a sufficient incentive to replace fossil fuels by carbon-free sources of energy. The insufficient incentive is further weakened by the fact that the allowance price has been highly volatile, creating great uncertainty about the profitability of development of and investment in green energy technologies. Against that background, critics of the ETS see national taxes on fossil fuel use and national subsidies to renewable energy within the ETS sector as a reasonable response to the fact that the ETS in itself has not 
been able to drive the transition to green energy at the pace needed. The critics argue that such national policy measures will in fact reduce total European emissions since the ETS cap on total emissions is non-binding due to the large allowance surplus.

On the other hand, defenders of the system argue that the ETS is working as intended in the basic sense that actual emissions do not exceed the emissions cap reflecting the political level of ambition regarding emissions reductions. According to the defenders, the substantial amount of trade in emission allowances indicates that the ETS also fulfills its purpose of reallocating abatement efforts towards emitters with the lowest marginal abatement costs, thus helping to reduce the total costs of emissions reductions. The defenders point out that the existence of an allowance surplus does not necessarily indicate that the ETS is inefficient. On the contrary, by saving allowances for future use when the emissions cap is expected to be tighter, firms are able to smooth their abatement costs over time, thus reducing the present value of costs. Finally, defenders of the ETS argue that the large allowance surplus and the resulting low allowance price is due in large part to the national subsidies to renewables which prevent a cross-country equalization of marginal abatement costs and will not succeed in cutting total emissions in the long run when the emissions cap becomes binding.

\section{A simple partial equilibrium model of the ETS 9}

To analyze the effects of the 2018 ETS reform and the impact of alternative national climate policies we set up a model of the allowance market which accounts for the rules governing the supply of emission allowances. The model determines time paths for the evolution of the allowance price and $\mathrm{CO}_{2}$ emissions from the ETS sector, given the time path for the annual issue of new allowances and the impact on allowance supply of the new Market Stability Reserve (MSR) taking effect from 2019. This section provides a

\footnotetext{
${ }^{9}$ The model is identical to the one in Silbye and Sørensen (2017) except that here we explicitly lay out its microfoundations in the Appendix. After having finished the development of the model, we became aware of the papers by Perino and Willner $(2016,2017)$ who use a very similar model, but with a different calibration leading to different conclusions. We discuss the relationship of our work to theirs in the final part of Section 4.
} 
non-technical presentation of the model, while the details can be found in the Appendix.

\subsection{The demand for emission allowances}

Emissions and, thus, demand for allowances come from many different companies and subsectors within the ETS sector. Instead of modelling emissions using a bottom-up approach that considers each subsector separately, we model one representative firm. As explained in the Appendix this approach leads to a linear emissions function of the form

$$
E_{t}=\bar{E}_{t}-b p_{t}, \quad E_{t} \geq 0,
$$

where $E_{t}$ is the actual emission of $\mathrm{CO}_{2}$ in year $t$ and, thus, the amount of surrendered allowances, $\bar{E}_{t}$ is the emission in year $t$ in the absence of the ETS, $p_{t}$ is the allowance price in year $t$, and $b$ is a parameter that measures the price responsiveness of emissions.

The specification in (1) allows for downward shifts in the emissions level even without ETS. This is due to progress in energy efficiency and in the relative efficiency of green energy technologies. To account for such factors which tend to reduce emissions at any given allowance price, we assume that emissions in the absence of ETS $\left(\bar{E}_{\text {, }}\right.$ ) fall by a constant $z$ percent per year.

By choosing the simple approach of a representative firm and a linear emissions function we cannot replicate the finer details of actual emissions, e.g., the kink when gas replaces coal on the electricity merit order. However, it allows us to look into the far future without having to make dubious guesses about the technologies to come.

\subsection{The supply of emission allowances}

New allowances are issued each year at a declining rate. If the rate to be used in the coming Phase IV is extrapolated, the last new allowances will be issued in 2057. Some allowances are auctioned by the EU member states whereas others are allocated freely; however, this distinction is not relevant to the model as the marginal opportunity cost of emitting $\mathrm{CO}_{2}$ is the same whether the emitting firm must pay for an allowance or refrain from selling one from its own stock of allowances. 
From 2019 the issuance of new allowances will be adjusted by the MSR mentioned in Section 2. A fraction of 12 percent of the total allowance surplus in the market must be withheld from the yearly auctions and transferred to the MSR if the surplus exceeds 833 million tons of $\mathrm{CO}_{2}$, which is almost half the current surplus. According to the recent agreement on ETS reform, this fraction is raised to 24 percent until the end of 2023. The rules for the MSR also stipulate that allowances amounting to 100 million tons of $\mathrm{CO}_{2}$ (or the entire remaining reserve if this is smaller than 100 million tons) must be released from the reserve and auctioned whenever the allowance surplus falls short of 400 million tons.

From 2023 there will be a cap on the amount of allowances that can be held in the MSR. Allowances above the cap will be automatically and permanently annulled. The cap will equal the amount of allowances that was auctioned during the previous year (by regulation, auctioned allowances amount to 57 percent of all issued allowances).

Taking the workings of the MSR into account, the allowance surplus at the end of a given year equals the surplus in the preceding year plus the MSR-adjusted issuance of new allowances and minus emissions. Each year, the European Commission makes an official count of the surplus to be used for the calculation of the MSR transfers.

\subsection{The equilibrium allowance price}

The representative firm of the model will only hold allowances for later use if it expects the allowance price to increase at a rate equal to or above the firm's required rate of return. Since any expected price increase above the required rate of return will make it very attractive to hold allowances, the demand for allowances will raise the current allowance price until the expected future increase in the price no longer exceeds the required return. In market equilibrium the actual price increase must thus equal the required rate of return, which therefore determines the price path as long as the allowance surplus in the market is positive. Note also that the allowance price will be positive only if the market expects that the surplus will vanish in some future period $T$ so that allowances become scarce. 
For a given choice of $T$, the model finds the initial price that balances total demand and supply up until year $T$. This suggests one explanation why the allowance price rose significantly from 2017 to 2018: The ETS reform that was finally agreed upon in March 2018 involves a substantial initial transfer of allowances to the MSR and introduces the automatic and permanent annulment of allowances above the cap, so forward-looking market agents will expect that the allowance surplus will vanish sooner than previously believed, generating increased demand today and higher prices.

Ideas for tightening of the MSR rules were discussed in public well before the final agreement on the ETS reform, so the reform was anticipated to some extent by the market. This helps to explain why the price started to go up already in late 2017. But since the final reform agreement following several years of hard bargaining resolved some of the uncertainty regarding the future of the ETS and probably increased market confidence in the system, it seems likely that holding allowances for future use or sale is now seen as a less risky investment. In that case the reform has lowered the risk premium included in the required rate of return, thereby providing an additional force that can drive up the allowance price.

\subsection{Measuring the effects of national climate policies}

In Section 5 we will use our model to analyse the effects on EU-wide emissions of two types of national climate policy: An annulment of emission allowances undertaken by an EU member state, or a policy measure such as a national carbon tax or a national subsidy to renewable energy that reduces the demand for ETS emission allowances in a member state.

A member state can implement the annulment policy either by abstaining from auctioning some of the emission allowances that have been allocated to it or by purchasing allowances in the market and withdrawing them from circulation. If the current supply of allowances were a binding cap on current emissions (i.e. if there were no allowance surplus), an annulment of, say, 1 million ton of allowances would immediately lead to a corresponding fall in emissions. However, in the current market situation with an allowance surplus, an annulment of allowances will only reduce 
emissions to the extent that it drives up the price of allowances. In this case we may measure the impact on emissions by the Coefficient of Emission Reduction (CER) defined as

$$
C E R_{t, H}^{S}=\frac{\text { Accumulated fall in emissions from year } t \text { until year } H}{\text { Cut in allowance supply in year } t}
$$

The superscript $S$ in $C E R_{t, H}^{S}$ indicates that we are considering a reduction in the supply of emissions allowances. The subscript $t, H$ means that this reduction is undertaken in year $t$ and that we are considering its total effect on the accumulated emissions up until some future year $H$ representing the time horizon of policy makers. For example, if $C E R_{2020,2050}^{S}=0.5$, an annulment of 1 million tons of emission allowances undertaken in 2020 will only reduce the total accumulated emissions over the period from 2020 to 2050 by half a million tons. Note that (i) if the supply of allowances were fully exogenous and (ii) the accumulated emissions exceed the accumulated issues of allowances in finite time, then the $C E R$ defined in (2) would always be 1 if the policy horizon is sufficiently long, i.e. if $H$ is sufficiently large. In other words, the annulment of an allowance would then always reduce the accumulated emissions by a similar amount even in the presence of a temporary allowance surplus.

However, from 2019 the allowance supply will in fact become endogenous due to the complex mechanics of the MSR described above. The cap on the MSR raises the possibility that annulment of allowances by individual member states may be partly offset by fewer annulments of allowances held in the MSR. In that case the CER defined in (2) will be smaller than 1 no matter how long the time horizon is. ${ }^{10}$

A member state policy such as a subsidy to renewable energy or a carbon tax that reduces the demand for emission allowances in year $t$ by one unit can be modelled as a unit reduction in the

\footnotetext{
10 The $C E R$ will also be smaller than 1 if condition (ii) is violated, i.e., if the allowance surplus never goes away, say, because rapid technical progress in green energy technologies drives the demand for allowances to zero as described in Scenario 2 in Silbye and Sørensen (2017).
} 
exogenous variable $\bar{E}_{t}$ in (1). By analogy to (2), the Coefficient of Emission Reduction associated with such a policy is defined as

$$
C E R_{t, H}^{D}=\frac{\text { Accumulated fall in emissions from year } t \text { until year } H}{\text { Cut in allowance demand in year } t}
$$

The $D$-superscript on the left-hand side of (3) indicates that we imagine any type of policy that reduces the demand for ETS emission allowances. There is a tight link between the coefficient $C E R_{t, H}^{S}$ defined in (2) and the coefficient $C E R_{t, H}^{D}$ specified in (3). The link may be explained as follows: According to (1) the demand for allowances reacts in a symmetric way to increases and decreases in the allowance price, so $C E R_{t, H}^{S}$ does not only measure the accumulated fall in emissions caused by a unit cut in the supply of allowances; it also measures the accumulated increase in emissions generated by a unit increase in allowance supply. A one ton increase in the supply of allowances has the same direct impact on the allowance surplus as a fall in the demand for allowances of one ton, so both policies will have the same effect on the allowance price. Hence the fall in the allowance price induced by a unit fall in allowance demand will increase the accumulated emissions by the amount $C E R_{t, H}^{S}$. The net effect on accumulated emissions of a policy that initially reduces emissions by one ton (thereby reducing the demand for allowances by one ton) will therefore be equal to $1-C E R_{t, H}^{S}$. In other words, we have the relationship $C E R_{t, H}^{D}=1-C E R_{t, H}^{S}$, where the number 1 on the right-hand side of the equation measures the initial fall in emissions, while $-C E R_{t, H}^{S}$ measures the offsetting subsequent increase in emissions caused by the fall in the allowance price. ${ }^{11}$

\subsection{Timing of emissions}

The $C E R$ can be used by policy makers to evaluate the climate impact of various national policy initiatives. However, the CER measures accumulated emissions and is indifferent to the timing of those emissions within the policy horizon. Yet the prospect of a long-lasting allowance surplus within the ETS gives reason to believe that emission cuts are being postponed for too long from a social perspective. In that case emission cuts have a lower social value the further into the future they are undertaken. The argument runs as follows: Cost-minimizing firms will abate emissions up to the point

${ }^{11}$ This result is proved mathematically in Silbye and Sørensen (2017). 
where their marginal abatement cost equals the allowance price. Ideally the allowance price should equal the Social Cost of Carbon (SCC), defined as the present value of the future damage costs caused by the emission of an extra ton of $\mathrm{CO}_{2}$. Many Integrated Assessment Models of the interaction between the economy and the climate system imply that, under an optimal climate policy, the SCC rises over time at a rate equal to the growth rate of GDP (see, e.g., Golosov et al. 2014, and Hassler et al. 2016). But when there is a surplus of emission allowances, the allowance price will rise at a rate equal to the required rate of return which will almost surely exceed the rate of economic growth since it is likely to include a considerable risk premium. Hence the marginal abatement cost will rise at a rate exceeding the growth rate of the $\mathrm{SCC}$, indicating that too little abatement is undertaken in the short run and too much is postponed until later. To account for this distortion, policy makers may want to assign a lower value to emission cuts that occur at a later point in time. This can be done by applying a discount rate to future emission cuts, as suggested by Silbye and Sørensen (2017). Such a procedure is in line with the extensive literature on the socalled Green Paradox of climate policy sparked by the contribution by Sinn (2008) which assumes that postponing emissions is socially desirable. ${ }^{12}$

As a pragmatic alternative to discounting, one may simply choose to ignore emission cuts occurring beyond some chosen policy horizon $H$. This is the approach adopted here. If instead one applies a discount rate to future emission cuts, it will only strengthen our conclusion below that national climate policies which reduce the demand for emission allowances are generally more effective than a policy of annulling allowances at the EU member state level (see Silbye and Sørensen 2017).

\section{The effects of the 2018 reform of the ETS}

We use a calibrated version of our model of the ETS to evaluate the effects of the 2018 reform on the likely evolution of the future allowance surplus and the future $\mathrm{CO}_{2}$ emissions from the sector. The main change in the system is the new Market Stability Reserve

12 See, e.g., Gerlagh (2011) and van der Ploeg and Withagen (2012). 
taking effect from 2019. The introduction of the MSR from that year was agreed upon already in 2015 , but without a cap on the total allowances held in the reserve. The 2018 agreement on the rules for ETS introduced the cap on the MSR and raised the rate of transfer of surplus allowances to the MSR from 12 percent to 24 percent in the period 2019-23.

To highlight the effects of these separate elements of the MSR, we will compare two scenarios: one in which the MSR follows the rules agreed upon in 2015, and one in which the reserve evolves according to the final rules decided in 2018. In both scenarios we assume that, starting from the beginning of Phase IV in 2021, the issuance of new emission allowances is reduced linearly at an annual rate of 2.2 percent of the average emissions cap in Phase II (up from the 1.74 percent annual reduction during Phase III), since this tightening of the system has been planned for a long time. Thus our analysis focuses on the effects of the MSR and assumes that the 2.2 percent annual reduction of new allowance issues will be maintained until the last allowance is issued in 2057.

\subsection{Calibrating the model}

We first calibrate the model to the market situation in 2017, setting the required expected annual return on allowances $(r)$ equal to 10 percent corresponding to the assumption made in the simulations by Perino and Willner (2016) and Sandbag (2016b). This is roughly in line with the study by Neuhoff et al. (2012) who found that the marginal investors holding ETS allowances as a speculative investment required expected returns in the order of 10-15 percent. It should be noted that a large portion of the allowance surplus is held by utilities and industry for hedging purposes and presumably at much lower required rates of return. In an extended version of the model we have allowed for a continuum of required returns, but this does not alter results significantly as the required return of the marginal investor is fairly stable. Our price sensitivity parameter $b$ in (1) is set equal to 2.2, implying that a rise in the allowance price of one euro causes a drop in emissions amounting to 2.2 million tons of $\mathrm{CO}_{2}$. Again, this accords with the assumption made in Sandbag (2016b) which is based on the price response of the market to date and studies of marginal abatement cost curves. 
The parameters $z$ and $\bar{E}_{0}$ are then calibrated so that the model reproduces the 1,754 million tons of $\mathrm{CO}_{2}$ emissions and the average allowance price of 5.8 euros per ton of $\mathrm{CO}_{2}$ observed in 2017, assuming that the market in 2017 correctly expected the linear annual reduction of new allowance issues to be raised to 2.2 percent from the start of Phase IV and that it expected the MSR rules agreed upon in 2015 to be activated from 2019. The resulting calibration is $z=0.0236$ and $\bar{E}_{0}=1.676 \mathrm{Mt}$. With this calibration based on the rules expected to prevail prior to the 2018 reform, the model predicts an average annual fall in emissions of 2.6 percent over the period 2017-2030, roughly identical to the average annual reduction of 2.5 percent observed between 2005 and 2017.

\subsection{Effect of the 2018 ETS reform}

Using this calibration we can illustrate the impact of the new MSR rules in the 2018 reform by comparing Figures 3 and 4 below. Figure 3 depicts how emissions and the allowance surplus available to the market would have evolved (according to our model) if the MSR rules agreed upon in 2015 had been maintained. We see that the MSR would have absorbed a large part of the allowance surplus that would otherwise emerge. The allowance surplus in Figure 3 peaks in 2018 and falls steadily in the subsequent years, partly because of the gradual fall in the issue of new allowances, and partly because of transfer of surplus allowances to the MSR. Still, the allowance surplus does not disappear until 2056. Moreover, the annual release of $100 \mathrm{Mt}$ of allowances from the reserve when the surplus falls below $400 \mathrm{Mt}$ means that annual emissions of $100 \mathrm{Mt}$ continue all the way up until 2090, due to an enormous allowance reserve accumulated until 2037 when the MSR peaks at around 5 Gt.

Figure 4 shows the predicted evolution of the allowance market

following the 2018 ETS reform. The model simulation underlying Figure 4 accounts for the strong increase in the allowance price observed between 2017 and 2018 as shown in Figure 2. Our model can explain this price hike if we assume that the ETS reform led to a reduction in the required rate of return from 10 percent to 7.44 percent. A fall in the required rate of return of this magnitude does not seem implausible, since the 2018 reform must have strengthened investor confidence in the future of the ETS, as discussed in Section 3. From Figure 4 we see that the new ETS rules will imply 
Figure 3 Evolution of emissions and allowance surplus with the MSR rules from 2015

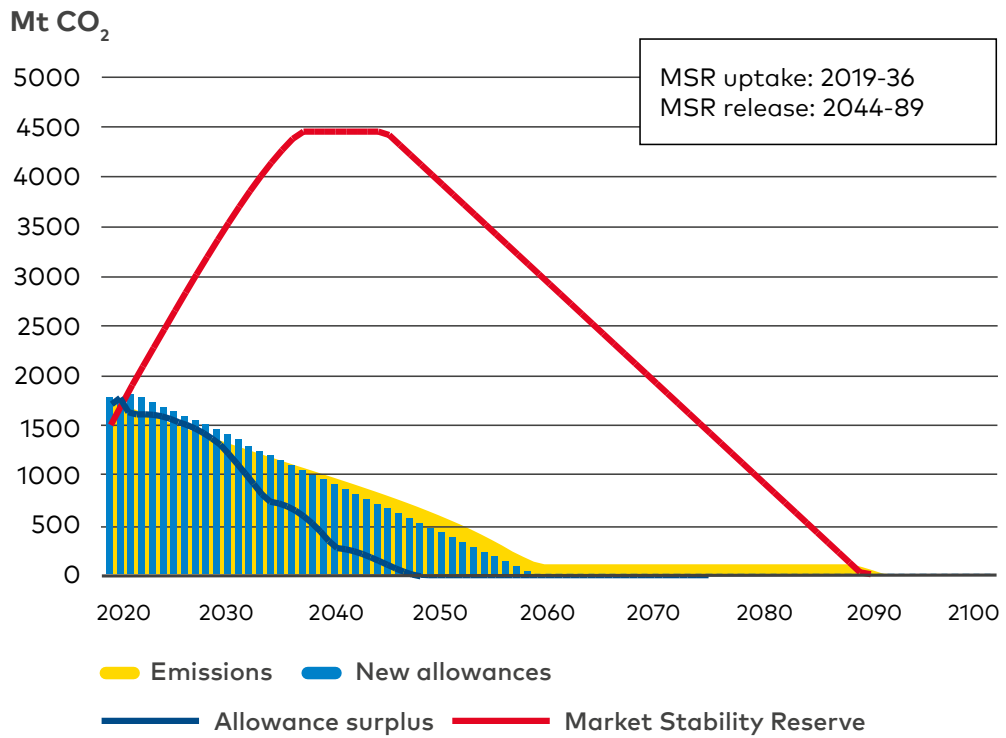

Source: Own calculations based on the model described in Section 3.

a large transfer of allowances to the MSR in the years after 2019 followed by a big chunk of automatic annulments in 2023. According to our model the MSR will continue to absorb allowances for a twenty-year period until 2039, but from 2050 until 2053 the MSR will release allowances as the allowance surplus falls below the level of $400 \mathrm{Mt}$ triggering releases. Again, the surplus is predicted to disappear around the mid-2050s.

Due to the new annulment mechanism a significant amount of allowances in the MSR will be annulled from 2023 until 2039, which is also the year where the allowance surplus becomes so small that the MSR uptake stops. Since allowances transferred to the MSR are taken from the annual flow of auctioned allowances determining the allowance cap in the reserve, the ending of the MSR uptake after 2039 causes a temporary increase in the allowance cap which triggers a cessation of annulments until 2043. In that year the previous year's newly issued auctioned allowances fall to a level that 
Figure 4 Evolution of emissions and allowance surplus with the MSR rules from 2018

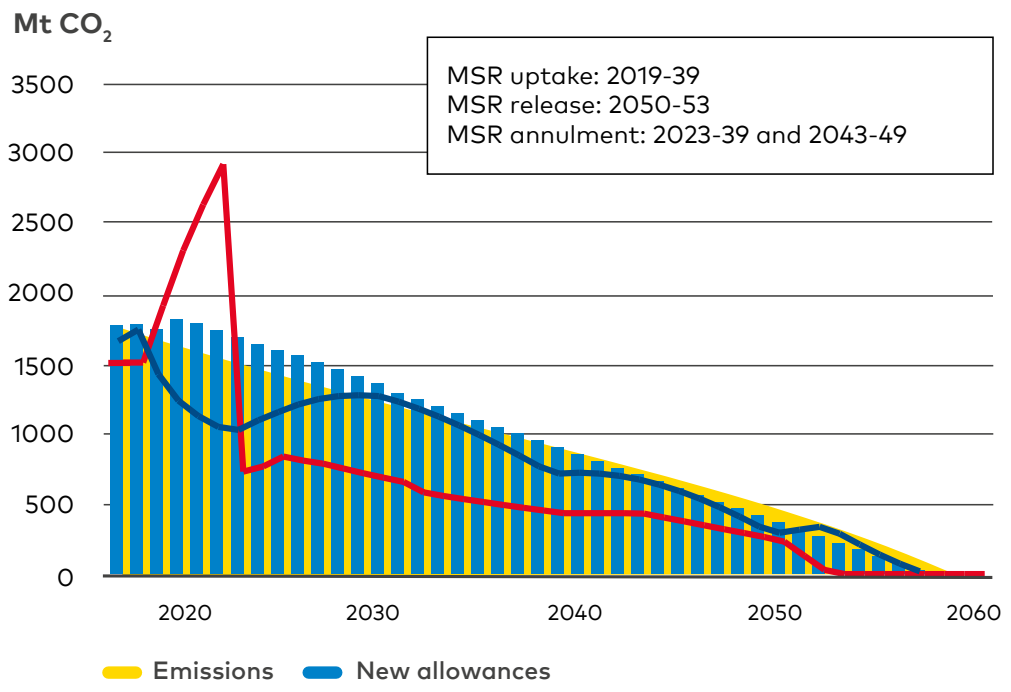

Allowance surplus

Market Stability Reserve

Source: Own calculations based on the model described in Section 3.

reactivates the cap, resulting in a new round of annulments in the period 2043-2049.

Note that the 2015 MSR rules would not have reduced the total accumulated volume of emissions but would only have shifted some emissions further into the future. By contrast, due to the new annulment mechanism, the 2018 ETS reform does reduce the accumulated emissions from 43,571 Mt to $38,597 \mathrm{Mt}$, representing an 11 percent cut. Nevertheless, it is striking that even after the 2018 reform the allowance surplus is still expected to persist until the mid-2050s as market participants react to the anticipated greater future scarcity of allowances by cutting their current emissions so as to save more allowances for future use.

\subsection{Comparison with previous quantitative studies of ETS reform}

In contrast to the picture painted in Figure 3, Perino and Willner (2016) predict that the allowance surplus under the 2015 MSR rules 
would have disappeared already in 2036, even though they use a partial equilibrium simulation model of the ETS very similar to ours. The reason for the difference is that they choose a value of our parameter $b$ (the price sensitivity of allowance demand) which is roughly nine times as high as in our calibration. Moreover, they assume that business-as-usual emissions are constant over time ( $z=0$ in our notation). If we had used their $b$-value, our calibration method would also have delivered a $z$-value close to zero. However, Perino and Willner's high $b$-value combined with their assumption that $z=0$ implies an average annual fall in emissions of less than one percent over the period 2017-2030. We find this implausible since the observed annual fall in emissions was 2.5 percent from 2005 to 2017 and since setting $z=0$ implicitly ignores the rapid technical progress in green energy technologies. Perino and Willner base their calibration of $b$ on a study by Landis (2015, Table 4), but the carbon price sensitivity of emissions in that study is derived from simulations with a computable general equilibrium model, so the resulting price sensitivity incorporates a host of general equilibrium effects that should not be included in an estimate of the parameter $b$ in a single emissions equation like (1).

In a subsequent paper, Perino and Willner (2017) simulate the effects of an MSR annulment mechanism like the one included in the 2018 ETS reform. Again, they foresee a relatively fast drop in the allowance surplus, which implies that the annulment mechanism will be activated in a much shorter time span than in our 2018 reform scenario in Figure 4. Their simulation does not replicate the observed sharp increase in the allowance price from 2017 to 2018 as they maintain a 10 percent required return. However, if we use their high $b$-value in our model, but allow for adjustment of the rate of return in order to replicate the current high allowance price, we get a result much closer to the one in Figure 4; that is, the allowance surplus disappears as late as 2050 and falls below the critical 833 Mt limit in 2032 compared to 2022 in Perino and Willner (2017) and 2038 in Figure 4. The speed at which the allowance surplus declines, especially how fast it drops below the $833 \mathrm{Mt}$ triggering a stop to the MSR uptake, is crucial for the effects of the climate policies considered in Section 5.

In a study undertaken on request from the Swedish government, the National Institute of Economic Research (2018) presents sim- 
ulations of the effects of the 2018 ETS reform based on two different model versions. In the first version, which is presented as the base case, emissions are totally insensitive to the allowance price and fixed at a high constant rate (emissions only decrease if there is a shortage of allowances in the given year). It is not surprising that this setup reduces the allowance surplus quite rapidly; it drops below $833 \mathrm{Mt}$ in 2024 and reaches zero in 2034. The second model version is very similar to the one set up by Perino and Willner and by us. The allowance surplus in this version is reduced much more slowly and stays above $833 \mathrm{Mt}$ until 2039. Thus, the second version produces results that are closer to ours than to those in Perino and Willner (2017).

To study the effects of the 2018 ETS reform, Beck and Kruse-Andersen (2018) construct their own partial equilibrium model of the allowance market. The demand for emission allowances is derived from the behaviour of a representative firm which maximizes the present value of its profits given by a profit function which is increasing in the level of emissions and in the relative efficiency of technologies for renewable energy production. The model allows the increase in this relative efficiency to be decreasing over time. Calibrating the model to match the ETS market situation in 2017, the authors project that the 2018 reform will imply an evolution of emissions and of the allowance surplus very similar to the one depicted in Figure 4.

The impression left by these studies and by our own analysis is that the projected evolution of the future allowance surplus hinges on the assumptions regarding technical progress in abatement technologies (as reflected in our parameter $z$ ), the required rate of return $(r)$, and the price sensitivity of emissions ( $b$ ). However, calibration of at least one of these parameters to replicate today's market situation seems to narrow the range of possible outcomes and points in the direction of a long-lasting allowance surplus.

\section{Effects of alternative climate national policies}

Many EU member states have strived to reduce emissions from their ETS sectors through policies that reduce the demand for emission allowances such as national subsidies to renewable 
energy and, in some cases, carbon taxes or energy taxes that do not exempt the ETS sector. Under an alternative national policy, followed until recently by the Swedish government under the name of utsläppsbromsen ('the emission brake'), a member state government may purchase ETS allowances and withdraw them from the market with the purpose of tightening the EU-wide emissions cap. A reduction of the emissions cap may also be achieved if the government abstains from auctioning some of the emission allowances allocated to it. In fact, several EU Member States will be allowed to meet part of their 2030 greenhouse gas reduction target for the non-ETS sector by auctioning fewer allowances in the ETS sector. Importantly, emission allowances that are cancelled as part of this so-called flexibility mechanism for meeting the non-ETS reduction target will still be counted as part of the total allowance surplus which may trigger an annulment of allowances due to the new cap on the MSR. By contrast, a national purchase and subsequent annulment of allowances that is not part of the non-ETS flexibility mechanism faces the risk that the resulting fall in the allowance surplus will cause fewer automatic annulments of allowances in the MSR.

We will now use our model of the ETS to compare the effects of such national climate policies on the $\mathrm{EU}$-wide $\mathrm{CO}_{2}$ emissions. A policy such as subsidies to renewables or a carbon tax that reduces the demand for allowances can be modelled as a one-time downward shift in our parameter $\bar{E}_{t}$ in the emissions function (1). We will refer to this type of policy as demand reduction. A national annulment policy such as the Swedish utsläppsbroms may be modelled as a one-time reduction in newly issued allowances, which triggers subsequent endogenous changes in the MSR uptake and release of allowances as well as changes in the number of MSR allowances that are automatically annulled. We will refer to this policy as annulment. Finally, we may model a national annulment of allowances under the specific rules of the non-ETS flexibility mechanism as a one-time reduction in newly issued allowances issues without affecting the allowance surplus used to calculate net transfers to the MSR. We will label this policy FM annulment.

\subsection{Effects of national climate policies on $\mathrm{CO}_{2}$ emissions}

Table 1 shows how effective the three alternative national climate policies are in reducing the accumulated $\mathrm{CO}_{2}$ emissions within the 
Table 1 Coefficients of Emission Reduction after the 2018 ETS reform

\begin{tabular}{|c|c|c|c|c|c|c|c|c|c|}
\hline \multirow[t]{2}{*}{$\begin{array}{l}\text { Policy } \\
\text { horizon } \\
\text { (H) }\end{array}$} & \multicolumn{3}{|c|}{$\begin{array}{l}\text { Demand reduction in year } \boldsymbol{t} \\
\qquad\left(\begin{array}{c}C E R_{t, H}^{D} \\
t\end{array}\right)\end{array}$} & \multicolumn{3}{|c|}{$\begin{array}{l}\text { Annulment in year } \boldsymbol{t} \\
\qquad\left(\begin{array}{c}C E R^{S} \\
t, H\end{array}\right)\end{array}$} & \multicolumn{3}{|c|}{$\begin{array}{l}\text { FM annulment in year } \boldsymbol{t} \\
\qquad\left(\begin{array}{c}C E R_{t, H}^{S} \\
t\end{array}\right)\end{array}$} \\
\hline & $t=2020$ & $t=2025$ & $t=2030$ & $t=2020$ & $t=2025$ & $t=2030$ & $t=2020$ & $t=2025$ & $t=2030$ \\
\hline$H=2030$ & 1.00 & 0.99 & 1.00 & 0.00 & 0.01 & 0.00 & 0.09 & 0.06 & 0.01 \\
\hline$H=2040$ & 0.99 & 0.96 & 0.94 & 0.01 & 0.04 & 0.06 & 0.25 & 0.22 & 0.18 \\
\hline$H=2050$ & 0.97 & 0.91 & 0.83 & 0.03 & 0.09 & 0.17 & 0.59 & 0.56 & 0.52 \\
\hline$H=2060$ & 0.94 & 0.83 & 0.66 & 0.06 & 0.17 & 0.34 & 1.11 & 1.08 & 1.05 \\
\hline
\end{tabular}

Note: The table considers marginal policy experiments where national climate policy reduces demand by 1 ton of $\mathrm{CO}_{2}$ in a single year; alternatively 1 allowance is annulled. FM refers to the specific rules if the annulment is used to meet the country's obligation in the non-ETS sector. The numbers show the aggregate reduction in emissions occurring up until year $H$.

Source: Own calculations based on the model described in Section 3.

ETS, measured by the Coefficients of Emission Reduction defined in (2) and (3). The table highlights the great importance of the new annulment mechanism in the MSR. For example, the accumulated emissions in 2060 (by this year all allowances in the system have been surrendered or annulled) will be reduced by 94 percent of the emissions cut achieved through a national policy measure that reduces the demand for allowances in 2020. In other words, since this policy measure will increase the allowance surplus, thus increasing the number of allowances transferred to the MSR and thereby causing more allowances to be permanently cancelled, only 6 percent of the initial cut in emissions will be offset by higher emissions elsewhere in the ETS sector.

Figure 5 provides a breakdown of the emission effects from a 1 ton reduction in the demand for allowances in 2020. The initial 1 ton emission reduction in 2020 falls slowly over time (solid dark blue graph) as lower allowance prices raise emissions in the subsequent years, reaching a total reduction of 0.94 ton in 2060 . This number matches the total automatic annulment of allowances by 2060 in the MSR (dashed light blue graph). In 2060, the total annulment equals the total net uptake to the MSR (solid light blue graph), since any allowance that has not left the MSR by 2060 must have 
Figure 5 Change in emission reduction, allowance surplus, net MSR uptake, and MSR annulment following a one ton national demand reduction in 2020

ton $\mathrm{CO}_{2}$

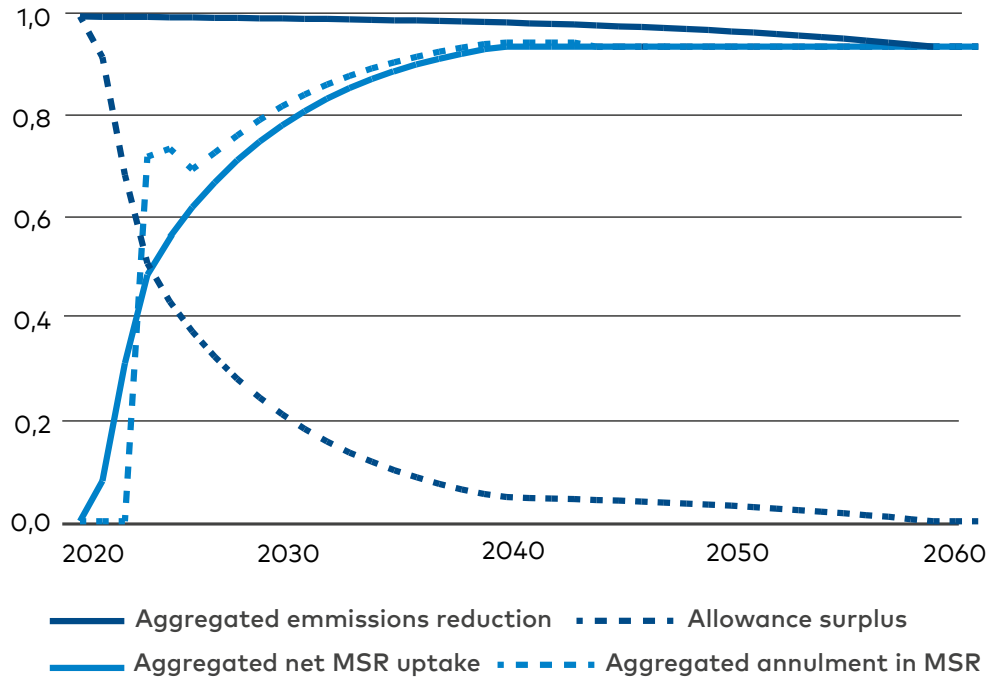

Note: The table considers marginal policy experiments where national climate policy reduces demand by 1 ton of $\mathrm{CO}_{2}$ in a single year; alternatively 1 allowance is annulled. FM refers to the specific rules if the annulment is used to meet the country's obligation in the non-ETS sector. The numbers show the aggregate reduction in emissions occurring up until year $H$.

Source: Own calculations based on the model described in Section 3.

been annulled by the MSR cap. The increase in the MSR uptake follows from a larger allowance surplus (dashed dark blue graph).

Table 1 reveals that the accumulated emissions reduction in 2060 declines if the demand reduction is undertaken in 2025 or 2030 rather than in 2020 . The reason is that a later policy year leaves a shorter period of time for the extra unused allowances to be soaked up by the MSR where they will end up being annulled. Remember that allowances are transferred to the MSR until 2039. Therefore, a demand reduction in $\mathbf{2 0 4 0}$ will have no lasting effect on emissions, i.e. $C E R_{2040,2060}^{D}=0$, as the automatic annulment in the MSR after 2039 becomes fixed. 
By contrast to the demand reduction measures, an annulment of allowances undertaken by an individual EU member state in 2020 will only reduce the accumulated emissions in 2060 by 6 percent of the initial annulment, since the annulment of allowances undertaken at the member state level will be largely offset by fewer annulments of allowances held in the MSR as the initial drop in the allowance surplus will cause fewer transfers of allowances to the reserve. The reduction in emissions increases if the annulment is postponed, since this will leave a shorter time span during which the cut in allowance supply at the member state level is counteracted by fewer annulments of allowances held in the MSR.

Instead of pursuing a general policy of annulment of the type described above, EU member states can choose (within limits set by the EU) to undertake annulment of emission allowances under the so-called flexibility mechanism. Such annulments will not reduce the recorded allowance surplus that governs the dynamics of the MSR, so this policy will in fact succeed in reducing emissions considerably in the long run, as shown in the last three columns in Table 1. Indeed, with $C E R$ values for $H=2060$ above 1, emissions are reduced by more than the initial annulment. The reason is that even though the annulment does not affect the recorded allowance surplus used to calculate the transfer to the MSR, the actual surplus of allowances available to the market is reduced, leading to higher allowance prices and lower emissions. This then increases the fictional allowance surplus used for the MSR uptake which increases the uptake as well as the automatic annulment in the reserve.

Still, we see that for policy horizons up until 2050, annulment under the flexibility mechanism is much less effective in cutting emissions than a policy that reduces the demand for allowances. Hence, if policy makers give high priority to reducing emissions fast, this type of allowance annulment is not effective.

In summary, if the supply of emissions allowances were a fixed number over the planning horizon, reducing this number would be an effective way to reduce emissions while reducing the demand for allowances would be ineffective. By contrast, if the supply over the planning period depends on demand, like after the ETS reform, demand-reducing policies are effective while annulment policies by individual countries are not. 
Table 1 only addresses the emission effects of the various policy measures. A full ranking must also take the cost side into account. The strong increase in the allowance price in 2018 has made allowance annulment significantly more expensive. At the same time prices of renewable energy continue to fall. These observations indicate that expansion of renewable energy will typically be a more cost-effective way to cut EU-wide emissions than annulling allowances. In Silbye and Sørensen (2018) we show how our formulas for the $C E R$ can be used to estimate the social cost-effectiveness of alternative national climate policies, drawing on the economic theory of consumer and producer surplus. For example, using the results in Table 1 plus Danish data on the cost of off-shore wind energy, we find that expanding the latter type of renewable energy involves a much lower social cost per unit of emissions reduction than annulment of allowances (including under the flexible mechanism) for any policy horizon.

\subsection{Sensitivity analysis}

The overall impression from Table 1 is that national subsidies or carbon taxes to promote renewable energy are generally more effective in reducing $\mathrm{CO}_{2}$ emissions from the ETS sector than annulments of allowances undertaken by individual member states, at least when undertaken well before 2040 . This subsection considers how robust this conclusion is to changes in key parameters.

The sensitivity of our results to a stronger response of emissions to the allowance price is illustrated in Table 3 where we have set our price sensitivity parameter $b$ at a value almost nine times as high as in our baseline scenario in Table 1, thereby following the assumption in Perino and Willner $(2016,2017) .^{13}$ We see that even with this significant parameter change, a policy that reduces the demand for allowances is still a far more effective way of reducing emissions than annulment of allowances at the national level, unless the annulment is undertaken within the flexibility mechanism (which only allows annulments within fairly narrow limits) and policy makers adopt a rather long time horizon. Note, however, that Table 2 only shows results for policy undertaken in 2020 . For instance, the long

\footnotetext{
${ }^{13}$ As mentioned in Section 4, when we raise the value of $b$, we recalibrate the other parameters in the model so that is still reproduces the initial market situation.
} 
Table 2 Coefficients of Emission Reduction after the 2018 ETS reform: Sensitivity to the price response of emissions (b) for a policy change in 2020

\begin{tabular}{|c|c|c|c|c|c|c|}
\hline \multirow[t]{2}{*}{$\begin{array}{l}\text { Policy } \\
\text { horizon } \\
(H)\end{array}$} & \multicolumn{2}{|c|}{$\begin{array}{c}\text { Demand } \\
\text { reduction in } 2020 \\
\left(C E R_{2020, H}^{D}\right)\end{array}$} & \multicolumn{2}{|c|}{$\begin{array}{c}\text { Annulment } \\
\text { in } 2 \mathrm{O} 2 \mathrm{O} \\
\left(\begin{array}{c}C E R_{2020, H}^{S} \\
)\end{array}\right.\end{array}$} & \multicolumn{2}{|c|}{$\begin{array}{l}\text { FM annulment } \\
\text { in } 2 \mathrm{O} 2 \mathrm{O} \\
\left(C E R_{2020, H}^{S}\right)\end{array}$} \\
\hline & $b=2.2$ & $b=19.8$ & $b=2.2$ & $b=19.8$ & $b=2.2$ & $b=19.8$ \\
\hline$H=2030$ & 1.00 & 0.97 & 0.00 & 0.03 & 0.09 & 0.23 \\
\hline$H=2060$ & 0.94 & 0.86 & 0.06 & 0.14 & 1.11 & 1.13 \\
\hline
\end{tabular}

Note: The table considers marginal policy experiments where national climate policy reduces demand by 1 ton of $\mathrm{CO}_{2}$ in 2020; alternatively 1 allowance is annulled. FM refers to the specific rules if the annulment is used to meet the country's obligation in the non-ETS sector. The numbers show the accumulated reduction in emissions occurring up until year $H$.

Source: Own calculations based on the model described in Section 3.

run $C E R$ for a demand reduction in 2030 changes from 0.66 to 0.23 , which is more substantial. Again, this emphasizes that the policy timing matters.

Table 3 shows the effects on the Coefficients of Emission Reduction of assuming a significantly lower required rate of return $r$ than in our baseline case. The rate of 2.92 percent in the table was derived from the same two-step calibration procedure as the one used in our baseline: In the first step we assumed $r=0.04$ and $b=2.2$ and calibrated the values of $\bar{E}_{t}$ and $z$ to enable the model to reproduce the emissions and the average allowance price observed in 2017 before the latest reform. In the second step we reduced the value of $r$ from 4 to 2.92 percent to enable the model to explain the allowance price hike between 2017 and 2018. We see that the low required rate of return and the implied lower rate of allowance price increase during the long phase with an allowance surplus makes an annulment policy even less effective compared to a policy of demand reduction, as the effect of a lower $r$ is more than offset by an increase in the calibrated value of $z$. However, if the annulment exploits the flexibility mechanism, it becomes more effective than the demand reduction in the very long run. 
Table 3 Coefficients of Emission Reductions after the 2018 ETS reform: Sensitivity to the required rate of return ( $r$ ) for a policy change in 2020

\begin{tabular}{|c|c|c|c|c|c|c|}
\hline \multirow[t]{2}{*}{$\begin{array}{l}\text { Policy } \\
\text { horizon } \\
(\text { H) }\end{array}$} & \multicolumn{2}{|c|}{$\begin{array}{l}\text { Demand reduction } \\
\text { in } 2 \mathrm{O} 2 \mathrm{O} \\
\left(C E R_{2020, H}^{D}\right)\end{array}$} & \multicolumn{2}{|c|}{$\begin{array}{c}\text { Annulment } \\
\text { in } 2 \mathrm{O} 2 \mathrm{O} \\
\left(C E R_{2020, H}^{S}\right)\end{array}$} & \multicolumn{2}{|c|}{$\begin{array}{c}\text { FM annulment in } \\
2 \mathrm{O} 2 \mathrm{O} \\
\left(C E R_{2020, H}^{S}\right)\end{array}$} \\
\hline & $r=2.92 \%$ & $r=7.44 \%$ & $r=2.92 \%$ & $r=7.44 \%$ & $r=2.92 \%$ & $r=7.44 \%$ \\
\hline$H=2030$ & 1.00 & 1.00 & 0.00 & 0.00 & 0.23 & 0.09 \\
\hline$H=2060$ & 0.99 & 0.94 & 0.01 & 0.06 & 1.40 & 1.11 \\
\hline
\end{tabular}

Note: The table considers marginal policy experiments where national climate policy reduces demand by 1 ton of $\mathrm{CO}_{2}$ in $2 \mathrm{O} 2 \mathrm{O}$; alternatively 1 allowance is annulled. FM refers to the specific rules if the annulment is used to meet the country's obligation in the non-ETS sector. The numbers show the accumulated reduction in emissions occurring up until year $H$.

Source: Own calculations based on the model described in Section 3.

The quantitative effects of alternative national climate policies reported above are rather similar to those found by Beck and Kruse-Andersen (2018) even though they use a different model of the ETS. Like us, they estimate that the MSR continues to soak up allowances until late in the 2030s in combination with a binding MSR cap that makes the annulment mechanism operative. On this basis they conclude that a national policy of demand reduction will be far more effective in reducing emissions than annulment of allowances at the national level (when annulment is not undertaken as part of the flexibility mechanism), as long as the national policy measures are undertaken during the 2020s. However, if a significant part of the national policy measures are implemented at a later point in time, a national annulment policy may become more effective than a policy that reduces the demand for allowances.

The National Institute of Economic Research (2018) also acknowledges that national demand-reducing policies may reduce the accumulated EU-wide $\mathrm{CO}_{2}$ emissions due to the new MSR annulment mechanism, but because their base case assumes a much faster elimination of the allowance surplus than we do, the NIER projects that the surplus drops below $833 \mathrm{Mt}$ in the mid-202Os whereby the MSR uptake ceases. They therefore argue that, rather than undertaking demand-reducing policies, it will be more cost- 
effective if the Swedish government purchases ETS allowances in the market and postpones their cancellation until allowances are no longer transferred to the MSR to secure a long-run reduction in total allowance supply. We find this idea intriguing, since it would seem to imply that a national policy of general annulments could be designed to generate the same effects as annulment under the flexibility mechanism. However, since the NIER base case does not allow for the underlying trend towards lower emissions, we believe that they significantly underestimate the time it will take for the allowance surplus to vanish. In our baseline scenario the MRS uptake continues until the end of the 2030s, so the revised uts/äppsbroms proposed by the NIER would not have a significant impact on emissions until after that time. The NIER proposal is in principle identical to purchasing and annulling allowances in the future but announcing it today. It is, however, questionable whether a member state can commit to such a policy in a credible way. The NIER proposal might by perceived by the market as more credible since money is put on the table right away, but the member state still has an ex post incentive to sell its allowances rather than annulling them when promised.

To wrap up, the model's prediction for the year when the allowance surplus drops below $833 \mathrm{Mt}$ is of crucial importance for the policy implications. If this year arrives significantly earlier than predicted by our model, allowance annulment becomes more effective and demand reduction less effective. However, our sensitivity analysis suggests that our overall conclusions are robust to significant changes in key parameters.

\section{Proposal for an efficiency-improving ETS reform}

While the substantial trade in emission allowances within the ETS suggests that the system has helped to reduce the aggregate EUwide costs of cutting emissions, the system has also been criticized for failing to deliver a sufficiently high and stable carbon price. This criticism ultimately led to the 2018 ETS reform which will fundamentally change the mechanics of the ETS, as we have seen above. In a recent paper, Gerlagh and Wan (2018) argue that the future cancellation of 'excess' allowances in the Market Stability Reserve 
will in fact stabilize allowance prices and bring the ETS close to the theoretically optimal way of regulating a stock pollutant like $\mathrm{CO}_{2}$ by ensuring an automatic reduction of allowance supply when a large allowance surplus signals that current marginal abatement costs are low. However, since the cancellation mechanism in the MSR only works with a lag, we believe it may fail to deliver the desired degree of allowance price stability that will significantly reduce the uncertainty regarding the profitability of investment in green energy technologies.

In a recent paper, Karp and Traeger (2017) propose a 'smart' capand-trade system under which the total cap on $\mathrm{CO}_{2}$ emissions per period would be $Q q(p)$, where $Q$ is the number of emission 'certificates' issued by the regulator, and $q(p)$ is the amount of $\mathrm{CO}_{2}$ that the holder of a certificate is allowed to emit. This 'redemption function' $q(p)$ is an increasing function of the price $p$ of the tradable certificates, so emissions are automatically allowed to increase when certificate prices are high (signaling high marginal abatement costs), and vice versa. Such a system would serve to stabilize the price of emitting a ton of $\mathrm{CO}_{2}$ which would be given by $p / q(p)$ and could be calibrated - via the calibration of the redemption function $q(p)$ - to attain the degree of price stability deemed optimal by policy makers.

However, in practice the complicated MSR rules praised by Gerlagh and Wan and the sophisticated smart cap advocated by Karp and Traeger may not be sufficiently transparent to market participants to establish the desired confidence in future carbon prices. Moreover, the prospect of a large and long-lasting allowance surplus indicated by our analysis (despite the recent ETS reform) suggests that the average future allowance price may not be sufficiently high to serve as a main driver of the green transition in Europe.

For these reasons we believe that when the next opportunity for a reform of the ETS arises, the complex and opaque MSR rules should be replaced by a price floor and a price ceiling for ETS allowances. A large strand of literature, starting with the contribution by Roberts and Spence (1976), has suggested that a mixed system combining tradeable emissions allowances with a minimum and a maximum allowance price would be more efficient than a pure emission tax scheme or a pure cap-and-trade scheme. In practice such a mixed 
system could be implemented through an auctioning procedure for emission allowances that includes a minimum price as well as a maximum price. If the bidding price of allowances hits the price floor, the issue of allowances is reduced to the degree needed to sustain the minimum price, and if the bidding price hits the price ceiling the allowance issue is expanded to prevent the allowance price from exceeding the maximum price. As Roberts and Spence showed, such a mixed system is more efficient because it imposes a penalty scheme on polluters which approximates the marginal damage cost curve better than a pure tax scheme or a pure capand-trade system. Over the years numerous authors have advocated variants of the mixed system proposed by Roberts and Spence, sometimes including only a price floor or a price ceiling. ${ }^{14}$ In short, the price floor and the price ceiling serve as safety valves that prevent the allowance price from drifting too far away from the true marginal social cost of pollution, thereby helping to reduce the welfare loss from imperfect information about abatement costs.

One might fear that an ETS reform involving a floor and ceiling for the allowance price may run into other difficulties raised by EU law and politics such as those mentioned by Hepburn et al. (2016). It would be important that a floor and a ceiling is not seen as a measure 'primarily of a fiscal nature', since that would require an unlikely unanimous approval in accordance with article $192 \$ 2$ of the Lisbon Treaty. Since the current rules for the ETS already have fiscal implications which would not be fundamentally changed by a transition to the mixed system described above, we find it hard to see why a transition to such a system with limit prices on auctioned allowances should trigger article 192. A second and potentially more serious obstacle is that the mixed system would require agreement on the minimum and maximum allowance prices by a qualified majority of EU member states. Perhaps the greater transparency of a system with explicit minimum and maximum prices is harder to agree on than the setting of the thresholds for the uptake, release, and annulment of allowances in the MSR.

${ }^{14}$ Contributions to this literature include Weitzman (1978), McKibbin and Wilcoxen (1997), Pizer (2002), Jacoby and Ellerman (2004), Newell et al. (2005), Murray et al. (2009), Burtraw et al. (2010), Fell (2016), and Kollenberg and Taschini (2016) among many others. Hepburn (2006) provides a thorough review of the many issues involved in designing a mixed system. 
Another concern is the one voiced by Salant (2016) who points out that uncertainty about the future rules for the ETS creates higher costs of achieving a given target for emissions reductions. A proposal for further reform of the system following years of hard bargaining over the MSR rules recently agreed could create renewed uncertainty which could reduce the efficiency of the market for allowances. However, since the recent ETS reform does not address the problem of price instability in the most direct and effective way, and since the ETS is likely to operate for several decades to come, we expect that the debate on the design of the system will continue. In any case, the new rules for the ETS agreed in 2018 do not seem sufficiently ambitious in the light of the 2015 Paris Agreement which will require all regions in the world to undertake much faster emissions reductions than currently planned if the target of keeping global warming well below two degrees Celsius is to be met. We therefore anticipate that new opportunities for reform of the ETS will arise in the future.

Finally, one might worry that since fossil fuel prices and ETS allowance prices could be negatively correlated, limiting the fluctuations of the allowance price could actually increase the volatility of the consumer price of energy. However, the study by Koch et al. (2014) found no significant relationship between coal prices and the allowance price and actually found a positive relationship between the price of natural gas and the allowance price, as a higher gas price induces a shift to more $\mathrm{CO}_{2}$-intensive coal-based energy technologies that drives up the demand for allowances. Moreover, the relative profitability of investment in green energy technologies rather than investment in fossil-based technologies depends on the carbon price and not on the absolute level of energy prices. For these reasons we believe that an ETS price floor and ceiling will in fact reduce energy price volatility and benefit investors in renewable energy.

\section{Conclusions}

The analysis in this paper leads to four main conclusions:

First, in the absence of further reform the surplus of emission allowances within the ETS is likely to persist for several decades. For a 
long time the system will therefore work differently than a textbook cap-and-trade system with a binding cap.

Second, the new Market Stability Reserve taking effect from 2019 is a fundamental change to the system that will endogenize the total supply of emission allowances. As a consequence, national policy measures undertaken in the short to medium term that reduce the demand for allowances will permanently reduce total EU-wide emissions.

Third, for an EU member state that wishes to take the lead in climate policy by annulling emission allowances, such a policy is highly ineffective if allowances are annulled in the short to medium term.

Fourth, when the next occasion for reform of the ETS arises, policy makers should turn the system into a mixture of price and quantity control by introducing a minimum and a maximum price of emission allowances. This will improve the efficiency of the system and make the complex and nontransparent rules for the Market Stability Reserve redundant.

\section{References}

Beck, U.R. and Kruse-Andersen, P. K. (2018), Endogenizing the Cap in a Cap-and-trade System: Assessing the Agreement on EU ETS Phase 4, Working Paper 2018:2, Danish Economic Councils.

Böhringer, C., Koschel, H. and Moslener, U. (2008), Efficiency Losses from Overlapping Regulation of EU Carbon Emissions, Journal of Regulatory Economics, 33(3), 299-317.

Böhringer. C., Löschel, A., Moslener, U. and Rutherford, T. (2009a), EU Climate Policy Up to 2020: An Economic Impact Assessment, Energy Economics, 31(2), S295-S305.

Böhringer. C., Rutherford, T. and Tol, R. (2009b), The EU 20/20/2020 Targets: An Overview of the EMF22 Assessment, Energy Economics, 31(2), S268-S273.

Boeters. S. and Koornneef, J. (2011), Supply of Renewable Energy and the Cost of EU Climate Policy, Energy Economics, 33(5), 1024-1034.

Burtraw, D., Palmer, K. and Kahn, D. (2010), A Symmetric Safety Valve, Energy Policy, 38(9), 4291-4932. 
Carbon Tracker Initiative (2018), Carbon Countdown: Prices and Policies in the EU-ETS, Report 21, August 2018.

Carlén, B., Dahlqvist, A., Mandell, S. and Marklund, P. (2018), EU ETS Emissions Under the Cancellation Mechanism: Effects of National Measures, Working Paper No. 151, National Institute of Economic Research.

Danish Council on Climate Change (2017), Det oppustede $\mathrm{CO}_{2}-$ kvotesystem, Retrieved December 17, 2018, from www.klimaraadet.dk/da/ analyser/det-oppustede-co2-kvotesystem.

Eichner, T. and Pethig, R. (2009), Efficient $\mathrm{CO}_{2}$ Emissions Control with Emissions Taxes and International Emissions Trading, European Economic Review, 53(6), 625-635.

Ellerman, A.D., Marcantonini, C. and Zaklan, A. (2016), The European Union Emissions Trading System: Ten Years and Counting, Review of Environmental Economics and Policy, 10(1), 89-107.

European Commission (2017), Report from the Commission to the European Parliament and the Council: Report on the Functioning of the European Carbon Market, COM(2017) 693 final.

Fell, H. (2016), Comparing Policies to Confront Over-allocation, Journal of Environmental Economics and Management, 80, 53-68.

Gerlagh, R. (2011), Too Much Oil, CESifo Economic Studies, 57(1), 79-102. Gerlagh, R. and Wan, R. J. R. K. (2018), Regulating Stock Pollutants, CESifo Working Paper 6950, CESifo Group Munich.

Golosov, M., Hassler, J., Krusell, P. and Tsyvinski, A. (2014), Optimal Taxes on Fossil Fuel in General Equilibrium, Econometrica, 82, 41-88.

Gronwald. M. and Hintermann, B. (2015), The EU ETS, in Gronwald, M. and Hintermann, B. (eds.), Emissions Trading as a Policy Instrument: Evaluation and Prospects, CESifo Seminar Series, Cambridge, MA: MIT Press.

Hassler, J., Krusell, P. and Nycander, J. (2016), Climate Policy, Economic Policy, 31:87, 505-558.

Heindl, P., Wood, P. and Jotzo, F. (2015), Combining International Cap-and-trade with National Carbon Taxes, in Gronwald, M. and Hintermann, B. (eds.), Emissions Trading as a Policy Instrument: Evaluation and Prospects, CESifo Seminar Series, Cambridge, MA: MIT Press.

Hepburn, C. (2006), Regulation by Prices, Quantities, or Both: A Review of Instrument Choice, Oxford Review of Economic Policy, 22(2), 226-247.

Hepburn, C., Neuhoff, K., Acworth, W., Burtraw, D. and Jotzo, F. (2016), The Economics of the EU ETS Market Stability Reserve, Journal of Environmental Economics and Management, 80, 1-5. 
Jacoby, H. D. and Ellerman, A. D. (2004), The Safety Valve and Climate

Policy, Energy Policy, 32(4), 481-491.

Karp, L. and Traeger, C. (2017), Smart Cap, Paper presented at the CESifo Area Conference on Energy and Climate Economics, Munich, 13-14 October 2017.

Koch, N., Fuss, S., Grosjean, G. and Edenhofer, O. (2014), Causes of the EU ETS Price Drop: Recession, CDM, Renewable Policies or a bit of Everything? New Evidence, Energy Policy, 73, 676-685.

Kollenberg, S. and Taschini, L. (2016), Emissions Trading Systems with Cap Adjustments, Journal of Environmental Economics and Management, 80, 20-36.

Landis, F. (2015), Final Report on Marginal Abatement Cost Curves for the Evaluation of the Market Stability Reserve. Dokumentation Nr. 15-01, ZEW, Mannheim.

McKibbin, W. J. and Wilcoxen, P. J. (1997), A Better Way to Slow Global Climate Change, Brookings Policy Brief No. 66, The Brookings Institution.

Murray, B. C., Newell, R. G. and Pizer, W. A. (2009), Balancing Costs and Emissions Certainty: An Allowance Reserve for Cap-and-trade, Review of Environmental Economics and Policy, 3(1), 84-103.

National Institute of Economic Research (2018), EU ETS, marknadsstabiliseringsreserven och effecter av annulleringar, Occasional Study No 2018:10, National Institute of Economic Research.

Neuhoff. K, Schopp, A., Boyd, R., Stelmakh, K. and Vasa, A. (2012), Banking of Surplus Emissions Allowances - Does the Volume Matter? DIW Berlin Discussion Papers 1196, German Institute for Economic Research.

Newell, R. G., Pizer, W.A., and Zhang, J. (2005), Managing Permit Markets to Stabilize Prices, Environmental and Resource Economics, 31(2), 133-157.

Perino, G. and Willner, M. (2016), Procrastinating Reform: The Impact of the Market Stability Reserve on the EU ETS, Journal of Environmental Economics and Management, 80, 37-52.

Perino, G. and Willner, M. (2017), EU-ETS Phase IV: Allowance Prices, Design Choices, and the Market Stability Reserve, Climate Policy, 17(7), 936-946.

Pizer, W.A. (2002), Combining Price and Quantity Controls to Mitigate Global Climate Change, Journal of Public Economics 85(3), 409-434.

Roberts, M. J. and Spence, M. (1976), Effluent Charges and Licenses Under Uncertainty, Journal of Public Economics, 5(3-4), 193-208. 
Salant, S. W. (2016), What Ails the European Union's Emissions Trading System?, Journal of Environmental Economics and Management, 80, 6-19.

Sandbag (2016a), Getting in Touch with Reality - Rebasing the EU ETS Phase 4 Cap, Report, Sandbag.

Sandbag (2016b), Puncturing the Waterbed Myth, Report, Sandbag.

Sinn, H.-W. (2008), Public Policies Against Global Warming: A Supply-side Approach, International Tax and Public Finance, 15(4), 360-94.

Silbye, F. and Sørensen, P. B. (2017), Subsidies to Renewable Energy and the European Emissions Trading System: Is There Really a Waterbed Effect?, Working Paper, Danish Council on Climate Change.

Silbye, F. and Sørensen, P. B. (2018), Towards a More Efficient European Carbon Market, Paper presented at the NEPR Conference on Climate Policy and the Nordics, Stockholm, 24 October 2018.

van der Ploeg, F. and Withagen, C. (2012), Is There Really a Green Paradox?, Journal of Environmental Economics and Management, 64(3), 342-63.

Weitzman, M. L. (1978), Optimal Rewards for Economic Regulation, American Economic Review, 68(4), 683-691. 


\section{Appendix}

This appendix lays out the mathematical details behind the model presented in Section 3.

\section{A.1 Deriving the emissions function}

A representative ETS firm wishes to minimize the present value of its expenses on emission allowances and abatement of its $\mathrm{CO}_{2}$ emissions. At the beginning of year one, this present value $(P V)$ is given by

$$
P V=\sum_{t=1}^{h}(1+r)^{-(t-1)}\left(p_{t} X_{t}+T A C_{t}\right),
$$

where $p$ is the real allowance price, $X$ is the firm's acquisition of emission allowances during the period, $T A C$ is its total real abatement cost, $r$ is the real discount rate, $t$ is the time period, and $h$ is the firm's planning horizon. The total abatement cost is assumed to increase more than proportionally with the volume of emissions abated, so the marginal abatement cost is positive and increasing. Assuming a quadratic abatement cost function for simulation purposes, we have

$$
T A C_{t}=\frac{1}{2 b}\left(\bar{E}_{t}-E_{t}\right)^{2}, \quad b>0,
$$

where $E$ is the actual emission of $\mathrm{CO}_{2}$, and $\bar{E}$ is the emission in the absence of ETS. The amount of emission allowances held by the firm in excess of its current emissions is denoted by $S$. This allowance surplus evolves as

$$
S_{t}=S_{t-1}+X_{t}-E_{t}, \quad S_{t} \geq 0, \quad S_{0}>0 \text { given, }
$$

where $S_{t}$ measures the allowance surplus at the end of period $t$. The constraint in (A3) that the allowance surplus can be positive but cannot be negative reflects the features of the ETS that banking of allowances for future use is permitted whereas borrowing of future allowances to cover current emissions is not. The firm chooses $X_{t}$ and $E_{t}$ so as to minimize the present value of its costs given by (A1) subject to the constraints (A2) and (A3), taking the current and rationally expected future level of the allowance price as given. 
Inserting (A2) and the first equality in (A3) into (A1) and multiplying by minus one, we can write the Lagrangian for this non-linear programming problem as

$$
L=-\sum_{t=1}^{h}(1+r)^{-(t-1)}\left[p_{t}\left(E_{t}+S_{t}-S_{t-1}\right)+\frac{1}{2 b}\left(\bar{E}_{t}-E_{t}\right)^{2}\right]+\sum_{t=1}^{h} \lambda_{t} S_{t},
$$

where the $\lambda$ 's are the Kuhn-Tucker multipliers associated with the inequality constraints. The first-order conditions for maximization of (A4) with respect to $E_{t}$ and $S_{t}$ are

$$
\begin{aligned}
& \frac{\partial L}{\partial E_{t}}=0 \Rightarrow \frac{1}{b}\left(\bar{E}_{t}-E_{t}\right)=p_{t}, \quad t=1,2, \ldots, h, \\
& \frac{\partial L}{\partial S_{t}}=0 \Rightarrow-(1+r)^{-(t-1)} p_{t}+(1+r)^{-t} p_{t+1}+\lambda_{t}=0, \quad t=1,2, \ldots, h .
\end{aligned}
$$

In addition, an optimal solution must satisfy the complementary slackness conditions

$$
\lambda_{t} \geq 0, \quad S_{t} \geq 0, \quad \lambda_{t} S_{t}=0, \quad t=1,2, \ldots, h
$$

Rearranging (A5), we get

$$
E_{t}=\bar{E}_{t}-b p_{t}
$$

which is equation (1) in Section 3.

\section{A.2 Evolution of allowance prices}

From (A7) we see that $\lambda_{t}=0$ if $S_{t}>0$. It then follows from (A6) that

$$
p_{t+1}=(1+r) p_{t} \quad \text { for } \quad S_{t}>0 .
$$

If $S_{t}=0$, (A5) implies that $\lambda_{t} \geq 0$ in which case we see from (A6) that

$$
p_{t+1}=(1+r) p_{t}-\lambda_{t} \Rightarrow p_{t+1} \leq(1+r) p_{t} \quad \text { for } \quad S_{t}=0 .
$$




\section{A.3 Mechanics of the MSR}

Let $M^{\text {OUT }}$ be the number of allowances released from the MSR in the year considered and let $M^{I N}$ be the number of allowances transferred to the reserve. If the allowance surplus at the end of year zero is $S_{0}$ and $Q$ is the issuance of new allowances, the cumulative surplus at the end of year $t$ will be

$$
S_{t}=S_{0}+\sum_{\tau=1}^{t}\left(Q_{\tau}-E_{\tau}-M_{\tau}^{I N}+M_{\tau}^{O U T}\right) .
$$

A fraction of the allowance surplus must be transferred to the MSR if the surplus exceeds 833 million tons of $\mathrm{CO}_{2}$. The transfer is based on the surplus recorded (almost) two years earlier, ${ }^{15}$ and the fraction to be transferred is 24 percent until the end of 2023 and 12 percent in the subsequent years. With end-of-year dating of stocks, we thus have

$$
M_{t}^{I N}=\left\{\begin{array}{ccc}
0.24 \cdot S_{t-2} & \text { if } S_{t-2}>833 \quad \text { and } t \leq 2023 \\
0.12 \cdot S_{t-2} & \text { if } \quad S_{t-2}>833 \text { and } t>2023 \\
0 & & \text { if } S_{t-2} \leq 833
\end{array}\right.
$$

Allowances amounting to 100 million tons of $\mathrm{CO}_{2}$ (or the entire remaining reserve if this is smaller than 100 million tons) must be released from the reserve whenever the allowance surplus recorded (almost) two years earlier falls short of 400 million tons. If the stock of allowances held in the MSR at the end of year $t-1$ is $M_{t-1}$ we therefore have

$$
M_{t}^{\text {OUT }}=\left\{\begin{array}{ccc}
\min \left\{100, M_{t-1}\right\} & \text { if } \quad S_{t-2}<400 \\
0 & \text { if } \quad S_{t-2} \geq 400
\end{array}\right.
$$

From 2023 there will be a cap (denoted by $C$ ) on the amount of allowances that can be held in the MSR. Allowances above the cap will be permanently annulled. The cap will equal the amount of al-

\footnotetext{
${ }^{15}$ More precisely, if the allowance surplus at the end of year $t$ exceeds $833 \mathrm{Mt}$, the transfer of a fraction of the excess amount to the MSR takes place from the start of September of year $t+1$ until the end of August in year $t+2$, so there is an almost two-year long time lag before the full transfer is completed. For ease of exposition, (A12) assumes a full two-year lag, but our simulation model correctly accounts for the actual time lag.
} 
lowances that was auctioned during the previous year. This amount is equal to 57 percent of newly issued allowances in the previous year plus any release of allowances from the reserve in the previous year (since releases must be auctioned) and minus any transfers of allowances to the reserve in the previous year (since these must be taken from the flow of new allowances that is auctioned). Hence the cap evolves as

$$
C_{t}=\left\{\begin{array}{ccc}
0 & \text { for } & t<2023 \\
0.57 \cdot Q_{t-1}+M_{t-1}^{O U T}-M_{t-1}^{I N} & \text { for } & t \geq 2023
\end{array}\right.
$$

The cumulative reserve in the MSR at the end of year $t$ can now be written as

$$
M_{t}=\min \left\{M_{t-1}+M_{t}^{I N}-M_{t}^{O U T}, C_{t}\right\}
$$

\section{A.4 Equilibrium}

The equations (A8) through (A15) specify the model. A price path $p_{1}, p_{2}, \ldots, p_{h}$ satisfying these conditions makes up an equilibrium, which can be found by an appropriate algorithm. 


\section{Comment on F. Silbye and P. B. Sørensen: \\ National Climate Policies and the European Emissions \\ Trading System}

\section{Svante Mandell ${ }^{1}$}

This paper sets out to answer four questions: (1) Has the ETS fulfilled its mission so far? (2) What are the prospects for the European carbon market after the latest reform of the ETS in 2018? (3) Are member state policies aimed at reducing national emissions from the ETS sector ineffective? (4) How can the future performance of the ETS be improved?

Questions (2) and (3) seem to be in focus. The first question, whether the ETS has fulfilled its mission so far, is answered basically by discussing different arguments in the literature. Even if there is no new analysis applied at this point, it is clearly an interesting and important discussion that serves as a good background for the remainder of the paper. Likewise, the answer to the fourth question, how to improve the ETS's future performance, is also more based on earlier literature. The idea is to implement a price floor and a price ceiling in the ETS such as to keep the emission allowance price within a certain range. This, too, is an important and interesting discussion which adds to the paper. Even if the idea as such is not new, the paper contains a valuable discussion regarding to what extent it is possible to implement it in the ETS.

Where the paper really adds to the literature, as well as the political debate, is on questions (2) and (3). To answer them, the authors set up a model for how the reformed ETS will operate. The model is calibrated to be in line with current data and is then used to illustrate likely consequences of the reform. Furthermore, the model is used to investigate the effects of unilateral measures to decrease domestic emissions from the ETS sector.

There are some other recent papers, referred to by the authors, that conduct similar exercises. The exact outcome differs between

${ }^{1}$ National Institute of Economic Research. Email: svante.mandell@konj.se. 
the papers, but the general understanding of the workings of the reformed ETS are similar. This is good. The reform entails a rather substantial change in how the system works in that the total emissions now become endogenous. Clearly, an understanding of the consequences of this and how it operates is of crucial importance to policy makers. Thus the paper is highly relevant and adds important insights not only to the science community but also, and perhaps even more so, to policy makers.

However, there are a few things that I find somewhat unclear and that could require some further discussion.

One crucial driver behind the consequences of the reformed ETS is for how long the total number of allowances in circulation (TNAC, referred to as 'the surplus' in the paper) remains above 833 million. If it drops, and remains, under this value the feed-in to the MSR stops. This in turn implies that the system reverts back to its original way of functioning under which domestic measures to reduce emissions do not influence total emissions. How long time it will take to reach this threshold depends on several factors, but the most important one is probably the demand for allowances. If the demand is high, TNAC falls faster and reaches the threshold earlier.

The approach adopted in the paper is to let the demand for allowances depend on how the allowance price develops. This approach seems realistic. The downside is that the model becomes more difficult to see through. In accordance with Hotelling's rule, the allowance price path must follow the required rate of return. For investors, this is assumed to be ten percent prior to the reform. It is also noted that firms that hold allowances for hedging purposes probably apply a rate of return far below this number. The authors are probably right in assuming that the reform increases the market's confidence in the future of the ETS and that this would decrease the risk. To account for this, they calculate what new required rate of return would be required, given the initial ten percent, to conform with the price increase observed recently. This is an interesting approach. It is not entirely clear to me how the authors disentangle the reduced-risk effect from what follows from the demand effect due to the large amount of allowances being annulled in the MSR from 2023. A different approach would have been to compare spot prices with future prices to calculate what 
price path the market anticipates. Such an approach would seem to result in substantially lower required rates of return.

When addressing question (2), the authors compare the system before and after the reform. This seems reasonable given the research question, but it does make it harder to understand which parts of the reform causes what outcomes. Comparing Figures 3 and 4. it is apparent that at least two things differ between the settings. First, the feed-in rate to the MSR is (temporarily) doubled after the reform. That is, a larger share of the TNAC is fed in to the MSR, which implies that the TNAC falls faster. Second, under the reformed system, a substantial amount of allowances in the MSR is cancelled in 2023. At least the latter is likely to increase the price of allowances (as they become scarcer in the future). As noted above, allowance prices may increase also due to decreases in risk. Given this, it is somewhat surprising that the emission levels under the reformed compared to the old system seem to be virtually identical up to around 2035. After that, emissions are lower under the reformed system.

Arguably, question (3) is the most interesting one, at least from a policy perspective. That is, given the reform, what are the consequences of unilateral domestic emission reductions? Under the old system, such measures could reduce the allowance price, but would not influence the total amount of greenhouse gas emissions (but could of course potentially be motivated by other aims). Knowing to what extent, and under what circumstances, such measures now impact total emissions obviously could have policy implications.

Silbye and Sørensen introduce a policy horizon in the analysis. As far as I understand, the purpose is to capture that earlier emission reductions are better from a climate perspective than later reductions due to the possibility of tipping points. According to the authors, this may be a reason for policy makers to adopt a relatively short policy horizon. I am not fully convinced by that argument.

There is, however, another aspect on the policy horizon that I find even more confusing. As can be seen by comparing Figures 3 and 4 , the fundamental difference in climate impact between the old and the reformed system occurs in later time periods. Then, under 
the old system, the MSR would feed back a substantial amount of allowances to the market for several years. However, under the reformed system, this will not happen. When the auction volumes go to zero, so will the number of allowances held in the MSR. Yes, the fact that the allowance prices under the reformed system will, for any given year, be higher than in the old will reduce emissions (that year). Nevertheless, the substantial difference in climate impact from the reformed system follows from the cancellation of a huge amount of allowances that would otherwise have been fed back to the market in later periods.

I believe this is potentially important because if one accept the notion that policy makers adopt a short policy horizon, what is then the difference between the old system (where the allowances were fed into the MSR but released back again on the 'other side' of the horizon) and the reformed one (where they are still fed into the MSR but - to a large extent - cancelled before they may be fed back)? Is it all driven by higher prices due to the reform? This would seem to be contradicted by the above mentioned comparison between Figures 3 and 4 that indicates virtually no differences in emission volumes between the two regimes occurring before 2030. My understanding is that for short policy horizons, there is virtually no difference (except possibly stemming from the price increase) due to the reform. The effect of a domestic emission reduction is an exactly corresponding reduction of total emissions if the policy horizon is short enough both in the old and in the reformed system. Given this view, it may be worth noting that the longest policy horizon studied stretches to 2060. As can be seen from Figures 3 and 4, this horizon ignores a substantial part of the period under which the MSR would be gradually emptied under the former regime.

In general, the policy recommendations are similar to those in other studies. Domestic measures to decrease ETS emissions now may have an impact on total emissions. That impact is larger the earlier the emission reduction occurs. Furthermore, and also in line with other studies, a strategy of governments buying allowances and annulling them now becomes less effective.

A general insight is that the timing of the emission-reducing measures matter. As discussed above, the limit on the policy horizon makes it difficult to say to what extent this is due to the fact that 
the reform has introduced a cancellation mechanism to the MSR or to the fact that emissions are reallocated to after the horizon. Even so, given the assumptions used, the impact of domestic reductions decreases over time such that reductions occurring from 2040 onwards will have zero impact on total emissions.

The paper thus indicates a window for effective domestic measures geared towards the ETS sector that is open for the coming two decades, albeit the effect is decreasing the later in this period the measures are implemented. It may be important again to note that a crucial determinant of for how long this window exists is the demand for allowances. The larger the demand, the earlier the window will be closed. That is, if the world evolves in a less favorable way, where emissions decrease at a slower pace, the less impact will domestic measures have. 


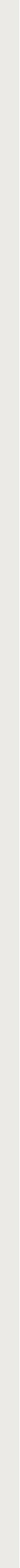




\section{Comment on F. Silbye and P. B. Sørensen: \\ National Climate Policies and the European Emissions \\ Trading System}

\section{Saara Tamminen ${ }^{1}$}

The Intergovernmental Panel on Climate Change concluded in their special report on global warming of 1.5 degrees Celsius (IPCC 2018) that the risks associated with two degrees warming are critically higher than with 1.5 degrees warming. In other words, societies around the world should decrease their emissions significantly faster than what has been planned until now e.g. in the Paris Agreement.

The IPCC special report provides four different emission paths that would keep the warming at 1.5 degrees. All of them show that the world has around 20-40 years to become carbon neutral. While two of the scenarios rely very heavily on carbon dioxide removal technologies, such as bioenergy with carbon capture and storage techniques, to limit the warming after 2050, the actual potential for large emission reductions through such measures is still uncertain. Significantly higher probabilities to limit the warming to 1.5 degrees are obtained by reducing current emissions as fast as possible. Global emissions should be cut to about half in the next ten years and to net zero by 2050 .

For many policy makers the most important question is then how to achieve such reductions in (global) emissions. Which policy instruments would be most effective and cost efficient in bringing along so fast emission reductions? In the EU area, around half of the GHG emissions are controlled by the EU Emission Trading System (EU ETS). As Silbye and Sørensen mention, typically any official changes to the EU ETS have taken years to negotiate. Given the fast pace required to reduce GHG emission, policy makers in the EU countries also need to consider possible national measures to fasten the pace of emission reductions in the ETS sectors.

\footnotetext{
${ }^{1}$ Sitra Innovation Fund. Email: saara.tamminen@sitra.fi.
} 
Silbye and Sørensen provide an important and interesting analysis on the effects of the new market stability reserve (MSR) on the functioning of the EU ETS. They arrive at the same interesting conclusion as Perino (2018): the new MRS punctures the waterbed effect. With waterbed effect I refer here to the reallocation effect of domestic overlapping climate policies that have previously simply transferred the emissions from one part of the ETS system to another without any overall reduction in the total GHG emission EU-wide. These results on the puncture of the waterbed effect are important to all policy makers in the EU ETS area and they provide new evidence on the possibility to get EU-wide emission reductions with overlapping domestic policies. In addition, the considerations of Silbye and Sørensen on the best ways to improve the EU ETS system further are very valuable from a policy perspective.

While Silbye and Sørensen and Perino (2018) reach the same conclusion on the effectiveness of overlapping domestic climate policies in reducing EU ETS area emissions, they do not provide any results on the cost effectiveness of such domestic policies. Should a policy maker who aims to fasten emission reductions introduce overlapping domestic policies or simply aim to tighten the GHG emission reductions driven by the EU ETS? Which options would be the most cost-efficient and how cost-efficient are overlapping policies in the ETS sector compared to emission reductions in the non-ETS sectors?

The most significant sources of national non-ETS emissions are transport, agriculture and waste. Evidence on the cost efficiency of different abatement methods seems to vary. A recent study by Sitra and McKinsey (2018) finds that Finland could reduce GHG emissions significantly with negative system costs by electrifying especially the transport sector and increasing wind power usage. Gillingham and Stock (2018) also conclude that wind power and low blending rates of ethanol have had recently relatively low abatement costs (but with substantial variation over type and use). In general, Brink et al. (2016) conclude that a variable price floor (an additional tax added to the ETS allowance price if necessary to reach a target price) would be the least-cost option to fix the EU ETS and increase the allowance price sufficiently to incentivise investments in clean technologies. With the new results of Silbye and Sørensen, it seems that e.g. overlapping support to low-cost 
technologies in ETS sectors or introducing a price floor to EU ETS sectors, even if in just a selection of ETS countries, could reduce EU-wide emissions in a relatively cost-efficient way.

An important part of the Silbye and Sørensen paper is the comparison of their modelling approach to the previous studies of Perino and Willner (2017) and the (Swedish) National Institute of Economic Research (2018). In particular, the authors show that the modelling assumption regarding especially the pace of technical progress in abatement technologies, the rate of required return and the price sensitivity of emissions can significantly affect the main results.

Further, the sensitivity analyses on how long the emission allowance surplus and intake of allowances to MSR might last are very important. Silbye and Sørensen also mention that some countries have considered buying emission allowances back and postponing their cancellation until allowances are no longer transferred to the MSR to secure a long-run reduction in total allowance supply. However, if the emission allowance intake will indeed continue all the way until 2038 as Silbye and Sørensen calculate (for comparison Perino and Willner 2017 estimate the intake to last only until year 2022), these policy measures might be risky since policy makers could have an incentive to sell unused allowances back in the future if their prices increase. This would mean, again, that cumulative emissions are not decreased in the end.

To conclude, Silbye and Sørensen provide important analyses on the functioning of the EU ETS with the MSR and on the effectiveness of overlapping domestic policies in decreasing EU-wide emissions. However, additional research is needed especially on the most cost-efficient ways to implement climate policies with the current ETS rules and on the most efficient ways to improve the functioning of the EU ETS in general.

\section{References}

Brink, C., Volleberg, H. R. J., and van der Werf, E. (2016), Carbon Pricing in the EU: Evaluation of Different EU ETS Reform Options, Energy Policy, 97, 603-617. 
Gillingham, K. and Stock, J. H. (2018), The Cost of Reducing Greenhouse Gas Emissions, Journal of Economic Perspectives, 32(4), 53-72.

Intergovernmental Panel on Climate Change (IPCC) (2018), Global Warming of $1.5^{\circ} \mathrm{C}$, Retrieved January 3, 2019, from https://www.ipcc.ch/ sr15/.

National Institute of Economic Research (2018), EU ETS, marknadsstabiliseringsreserven och effekter av annulleringar, Special Study 2018:10.

Perino, G. (2018), New EU ETS Phase 4 Rules Temporarily Puncture Waterbed, Nature Climate Change, 8, 262-264.

Perino, G. and Willner, M. (2017), EU-ETS Phase IV: Allowance Prices, Design Choices, and the Market Stability Reserve, Climate Policy, 17(7), 936-946.

Sitra and McKinsey (2018), Cost-efficient Emission Reduction Pathway to 2030 for Finland: Opportunities in Electrification and Beyond, Sitra Studies 140. 


\title{
Are Climate Policies in the Nordic Countries Cost-Effective?'
}

\author{
Björn Carlén ${ }^{2}$
}

Bengt Kriström ${ }^{3}$

\section{Abstract}

Nordic climate policy can become more cost-effective. Available estimates show that marginal abatement costs of the non-ETS sector may differ substantially between the Nordics and other European countries. Hence, by engaging in intergovernmental emissions trading on behalf of their non-ETS sectors, the climate goals of the Nordic countries for 2030 may be reached at lower costs. Ample within-country opportunities also exist, such as the removal of ineffective subsidies and overlapping regulations. There are also gains to be had from policy coordination among the Nordic countries.

Keywords: Climate policy, cost-effectiveness, international emissions trading. JEL codes: Q54, Q58.

\footnotetext{
1 We are grateful to Lars Calmfors, John Hassler and the referees for useful comments and thank Berit Hasler, Lars-Gårn Hansen, Juha Honkatukia, Thorolfur Matthason, Knut-Einar Rosendahl, Erik Romstad and Rauli Svento for giving pointers to the literature on economic analysis of climate policy in the Nordic countries.

${ }^{2}$ National Institute of Economic Research, Sweden. Email: bjorn.carlen@konj.se.

${ }^{3}$ SLU CERE. Email: bengt.kristrom@konj.se.
} 


\section{Introduction}

Along with the EU, the Nordic countries aim to achieve a reduction of greenhouse gases by at least 40 percent compared to 2005 by 2030. Briefly, Denmark aims at a complete decarbonisation of energy supply, Finland envisions a reduction of 80 percent in 2050 within a larger international effort, Iceland targets a net 50-75 percent cut, and Norway and Sweden both aim at zero net emissions by 2050 and 2045, respectively. Overall, these reductions go beyond internationally agreed goals and demonstrate a willingness to maintain a relatively ambitious climate policy. ${ }^{4}$ At the same time, the contribution to global emission reductions is small. In addition, it is widely agreed that the marginal abatement costs in the Nordic countries are high in an international comparison. On top of this, the Nordic countries are small open economies in which energy-intensive industries (which may thus face relatively high costs of emission reductions) are important.

These facts translate into a familiar dilemma; how to combine high climate ambitions with economic realities? This question has been discussed at great length in the environmental economics literature ${ }^{5}$ The pros and cons of an ambitious climate policy involves discussions about carbon leakage, technological spill-overs, firstmover advantages, demonstration effects ('others might follow'), exempting competitive sectors, and much more, including our moral obligations as rich countries. While we touch upon some of these arguments, we bring a rarely discussed option to the table: bilateral agreements between EU members with different marginal abatement costs in their non-ETS sectors, i.e. sectors that are not part of the EU emission trading system for climate gases. Overall, our main focus is the identification of marginal cost disparities between the Nordics and and other European countries as well as between the Nordic countries.

While the particulars of the domestic carbon policies differ among the Nordic countries, there is an important similarity, which we call the dual carbon economy. The non-ETS sector, most importantly

\footnotetext{
${ }^{4}$ Kjellén (2007) documents the long history of having an ambitious environmental policy in the case of Sweden.

${ }^{5}$ Hoel (2012) is a useful summary of the arguments involved.
} 
the transportation sector, does not face the carbon price on the EU(+) permit market, and therefore may not face the same marginal cost. Consequently, there may be both within-country and between-country marginal cost differences. Exploiting such differences means that climate policy can be made more efficient. Our conceptual framework helps unravel the key issues involved. By utilizing existing flexibility mechanisms within the EU to reduce or eliminate certain between-country tax disparities and discard several inefficient subsidy schemes, the Nordic 'carbon footprint' can be reduced without allocating more resources to climate policy than we currently do.

To set the stage, Section 2 begins by explaining our framework. Section 3 describes the existing climate-policy framework and how it enables international emissions trading. Section 4 gives a brief description of the Nordic countries' climate policies. Section 5 assesses potential cost savings from intergovernmental carbon dioxide $\left(\mathrm{CO}_{2}\right)$ emissions trading between the Nordics and other European countries. The section also points at some overlapping policies in the Nordic countries. Section 6 brings the analysis together and offers policy implications. Section 7 concludes.

\section{A framework}

To identify the welfare effects of international emissions trading, we set up a simple model that in some important ways resembles the climate-policy structure imposed by the EU. Section 2.1 briefly presents the model (a formal description is given in an appendix). A key idea is the holistic perspective: in principle, the framework includes all of the many repercussions that a change of climate policy will cause in a modern market economy. To keep the framework manageable, we make a number of simplifying assumptions. We explain them in Section 2.2.

\subsection{The model}

Consider a region (the world can be one region) with more than one country, each with a two-sector 'perfect' market economy. Two economic instruments are used to control $\mathrm{CO}_{2}$ emissions: a regional emissions-permit market and a domestic carbon tax. The permit market is used in Sector 1 where a representative firm competes on 
the regional competitive market, while the tax is used in domestic Sector 2 which does not export its production. The tax revenue is returned to a representative household as a lump sum. In the background the rent from the permits is also returned.

In each country, the representative firm in Sector 1 must buy emission permits for its operation; each permit can be bought on a perfect market. The representative firm in Sector 2 pays a per-unit emission tax on its emissions.

The consumer faces market prices on the goods it consumes and has income from several sources: labour, taxes and permits (returned lump-sum), profits (because the consumer owns the firms). Thus, we assume that the firm buys permits directly from the household, with a perfect market of permits operating in the background. Finally, the household is affected negatively by emissions generated in the production sectors.

Consider now a region consisting of two countries, each using a certain emission tax and where the total number of emission permits has been agreed upon. In general equilibrium, supply is equal to demand in all markets. If the carbon tax in one country is raised, this changes the equilibrium as all the markets in the region adjust. For example, the tax might increase transportation costs and indirectly the cost of production in the export sector and hence 'competitiveness' in the country that raises the tax. Our framework provides a way to keep track of all the direct and indirect effects and adding up these to obtain the net welfare effects.

In the Appendix, we detail a more comprehensive reform mathematically, in which we allow the tax rates and the emission levels to change. It turns out that the welfare effects can be rather simply computed. Let us here briefly explain the intuition, which is based on an accounting of the benefits and the costs. We begin with the environmental benefits.

Suppose the intent is to sharpen climate policy in the region using the available policy instruments. In this context, we raise the price of carbon in the economies involved, either directly via a tax or indirectly by reducing the number of permits. Therefore, emissions are reduced. From the point of view of the household, the environmental 
benefits are independent of where the emissions are reduced. These spill-over effects are a main feature of climate policy, but we do not discuss free-riding possibilities and strategic aspects; our main aim is to simply account for the total benefits and costs of a comprehensive policy reform. The point is that any reduction of the total emissions are assumed to benefit the households of the region. In reality, such benefits will be distributed in rather complex ways (inhabitants of the Nordic countries might actually gain from a warmer world, as we discuss further below). Because many of the environmental benefits involve goods and services that are not priced in markets, such as biodiversity, it is difficult to measure these benefits in monetary terms. There is a substantial literature in environmental economics on how this can be done, but we do not discuss this problem. As we will see, a strong efficiency argument can be made that we do not need to measure the benefits if there are marginal cost disparities.

In general, the benefits of the reform we are considering must be compared to the cost. Profit maximizing firms will choose emissions and abatement efforts such that the marginal cost of reducing emissions is equal to the price on emissions they face, For firms in Sector 1, this is the emission permit price and for firms in Sector 2, it is the tax. Consequently, if there is a difference between the tax and the permit price, or between the tax levels in different countries, there is also a difference between marginal costs. If so, we can find re-allocations between emission sources that make climate policy more cost-effective.

\subsection{Discussion about some simplifying assumptions}

There are a number of aspects of our model that needs to be discussed in more detail. Its main prediction is straightforward; if there are marginal cost disparities, there are efficiency gains to be had by trading (in a general equilibrium framework). Efficiency is one important policy parameter, and so is distribution.

\section{Distributional issues}

The distributional issues are very important to the discussion of climate policy. There will be winners and losers regardless of how we reach any climate goal. First of all, it is well-known that the physical impact of climate change is very asymmetric. Thus, to emit a ton of carbon may result in a welfare gain for the 'North', but entail a significant welfare loss for the 'South'. Brännlund (2017) reviews the 
literature, with a focus on Sweden. He finds that northern Europe faces increasing risks of floods and landslides, but these are counterbalanced by increased agricultural, forest and hydropower production as well as by lowered costs for heating. According to Brännlund's calculations, the effect on Swedish GDP of climate change is very slightly positive. ${ }^{6}$ Such results illustrate the complexity of global climate policy and are quite independent of our policy proposals, since they provide a practical way to make policy more cost-effective, i.e. lower the cost of attaining a given emissions target.

The physical impact is one side of the coin, how we distribute the costs for reaching any particular goal is the other. The main message from the literature is that climate policy tends to be regressive, i.e. the poorer part of the population will typically shoulder a disproportionate share of the costs.

As noted, we simply sum the welfare changes without weighting the winners and losers differently (a utilitarian approach). This is the standard approach in the environmental economics literature, and also in many other strands of economics. Whether efficiency and distribution can be separated is a matter of long debate within the profession. Our approach can be generalized to handle the distributional issues using 'distributional weights', so that different subsets of the population are given a different welfare weight. We do not pursue this generalization here.

\section{Technical development}

Nordic climate policy provides many examples of support to technological progress. The Nordic Council (2017, p. 9) argues 'Their governments aim to support green technologies by encouraging public-sector purchasers to serve as role models and help to build markets by favouring low-carbon options in areas such as transport, buildings and catering.' In the academic literature, a strong case for subsidizing technological progress, the 'energy technology R\&D budget' has been advanced by Alfsen and Eskeland (2007). Rather than embarking on expensive domestic emission cuts, they argue that it might be better to support technological development that in the end gives a demonstration effect. It is difficult to evaluate this argument empirically, but one of the merits of the proposal is that it does not point

${ }^{6}$ See $\mathrm{p} 46$. 
to subsidizing any particular technology. Demonstration effects are particularly difficult to pin down empirically.

It would be possible to amend our model with a mechanism that supports technological progress at some opportunity cost, but then our results will depend on how we model endogenous technical change. Because our framework is holistic, we must consider subsidies in an economy-wide context; why are the same kinds of arguments not valid for other sectors of the economy? That said, there are several examples from the literature in which the subsidy mechanism is included and shown to reduce the costs of ambitious climate policy. Invariably, such efforts ignore the fact that subsidies could have been used in other sectors.

A conceptually much simpler case is when technological progress is exogenous, and not explained within the model. It is not difficult to show that exogenous technological progress must be beneficial to the economies in our model. Note, however, that technological progress in this simple framework also has a public-finance effect. If, for example, there is a significant switch to electric cars, which certainly is in the cards, this might have significant effect on public-sector revenues from carbon taxes on fossil fuels.

\section{The Porter hypothesis and competitiveness arguments}

Porter (1991) introduced what has become known in environmental economics as the 'Porter-hypothesis.' He argued that stricter environmental regulations are associated with much lower costs than traditionally assumed: in fact, the costs could be negative. The Nordic Council summarizes rather well the typical Porter-style arguments 'Building up local markets for green technologies helps new businesses to create new, green jobs and build up a base for exports that can be expected to boom as other regions seek ways to respond to the global climate challenge.' (Nordic Council 2017, p.9) However, empirical assessments do not to give strong evidence for the hypothesis. ${ }^{8}$ This includes a scrutiny of whether or not stricter environmental regulations in itself are able to 'create jobs', some-

\footnotetext{
${ }^{7} \mathrm{~A}$ more refined and longer version of the argument is in Porter and van der Linde (1995).

${ }^{8}$ See e.g. Palmer et al (1995). A critical assessment based on Swedish data and a comprehensive literature survey is Brännlund (2007). A more positive review of the evidence is Ambec and Lanoie (2008).
} 
times called 'green jobs'. The argument is hard to evaluate, because it depends on the details of the regulation considered. If we include incentive-based instruments in Porter's 'stricter regulation', it is not difficult to find results that point either way; ambitious climate policy may increase jobs, or it may not. What we can conclude is that there is no strong evidence of any 'job creation' effect of stricter climate policy.

There have also been some recent attempts to go beyond the assumptions of rational economic agents ${ }^{9}$, which seem to be needed in order to provide support for the Porter hypothesis. The main lesson from the point of view of our simple framework is that any such extension must rest on an economy-wide perspective. It would require a substantial extension of received theory to undertake such an analysis with the whole economy in mind; in particular, it would require alternative definitions of cost efficiency and other key concepts. How to rank policies in such an economy will depend on how we model 'irrational' economic agents.

\section{Carbon leakage}

Carbon leakage is usually defined as a case when emitting activities move to countries with less stringent environmental policy. Intertemporal carbon leakage may also occur and refer to a reallocation of emissions over time (typically so that they come earlier than expected). We use a static framework, which is not well suited to study dynamic issues such as the so-called Green Paradox. Proponents of the Green Paradox argue that an announcement of a gradually stricter climate policy induces oil producers to 'start selling, when the selling is good'. Paradoxically, announcing an upcoming sharpening of climate policy may therefore increase emissions 'today', emissions that otherwise would have come later. An early contribution along this line is Sinclair (1994); the literature today on this topic is substantial. ${ }^{10}$ How important the Green Paradox really is remains a research topic. It has increasingly been realized that there are several counterbalancing forces. For example, a reallocation of oil production towards the present may decrease interest rates via increased global savings, which according to the standard model

${ }^{9}$ See Bernheim and Rangel (2009) for this extension and Smith and Moore (2011) for a critical discussion.

${ }^{10}$ See van der Ploeg and Withagen (2015) for a survey. 
(the Hotelling model) tends to slow down extraction. The simplest Hotelling model, which assumes away extraction costs, predicts that the price of oil increases at the rate of interest in equilibrium, since the two ways of holding assets in the model (in the ground or in the bank account) must offer the same rate of return. Therefore, a ceteris paribus lowering of the interest rate tends to slow down extraction, because the rate of return on keeping the oil in the ground is higher.

Although we will not explicitly deal with intratemporal leakage, one of our main points is that the Nordic energy taxation is relatively well harmonized (at least in the transportation sector); there are no 'pollution havens' in the Nordic countries (see Section 4 for details about energy taxation). The literature on intratemporal leakage is inconclusive; the estimates vary by a wide margin (from negative to positive)..$^{11}$

Finally, by way of illustration of the theme in this section, we note that just before the introduction of the bonus-malus scheme (the 1st of July 2018), there was a substantial increase in the number of diesel/gasoline cars sold in Sweden (Statistics Sweden 2018). This scheme essentially entails an increasing malus or a decreasing bonus in the vehicle tax based on the carbon emission characteristics of a vehicle that entered the official registry after 1 July 2018. Bonus-malus arguably illustrates how a policy can contribute to intertemporal carbon leakage. More importantly, it is an example of an inefficient and overlapping policy, because it does not focus on the $\mathrm{CO}_{2}$ emission, but rather on ownership of a vehicle that operates in a system with an already existing carbon tax. This example also serves as a bridge to the remaining part of the paper, in which we will discuss how a more cost-effective climate policy can be shaped in the Nordics. We begin by outlining the climate policy in general terms, then describe the situation in the Nordics, after which we present an empirical analysis of our main policy proposal.

${ }^{11}$ See Böhringer et al. (2017). 


\section{The climate policy landscape}

The threat of large and rapid climate changes is a global public bad. International co-ordination is thus needed. This section gives a brief description of the policy response by the global community and the $E U$, respectively. EU climate policy is key to the shaping of individual European countries' climate policies.

\subsection{International agreements}

The first attempt to operationalize an international climate treaty was the Kyoto Protocol. The Protocol set a cap for the industrialized countries' total emissions of greenhouse gases for the period 200812 and assigned national tradable emission quotas to the participating countries. ${ }^{12}$ The idea was that the developing countries would join later and that the overall cap would shrink over time. However, the developing countries did not come along. A second set of emission quotas for the rich countries for the period 2013-20 was negotiated, but it was clear that the world had to look for another way of global co-ordination.

The Paris Agreement (United Nations 2015) was negotiated in 2015. Its goal is to keep the global mean temperature increase well below two degrees Celsius (relative to the pre-industrial level) and an ambition to stop the increase at 1.5 degrees Celsius. Under the agreement, each participating country announces how much it plans to reduce its greenhouse gas emissions, the so-called Nationally Determined Contribution (NDC). Over time, the countries are supposed to announce new, more ambitious contributions. A basic tenet of the agreement is that peer review and political pressure will produce such a development. It may be argued that the Paris Agreement has succeed where the Kyoto Protocol failed, because it also includes developing countries. About 180 countries have ratified the agreement.

The Paris Agreement defines two flexible mechanisms - ITMOS (Internationally Transferred Mitigation Outcomes, Article 6.2) and a project-based mechanism (Article 6.4) akin to the Clean Develop-

12 The protocol also defined three different forms of emissions trading: International emissions trading (IET), Joint implementation (JI) and the Clean Development Mechanism (CDM). 
ment Mechanism of the Kyoto Protocol. However, a setting where countries determine their own 'emission quotas' is not well suited for international emissions trading since both seller and buyer countries then have incentives to increase their emission quotas (see Helm 2003).

\subsection{EU's Climate policy}

The EU has announced that it will reduce its greenhouse-gas emissions with at least 40 percent to the year 2030 relative to 1990 (European Commission 2014); the long-term target is a reduction by 80-95 percent to 2050. EU's climate policy is divided into three sectors; the EU ETS (EU Emission Trading System), the ESR (Effort Sharing Regulation) and the so-called LULUCF (Land Use, Land-Use Change and Forestry). Below we give a brief description of these agreements. The purpose is to review the opportunities for emissions trading which the framework gives the participating countries.

\section{The European Union Emissions Trading System (EU ETS)}

The EU ETS covers emissions of $\mathrm{CO}_{2}$ and certain other greenhouse gases from energy intensive industries and energy industries and $\mathrm{CO}_{2}$ emissions from aviation in the EEA (the EU plus Iceland, Liechtenstein and Norway). ${ }^{13}$ The system covers more than 11000 installations and about 45 percent of the $\mathrm{EU}^{\prime} \mathrm{S} \mathrm{CO}_{2}$ emissions. Each participating firm must surrender a permit to the regulator for every ton $\mathrm{CO}_{2}$ it emits. $^{14}$

The EU ETS establishes a European-wide price signal. After the financial crisis 2008, the permit price hovered for long at levels deemed too low to be consistent with the EU's long-term objectives. The system has therefore been reformed prior to its fourth phase (2021-30). Major elements of this reform are (i) a faster reduction of the number of permits that annually is added to the system, implying that no more permits will be added to the system around 2055, (ii) the establishment of the so-called market stability reserve, and (iii) the creation of an automatic annulment mechanism (European Council/Council of the European Union 2018). In brief, the system

\footnotetext{
${ }^{13}$ Special emission permits are issued to the aviation industry. While flight companies may buy and use ordinary EU ETS permits, land-based firms cannot buy and use aviation permits.

${ }^{14}$ Firms that fail to do that have to pay a fine amounting to 100 euros for every permit missing.
} 
Figure 1 The (futures) permit price in EU ETS 2008-18, EUR/ton

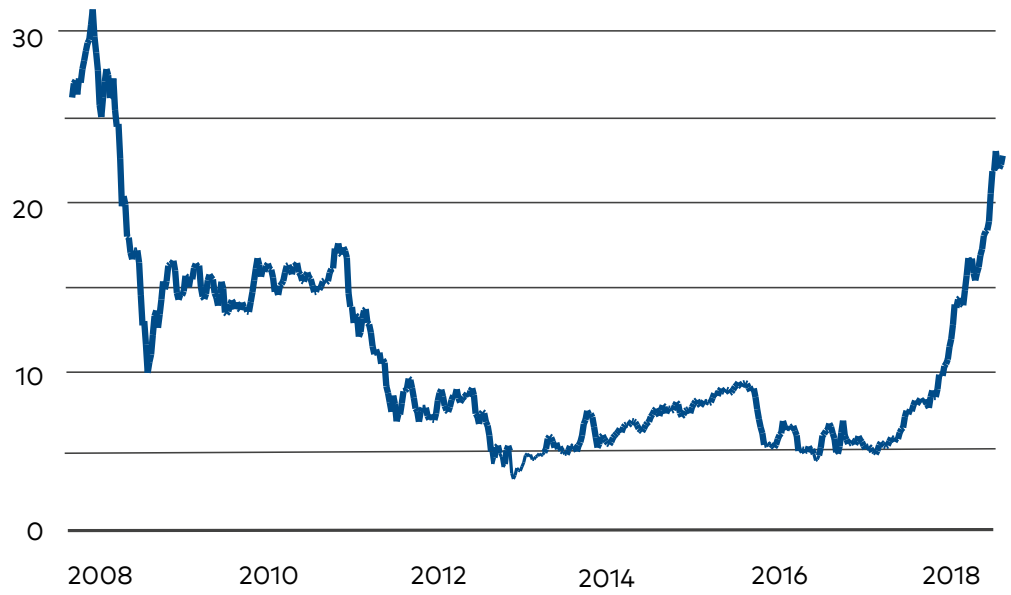

Note: Historical Futures Prices: ECX EUA Futures, Continuous Contract \#1. Non-adjusted price based on spot-month continuous contract calculations. Source: https://sandbag.org.uk/carbon-price-viewer/.

works as follows. When the private bank of permits exceeds 833 million, some permits will be transferred to the market stability reserve instead of auctioned to the market. Beginning 2023, the volume in the reserve is compared to the auction volume, and if it is larger the difference is annulled. Under the new rules a large volume of permits is expected to be subtracted from the system. ${ }^{15}$ The reform is one important reason for why the permit price has quadrupled since last summer (see Figure 1). The minimum price recorded is about three euros per ton and the maximum 30.5 euros.

The reformed EU ETS implies that additional policies that reduce the demand for emission permits (e.g. subsidies to electricity produced using renewable energy) now may lead to a reduction of the system's overall cap. How effective such additional policies turn out to be depends on several variables, e.g. how the demand for permits

${ }^{15}$ NIER (2018) indicate that about 2.5-3 billion permits are expected to be subtracted from the system during the 2020s. Silbye and Sørensen (2019) assess that up to 2050 about 5 billion permits will be annulled. 
evolves and the timing of the additional policies (see National Institute of Economic Research (NIER 2018)).

\section{The Effort Sharing Regulation (ESR)}

The ESR is an agreement that sets a cap for member states' greenhouse-gas emissions from sources outside the EU ETS, i.e., nonenergy intensive industries, households and services, and domestic transportation. The agreement states that total emissions from the member states' non-ETS sectors in 2030 shall be 30 percent lower than in 2005 and distributes national emission reductions obligations to the member states. Richer countries, such as Sweden and Luxembourg are, for the period 2021-30, obliged to reduce their yearly emissions in a linear fashion to a target level in 2030 that is 40 percent lower than in 2005. The corresponding target levels for Denmark and Finland are 39 percent. Poorer countries, such as Bulgaria and Rumania, are given target levels for 2030 that are just slightly below or equal to their 2005 emission levels. It is up to the member states to design policies that fulfil these obligations. ${ }^{16}$

\section{Land Use, Land-use Change and Forestry (LULUCF)}

The LULUCF sector covers greenhouse-gas emissions from and changes in carbon stored in land and forests. Under this regulation, member states must ensure that greenhouse-gas emissions from their LULUCF sector are offset by at least an equivalent removal of $\mathrm{CO}_{2}$ from the atmosphere during 2021-30. Member states that do not comply have to cover their deficits by surrendering ESR quota units to the EU. By convention carbon emission from combustion of biomass and biofuels within the EU ETS and ESR sectors are counted as zero (more on this in Section 7). ${ }^{17}$ Instead, these emission volumes enter as negative posts in the member states' accounts of their storage of carbon.

\section{Flexibility options in the EU's climate policy framework}

In contrast to the EU-ETS, which gives a region-wide permit price, the ESR will produce country-specific prices/tax rates that may vary substantially across both countries and time, should the countries follow their linear emission reductions obligations. Only by

\footnotetext{
${ }^{16}$ A member state that fails to meet its obligation will see its emission reductions obligation for the next year increased with an amount equal to the shortfall multiplied with a factor 1.08.

17 The European Parliament and the Council of the European Union (2018).
} 
chance would this allocation of abatement efforts lie close to the cost-effective one. To increase the cost effectiveness of its climate policy, the EU has therefore defined several so-called flexibility mechanisms for the ESR sectors (European Commission 2018). The most prominent ones are:

- Member states may borrow emission quota units from the next allocation period (up to five percent of the succeeding five years' allotment) and may save unused emission quota units to future allocation periods.

- Some member states (including all Nordic member states) may transfer EU ETS emission permits (up to a limit) to its ESR sector. In other words, by reducing the number of permits it auctions off to its EU ETS firms, the member state may increase its emission cap for its ESR sector.

- A member state may sell up to five percent of its yearly quota allotment to other member states. A member state that over-complies may sell part of or all unused emission quota units to other member states.

- Member states may up to a limit transfer so-called LULUCF credits to its ESR sector.

These flexibility mechanisms may be used to reduce marginal abatement costs differences across member states' ESR sectors, much in the same way that EU ETS does across energy intensive firms. What seems to be missing are mechanisms that allow for large transfers of abatement efforts between the EU ETS and ESR sectors.

As mentioned above, the EU intends to meet its 2030 target of 40 percent reduction of its domestic emissions (relative to 1990) by the ETS reducing its emissions by 43 percent and the ESR with 30 percent (relative to 2005). Since these targets are formulated in terms of EU-wide emission levels, the EU cannot use the flexibility mechanisms of the Paris Agreement to reduce or eliminate any cost differences between the EU ETS and the ESR or between these sectors and the rest of the world. 


\section{The Nordic countries}

This section gives a brief description of the emission developments of the Nordic countries, their climate-policy objectives and palettes of policy instruments.

\subsection{Nordic countries: emission developments and policy objectives}

It is instructive to study how $\mathrm{CO}_{2}$ emissions have developed over time. Figure 2 displays the long-term development (1850-2012) of the Nordic countries' $\mathrm{CO}_{2}$ emissions per capita. From 1950 up to the mid-1970s, the countries exhibit fast growth in their per capita emissions. Thereafter, the positive trend has been either stopped or turned into a negative one for all countries except Norway. The continuing growth in Norway is mainly due to an expanding oil-extraction sector.

Since 1975 real GDP has doubled in all Nordic countries. For Norway, it has tripled. So, at least for the last 40 years we have seen a decoupling between economic growth and $\mathrm{CO}_{2}$ emissions. It is tempting to assert an 'environmental Kuznets curve' for all countries except Norway. Thus, with the exception of Norway, the $\mathrm{CO}_{2}$ emissions per capita increased up to a certain point, after which they turned back, while economic growth continued. Iceland, Norway and Sweden have, for some time, essentially not used fossil fuels in electricity generation. Denmark and Finland have an energy system that uses more fossil fuels than the others.

Because the energy-intensive industries in the Nordic countries are covered by the EU ETS, the main task for the Nordic governments is to control the emissions from their non-EU ETS sectors. Since Norway and Iceland are not EU-members, they are not covered by the ESR. However, both Norway and Iceland have announced intentions of conducting their future domestic climate policies jointly with the EU..$^{18}$ Below we assume that this intention will be fulfilled.

Table 1 displays the climate policy objectives of the Nordic countries. All countries have ambitious long-term targets of being low-carbon

\footnotetext{
18 See Norwegian Ministry of Climate and Environment (2017) and Icelandic Ministry for the Environment and Natural Resources (2018a), respectively.
} 
Figure 2 Per capita $\mathrm{CO}_{2}$ emissions (metric tons) in the Nordic countries 1833-2012

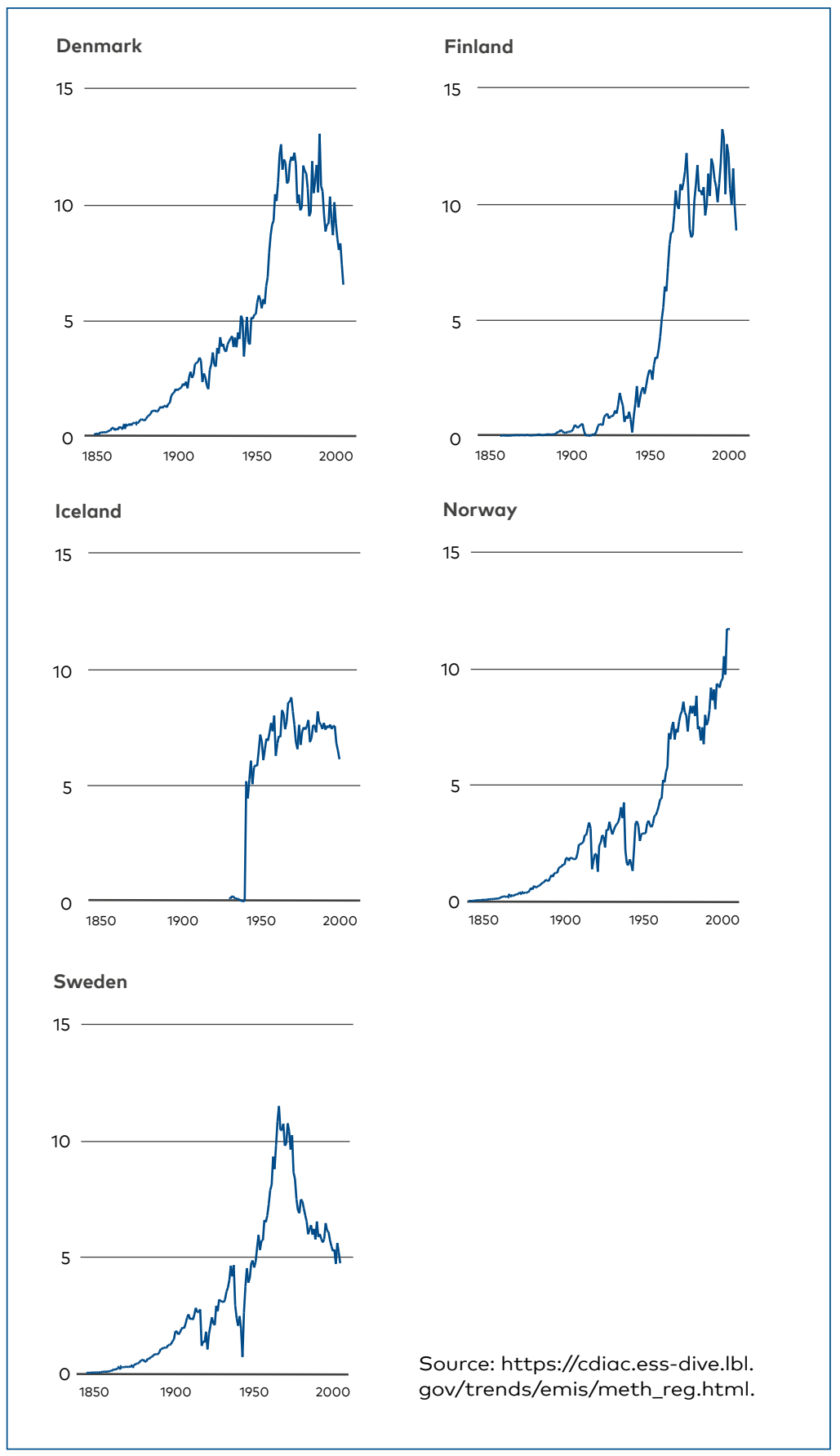


Table 1 The Nordic countries' national (ESR) emission reduction targets

\begin{tabular}{|l|l|l|} 
& $\begin{array}{l}\text { 2030, percent relative to } \\
2005\end{array}$ & $\begin{array}{l}\text { 2050, percent relative } \\
1990^{*}\end{array}$ \\
\hline Denmark & 39 & $80-95$ \\
\hline Finland & 39 & $80-95$ \\
\hline Iceland & $39^{\star *}$ & climate neutral \\
\hline Norway & climate neutral $(40)^{\star *}$ & $80-95$ \\
\hline Sweden & $59(40)$ & $85^{\star \star *}$ \\
\hline EU & 30 & $80-95$ \\
\hline
\end{tabular}

Notes: * Targets comprise both the EU-ETS and the ESR sector. ** Assumed ESR targets. Norway expects a target of about 40 percent. For Iceland we assume an emissions-reductions target around 39 percent since this country lies between Finland and Denmark in terms of GDP per capita. ${ }^{\star \star \star}$ The Swedish long-term target amounts to zero net emission in 2045 , thereafter negative net-emissions.

Source: European Commission (2016) and Norwegian Ministry of Climate and Environment (2017).

societies by 2050 , i.e. to reduce their domestic greenhouse-gas emission levels by at least 80 percent. When it comes to mid-term objectives some differences can be observed, however. While Denmark and Finland stick to their ESR commitments and state that they may use flexible mechanisms to fulfil them, ${ }_{1}^{19}$ Sweden has stated a national emissions target substantially below its ESR obligation and has limited the use of flexible mechanism. ${ }^{20}$ Some countries also include targets for sectors that exclude them from participating in international emissions trading. For instance, Sweden has set an emission target for domestic transportation (excluding aviation) saying that by 2030 this sector's emissions shall be 70 percent below the level in 2010 (Miljö och jordbruksutskottet 2017). Finland has set a target of phasing out coal from its energy system by 2030 (Finish Ministry of Economic Affairs and Employment 2018). In contrast, Norway aims at being climate neutral by 2030 , to a large extent by the means of buying emission credits from abroad (Norwegian Ministry of Climate and Environment 2017).

\footnotetext{
${ }^{19}$ See Danish Ministry of Energy, Utilities and Climate (2017) and Finnish Ministry of the Environment (2017), respectively.

20 Sweden has stated a 59 percent reduction relative to 2005 instead of 40 percent (Miljö och jordbruksutskottet 2017). Eight percentage points may be attained through complementary measures (LULUCF credits or flexible mechanisms).
} 
As shown by Table 1, the Nordic countries have substantially more ambitious emission reduction targets than the $E U$ as a whole. It should be noted that there is a large spread in the EU countries' emission reduction obligations - from Sweden's 40 percent to Poland's, Hungary's and Latvia's obligations that all lie below ten percent. For Bulgaria the obligation is zero.

In addition to engaging in bilateral emissions trading with other member states, Denmark, Finland and Sweden may transfer EU ETS permits to their ESR sectors corresponding to two percent of their emission levels in 2005 and up to some limits use LULUCF credits to meet their ESR targets (European Commission 2018). This limit is 3.6 percent of the emission level in 2005 for Denmark, 1.4 percent for Finland and 1.1 percent for Sweden. Consequently, Denmark, Finland and Sweden have significant flexibility in choosing emission levels that comply with international climate agreements. If Iceland and Norway join the ESR, they would also enjoy these opportunities.

\subsection{Nordic countries: policy instruments}

The Nordic countries have rather comprehensive climate policies. The main bulk of their $\mathrm{CO}_{2}$ emissions are priced, either by EU ETS or national carbon taxes. In addition, there is a clear tendency to promote bio-energy use. Bio-fuel users often pay lower energy taxes than users of fossil fuels and all the Nordic countries have renewable energy quotas for transportation fuels. Furthermore, all countries have excises on cars and vehicle taxation that are differentiated with respect to the vehicle's specific $\mathrm{CO}_{2}$ emissions or fuel consumption. There are also programs subsidizing so-called climate investments. Table 2 summarizes the policy instruments employed in the Nordic countries.

In addition to the instruments listed in the table, several countries have additional support schemes for bio-fuel use and/or production. For instance, Denmark subsidizes investments in biogas plants. Finland has a bio-fuels quota for heating of building and use of light fuel oil for machinery. Norway will in 2020 introduce a ban on the use of mineral oil for heating of buildings.

Table 3 states the current carbon and energy tax rates on gasoline and diesel for transportation use in the Nordic countries. Both the carbon and the energy tax rates vary substantially between the Nor- 
Table 2 Climate policy instruments in the Nordic countries aimed at non-EU-ETS emissions

\begin{tabular}{|c|c|c|c|c|c|}
\hline & Denmark & Finland & Iceland & Norway & Sweden \\
\hline $\begin{array}{l}\text { Energy } \\
\text { taxation }\end{array}$ & $x$ & $x$ & $x$ & $x$ & $x$ \\
\hline $\begin{array}{l}\text { Carbon } \\
\text { taxation }\end{array}$ & $x$ & $x$ & $x$ & $x$ & $x$ \\
\hline $\begin{array}{l}\text { Reduced } \\
\text { tax rates on } \\
\text { bio-fuel use } \\
\text { outside quotas }\end{array}$ & $x$ & & $x$ & $x$ & $x$ \\
\hline $\begin{array}{l}\text { Quota for } \\
\text { bio fuels for } \\
\text { transportation }\end{array}$ & $x$ & $x$ & $x$ & $x$ & $x$ \\
\hline $\begin{array}{l}\mathrm{CO}_{2}^{-} \\
\text {differentiated } \\
\text { vehicle } \\
\text { taxation or } \\
\text { bonus/malus }\end{array}$ & $x$ & $x$ & $x^{*}$ & $x^{*}$ & $x$ \\
\hline $\begin{array}{l}\text { Support } \\
\text { to climate } \\
\text { investments }\end{array}$ & $x$ & & $x$ & $x$ & $x$ \\
\hline $\begin{array}{l}\text { Feed-in- } \\
\text { tariff/green } \\
\text { electricity } \\
\text { certificates }\end{array}$ & $x$ & $x$ & & $x$ & $x$ \\
\hline
\end{tabular}

Note: * In addition no VAT on electric vehicles or public procurement of lowemissions vehicles.

Sources: Danish Ministry of Energy, Utilities and Climate (2017), Finnish Ministry of the Environment (2017), Icelandic Ministry for the Environment and Natural Resources (2018), Norwegian Ministry of Climate and Environment (2017) and Swedish Ministry of Environment and Energy (2017).

dic countries, but the total energy taxation varies less, ranging from 631-702 euros per $\mathrm{m}^{3}$ for gasoline and 471-570 euros per $\mathrm{m}^{3}$ for diesel. The Nordic countries' tax rates (carbon plus energy) on gasoline and diesel lie close to or over the mean tax rates in the EU (Fuel Europe 2018).

The energy taxation on fossil-fuel use in the industry exhibits a more fragmented picture (see Table 4). Some countries have large programs supporting investments that reduce greenhouse-gas emissions in the ESR. For instance, in Norway the state-owned com- 
Table 3 Tax rates on gasoline and diesel for transportation use 2018 in the Nordic countries, euros per $\mathrm{m}^{3}$

\begin{tabular}{|l|l|l|l|}
\hline & $\mathrm{CO}_{2}$ tax & Energy tax & Total tax \\
\hline Denmark & & & \\
\hline $\begin{array}{l}\text { Gasoline } \\
\text { Diesel }\end{array}$ & 55.8 & $\begin{array}{l}574.9 \\
409.4\end{array}$ & $\begin{array}{l}630.7 \\
471.7\end{array}$ \\
\hline Finland & & & \\
\hline $\begin{array}{l}\text { Gasoline } \\
\text { Diesel }\end{array}$ & 173.8 & 521.9 & 702.5 \\
\hline Norway & 199.0 & 327.7 & 530.2 \\
\hline $\begin{array}{l}\text { Gasoline } \\
\text { Diesel }\end{array}$ & 121.6 & 541.9 & 663.5 \\
\hline Sweden & 139.4 & 393.1 & 532.5 \\
\hline $\begin{array}{l}\text { Gasoline } \\
\text { Diesel }\end{array}$ & 255.3 & 391.6 & 646.8 \\
\hline
\end{tabular}

Note: Due to its smallness Iceland is excluded.

Source: National tax administrations.

pany Enova gives grants to i.a. projects that are deemed to reduce such emissions. Enova's budget amounted to 287 million euros in 2018 and so far, the program has contributed to more than 7000 projects (Bruvoll et al. 2018). The Swedish programme Klimatklivet supports investments deemed to reduce greenhouse-gas emissions at the local and regional levels. Between 2015 and June 2017 the programme granted support to over 1000 projects, totalling 117 million euros (Isberg et al. 2017). Sweden has also subsidized the purchase of electric propelled vehicles (bicycles and boats).

It should be noted that investment subsidies and differentiated vehicle taxation only give incentives to specific adjustments, e.g., fuel switching and vehicle choice. However, they add to the incentives given by the carbon tax. The result is a set of complex incentives that are far from uniform.

In addition to the policy instruments listed in Table 2, the countries also have several instruments aimed at activities already covered by the EU ETS. This goes for the feed-in-tariff system/green-electricity certificates for electricity produced by renewable energy resources. 
Table 4 Tax rates on industrial use of natural gas, oil products coal, coke and coal gases 2015 in the Nordic countries, euros per ton $\mathrm{CO}_{2}$

\begin{tabular}{|l|l|l|l|}
\hline & $\mathrm{CO}_{2}$ tax & Energy tax & Total tax \\
\hline Denmark & & & \\
\hline Natural gas & 11.4 & 42.9 & 54.3 \\
Oil products & 2.9 & 11.4 & 14.3 \\
Coal, coke and coal gases & 2.9 & 22.9 & 25.8 \\
\hline Finland & & & \\
\hline Natural gas & 40.9 & 30.7 & 71.6 \\
Oil products & 23.9 & $10.2(20.4)$ & $34.1(44.3)$ \\
Coal, coke and coal gases & 20.5 & 8.5 & 29.0 \\
\hline Norway & & & \\
\hline Natural gas & 44.1 & 0 & 44.1 \\
Oil products & 8.8 & 29.4 & 38.2 \\
Coal, coke and coal gases & 0 & 0 & 0 \\
\hline Sweden & & & \\
\hline Natural gas & 12.3 & $12.3(80.1)$ & $24.6(92.4)$ \\
Oil products & 15.4 & $6.2(21.6)$ & $21.6(37.0)$ \\
Coal, coke and coal gases & 15.4 & $6.2(37.0)$ & $21.6(52.4)$ \\
\hline
\end{tabular}

Note: Values within parentheses ignore fuel tax credit or tax expenditure. Source: OECD (2018).

Moreover, Sweden and Finland levy (a reduced) carbon tax on fossil fuel use in heat production. Norway has a so-called base tax on mineral oils used for heat production to prevent fuel switching. In this country, the petroleum sector pays a carbon tax and domestic aviation pays a $\mathrm{CO}_{2}$ tax. Norway also has a program for developing carbon-capture-and storage technologies.

Sweden supports households that invests in own solar power production. In 2018, the country introduced a 'carbon tax' on flights to and from Sweden. Although the purpose of the tax is to reduce carbon emissions from aviation, the tax is levied on the ticket and amounts to 5.9 euros for a domestic flight irrespectively of the actual emissions. For international flights the tax may be up to 39 euros. The Swedish program Industriklivet supports projects aiming at reducing greenhouse-gas emissions from industrial processes. Support is given to pilot and demonstration projects as well as research and 
innovation projects. The budget for the program equals 29 million euros per year during 2018-2040.

Some of these policy measures are clearly aiming at developing new technologies, for instance the Norwegian carbon-capture and storage program and the Swedish program Industriklivet. For other measures, it is difficult to identify such a component. This raises a question of overlapping policies, which we discuss in Section 5.2.

To summarize: when it comes to fuels for transportation, the taxation is rather uniform across the Nordic countries with tax rates close to or higher than the mean rates in the EU. In addition, the Nordic countries have more ambitious emission reduction obligations for their ESR sectors than virtually all other EU countries. Larger marginal-cost differences between the Nordics and the EU could therefore be expected in the future, should the countries fulfil their obligations unilaterally. Finally, in addition to the carbon and energy taxation, the Nordic countries have employed a number of other instruments, e.g. $\mathrm{CO}_{2}$-differentiated vehicle taxation and programs supporting climate investments. The incentives given by these instruments add to the ones given by the fuel taxation, resulting in quite strong incentives for certain types of adjustments such as fuel switching and choosing electric vehicles. In other words, the policies induce incentive structures that are far from uniform.

\section{A sample of empirical studies}

The cost effectiveness of the climate policy can be increased in several ways. They all deal with reducing or eliminating marginal abatement cost differences between emitters. However, the EU's aggregate emissions target gives no room for using the flexible mechanism of the Paris Agreement to reduce any cost differences between EU and the rest of the world. Below we focus on two ways of improving the cost-effectiveness of the EU's and the Nordic countries' climate policies: (i) inter-governmental emissions-trading on behalf of the countries' ESR sectors and (ii) eliminating the amount of overlapping national policies. 


\subsection{Gains of emission-trading between non-EU ETS sectors - a Nordic perspective}

Ideally one would like to use a numerical general equilibrium model over the European economy when assessing the potential gains from inter-governmental carbon emissions trading between the Nordics and the other European countries. We use a simpler approach, inspired by our theoretical model.

Both the Nordic countries and the EU countries present so-called reference scenarios for their greenhouse-gas emissions, i.e. emission projections calculated under the assumption of frozen policies (here the policies that prevailed 2013 or 2016). These reference scenarios provide information about the need for policy adjustments. Below we calculate the tax increases that are needed to reduce the countries' use of gasoline in 2030 in proportion to their emission-reduction targets, given various assumptions regarding the price sensitivity of the gasoline demand. In line with the model described in Section 2, we then interpret the difference in the resulting tax rates as the marginal gains from bilateral intergovernmental emissions-trading.

Table 5 states the greenhouse-gas emission levels 2030 in the reference scenarios of the Nordic countries and relates these levels to the countries' national emission targets for 2030, and ditto for the whole EU.

Table 5 shows that the relative emission gap to the national emission target (the last column) varies among the Nordic countries, from 20 percent for Denmark to 34 percent for Sweden. For the Nordic countries as a whole the relative gap amounts to 36 percent, substantially larger than the EU's 12 percent. This is because the Nordic countries have more ambitious climate targets than the average EU country.

Assuming a common price elasticity for the gasoline demand and noting that the Nordic countries already have higher consumer prices on gasoline, ${ }^{21}$ it may be inferred that the Nordic countries must increase their gasoline tax rates more than the average EU country to reduce gasoline use in proportion to their relative emission gaps (see the last column of Table 5). ${ }^{22}$ Table 6 shows how much

\footnotetext{
${ }^{21}$ See Fuels Europe (2018). Rewrite to get $d p=\frac{d u}{u} \frac{p}{\epsilon}$. Since $-\frac{d u}{u}$ and $p$ is higher for the Nordic countries than for the average EU country, their tax/price increment must exceed those of the average EU country.
} 
Table 5 The Nordic countries' 2030 reference scenarios for non-EU-ETS emissions, target levels and emission gaps for $\mathrm{CO}_{2}$

\begin{tabular}{|l|l|l|l|l|l|}
\hline & $\begin{array}{l}2005 \\
\text { million } \\
\text { tons }\end{array}$ & $\begin{array}{l}\text { Ref. } \\
\text { scenario } \\
\text { million } \\
\text { tons }\end{array}$ & $\begin{array}{l}\text { Emission } \\
\text { target } \\
\text { million } \\
\text { tons }\end{array}$ & $\begin{array}{l}\text { Gap } \\
\text { million } \\
\text { tons }\end{array}$ & $\begin{array}{l}\text { Gap } \\
\text { relative to } \\
\text { reference, } \\
\text { percent }\end{array}$ \\
\hline Denmark & 40 & 30.5 & 24.3 & 6.2 & 20 \\
\hline Finland & 33.7 & 26,6 & 20.6 & 6 & 23 \\
\hline Norway & 27.6 & 23.1 & $16.6^{\star}$ & 6.5 & 28 \\
\hline Sweden & 41.8 & 26 & 17.1 & 8.9 & 34 \\
\hline & & & & & 27.6 \\
\hline $\begin{array}{l}\text { Nordic } \\
\text { countries }\end{array}$ & 143.1 & 106.2 & 78.6 & 26 \\
\hline EU & 2808 & 2238 & 1966 & 272 & 12 \\
\hline
\end{tabular}

Note: * Assuming that Norway has an ESR obligation of -40 percent.

Source: Danish Energy Agency (2017), Finnish Ministry of the Environment (2017), Norwegian Ministry of Climate and Environment (2017), Swedish Environmental Protection Agency (2017), European Commission (2016).

the countries' tax rates must increase, relative to the respective reference scenario, given different assumptions of a common demand elasticity for gasoline.

Table 6 tells us that, unless the price elasticity of fossil-fuel demand varies across the countries in a peculiar way, unilateral fulfilments of the countries' 2030-emission targets implies increasing differences between the Nordic countries' tax rates and ditto of the median EU country. ${ }^{23}$ Focusing on the case with a price elasticity of the difference in fuel tax per litre gasoline in 2030 between Sweden and the EU median country would amount to 0.44 euros, which corresponds to 0.19 euros per $\mathrm{kg} \mathrm{CO}$. A comparison with the countries that have been allotted emission quotas close to the emission levels in their reference scenarios (e.g. Rumania and Bulgaria) would reveal even larger differences.

${ }^{23}$ If we instead use the Swedish sector target for domestic transportation, the factor for Sweden increases to 3.5 in the case with elasticity $=-0.5$ and to 2.6 in the case with elasticity $=-0.8$. 
Table 6 Factor to multiply today's gasoline tax to reach emission targets in 2030

\begin{tabular}{|l|l|l|}
\hline & elasticity $=\mathbf{- 0 . 5}$ & elasticity $=-\mathbf{0 . 8}$ \\
\hline Denmark & 1.9 & 1.6 \\
\hline Finland & 1.9 & 1.6 \\
\hline Norway & 2.2 & 1.8 \\
\hline Sweden & 2.5 & 1.9 \\
\hline & & \\
\hline Median EU country & 1.5 & 1.3 \\
\hline
\end{tabular}

Note: EU median country in terms of gasoline taxation is Slovakia.

Source: Own calculations.

In line with the model in Section 2 the difference between the tax rates in two countries informs us about the marginal welfare gains that are possible to reap by reallocating abatement efforts among the countries. It should be noted that this assessment concerns the total gains of such a reallocation of abatement efforts. As pointed at above, the climate framework of the EU includes mechanisms that may be used for that purpose. Such emissions trading bears the promise of the EU advancing faster towards a low-emitting society. After all, lower cost often means that one wants more of a good.

\subsection{Some examples of overlapping policies in the Nordic countries}

As noted above the Nordic countries have overlapping policies both in the ETS sector (e.g. support to power production using renewable energy resources) and the ESR sector (e.g. energy tax deductions for bio fuels, $\mathrm{CO}_{2}$-differentiated vehicle taxation and schemes supporting emission reducing investments).

A major advantage with carbon taxation is that it gives households and companies incentives to undertake all kind of adjustments such as abstaining from an activity, fuel switching and/or choosing a more energy- or carbon-efficient solution. Directed support schemes do not do that. Nevertheless, such measures can have a role to play in a cost-effective climate policy if they fill gaps in the taxation or if they can be motivated by other objectives. 
However, often complementary policy measures lie on top of carbon and energy taxation, rather than filling policy gaps. NIER (2017) studies the incentives given by Swedish policies aiming at reducing $\mathrm{CO}_{2}$ emissions from personal road transports. The study finds that for some adjustments, such as choosing an electric car or using biofuels, the incentives add up to $0.39-0.68$ euros per $\mathrm{kg} \mathrm{CO}_{2}$ avoided. Corresponding incentives for an efficient fossil-fuel driven car equalled 0.2 -0.4 euros per $\mathrm{kg} \mathrm{CO}$. At the same time, the carbon tax ( 0.11 euros per $\mathrm{kg} \mathrm{CO}_{2}$ ) is the only instrument targeting the car transportation activity. Therefore, the Swedish policy gives an incentive structure that is far from uniform over possible adjustments.

Isberg et al. (2017) evaluate the Swedish program Klimatklivet and find that the investment support given is not directed at activities with a low $\mathrm{CO}_{2}$ price. They find a large variation in the investment cost per assumed emission reduction unit, from 0.1-0.8 euros per kg $\mathrm{CO}_{2}$ avoided, over and above other climate-motivated policies (carbon tax and no energy tax).

Bruvoll et al. (2018) evaluate several Norwegian support schemes, i.a. those administrated by Enova. The study finds that many of the support schemes are well designed and contributes to a cost-effective reduction of greenhouse-gas emissions. The study also finds that some support schemes induce activities that reduce emissions at high costs, over 0.2 euros per $\mathrm{kg} \mathrm{CO}_{2}$ deemed avoided.

\section{Policy implications}

Our framework and the empirical analysis, together with studies undertaken in the Nordic countries that are focusing on efficiency in climate policy, suggest that there are several possibilities to improve climate policy. We have pointed to a number of opportunities for a more efficient Nordic policy. Our analysis above stressed the various overlapping regulations, typically when an instrument is added to a sector already covered by the EU ETS, the use of sectoral goals and the widespread use of a variety of subsidies (again, not seldom in sectors already covered by the ETS). To this list we can add infrastructure investment (high-speed trains, in particular), often seen 
as a part of a progressive climate policy. One difficulty in evaluating such investments from a climate perspective is technological progress. Since electrical vehicles are likely to dominate transportation when high-speed trains become available, it is not obvious that the trains replace much fossil-fuel-based transportation. In addition, all Nordic countries have instruments giving strong incentives to influence vehicle choices. There is thus ample scope for improving the structure.

Our most important proposal is for the Nordic countries to use existing flexibility mechanisms in the current EU-policy packages. Norway and Iceland are not part of ESR but have stated that they want to be. There are significant marginal cost disparities in the non-ETS sectors between the Nordic countries and several other EU countries. It is possible within the current flexibility mechanisms to arrange non-ETS trades between the Nordic countries and other EU countries. Since such trades are voluntary and between governments, it is hard to see why this opportunity should not be explored. Indeed, perhaps except for Sweden, the Nordic countries seem positive to using flexibility mechanisms that entail reducing emissions elsewhere. An advantage with focussing on EU agreements is an existing and far-reaching intra-state co-operative framework. While even less costly opportunities may exist on a global scale, they might be more difficult to implement. If the Nordic countries combine their efforts, perhaps led by the Nordic Council, significant resources may be available to allow for material welfare improvements in the recipient countries. To make this discussion concrete, consider the fact that Bulgaria has an ESR 2030 emissions reduction obligation of zero percent relative 2005 and the Nordic countries at least 39 percent (Table 1). Our calculations suggest that there are material differences in marginal costs between the Nordics and Bulgaria. For any given amount of resources expended, using the flexibility options reduces climate impact. Alternatively, any given reduction target can be reached at a lower cost. However, it does require an acceptance of the idea of reducing emission elsewhere, rather than domestically. 
In addition, there are intertemporal options ${ }^{24}$ : some small possibilities to use ETS permits to comply with ESR and also possibilities to use the existing LULUCF credits. Our framework does not cover carbon capture, but we briefly discuss here some aspects of this option. For quite some time the possibility to use forests as a carbon sink has been discussed in the economics literature. Because Finland, Norway and Sweden are endowed with substantial forest resource this option could also be considered. Lintunen and Uusivuori (2016) provide a forest-sector analysis and look at the benefits and costs of carbon storage. Their model includes a carbon-cycle module and the multiple uses of forest biomass. One of their more interesting arguments is that it is not correct to view wood use as emission free. As we have noted, this is to be contrasted with how the energy taxation considers wood use as biofuels in the Nordic countries.

Lintunen and Uusivuori's proposal includes a comprehensive tax system with net subsidies, so that forest owners are paid for the uptake (and conversely for releases). The practical challenges to develop such a scheme are many, but it is still a possibly useful policy option in countries with a rich forestry base. Of course, there are many other policy goals that cover forests, including biodiversity goals, and more generally, the move to a 'bio economy' (including, for example, rather extensive plans in Finland to increase biofuels production).

Our recommendations can be considered alongside the current Nordic strategy for co-operation in climate policy, as described in Nordic Council of Ministers $(2017,2018)$. According to this, 'The primary objective of Nordic co-operation on the environment and climate must be to make a major contribution to the implementation of the Paris Agreement and Agenda 2030, both within the Nordic Region and at global level'. (Nordic Council of Ministers 2018, p. 13). Our proposed 'action plan' for Nordic co-operation seems to stress the possibilities within the EU mechanisms more, but the recommendations do point to the necessity of international co-operation.

\footnotetext{
${ }^{24}$ These imply borrowing emission quota units from the next allocation period and saving unused emission quota units to future allocation periods.
} 


\section{Conclusions}

Nordic climate policy can become more cost-efficient within currently existing policy frameworks, in particular using the existing EU frameworks to a larger extent than today. The most important pathway to explore is to try to even out the marginal cost of emissions in the non-trading sector, by agreements with countries within the EU. Since bilateral governmental agreements are purely voluntary, the key constraint appears to be the willingness to go beyond national borders in reaching domestic goals.

The prevalence of overlapping regulations is another target for those who seek to improve climate policy in the Nordic countries. In addition, there are a number of measures available within each Nordic country that help reduce existing marginal cost differences: climate-related subsidies and sectoral goals are important examples. Finally, Nordic countries with a substantial forest base are continuing to explore the role of forests in climate policy, which is another promising way forward.

While the Nordic countries have for long been used as internationally leading examples of how a modern and progressive climate policy can be shaped, their climate policies can be made considerably more efficient.

\section{References}

Alfsen, K. H. and Eskeland, G. S. (2007), A Broader Palette: The Role of Technology in Climate Policy, Report to the Expert Group for Environmental Studies 2007:1, Swedish Ministry of Finance.

Ambec, S. and Lanoie, P. (2008), Does it Pay to Be Green? A Systematic Overview, Academy of Management Perspectives, 22(4), 45-62.

Bernheim, B. D. and Rangel, A. (2009), Beyond Revealed Preference: Choice- Theoretic Foundations for Behavioral Welfare Economics, The Quarterly Journal of Economics, 124(1), 51-104.

Brännlund, R. (2007), Miljöpolitik utan kostnader? En kritisk granskning av Porterhypotesen, Report to the Expert Group for Environmental Studies 2007:2, Swedish Ministry of Finance. 
Brännlund, R. (2017), Kostnader och intäkter i Sverige av långsiktiga klimatförändringar - en litteraturöversikt, Special Study 60, National Institute of Economic Research.

Böhringer, C., Rosendahl, K. E., and Briseid Storrsten, H. B. (2017), Robust Policies to Mitigate Carbon Leakage, Journal of Public Economics, 149(C), 35-46.

Bruvoll, A., Midttømme, K., Tennbakk, B., Fjose, S., Høiseth-Gilje, K., Myklebust, A., Rosendahl, K. E., Skjeflo, S., Sjoner Syrstad, R. and Stokke, O. M. (2018), Områdesgjennomgång av stötteordninger i klimatpolitiken, Menon-publikasjon nr. 1/2018, Menon Economics.

Danish Energy Agency (2017), Memo on New Estimate of Non-ETS Deficit for the Period 2021 to 2030, Danish Energy Agency. https://ens.dk/sites/ ens.dk/files/Analyser/memo_on_new_estimate_of_non-ets_deficit_for_ the_period_2021_to_2030.pdf.

Danish Ministry of Energy, Utilities and Climate (2017), Denmark's Seventh National Communication and Third Biennial Report - Under the United Nations Framework Convention on Climate Change, Danish Ministry of Energy, Utilities and Climate.

European Commission (2014), A Policy Framework for Climate and Energy in the Period from 2020 to 2030, Retrieved December 31, 2018, from https://eur-lex.europa.eu/legal-content/EN/ALL/?uri=celex:52014DC0015.

European Commission (2016), EU Energy, Transport and GHG Emissions Trends to 2050 - Reference Scenario 2013, Luxembourg: Publications Office of the European Union.

European Commission (2018), Effort Sharing 2021-2030: Targets and Flexibilities, Retrieved December 31, 2018, from https://ec.europa.eu/clima/ policies/effort/proposal_en.

Finnish Ministry of the Environment (2017), Government Report on Medium-term Climate Change Policy Plan for 2030, Reports of the Ministry of the Environment 21en/2017.

Finish Ministry of Economic Affairs and Employment (2018), https://tem. fi/en/article/-/asset_publisher/ministeri-tiilikainen-kivihiilen-kielto-2029kannustepaketti-nopeille-luopujille.

European Council/Council of the European Union (2018), https://www. consilium.europa.eu/en/policies/climate-change/reform-eu-ets/

Fuels Europe (2018), Fuel Price Breakdown, Retrieved December 31, 2018, from https://www.fuelseurope.eu/knowledge/refining-in-europe/ economics-of refining/fuel-price-breakdown/.

Helm, C. (2003), International Emissions Trading with Endogenous Allowance Choice, Journal of Public Economics, 87(12), 2737-2747. 
Hoel, M. (2012), Klimatpolitik och ledarskap: vilken roll kan ett litet land spela?, Report to the Expert Group for Environmental Studies 2012:3, Swedish Ministry of Finance.

Icelandic Ministry for the Environment and Natural Resources (2018a), Iceland's Climate Action Plan for 2018-2030 - Summary, Icelandic Ministry for the Environment and Natural Resources.

Icelandic Ministry for the Environment and Natural Resources (2018b), Iceland's Seventh National Communication and Third Biennial Report Under the United Nations Framework Convention on Climate Change, Icelandic Ministry for the Environment and Natural Resources.

Isberg, U., Jonsson, L., Pädam, S., Hallberg, A., Nilsson, M. and Malmström, C. (2017), Klimatklivet - en utvärdering av styrmedlets effekter, Stockholm: WSP Sweden.

Johansson, P-O. and Kriström, B. (2016), Cost-benefit Analysis for Project Appraisal, Cambridge: Cambridge University Press.

Kjellén, B. (2007), Svensk politik för miljö och hållbar utveckling i ett internationellt perspektiv - En förhandlare reflekterar, Report to the Export Group for Environmental Studies 2007:3, Swedish Ministry of Finance.

Lintunen, J. and Uusivuori, J. (2016), On the Economics of Forests and Climate Change: Deriving Optimal Policies, Journal of Forest Economics, 24, 130-156.

Miljö och jordbruksutskottet (2017), Miljö och jordbruksutskottets betänkande 2016/17: MJU24, https://data.riksdagen.se/fil/3E35D8B2CDB8-42A6-97FE-74208F957D75

NIER (2017), Miljö, ekonomi och politik 2017, Report, National Institute of Economic Research.

NIER (2018), EU-ETS, marknadsstabilitietsreserv och effekt av annulleringar, Occasional Study No 2018:10, National Institute of Economic Research.

Nordic Council (2017), Nordic Action on Climate Change, Copenhagen: Nordic Council of Ministers.

Nordic Council (2018) The Nordic countries in the green transition - more than just neighbours: Strategic recommendations for Nordic co-operation on the environment and climate in the run-up to 2030, Copenhagen, Nordic Council of Ministers.

Norwegian Ministry of Climate and Environment (2017), Norway's Seventh National Communication - Under the United Nations Framework Convention on Climate Change, Norwegian Ministry of Climate and Environment. 
OECD (2018), Taxing Energy Use 2018: Companion to the Taxing Energy Use Database, Paris: OECD Publishing.

van der Ploeg, F. and Withagen, C. (2015), Global Warming and the Green Paradox: A Review of Adverse Effects of Climate Policies, Review of Environmental Economics and Policy, 9(2), 285-303.

Palmer, K., Oates, W. E. and Portney, P. (1995), Tightening Environmental Standards: The Benefit-Cost or the No-Cost Paradigm?, Journal of Economic Perspectives, 9(4), 119-132.

Porter, M. (1991), America's Green Strategy, Scientific American, 264(4), 33-35.

Porter, E. M. and van der Linde, C. (1995), Towards a New Conception of the Environment - Competitiveness Relationship, Journal of Economic Perspectives, 9(4), 97-118.

Silbye, F. and Sørensen, P. B. (2019), National Climate Policies and the European Emissions Trading System, this volume.

Sinclair, P. J. N. (1994), On the Optimal Trend of Fossil Fuel Taxation, Oxford Economic Papers, 46, 869-877.

Smith, V. K. and Moore, E. M. (2011), Does Behavioral Economics Have a Role in Cost-Benefit Analysis?, in Johansson, P-O. and Kriström, B. (eds.), Modern Cost-Benefit Analysis of Hydropower Conflicts, Cheltenham: Edward Elgar.

Statistics Sweden (2018), https://www.scb.se/en/finding-statistics/ statistics-by-subject-area/transport-and-communications/road-traffic/ registered-vehicles/pong/statistical-news/new-registrations3/.

Swedish Environmental Protection Agency (2017), Med de nya svenska klimatmålen i sikte, Report 6795, Swedish Environmental Protection Agency.

Swedish Ministry of Environment and Energy (2017), Sweden's Seventh National Communication on Climate Change - Under the United Nations Framework Convention on Climate Change, Swedish Ministry of the Environment and Energy.

The European Parliament and the Council of the European Union (2018), Regulation (EU) 2018/841 of the European Parliament and of the Council of 30 May 2018, Official Journal of the European Union, OJ L 156, 19.6.2018, p. 1-25.

United Nations (2015), Paris Agreement, Paris: United Nations. 


\section{Appendix: Our framework}

The framework is based on general equilibrium model, augmented with an externality. We perturb an existing equilibrium to derive a cost-benefit rule (see Johansson and Kriström 2016 for a general introduction to this approach). A representative firm in each sector produces a good $x_{i}, i=1,2$, at a given price $p_{i}$. Production costs are disregarded. Both types of firms emit an externality $z_{i}, i=1,2$, with an emissions technology, so $z_{i}=g^{i}\left(x_{i}, \alpha_{i}\right)$, where the technology is smooth, increasing in $x_{I}$ and decreasing in abatement effort $\alpha_{i}$. For simplicity, we assume that the emission technology is linear, i.e. $z_{i}=\alpha_{i} x_{i}, \alpha_{i}>0$. We assume that emission technology is constant, although it is a straightforward exercise to study exogenous technological change within this framework.

Firms of type 1 must buy emission permits for its operation. Each permit can be bought at price $p$ on a perfect market. The number of permits is $A$ (this number can vary between countries). We will assume that the price of permits is positive, so that the emission constraint is always binding. Firms of type 2 pay a per-unit emission tax $t$ on its emissions.

The profit functions are written as

$$
\begin{aligned}
& \pi_{1}=p_{1} x_{1}-p \alpha_{1} x_{1} \\
& \pi_{2}=p_{2} x_{2}-t \alpha_{2} x_{2} .
\end{aligned}
$$

In each country, there is a representative household equipped with a standard indirect utility $V$ function with the usual smoothness and convexity properties (here decreasing in prices and emissions, and increasing in income),

$$
V=V\left(p_{1}, p_{2}, Y, z_{1}, z_{2}\right)
$$

where income is $Y=\pi_{1}+\pi_{2}+t z_{2}+p A$. This means that the permits are given to the households directly. Thus, we can take the view that the firm buys permits directly from the household, with a perfect market of permits operating in the background and not detailed here. The utility function also represents the social welfare function when there is only one country in the region. Finally, we will use the 
marginal value of income $\lambda \equiv \partial V / \partial Y$ frequently below to convert from the utility metric into 'money'.

First-order conditions for the firm entail that $\partial \pi_{i} / \partial x_{i}=0$. Hotelling's lemma provides the demand and supply functions for $x_{i}$ (and all markets that are suppressed in the model). We assume, as noted, that the price of permits is positive and that this market is in equilibrium. The equilibrium depends on the (implicit) endowments of capital, labour and other resources as well as the exogenously given tax and the given number of permits.

Emissions are of only of one type and perfectly mixed, e.g., $\mathrm{CO}_{2}$. We consider two countries (or groups of countries) that make up the region. We need to do some book-keeping and therefore write out the regional indices, $j=1,2$ :

$$
V^{j}=V^{j}\left(p_{1}, p_{2}, Y^{j}, Z\right)
$$

where $Z=z_{1}^{1}+z_{2}^{1}+z_{1}^{2}+z_{2}^{2}$, i.e. the sum of all emissions generated. There is also an implicit burden-sharing agreement, determining the share $\beta_{1}+\beta_{2}=1, \beta_{j}>0$, of aggregate emission permits given to each country. We could also interpret the share parameters as a way of distributing the revenues from an auction of the emissions permits. There is a carbon tax in each country, which is set to a value in the status quo ante; it is exogenous to the model. It might reflect a determination to grab any 'first-mover' advantage, or any other reason that is not explained by the model, such as a common regional goal.

We follow a bulk of the literature and set $W=\sum V^{j}$. In addition, we suppose that $\lambda_{j}=\bar{\lambda}$, i.e. that income is initially distributed such that the marginal utility of money is equal in the two regions. Thus, there is no additional motive to redistribute income between the countries. To save some notation, interpret $z_{1}$ and $z_{2}$ as the emission generated in total in the two countries. We now consider a perturbation of the general equilibrium that we assume to exist in the status quo. There are two types of given policy parameters, the tax and the number of permits. A perturbation here means that we consider a small change in these parameters and how the economy reacts to these changes. Technically, we totally differentiate W, use Hotelling's 
lemma, the equilibrium conditions and the income identity. Alternatively, we can take partial derivates of each of the parameters in $W_{\text {, }}$ sum the results, invoke Hotellings lemma and the equilibrium conditions. In both cases, simple algebraic manipulation finally leads to:

Proposition If $W=\sum V^{j}$, the emissions are perfectly mixed so that $Z=z_{1}+z_{2}$, and $\lambda_{j}=\overline{\bar{\lambda}}$, the general equilibrium welfare change in monetary terms due to a small perturbation of emissions is

$$
\frac{d W}{\bar{\lambda}}=\left(p+\sum \frac{V_{z}^{j}}{\bar{\lambda}}\right) d Z+\left(t^{1}-p\right) d z_{2}^{1}+\left(t^{2}-p\right) d z_{2}^{2}
$$

The first part of the right-hand-side is a Samuelson-type condition, so that the price of permits (= the marginal cost of reduction) is, in optimum, equal to the sum of the willingness to pay for reducing emissions it (or the marginal disutility converted into money of increasing emissions). This part looks non-intuitive at first, whence $p$ is related to the sum of all emissions in the permit market which covers only a part of the total emissions. However, in the second two parts of the expression we deduct $p d z_{2}^{j}$, which then nets out to the value of the change of the total emissions in the trading sector. To this we add the emissions in the non-trading sector, valued at the prevailing tax, so that the book-keeping of the emission change is correct.

We can use the model above to show that as long as $p$ differs from $t^{1}$ or $t^{2}$ it is possible to reduce the costs of attaining the aggregate emissions target by reallocating abatement efforts. For instance, consider a transfer of emission permits from sector 1 to sector 2 in country 1 . Since such a transfer does not change total emissions from the region (i.e. $-d\left(z_{1}^{1}+z_{1}^{2}\right)=d z_{2}^{1}$ and $d Z=0$ ), we have from (A3) that $\frac{d W}{\bar{\lambda}}=\left(t^{1}-p\right) d z_{2}^{1}$ which is positive as long as $t^{1}>p$. The avoided costs in the non-trading sector of country 1 exceeds the extra cost incurred in sector 1 .

In the same manner, the welfare effects of a transfer of emission quota units between the two taxed sectors (i.e., $d z_{2}^{1}=-d z_{2}^{2}$ and $d Z=0$ ) equals $\frac{d W}{\bar{\lambda}}=\left(t^{2}-t^{1}\right) d z_{2}^{2}$. 


\section{Comment on B. Carlén and B. Kriström:}

Are Climate Policies in the Nordic Countries Cost-Effective?

\section{Peter K. Kruse-Andersen ${ }^{1}$}

The implicit assumption in this analysis seems to be that the political goal is to minimize the costs of reaching the 2030 and 2050 (or 2045) climate targets. It is well known that the cost-effective way to reach a given emission target is to equalize the marginal cost of pollution emission between sources (Baumol and Oates 1971). This is also shown by the theoretical model in the article.

However, policymakers might not only care about the national emission targets but also about global emissions and thereby carbon leakage. It is, for instance, evident from the comment by the Danish Ministry of Finance on a recent report from the Danish Economic Councils that some Danish policymakers care about carbon leakage (Danish Economic Councils 2018, p. 222224).

If policymakers, in addition to the national emission targets, want to reduce carbon leakage, it is generally not optimal to equalize the marginal cost of pollution emission within the country. Instead, sectors more exposed to carbon leakage should face lower emission taxes (Hoel 1996, Sørensen 2018). ${ }^{2}$

Additionally, other factors besides climate change mitigation motivate taxes on fossil fuels. These factors include other externalities like local air pollution and energy security issues. To identify ineffective climate policies, these other factors must be taken into account. This aspect is largely ignored in the analysis.

Overall, the article assesses the cost-effectiveness of Nordic climate policies through a rather narrow lens. The policy proposals of the article must be interpreted with this limitation in mind.

\footnotetext{
${ }^{1}$ Department of Economics, University of Copenhagen.

Email: peter.k.kruse-andersen@ecom.ku.dk.

${ }^{2}$ Assuming that the government cannot use import subsidies and export taxes.
} 


\section{The time perspective matters}

The cost-effectiveness of the Nordic climate policies must be considered in a dynamic perspective where both the 2030 EU obligation and the long-run (typically 2050) emission target is taken into account. The article discusses some dynamic aspects, but in the end, the analysis builds on a static framework. This is particularly problematic when the article addresses the EU flexibility mechanisms. These mechanisms can potentially reduce the cost of fulfilling the EU 2030 obligation concerning the non-ETS (or ESR) sector. However, using these mechanisms reduces domestic climate change investments before 2030, which increases the necessary investments after 2030 to reach the long-run (typically 2050) target. Whether it is a good idea to postpone these investments is an open question. It depends on time discounting, expected technological progress, potentially nonlinear investment costs as well as the cost of employing the flexibilities. In any case, the analysis underestimates the costs of using the flexibility mechanisms, as the dynamic aspects of the investment problem are largely ignored.

\section{On the use of the intergovernmental emission trading flexibility}

The article finds that the Nordic countries should purchase nonETS emission rights from other EU member states. The idea is to exploit marginal abatement cost discrepancies between EU member states.

This recommendation has at least four problems. Firstly, some EU countries might not have binding non-ETS emission obligations for 2030 (Danish Council on Climate Change 2016). Hence transferring non-ETS emission rights from these countries to the Nordics will result in substantial carbon leakage. This is an additional cost if policymakers care about carbon leakage. Secondly, as discussed above, exploiting this flexibility mechanism only postpones the transition to a low-emission economy, and this is not necessarily cost-effective. Thirdly, as discussed above, the analysis largely ignores other reasons for taxing fossil fuels in the Nordics. Hence, the emission cost discrepancies highlighted in the analysis might be overrated. 
Finally, cost discrepancies in carbon emissions between the Nordic countries and other EU member states might reflect inefficient domestic policies. In light of the ambitious long-run emission targets of the Nordic countries, it seems appropriate to first identify the cost-effective national policies before jumping to the conclusion that the Nordic countries should buy emission rights from other EU member states. Current inefficiencies might be substantial. An analysis by the Danish Economic Councils (2018) finds large marginal abatement cost differences across sectors in Denmark, indicating a non-negligible potential for cost reductions. It remains unknown how large the emission cost discrepancies between the Nordic countries and other EU member states are given costeffective domestic climate policies in the Nordics.

All in all, I am not convinced that purchasing non-ETS emission rights from other EU member states is in the interest of the Nordic countries.

\section{The ETS flexibility mechanism}

While the analysis emphasizes the potential use of the intergovernmental non-ETS emission-trading flexibility, there is little emphasis on ETS flexibility: Denmark, Finland, and Sweden can reduce their 2030 non-ETS sector obligations by cancelling ETS allowances (EU 2018). Taking a 2030 perspective, the Danish Economic Councils (2018) find that the cost-effective non-ETS sector regulation involves ETS allowance cancellations. One advantage of this flexibility compared to intergovernmental emission trading is the negative carbon leakage associated with this particular type of allowance cancellations (Beck and Kruse-Andersen 2018). Nevertheless, the use of this flexibility is challenged by currently high allowance prices, and the fact that it only postpones the investments necessary to reach the long-run emission target.

\section{Overlapping policies}

The analysis proposes an elimination of overlapping national climate policies. This point has been emphasized many times before in a Nordic context (e.g., Danish Economic Councils 2018). It is well 
known that overlapping climate policies are associated with nonnegligible additional costs (e.g., Böhringer et al. 2016). Nonetheless, the latest EU ETS reform punctures the so-called waterbed effect. Thus, national subsidy schemes in the ETS sector can now reduce ETS sector emissions at the EU level. ${ }^{3}$ The reform thereby reduces the degree of overlap between national and EU-wide policies in the ETS sector. An interesting discussion missing in the article is how this affects optimal regulation of the national ETS sectors given the ambitious long-run emission targets and supplementary climate targets like the 2030 renewable energy target for Denmark.

\section{References}

Baumol, W. and Oates, W. (1971), The Use of Standards and Prices for Protection of the Environment, The Swedish Journal of Economics, 73(1), 42-54.

Beck, U. and Kruse-Andersen, P. K. (2018), Endogenizing the Cap in a Cap-and-trade System: Assessing the Agreement on EU ETS Phase 4, Working Paper 2018:2, Danish Economic Councils.

Böhringer, C., Keller, A., Bortolamedi, M. and Seyffarth, R. A. (2016), Good Things do not Always Come in Threes: On the Excess Cost of Overlapping Regulation in EU Climate Policy, Energy Policy, 94, 502-508.

Danish Council on Climate Change (2016), Danmark og EU's 2030klimamål: Analyse af kommissionens forslag til reduktionsmål uden for kvotesektoren, Report.

Danish Economic Councils (2018), Economy and Environment 2018, Report.

EU (2018), Regulation (EU) 2018/842 of the European Parliament and of the Council of 30 May 2018 on Binding Annual Greenhouse Gas Emission Reductions by Member States from 2021 to 2030 Contributing to Climate Action to Meet Commitments under the Paris Agreement and Amending Regulation (EU) No 525/2013.

Hoel, M. (1996), Should a Carbon Tax be Differentiated Across Sectors?, Journal of Public Economics, 59(1), 17-32.

Perino, G. (2018), New EU ETS Phase 4 Rules Temporarily Puncture Waterbed, Nature Climate Change, 8(4), 262-270.

Sørensen P. B. (2018), Energy Taxes and Cost-effective Unilateral Climate Policy: Addressing Carbon Leakage, Working paper, July 2018.

\footnotetext{
${ }^{3}$ See Perino (2018), Beck and Kruse-Andersen (2018) and Silbye and Sørensen in this issue.
} 
Comment on B. Carlén and B. Kriström:

Are Climate Policies in the Nordic Countries Cost-Effective?

\section{Åsa Löfgren ${ }^{1}$}

The article by Carlén and Kriström contains some important messages. Perhaps the most important one is the claim that EU should extend the carbon pricing of the EU Emissions Trading Scheme (EU ETS) to include also non-ETS sectors.

To cite the authors: 'The most important pathway to explore is to try to even out the marginal cost of emissions in the non-trading sector, by agreements with countries within the EU.'

This important claim is very much the same as the well-known result derived from basic environmental economics, i.e. that marginal cost differences can be exploited to achieve welfare improvements. The novelty is that the authors develop a model that takes into account both direct and indirect economic impacts of a change in policy. Also, the paper reminds the reader about the important point that the larger the marginal cost differences between sectors or regions, the more there is to benefit from a uniform carbon price.

Another important message relates to carbon pricing in general, where the authors join the choir of economists (to whom I belong) who argue that a carbon price is an important and cost-effective tool to mitigate climate change.

To cite Carlén and Kriström: 'A major advantage with carbon dioxide taxation is that it gives households and companies incentives to undertake all kind of adjustments such as abstaining from an activity, fuel switching and/or choosing a more energy- or carbon-efficient solution.'

Another recent example of economists arguing for the benefits of a carbon price was published in the Wall Street Journal (Opinion) on January 16, 2019 (Economists' Statement on Carbon Dividends) and

${ }^{1}$ Department of Economics, University of Gothenburg.

Email: asa.lofgren@economics.gu.se. 
signed by more than twenty recipients of the Nobel Memorial Prize in Economics and other distinguished economists. The piece stated that 'A carbon tax offers the most cost-effective lever to reduce carbon emissions at the scale and speed that is necessary'.

Given the overwhelming support from economists for the use of a carbon price, it is perhaps surprising that economic reasoning seemed to play a minor role in the Paris negotiations in 2015, and that increased fuel or carbon taxes are often met with fierce resistance and lobbying. A recent example is the yellow-vest movement in France which shows that increasing, or even implementing, a carbon price might prove politically challenging. Hence, if we as economists want our knowledge to have a policy impact, we should perhaps reflect on how well our theories, messages and communication relate to the complexities of the political reality and incorporate such restrictions in our analytical framework. In particular we should consider how to design effective climate polices that are also implementable, for example that take into account distributional aspects, at the same time as creating incentives for long-term investments to achieve emissions reductions. Of course for many economists, moving from the first best in theory to something which is second best in theory, but optimal in reality (given political constraints), might be considered unappealing from a normative standpoint.

Carlén and Kriström use a static model that is quite stylized with the aim of identifying (non-dynamic) welfare effects of international emissions trading. Notably, the authors also discuss some of their model's simplifying assumptions at some length (including distributional issues, technical development, and competitiveness aspects). However, a static model has some weaknesses when it comes to understanding the dynamics of climate policy (time is an inherent aspect of the climate change challenge), in particular for analyzing short- versus -long run efficiency. In this context I would like to point to the role of overlapping policy instruments in particular.

Overlapping policies can, as pointed out by Carlén and Kriström, be quite ineffective. Exceptions are of course if policies are implemented to correct for other market failures (such as positive spillover effects from innovation). The authors provide examples of overlapping policies in the Nordic countries that give rise to large variations in cost per $\mathrm{kg} \mathrm{CO}_{2}$ (such as subsidies for buying electric cars or using 
biofuels). However, in line with the recent perspective piece by Pahle et al. 2018), I hold the (strong) belief that regulations and overlapping policies can be important parts of a policy pathway towards more stringent targets and more ambitious carbon pricing.

Pahle et al. aim to reconcile the view that cost-ineffective policies reduce welfare with the view that 'politically achievable incremental progress' has a value even if the policies are cost-ineffective in the short run. The idea is that incremental steps are crucial for building up to a more ambitious (and more cost-effective) climate policy over time. Two important examples are given: Firstly, the German support for renewable energy (the Renewable Energy Act, EEG, implemented in 2000) which enabled further deployment of solar photovoltaic modules by reducing costs over time. Secondly, California where technology standards implemented in 2002 showed the feasibility of emissions reductions, which in turn was important for the implementation of the economy-wide emissions cap (to be achieved in 2020). The main point is that overlapping policies, or regulations, in combination with a moderate carbon price can provide important signals to investors that policy makers are committing to an ambitious future climate policy (even if the necessary carbon price level to reach the target is currently not politically feasible). This in turn might reduce cost over time. Again, I think that how we view this type of framework depends crucially on whether we tackle the problem from a normative perspective or are willing to incorporate the political reality.

Hence, going to back to the beginning of this comment, I think that Carlén and Kriström make an important point that the EU should extend the carbon pricing of the EU Emissions Trading Scheme (EU ETS) to include also non-ETS sectors to make the Nordic countries' climate policies more effective. However, in light of the remarks made above, I would like to encourage a discussion about the time frame and the potential signal such an extension would produce. Would it increase cost-effectiveness also in the long-run? If not, how could an extension be designed (e.g. stepwise with increased stringency)? These are the types of questions I think we, as economists, need to ask ourselves if we want to stay relevant for policy making in practice. 


\section{References}

Pahle, M., Burtraw, D., Flachsland, C., Kelsey, N., Biber, E., Meckling, J., Edenhofer, O., and Zysman, J. (2018), Sequencing to Ratchet up Climate Policy Stringency, Nature Climate Change, 8(10), 861-867.

Wall Street Journal (Opinion) (2019), Economists' Statement on Carbon Dividends, retrieved January 23, 2019, from https://www.wsj.com/articles/ economists-statement-on-carbon-dividends-11547682910. 


\title{
Global Impact of National Climate Policy in the Nordic Countries
}

\author{
Mads Greaker ${ }^{1}$, \\ Rolf Golombek ${ }^{2}$ \\ Michael Hoel ${ }^{3}$
}

\begin{abstract}
The Nordic countries have engaged in ambitious policies to reduce greenhouse gas emissions. This might convince other countries to be more ambitious. We explore mechanisms by which small countries can affect emission reduction programs in other countries. Development of improved clean technologies seems to be the most viable of these mechanisms. Inspired by the philosopher Kant, the Nordic countries may also follow an ambitious climate policy because they want to do their share of a global effort to halt climate change. They should then consider whether they want other countries to follow their choice of policies.
\end{abstract}

Keywords: climate policy, climate-friendly technology, green business, reciprocity, Kantian preferences, moral obligation.

JEL codes: O38, Q54, Q55, Q58.

\footnotetext{
1 Oslo Metropolitan University and Statistics Norway. Email: mads@oslomet.no.

${ }^{2}$ The Frisch Center. Email: rolf.golombek@frisch.vio.no.

${ }^{3}$ Department of Economics, University of Oslo and Scientific Advisor, The Frisch Center.

Email: m.o.hoel@econ.vio.no.
} 


\section{Introduction}

In the fall of 2018, the Intergovernmental Panel on Climate Change (IPCC 2018) issued their latest report on the impacts of global warming of $1.5^{\circ} \mathrm{C}$ above pre-industrial level and global greenhouse gas emissions pathways in line with this target. The report stresses the difference in climate-related costs to societies between a warming of $1.5^{\circ} \mathrm{C}$ and $2.0^{\circ} \mathrm{C}$. Biodiversity loss is expected to be strikingly more severe, the number of extreme weather events significantly more numerous, the expected sea level rise higher, etc. The report also makes it clear that it will be very difficult not to exceed $1.5^{\circ} \mathrm{C}$ average global warming. Even if countries comply with their emission reduction pledges in the Paris Agreement, the world is on a course to $3^{\circ} \mathrm{C}$ warming or more.

The Nordic countries have all adopted the target of maximum $2.0^{\circ} \mathrm{C}$ global warming and committed to work towards maximum $1.5^{\circ} \mathrm{C}$ global warming. This is not only 'cheap talk' by Nordic governments. The targets manifest themselves in ambitious climate policies in all the five Nordic countries, the most obvious examples being:

- The promised total greenhouse gas emission (GHG) reductions exceed those of other comparable industrialized countries.

- Taxing of energy and/or greenhouse gas emission-related activities are higher than in other comparable countries.

- The countries have introduced a range of technology and sector-specific climate policy measures.

For instance, in the Paris Agreement the Nordic countries, together with the EU, have set more ambitious targets for emission reductions than other industrialized countries such as Australia, Canada, Japan and the US. ${ }^{4}$ Another example could be gasoline prices, assuming that they reflect country-specific energy and emission taxation. If we compare OECD countries with respect to gasoline prices, we find that the Nordic countries on average have more than 20 percent higher prices than the average of the other countries. ${ }^{5}$

\footnotetext{
${ }^{4}$ Measured as percentage reduction in GHG from a historical year. See Table A.1 in Appendix A.1. The US has decided to withdraw from the agreement (in 2020 or later).

${ }^{5}$ The data are for an arbitrary day in 2018 (see Figure A.1 in Appendix A.2).
} 
Finally, with respect to technology-related climate policy measures, there are ample examples of greenhouse gas abatement subsidies to industries that participate in the European Emission Trading System (ETS). The cost of these measures indicates that it would be less expensive to reduce emissions by buying ETS permits. ${ }^{6}$ There are also a range of subsidies and performance standards for sectors outside the EU ETS.

The total emissions from the Nordic countries only constitute a tiny share (less than 0.5 percent) of global emissions. Hence, the direct effect of Nordic countries reducing their emissions on global temperatures is miniscule. One way to rationalize ambitious climate policies in the Nordic countries is that these policies motivate other countries also to follow more ambitious policies. In this way, the ambitious climate policies in the Nordics may have a larger effect. The Nordic countries could also pursue ambitious climate policies out of a moral obligation; 'we should do the Nordic countries' share of a global effort to halt climate change.' Acting according to a moral obligation will also have implications for global emissions, and there could be a conflict between 'doing the right thing' from a national perspective and 'doing the right thing' from a global perspective.

In general, outlining the global consequences of different ambitious Nordic climate policies is, regardless of the motivation for the action, worth analysing. Our main aim is thus to uncover potential global effects of an ambitious climate policy in a small country. We do not aim to explain why Nordic politicians have chosen the climate policies we currently observe. Instead, we will evaluate to what extent the current Nordic mix of climate policies is likely to have desirable global effects. For instance, we conjecture that no Nordic country would like its policy to increase greenhouse gas emissions in other countries, and certainly not to increase global emissions in spite of domestic emissions declining.

The rest of the article proceeds as follows. Section 2 examines current Nordic climate policies in more detail. Interestingly, we find that the policies are not well aligned. For instance, with respect to road transport, Norway pursues a proactive electric vehicle policy, while

${ }^{6}$ See, however, note 7 below. 
Sweden and Finland rely more on biofuels substitution. Moreover, Norway seems to be alone aiming to develop carbon capture and storage technologies.

Section 3 discusses potential mechanisms that a small country may pursue to make ambitious climate policies worthwhile. We divide the explanations into two over-arching theory choices. On the one hand, we have explanations relying on modelling countries as only maximizing their own welfare. This is discussed in Section 4. On the other hand, in Section 5 we discuss theories that let countries in one way or the other consider the welfare of other countries when making their choices.

In Section 6, we contrast current climate policies in the Nordic countries with our analysis of potential global effects of Nordic policies. We only discuss climate policies with point of departure in the 2030 targets, and we take the common EU GHG emission reduction targets for 2030 as given. For example, if the purpose of Nordic politicians is to motivate other countries to set more ambitious emission reduction targets, policies should focus on clean technology development. Moreover, research and development (R\&D) should be directed at clean technologies that have a market outside the Nordics. Finally, the global impact could possibly be larger if Nordic R\&D policies for clean technologies were better coordinated.

Having a technological focus does not run into conflict with a moral duty to 'do the Nordic countries' share of a global effort to halt climate change.' In our opinion, this duty can be understood as Kant's categorical imperative to act 'as if the maxim of your action were to become through your will a general natural law'. Nordic countries should thus ask to what extent their climate policies constitute examples that they would want other countries to follow. In our opinion, not all types of Nordic climate policies pass this test. For instance, would Nordic countries like other countries to copy their ambitious biofuels policies given all the uncertainty surrounding the climate effects of biofuels? Moreover, does it makes sense from a global point of view to restrict a majority of the emission reductions to be carried out within the jurisdiction of a country instead of utilizing the potential costs savings from emission trading? 


\section{Climate policy in the Nordic Countries}

\subsection{Emission reduction targets}

In December 2015, all the Nordic countries together with nearly all nations of the world stated their commitment to the Paris Agreement on climate change. As a part of the treaty, all countries should submit their planned greenhouse gas (GHG) emission reduction, which the treaty refers to as Nationally Determined Contributions (NDCs). The EU submitted a common NDC, and Iceland and Norway teamed up with the EU, and stated that they aimed to fulfil their NDCs together with the EU.

The EU, together with Iceland and Norway, committed to reduce emissions by 40 percent compared to 1990 levels. This is significantly more than the emission reductions promised by Australia, Canada, Japan and the US. Pursuant to EU's NDC, the EU has set one target for the emission sources covered by the EU Emission Trading System (ETS) and another target for the sources outside of the ETS, the socalled Effort Sharing Regulation (ESR) sector. For the ETS, the EU member states have a joint responsibility to reduce emissions by 43 percent compared to 2005 levels. Since the ETS facilitates trading in emissions permits between firms across the EU states, additional climate measures directed at ETS firms in the Nordic countries will to a large extent only relocate emissions to other EU countries, and only under certain circumstances reduce total emissions from the ETS.7 This apparently does not stop Nordic countries from having additional policies for ETS firms, as we elaborate on later.

For the ESR sector, the EU has committed to reduce emissions by 30 percent compared to 2005 levels. ${ }^{8}$ Moreover, the Nordic EU countries have agreed to do more than the average emission reductions: Sweden must reduce non-ETS emissions by 40 percent, and Finland and Denmark by 39 percent, more than any other EU country. While Sweden, Denmark and Finland are EU members, Norway and Ice-

\footnotetext{
${ }^{7}$ Recent changes made to the EU ETS suggest that additional emission reductions taken on by an EU ETS firm may reduce the total available amount of emission permits, and thus that there is not 100 percent leakage as usually assumed (see Perino 2018 and Silbye and Sørensen 2019).

8 Together, 43 percent reduction for the ETS and 30 percent reduction for the NonETS compared to 2005 levels, should yield a total reduction of 40 percent compared to the 1990 level.
} 
land are only affiliated with the EU through the European Economic Area agreement. As mentioned, both countries aim to participate fully in EU's climate policy, and we can thus treat them as EU members in our analysis. Furthermore, like the Nordic EU countries, Norway and Iceland will likely have to reduce their non-ETS emissions by 40 percent or slightly less.

Except for Iceland, all Nordic countries have ratified a climate change act. All these acts state that the country should become a low-emission society before 2050 (2045 in Sweden). In Denmark, the political parties in the parliament have now agreed that Denmark should be 'climate gas neutral' by $2050 .{ }^{9}$ Finland does not explicitly define what they imply by a low emission society, while Sweden states that it will reduce emissions from Swedish territory by 85 percent by 2045 compared to 1990 levels. Norway's goal for 2050 is similar to Sweden's: an 80-95 percent reduction of emissions compared to the 1990 level. However, according to the Norwegian climate change act, Norway may attain some of these reductions through the ETS. All Nordic countries except Iceland communicated these goals as NDCs to the Paris Agreement.

Concerning emission reduction targets for 2030, the Nordic climate change acts restate the common EU contribution to the Paris Agreement: a 40 percent reduction compared to the 1990 level. Furthermore, since the 30 percent reduction target for the ESR sector has been broken down to individual EU country levels, the acts deal in more detail with how the Nordic countries will reach their ESR targets. All Nordic countries seem determined to do a large share of emissions reduction in the ESR sector within their borders. They have signalled that they will only make limited use of the flexible mechanism the EU will introduce for the ESR sector. For instance, the Nordic countries have sectoral policies for ESR emission reductions like biofuels blending mandates for transport fuel, targets for number of electric vehicles sold, plans for emission reductions from agriculture, etc.

We find it strange that the Nordic politicians seem to downplay the flexible mechanism for the ESR sector. First, the Nordic countries may use a limited amount of ETS credits to fulfil their 2030 ESR tar-

${ }^{9}$ See Danish Ministry of Energy, Utilities and Climate (2018). 
get. Second, also up to a limit, they may use carbon sequestration by land and forests. Finally, there will be a scheme for trading in ESR emission allowances among EU countries. For example, a country that over-complies with its ESR target may sell allowances to other countries. There is clearly some uncertainty as to how the ESR trading is going to function; to date the EU has not established any institutions to organize and monitor this trading. Moreover, no one knows what the prices will be for an ESR emission allowance. Analyses by, for instance, Aune et al. (2015), and Aune and Fæhn (2016) suggest that these prices may turn out to be considerably higher than the permit prices in the ETS. On the other hand, according to the EU the 43 and 30 percent targets were set such that marginal GHG abatement costs approximately should be equalized between the ETS and the ESR sector. ${ }^{10}$

\subsection{Examples of additional policy measures in the ETS sectors}

The ETS regulates all emission from the ETS sectors in the Nordic countries. Due to the gradual reduction of the amount of emission permits administered from the EU, no Nordic country needs any additional policies to reach the emission reduction target of 43 percent compared to the 2005 level. In spite of this, there are a number of additional policies in the Nordic countries for the ETS sectors:

- In Sweden, there is a subsidy program called Industriklivet (the 'Industry Leap') which donates up to 300 million SEK per year to emission reduction projects within process industries. Norway has a similar program named Enova, which has a total budget of 2.5 billion NOK. A large part of this support goes to the maritime transport sector in Norway.

- Denmark has a range of subsidies to renewable energy. The subsidy scheme differentiates between (i) technology, e.g. on-shore wind, off-shore wind, solar, bio, etc., (ii) scale, e.g. home installations versus power plant size installations, and (iii) area of application, e.g. electricity production, heat production, process industry, etc. Finland also has subsidies to renewable energy.

- Sweden and Norway have a common green certificate system subsidizing wind, solar and new waterpower installations.

${ }^{10}$ See European Commission (2018). 
- Norway has a separate carbon capture and storage (CCS) program, which currently is considering two projects: a cement factory and a waste-burning facility; the first project is covered by the ETS.

- $\quad$ Finland will ban all use of coal for power production by 2030.

- Norway is the first country in the world to introduce a blending mandate for biofuels in aviation (aviation within EU territory is covered by the ETS). Norway also has a carbon tax on fuel for domestic flights.

\subsection{Examples of policy measures in the ESR sector}

The main policy measure in the Nordic countries for the ESR sector is taxation of fossil fuels. As mentioned, gasoline is heavily taxed in the Nordics with prices on gasoline being more than 20 percent higher than in other OECD countries. Furthermore, all Nordic countries have a number of sector-specific policies for ESR emissions:

- Promotion of biofuels, both by encouraging domestic production and by increasing blending mandates, are essential ingredients of both the Finnish and Swedish policies. Both countries have a large forestry sector, and producing biofuels from forests material seems to be in focus. Sweden aims to reduce emissions from domestic transport by 70 percent before 2030, which seems hard without a massive substitution of fossil fuels with biofuels. Finland wants to have 30 percent blending of biofuels by 2030 .

- Norway has a proactive policy with respect to electric vehicles. These vehicles are exempted from both value added tax and vehicle registration tax, which for some of the more expensive brands can make up more than 50 percent of their sales price. Electric vehicles also enjoy cheaper access to toll roads, cheaper parking and access to bus lines. There exist several studies of the cost of reducing $\mathrm{CO}_{2}$ emissions by switching from fossil cars to electric vehicles (see e.g. Holtsmark and Skonhoft (2014) and the Norwegian Environmental Agency 2016). All studies show that electric vehicle abatement costs exceed the current permit prices in the EU ETS by a large margin.

- Finland will ban all use of coal for district heating by 2030 . Finland also has a subsidy to electric vehicles, although with $€ 2000$ per vehicle it falls short of the Norwegian subsidies. 
- In Sweden there is a program called Klimatklivet (the 'Climate Leap'), which sponsors GHG abatement projects for the ESR sector. Examples are zero-emission construction machines, production of biogas, charging stations for electric vehicles etc.

- Norway and Iceland sponsor electric ferry connections. The Norwegian road authorities offer concessions on certain routes to ferry companies that supply zero-emission connections. The goal is to have 50 ferries in operation by 2020 . Iceland will soon have its first electric ferry operating between the Westman Islands and the mainland.

- Iceland aims to phase out fossil fuels in transport. From 2030, new registrations of gasoline and diesel cars will not be accepted. Moreover, Iceland is considering a rebate system for existing gasoline and diesel cars to speed up their replacement with zero-emission cars. ${ }^{11}$

\section{Rationales for ambitious climate policies}

In economic models of international climate policy, it is regularly assumed that states act as a monolithic entity that maximizes the welfare of a representative citizen. To know the global effects of ambitious Nordic climate policies, we must make assumptions about the preferences of the representative citizen in other countries - not only the Nordics. Here we will follow two routes as pictured in Figure 1 below.

Along the left branch of the figure, we will explore different rationales assuming that the representative citizen only cares about herself, that is, not citizens in other countries. The state is then acting only in its own self-interest. In the right branch of the figure, we change the strong assumption that the representative citizen only cares about herself. Instead, the citizen could be concerned with the welfare of others, or she could be wanting to 'do the right thing' independent of own welfare. In the case corresponding to the right branch, states will consider also the welfare of other states in some way.

${ }^{11}$ See Government Offices of Iceland (2018). 


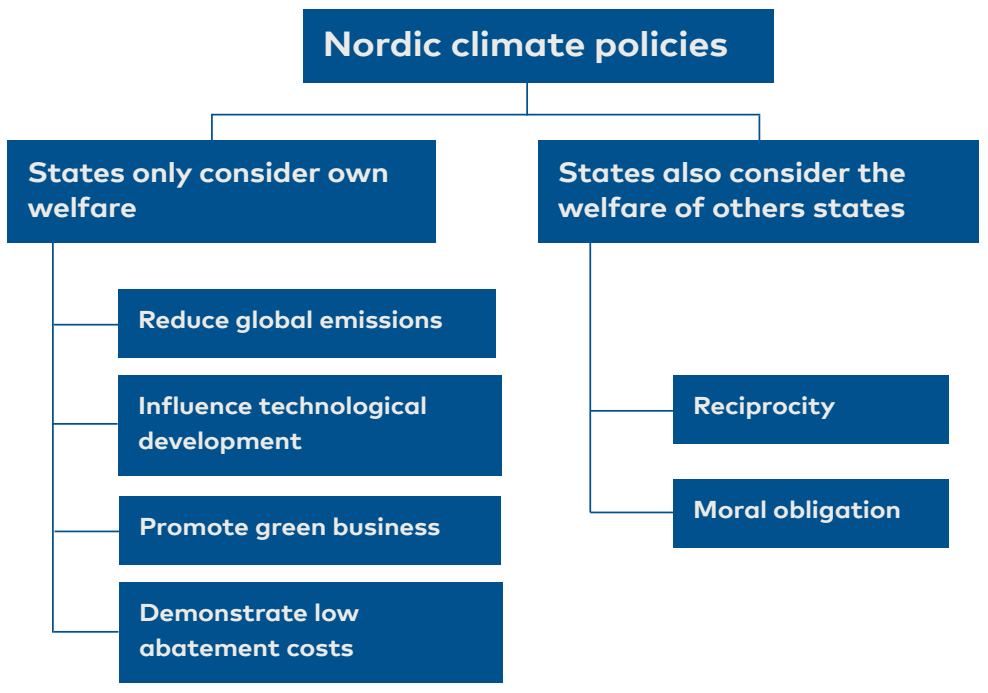

The representative-citizen assumption is clearly a large simplification. The Nordic countries are all democracies with political parties catering to different sub-groups of society. Not all citizens of the Nordic countries stand to lose on an excessive climate policy, although the country as a whole might lose. For instance, forest owners and the paper and pulp industries in Sweden, Finland and Norway may benefit from these countries' biofuel policies. Moreover, large parts of the population may be equally well off; city dwellers working for the public sector will have less local pollution, and in exchange for higher energy prices they may benefit from a richer state (due to higher carbon taxes). A ruling party may win the election based on these groups, and hence enact policies that reduce overall welfare, while a political minority bears the losses. But since we do not aim to explain why Nordic politicians have chosen the climate policies we currently observe, we will not explore political-economy models further in this paper. Below we will keep the assumption that the state acts in the interest of a representative citizen, who might or might not have preferences covering more than only her own individual welfare. 


\section{States act only in their own self interest}

In Paris, all countries agreed to limit the temperature increase to well below $2.0^{\circ} \mathrm{C}$. On the other hand, even if all countries live up to their NDCs, the temperature increase by 2100 will be $3-4^{\circ} \mathrm{C}$ (United Nations 2017). The Nordic countries may hope to decrease this gap by increasing their GHG abatement. However, looking at the current and future composition of GHG emissions among countries, it seems naive to expect that extra emission reductions in the Nordics should have any direct significant impact on global temperature levels.

First, the industrialized countries as a whole make up a shrinking share of world emissions. Even if all OECD countries and China should take prudent action, climate change seems impossible to halt without engaging the developing countries (Hoel and Holtsmark 2012).

Second, additional GHG emission reductions in one country could result in increased GHG emissions in other countries through so-called carbon leakage. Bohm (1993) was one of the first to point out that if some countries reduce their consumption of fossil fuels in order to reduce GHG emissions, the price on fossil fuels will go down, leading other countries to use more fossil fuels. This is further elaborated on in Hoel (1994) and Calmfors et al. (2008). The latter analysis suggests that extra emission reductions in the Nordics could be totally offset by emission increases elsewhere. Furthermore, a more stringent climate policy in a region could induce emission-intensive firms to relocate to regions with laxer climate policies, as suggested by Mæstad (2001).

Finally, other countries may also actively change their climate policies as a response to a more ambitious policy in the Nordics. Since a warming climate likely affects every state negatively in one way or the other, every state has a private incentive to reduce emissions. Thus, even in the situation without a climate treaty, we would observe that states set GHG emission reduction goals. In the economic 
literature, the Nash equilibrium ${ }^{12}$ in emission reduction goals in this kind of non-cooperative game has been extensively studied.

First, it is straightforward to show that in such a situation the sum of the individual countries' emission reductions falls short of the globally optimal level of emission reduction. This sub-optimal outcome reflects a prisoner's dilemma situation. Second, Hoel (1992) finds that if one state becomes more ambitious, the other states likely respond with less ambitious emission reduction goals. This is clearly not what Nordic politicians hope to achieve by promoting an ambitious domestic climate policy. Setting ambitious emission reduction goals may however spur more technological development, and as we discuss below, this can affect other countries in a more desirable direction.

\subsection{Influence technological development through R\&D policy}

R\&D entails (at least) two types of market failures. First, production of new knowledge not only benefits the ones conducting the research, but diffuses in various ways through the research community and may benefit all other researchers in the same field. This is often called the 'standing-on-shoulders' effect. It is explicitly modelled in the economic growth literature by allowing past research to make current research more efficient (see for instance Romer 1990). Second, successful research often leads to a patent, which allows the researcher to act as a monopoly for a limited period. In spite of the monopoly rights, the patent owner is still not able to appropriate the full social surplus from her innovation (see Arrow 1962). Both effects imply that the private incentives to innovate may be insufficient, and that the government can improve welfare by supporting innovation in various ways.

Economists tend to stress that innovation support should be neutral. For instance, all innovation projects should receive the same subsidy independent of whether it is a new medicine, a new way of drilling for oil or an improvement in the batteries used for electric cars. Recent research has challenged this view. Acemoglu et al. (2012) consider an economy with two sorts of inputs: dirty and clean. The dirty input leads to the build-up of a stock of pollution, which eventually

\footnotetext{
${ }^{12} \mathrm{~A}$ Nash equilibrium is a situation in which every agent has chosen her best action given the choice of actions of all the other agents.
} 
will cause an environmental disaster. The clean input has no such external effect, but is initially more costly than the dirty input because historically fewer researchers have been developing the clean input production technology. Acemoglu et al. show that under certain conditions the regulator would benefit from both an emission tax and a directed research subsidy to clean research. The reason, as shown by Greaker et al. (2018), is that the external knowledge spillovers in dirty research have lower social value than the external knowledge spillovers in clean research. To avoid an environmental disaster, the economy must stop using dirty inputs in the future, and hence, knowledge that helps improve this technology is of less value.

Most researchers agree that in order to limit global temperature increase to $2^{\circ} \mathrm{C}$, the world needs to develop new clean technologies. The Nordic countries, together with the EU, seem to have as their objective to redirect research funds into clean technologies. ${ }^{13}$ The crucial mechanism in Acemoglu et al. (2012) is that, as long as the current state of knowledge is largest for dirty technologies, research will continue within these technologies due to the standing-on-shoulder effect. If the state of knowledge within clean technologies can be brought up to the level of the dirty technologies, the process of clean inputs taking over for the dirty inputs can start to happen by itself. Clean technologies may then displace dirty technologies even without an environmental policy. Hence, technology policy could achieve what environmental policy so far has not achieved: to curb carbon emissions.

One crucial assumption in this literature is that clean and dirty technologies belong to different knowledge bases. Greaker et al. (2018) relax this assumption, and demonstrate that a technology policy directed towards clean technologies then loses much of its appeal. On the one hand, the recent empirical literature seems to confirm that there exist separate knowledge bases for clean and dirty technologies. ${ }^{14}$ On the other hand, there exists anecdotal evidence of the opposite such as floating windmills based on offshore oil-exploration technology.

\footnotetext{
${ }^{13}$ One exception is Norway, which also sponsors research in oil and gas extraction

${ }_{14}$ See Aghion et al. (2016) for a study of innovations in the car industry and

Dechezleprêtre et al. (2013) for more examples of clean technologies.
} 
Another crucial assumption is that clean and dirty technologies can readily substitute each other. To the extent that clean and dirty technologies can serve the same purposes, clean technologies will displace dirty technologies (almost) completely once they become competitive, and directed technology policy alone can curb carbon emissions. On the other hand, if for many purposes clean technologies cannot easily substitute dirty technologies, it becomes difficult for technology policy alone to curb emissions. ${ }^{15}$

There are studies indicating a low level of substitutability between dirty and clean technologies. Ambec and Crampe (2012) consider deployment of intermittent renewable power technologies, e.g. wind and solar, in the electricity market. They find that due to intermittency problem, wind and solar may become complementary to fossil technologies, such as gas power, at high levels of deployment. On the other hand, the degree of substitutability may also be affected by innovation. Lazkano et al. (2017) study development of electricity storage technologies, and argue that they increase substitutability between clean and dirty technologies.

Finally, Acemoglu et al. (2012) do not define 'clean technologies'. Greaker et al. (2018) discuss whether electricity production technologies, such as solar cells, wind batteries and electric engines for mobility, could constitute a separate knowledge base. Moreover, they speculate whether petroleum and coal extraction, and the internal combustion engine, make up the dirty knowledge base. ${ }^{16}$. Clearly, there exist intermediate cases: carbon capture and storage is based on the dirty knowledge platform, but could all the same reduce emissions. Biofuel is likewise based on the internal combustion engine and industrial processing similar to an oil refinery. If we were to follow the policy recommendations from Acemoglu et al., governments should abstain from supporting R\&D in these technologies. On the other hand, in their model all dirty technologies produce intermediates that are bound to cause emissions.

\footnotetext{
${ }^{15}$ Acemoglu et al. (2012) use a CES production function in which clean and dirty intermediates are combined to produce a final product. With a CES elasticity of substitution higher than 1, technology policy alone can curb emissions, although it becomes economically inefficient to use only a technology policy if the CES elasticity is close to 1 . With a CES elasticity lower than 1 , technology policy must be supplemented by an emission tax in order to reduce emissions.

${ }^{16}$ This is in accordance with the empirical study by Dechezleprêtre et al. (2013).
} 
Bijgaart (2017) extends the model of Acemoglu et al. (2012) by introducing two regions. She shows that if a region contains the majority of researchers, this region can possibly redirect technical change from dirty to clean technologies. The mechanism is that a critical mass of countries does so much clean research that the knowledge base in this technology overtakes that_of the dirty technology. Researchers from the rest of the world would then also move to clean innovation, and clean technologies would increase their competitiveness towards dirty technologies forever after. A consorted effort by the Nordic countries, the rest of the EU and a set of US states (like California) could possibly achieve such a tipping effect. According to Bijgaart, the EU including the Nordic countries are too small to tip the balance alone. However, another branch of the literature explicitly studies strategic technology policy, which allows small countries to influence emissions abroad through the right type of clean R\&D.

\subsection{R\&D as a strategic investment}

The Paris Agreement is based on voluntary GHG emissions reduction contributions by the individual countries, so-called Nationally Determined Contributions (NDCs). Industrialized countries may therefore use technology policy strategically to influence future NDCs of other countries. Buchholz and Konrad (1994) and Stranlund (1996) were two of the first contributions studying such uses of technology policy.

Both contributions distinguish between an industrialized country and a developing country. The industrialized country can invest in $R \& D$ that lowers its own cost of abatement or in R\&D that lowers cost of abatement in the developing country. Hence, the technology that lowers cost of abatement differs between the industrialized and the developing country. The developing country is assumed not to be able to invest in R\&D due to lack of either competence or funding.

Each country decides on its level of abatement. Let $A_{1}$ be of the level of abatement in the industrialized country, henceforth referred to as Country $1_{1}$ and let $A_{2}$ be the level of abatement in the developing country, which is henceforth referred to as Country 2. Consider first the case prior to investment in R\&D. For each hypothetical level of abatement in one country, say, Country 1 , there is a level of abate- 
Figure 2 Strategic investments in abatement technology

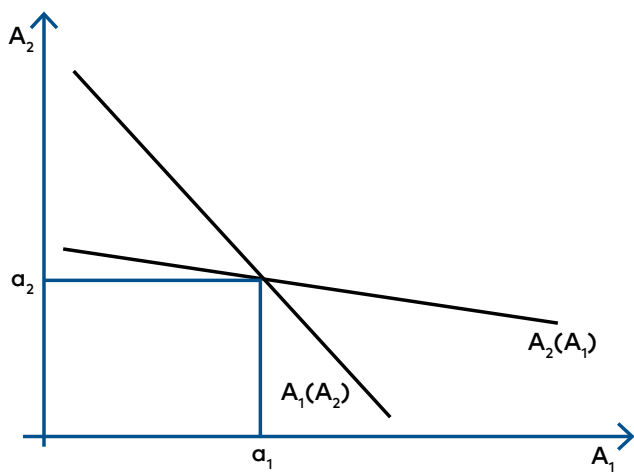

Panel a: No R\&D investment.

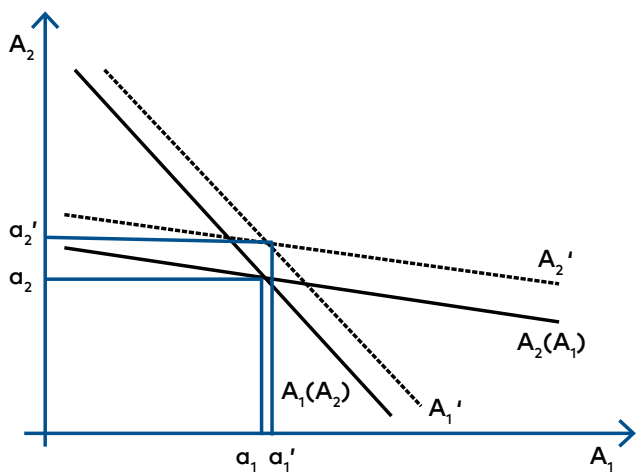

Panel b: Optimal strategic R\&D investments in the industrialized country.

ment in Country 2 that maximizes the welfare of the latter country. This relationship is referred to as the optimal reaction curve of Country 2. Similarly, Country 1 has an optimal reaction curve that for each level of abatement of Country 2, assigns the level of abatement of Country 1 that maximizes the welfare of the latter country.

If the level of abatement in one country increases, total abatement also increases (that is, total emissions decrease). This reduces costs of carbon emissions of the second country. Under standard assumptions, it is then optimal for the second country to decrease its own level of abatement. Hence, the higher the abatement of the one 
country, the lower is abatement in the other country. This situation is depicted in Figure 2, panel (a). Here, $A_{2}\left(A_{1}\right)$ is the (downward sloping) reaction curve of Country 2 , whereas $A_{1}\left(A_{2}\right)$ is the (downward sloping) reaction curve of Country 1.

The outcome of the game (prior to R\&D investment) is given by the point $\left(a_{1}, a_{2}\right)$, that is, the industrialized country chooses $a_{1}$ as its level of abatement, whereas the developing country chooses $a_{2}$. Graphically, the point $\left(a_{1}, a_{2}\right)$ is found where the two reaction curves intersect. In this point both countries are on their (optimal) reaction curves. Therefore, given the choice of abatement of the other country, the country considered cannot make a better choice than the one chosen. This means that $\left(a_{1}, a_{2}\right)$ is a Nash equilibrium.

Recall that the industrialized country, that is, Country 1, can invest in two types of R\&D: one that lowers its own cost of abatement, and another that lowers cost of abatement in the developing country. Further, assume that R\&D is determined prior to abatement. If the industrialized country invests in R\&D that lowers its own cost of abatement, then for any given level of abatement in the developing country, it is now optimal to choose a higher level of own abatement than prior to the investment. Therefore, the reaction curve of Country 1 shifts outwards in the diagram; this is depicted by the curve $A_{1}{ }^{\prime}$ in panel (b). As can be seen, investment in R\&D that lowers the own cost of abatement changes the Nash equilibrium (the intersection of the two reaction curves) so that the industrialized country now abates more, whereas the developing country abates less.

If, alternatively, the industrialized country invests (only) in R\&D that lowers cost of abatement in the developing country, the reaction curve of the developing country shifts outwards $\left(A_{2}{ }^{\prime}\right.$ is the new reaction curve of Country 2 ). In the Nash equilibrium in this case, abatement in the developing country has increased (reflecting that abatement has become cheaper there), whereas abatement in the industrialized country has been lowered (reflecting that once the developing country increases its abatement, it is beneficial for the industrialized country to respond by less abatement).

The industrialized country is aware of how investment in the two types of R\&D shifts the reaction curves. Under standard assumptions, it is optimal for the industrialized country to invest in both 
types of R\&D. Typically, the outcome is that both countries choose more abatement than in the hypothetical case of no R\&D investment. This is shown in panel (b) of the diagram by the intersection of the two dashed reaction curves resulting in the abatement levels $a_{1}{ }^{\prime}$ and $a_{2}{ }^{\prime}$. In fact, since by assumption R\&D investments reduce abatement costs, both countries benefit from the investments.

A similar mechanism is studied by Golombek and Hoel (2004). In their paper, industrialized countries' R\&D spur abatement in other countries through technology spillovers, that is, there is a positive externality. In Golombek and Hoel, an industrialized country invests in R\&D to reduce its own cost, and as a by-product developing countries' costs are also reduced. This would lead industrialized countries to invest heavily in R\&D, thereby increasing abatement in all countries.

Greaker and Hagem (2013) introduce permit trade between industrialized and developing countries to the game depicted in Figure 2 . In this case, investment in both types of R\&D also has an effect on the future permit price, and not only on the emission reduction targets of the two players. For instance, investments in the type of R\&D that reduces industrialized countries' abatement costs will also reduce industrialized countries' future payments for emission permits to the extent that they will become net permit buyers. This provides an additional incentive for industrialized countries to invest in R\&D. However, due to the complexity of the model, the authors do not obtain unambiguous theoretical results with respect to strategic investment in abatement technologies. Instead, they run several numerical simulations and find in these that industrialized countries invest heavily in both types of technologies.

So far, we have discussed strategic investment in R\&D assuming that there exists no climate treaty that obliges countries to abate more than they do in the Nash equilibrium. There exists a large literature analysing the prospects for self-enforcing climate treaties that involve higher levels of abatement than in the Nash equilibrium. Barrett (1994), who found that a self-enforcing climate treaty would only attract a small sub-set of countries, and thus achieve little with respect to reducing global emissions beyond the Nash equilibrium levels, pioneered this literature. A treaty is self-enforcing when no country wants neither to leave, nor to enter, the treaty. There is a 
strong incentive to leave a treaty, especially when the treaty has many members. A treaty with many member countries will set ambitious emission reduction targets since the externalities countries impose on each other by their emissions largely become internalized. Thus, if a country leaves, it can save large abatement costs, and at the same time free-ride on the remaining members' ambitious reduction targets. Due to this effect, the self-enforcing treaty will consist of only few member countries, who will set only modest emission reduction targets. Since Barrett's (1994) contribution this main result has been modified in many ways. For instance, McGinty (2007) studies asymmetric countries that can promise side payments to attract members to the treaty, and Harstad et al. (2018) examines treaty formation as a dynamic game with technology investments that reduce the incentive to free-ride. Here we will focus on the effect of technology investment, but in a simpler way than in Harstad et al. (2018).

The key parameters in the Barrett model are the individual country's benefit and cost of GHG abatement. If the cost is relatively large compared to the benefit, the Nash equilibrium emission reduction levels will be very modest, and there will be a lot to gain from a climate treaty enforcing all countries to abate more. However, as already explained, such a treaty is not self-enforcing (in the Barrett set-up). Beisland (2013) studies the incentives for a single country to conduct R\&D that lowers the cost of abatement for all countries. If the country acts non-strategically, and only minimizes its own abatement cost, the level of R\&D may be modest since no country is particularly ambitious with respect to emission reductions. If, on the other hand, the country acts strategically, investment will be a lot higher. The reason is that lower abatement costs will not only increase future abatement by both signatories and non-signatories, but also increase the number of member countries in the treaty. Thus, R\&D investments can be used as a tool to increase both the breadth and depth of future climate treaties. ${ }^{17}$

The contributions of Buchholz and Konrad (1994), Stranlund (1996), Golombek and Hoel (2004) and Beisland (2013) all have one thing in common: The R\&D investment must reduce the GHG abatement

${ }^{17}$ Other contributions also looking into this are Urpelainen $(2011,2013)$ and Hoel and de Zeuve (2014). The conclusions are in line with those of Beisland (2013). 
costs of other countries, thereby giving them an incentive to reduce their emissions.

\subsection{Technology policies which spur the adoption of new technologies}

So far, we have discussed R\&D and the market failures connected to R\&D. There may also be positive externalities in the diffusion of a new technology. There is ample evidence, among others from windmills, electric vehicle batteries and solar cells, that the unit cost falls as production of the technology accumulates (e.g. International Energy Agency 2000). Researchers illustrate the relationship between the unit cost and accumulated production by so-called learning- or experience curves, the names referring to the process by which the unit cost falls. The cost reduction is often assumed to be a constant fraction per doubling of accumulated production.

Clearly, if a private firm cannot appropriate all of its experience with a new technology, and this experience benefits other similar firms, we have a positive externality. It may then be welfare-improving for governments to support the initial diffusion phase of a new technology. Rosendahl (2004) studies the implications for climate policy when abatement costs are declining in accumulated abatement. There are two regions; an industrialized one, in which experience accumulation takes place, and a developing one, which passively reaps the benefits of a low-cost abatement technology. The paper shows that climate policy, represented by a carbon tax, should be more ambitious in the industrialized than in the developing region. The result follows from the positive experience externalities, that is, every extra use of abatement in the industrialized region today decreases future costs of abatement in both regions.

Learning curves have an intuitive appeal: Anecdotal evidence suggests that experience reduces costs. However, regressing unit costs on accumulated sales seems too simple to be used as a basis for policy. As sales of a product picks up, several parallel processes likely contribute to the decline in costs. R\&D to lower the cost of production of the new product is not put to a halt because the product is brought to market; rather, it may be intensified. A larger market may allow for economies of scale, also reducing unit costs, but here there are no positive knowledge externalities. Furthermore, the technology may benefit from R\&D in other closely related fields. Nordhaus 
(2009) points to some of these effects, and conjectures that the estimated learning rates are exaggerated.

Network externalities may also halt the diffusion of a new technology. According to Farrell and Klemperer (2007), the consumption of a good has positive network effects if one agent's purchase of the good increases the incentive of other agents to purchase the good. Recent research suggests that electric cars satisfy this condition. The network externality is indirect, as it mainly results from a wider range of complementary goods and services. For example, Zhang et al. (2016) find, based on data from Norway, that access to charging stations has a strong positive effect on willingness to pay for an electric vehicle. Moreover, Li et al. (2017) use data from the US and estimate a model that combines electric vehicle sales with the number of charging stations. They find that a ten percent increase in the number of charging stations increases electric vehicle demand by eight percent. Even if current climate policy has fully internalized the pollution externality of gasoline cars, the network externality could warrant subsidies to electric vehicles and/or charging stations (see Greaker and Midttømme 2016).

While network externalities to some extent are mainly a national problem, experience effects are international. That is, if network effects are important for the adoption of electric vehicles, a nation may find it worthwhile to subsidize electric vehicles temporarily, independent of any international effects. Accumulated experience, on the other hand, depends on global accumulated sales of a technology. For a single, small nation, or even for the Nordic countries taken together, building up the accumulated experience with a technology, such that costs are significantly decreased, is harder to accomplish. Nevertheless, for some carefully chosen technologies, the effort of a single country may matter. For example, the high electric vehicle sales in Norway may have contributed significantly to the decline in electric vehicle battery cost. Furthermore, the success of the Tesla brand, which has had a large share of its sales in Norway, seems to have spurred incumbent car companies to develop their own high-quality electric vehicles.

\subsection{Promote green business}

We have shown that the Nordic states could possibly benefit from subsidizing clean technology development such that other states 
can get access to cheaper abatement options. However, they also want Nordic firms to control these technologies through secrecy or patents, that is, to promote profitable export firms. Greaker and Rosendahl (2008) and Greaker et al. (2016) examine green export promotion. There are in principle two ways in which a country could promote development of green technologies. First, the country could set tough emission standards and/or subsidize GHG abatement to create a larger home market for green technologies. Second, the country could support domestic green-technology firms either indirectly through $R \& D$ funding or directly through production subsidies.

Setting ambitious emission standards to create a larger home market is analysed in Greaker and Rosendahl (2008). Such a strategy would spur domestic R\&D, but as long as trade barriers are moderate, it will also trigger more R\&D by foreign green-technology suppliers. Consequently, the domestic green industry does not get a first-mover advantage by this policy. On the other hand, the policy may lead to more intense competition between abatement technology suppliers, thereby improving welfare. Greaker and Rosendahl also analyse subsidies to domestic firms' green R\&D. They find that such subsidies should always accompany the efforts to create a larger home market for green technologies.

Fischer et al. (2017) develop these ideas further, and compare policies directed at the downstream polluting industries with policies directed at the upstream abatement technology suppliers. One conclusion is that policies directed at the upstream abatement technology firms are more robust both with respect to reducing global emissions and to promote new green businesses. The contributions by Greaker and Rosendahl (2008) and Fischer et al. (2017) can thus be seen as more detailed analyses of strategic technology policy.

\subsection{Technology policy to demonstrate low abatement costs}

Heal and Kunreuther (2017) discuss the concept of tipping, cascading and entrapment. Their point of departure is that a game involving many countries negotiating a climate treaty may have many equilibria. One equilibrium may be no treaty, while other equilibria could imply broad cooperation and deep emission cuts. The equilibrium with no treaty is an example of an entrapment. In such a situation, a small number of players may be able to tip the equilibrium into one of the more desirable equilibria. With tipping, all other play- 
ers follow suit, while with cascading, other players follow one by one, each incentivizing the next player to change strategy. Heal and Kunreuther view clean technological development, promoted by a group of technologically advanced countries, as a strategy that could trigger cascading. This is in line with the ideas we have discussed above.

It is also possible to think of another cascading mechanism. No country can currently know what it will cost to become a 'low-emissions society'. For instance, it is hard to predict future cost reductions for renewable power, batteries and hydrogen-based solutions. Moreover, it is hard to say how easily consumers will adapt to eating less meat, flying less, etc. In a situation in which no country knows the true costs of drastically cutting GHG emission, the country with the most optimistic belief about costs could find it worthwhile to reduce emissions drastically if that makes other countries update their believes about costs.

In Appendix A.3, we sketch a model with cascading based on imperfect information and updating of beliefs. We show that it may be optimal for a country to cut emissions drastically as long as there is a significant probability that other countries will follow. They will only follow as long as it is privately optimal for them. In our opinion, this likely requires the true GHG abatement costs to be much lower than widely believed. We suspect that the world is not yet there despite the large advances in GHG abatement costs in recent years. This reinforces our argument that more technological development is needed.

Large national co-benefits of GHG mitigation, such as reduced local pollution and less oil dependence, will also make it more probable that other countries will follow if first-mover countries can demonstrate that the true GHG abatement costs are lower than expected. This suggests looking for technologies with significant co-benefits for developing countries.

\section{States also consider the welfare of other states}

In economic models of international cooperation on climate change, researchers mostly assume that nations act in pure self-interest. If we further assume that political decision makers act in the inter- 
est of their citizens, it follows that citizens also must be motivated by pure self-interest. This is not in accordance with ample evidence from lab and field experiments that show that people also consider the well-being of others when making choices. It is, however, hard to disentangle exactly what is driving such behaviour.

\subsection{Reciprocity and warm glow}

Andreoni (1990) introduced the concept of warm glow. It implies that consumers' utility increase both from contributing to a public good and from the public good in itself. Framed in this manner, warm glow can explain observed attitudes towards the environment, recycling of garbage, voluntary acquisition of GHG emission permits when flying, participating in organized beach tidying, etc. On the other hand, we find it hard to argue for ambitious climate policy measures based on warm glow. First, it is not clear whether warm glow is something you get only if you contribute to a public good by your own actions, or if the state can act on behalf of you. Second, we lack a deeper understanding of the correspondence between type of actions and the amount of warm glow. Whereas Andreoni simply postulated the 'warm glow' effect, it is still not completely clear to what extent an underlying mechanism explains the effect. One possibility is that warm glow could be an evolutionary inherited trait that leads to better outcomes for a group as a whole. This leads us to the recent literature on Kantian preferences, with contributions from (among others) Alger and Weibull (2016a, 2016b), which is discussed below.

Another mechanism that could lead to better outcomes for a group as a whole is reciprocity. Reciprocity refers to the mechanism that if one actor gives something to another actor, she will get something in return at a later point in time. Reciprocity has been extensively studied in the experimental economics literature. One example is the trust game: A player receives an amount of money. The player decides the share she wants to keep; the remaining share is given to the second player. The amount she gives to the second player is multiplied by some factor, and the second player decides how much to give back to the first player. If the first player believes that the second player is egoistic, the first player will not give anything to the second player as this player is expected to keep all the gain herself. The predicted equilibrium outcome of this game is thus that the first player keeps all money to herself, while the socially optimal action is 
to give the whole amount to the second player. The literature shows that the predicted equilibrium actions are rarely played. The first player regularly sends away some amount, and is also receiving an amount back. For example, Croson and Buchan (1999) find that 85 percent of the second players return more money than was originally sent. Moreover, there is a clear sign of reciprocity: the higher share the first player gives to the second player, the higher share the second player returns to the first player.

Another type of experiment that can throw light on the reciprocity mechanisms is the ultimatum game. In the ultimatum game, a player receives a sum of money and proposes a sharing rule to the other player. The other player can either approve the sharing rule or reject it. In the case of approval, the sharing goes through, while in the case of rejection, none of the players gets anything. The equilibrium in this game is also that the first player keeps all the money; the second player might as well accept the offer from the first player as he will not get anything if he rejects the offer. Again, the literature shows that the predicted equilibrium actions are rarely played. The first player typically proposes to share more than 20 percent to the other player, and the other player often rejects offers of less than 20 percent. The observation that the second player rejects small offers is seen as examples of negative reciprocity, that is, players are willing to punish players with 'unfair offers' even if they are hurt themselves.

There is of course a question of whether the reciprocity mechanism is valid for countries trying to cooperate on limiting climate change. The experiments are carried out in stylized settings with players that act as individuals. Thus, transferring the results to countries, acting in complicated, multi-dimensional international settings may seem naive. Experiments with groups of agents instead of individuals have been run. This could increase the external validity vis-a-vis an international climate policy setting. Bornstein and Yaniv (1998) and Cox (2002) both find that groups give less than individuals in the trust game. However, Cason and Mui (1997) find that when groups play the ultimatum game, the most generous member of a group tends to end up deciding how much should be offered to the other group. This indicates that it is difficult to predict the behaviour of countries based on experiments with individuals. Moreover, a group in an ex- 
periment is far from a nation with a representative democracy or a nation with a ruling party.

It is also important to understand the underlying cause for the observed reciprocity mechanism Some, among others Fehr and Schmidt (1999), have proposed that inequality aversion is driving the results, that is, agents experience a loss in utility from an unjust distribution of wealth. If this is the case, it seems unlikely that other countries will reciprocate an ambitious climate policy in the Nordic countries. Ambitious climate policies set by a small country will only in the very long run, and only to a very limited extent, increase the welfare of other countries. Other countries will therefore not necessary feel obliged to reciprocate.

Another possible explanation for the observed behaviour is that the players act as if they are playing a repeated game. In a repeated game, contributing to a public good may be an equilibrium strategy. Initiating an ambitious climate policy may be a way of trying to establish an equilibrium in which all countries have more ambitious climate policies. However, countries must in this case also be ready to punish those countries that defect, e.g. do not initiate policies that are more ambitious. As far as we can see, such a tit-for-tat strategy has no role in the Nordic climate policies.

Finally, reciprocity may be an inherited trait: we punish those who treat us unjust although we lose from it, and we reward those who give us favours. It can be discussed to what extent ambitious climate policies in the Nordic countries are viewed as 'favours' by other countries. The developing countries are demanding that industrialized countries should do more towards climate change. Thus, in their opinion, the Nordic countries are just doing what they at least ought to be doing. If so, 'ambitious' Nordic climate policies will not trigger more ambitious climate policies in the developing world.

In our opinion, there may be reasons for considering other countries utility when a country decides its own climate policy. This should, however, not be based on what the country might get back from other countries, but rather on the moral obligation of the country vis-a-vis climate change. 


\subsection{Moral obligation}

Another mechanism that could lead a state to consider other states' welfare is so-called Kantian optimization. According to Kant (1785) you should 'always act in such a way that you can also will that the maxim of your action should become a universal law'. Grafton et al. (2017) and Alger and Weibull (2016a) study the actions of people who have a degree of so-called Kantian preferences.

A person who has moral preferences values every action assuming that all other persons make the same action. This can easily be defined for pairwise interactions. Following Alger and Weibull (2016a), let $\pi(x, y)$ denote the payoff to a consumer who plays strategy $x$ when the other consumer plays strategy $y$. A consumer with Kantian preferences will then maximize:

$$
U(x, y)=(1-\gamma) \pi(x, y)+\gamma \pi(x, x),
$$

where $\gamma$ is the individual's degree of Kantian preferences. The first term in the expression for $U(x, y)$ is a normal utility term; with $\gamma=0$, the agent maximizes this expression given the action of the other consumer. As already explained, in a game where each country sets its emission reduction goal individually, the Nash equilibrium is not socially optimal, that is, the emission reductions are too low. The second term is the agent's utility in the hypothetical situation in which the other agent was to follow the action of the first agent. With $\gamma=1$, the agent has pure Kantian preferences and values every action by considering what would happen to own material well-being if every other agent were to follow this action. If people have Kantian preferences, they may vote for politicians that want to take stronger actions towards climate change. This would have the following implications for panel (a) in Figure 2:

The sloped solid lines are the original reaction curves from panel (a) in Figure 2 (without R\&D investments). We then introduce Kantian preferences to Country 1 . This shifts and pivots Country 1's reaction curve outwards, that is, from $A_{1}$ to $A_{1}^{\prime}$ (or all the way to the vertical $A_{1}^{\prime \prime}$, which appears when $\gamma=1$ ). The reason is that Country 1 now considers its welfare if Country 2 were to follow the actions of Country 1. Hence, Country 1 will now do more abatement for every level of abatement in Country 2 since the country benefits from 
Figure 3 GHG abatement game with Kantian preferences

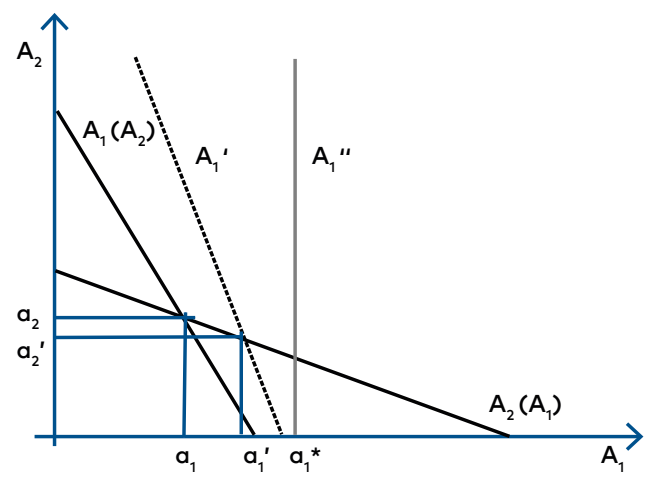

more abatement by Country 2. Country 1 also becomes less sensitive to changes in abatement levels in Country 2.

At the extreme, when $\gamma=1$, the country does its part of a globally optimal climate agreement $a_{1}{ }^{*}$ independent of what Country 2 does. Furthermore, if both countries have $\gamma=1$, they would both do their part of a globally optimal climate agreement. In the original equilibrium $\left(a_{1}, a_{2}\right)$, both countries optimize their welfare taking the action of the other country as given. On the other hand, with pure Kantian preferences $(\gamma=1)$, both countries optimize their welfare taking as given that the other country will follow their actions. In this way they escape the prisoner's dilemma situation completely. ${ }^{18}$

Alger and Weibull (2016b) use the Kantian preference structure to analyse a dynamic game in which people frequently meet in groups to play a public good game. ${ }^{19}$ They show that preferences of the type described above with $\gamma>0$ will emerge from an evolutionary process in which agents inherit beneficial traits. The authors therefore predict that Kantian preferences may be more widespread than what we tend to think. This implies that other countries also may act as if their citizens had (partly) Kantian preferences. Other countries would then be less sensitive to changes in the abatement level of the Nordic countries. For instance, the reduction in abatement

\footnotetext{
${ }^{18}$ As briefly explained in the beginning of Section 4, a prisoner's dilemma is a situation in which every agent does her best (given the actions of the others), but the outcome for the group as a whole is inferior to other possible outcomes.

${ }^{19}$ For example, a game like the trust game described in the previous section.
} 
from $a_{2}$ to $a_{2}{ }^{\prime}$ would be smaller than shown in Figure 3.

Grafton et al. (2017) study the interaction between pure Kantian agents (with $\gamma=1$ ) and pure selfish agents in a game inspired by climate change. It is shown that increased occurrence of Kantian players improves the welfare of both Kantian and selfish players.

Greaker et al. (2013) explore the implication of Kantian preferences further, albeit in a different setting. They ask how one should evalvate national climate policies. The authors argue that as long as current climate treaties are insufficient to reach the agreed upon goals of limiting global warming, the criterion should be to what extent the country complies with a hypothetical sufficient treaty. The authors further operationalize this concept along three dimensions. First, current carbon prices in a country should be compared to carbon prices that would limit the global temperature increase to well below $2.0^{\circ} \mathrm{C}$. Second, current emission levels minus emission reductions carried out abroad should be consistent with a fair allocation of the remaining global carbon budget..$^{20}$ Thus, national emission levels in itself are not a criterion. On the other hand, it is not straightforward to say what constitutes a fair allocation of the global carbon budget. ${ }^{21}$ Finally, the country should actively direct R\&D funds to clean technology development. The rationale is that if a sufficient climate treaty were in place, the private incentives for conducting clean R\&D would be higher. In particular, the incentives would be higher for those technologies that have a worldwide application. $^{22}$

Citizens in the Nordic countries may have voted for politicians that choose climate policies inspired by Kant's categorical imperative. In our opinion, it is then the responsibility of politicians to enact a Kantian climate policy that minimizes any potential conflicts between 'doing the right thing' in a moral sense and 'doing the optimal thing' with respect to limiting climate change. The problem arises because the argument 'it is a moral duty' can be used to ad-

\footnotetext{
20 The global carbon budget is the amount of carbon dioxide emissions we can emit while still having a fair chance of limiting global temperature rise to $2.0^{\circ} \mathrm{C}$ above preindustrial level.

${ }^{21}$ See Greaker et al. (2013) for a discussion of various allocation principles for the global carbon budget.

22 The authors argue that a high carbon price at home is an insufficient incentive for clean technology R\&D since the patents from this would have had a market abroad also if a sufficient treaty were in place.
} 
vocate a wide range of climate-related actions. For instance, one potential pitfall is to focus on national emission reduction targets that cannot be met without introducing technology standards with questionable global emission effects. Another potential pitfall is to introduce policies that conflict with other international obligations such as, for instance, the rules imposed by WTO membership or EU membership. An example of the latter could be to subsidize extensively Nordic firms' investments in GHG abatement equipment, which could be seen as muddling with the EU ETS. Nordic politicians should therefore always ask to what extent their climate policies constitute examples that the Nordic countries would like other countries to copy (precisely as in the model of Alger and Weibull 2016b).

A question of special interest for Norway is whether Norway should avoid developing oil and gas fields that would not have been profitable if a sufficient climate treaty were in place. On one hand, it could be argued that a sufficient climate treaty would leave it up to each sovereign state to reduce emissions from their territory, and hence emissions from the use of Norwegian oil and gas in other countries cannot be the responsibility of Norway. On the other hand, it is not yet clear whether a future climate treaty will involve some restrictions on coal, oil and gas exports. Moreover, as pointed out by Leroux and Spiro (2018), arctic oil exploration by Norway will lead to further technology development, which will benefit Russian arctic oil exploration in the future. ${ }^{23}$

Finally, in our opinion, spurring the development of clean technologies would fit with a Kantian climate policy. Note that we can deduct from Figure 3 that the effect of technology investments would be similar in Figure 2 (panel b). Hence, R\&D investment in technologies with a global application would still have desirable global effects.

\section{Discussion}

In Section 2 we discussed Nordic climate policies and concluded that they are ambitious compared to those in other OECD coun-

${ }^{23}$ See Holtsmark (2019) for a further discussion of this topic. 
tries, in particular countries outside the EU. Then in Sections 3-5 we explored various rationales for ambitious climate policies in small, open economies like the Nordics. Of these mechanisms, we found clean technology development most likely to induce global emission reductions.

In our opinion, the Nordic countries could take two routes with respect to technological development. One route seeks to develop the state of knowledge of the large category of clean technologies. Such development could include deployment of emerging clean technologies that promotes cost reductions from learning by doing. However, to succeed it may be decisive to cooperate within a larger unit such as the EU, and preferably, even larger units including US states like California and countries like Canada, Japan, etc.

The second route would be to focus on areas in which the Nordic countries have expertise, and consider which innovations can be expected to have a global market. This is not completely unrealistic; Norwegian offshore oil and gas technology is used over the whole world, and Denmark is a world-leading windmill producer. In the near future, a further expansion of windmills may happen off-shore, and therefore windmills may be a promising area for increased Nordic cooperation. However, to determine R\&D budgets in this way requires Nordic governments to 'pick winners'. We acknowledge that this is difficult, and that government bodies often lack detailed information about markets that is necessary to make well-founded decisions. On the other hand, as already discussed, innovation creates spillovers that the innovator does not fully capture or profit from. As a society, we therefore want to promote innovation, but due to financial restrictions, we cannot promote all innovations. Hence, innovation policies are already largely geared at picking winners, e.g., the best ideas with the largest spillovers. What we propose is to shrink the set of potential research and/or demonstration projects that get innovation support somewhat more, that is, focus on clean technologies with a global market potential.

To learn more about the market potential for different clean technologies, a start could be to draw on the various technology-specific studies that examine GHG mitigation scenarios. Two examples are International Energy Association's (2017) and Luderer at al. (2012); the latter collects results from several independent model studies. 
Note that some of the GHG mitigation scenarios also include endogenous R\&D investments. For instance, Bosetti et al. (2009) find that increased R\&D investments in currently known electricity technologies, such as solar, nuclear and CCS, are highly desirable. Other studies examine the potential for cost reductions from R\&D in GHG mitigation technologies. One example is Baker et al. (2015); they compare and aggregate expert elicitation data about energy technology in order to identify technologies which may benefit the most from increased R\&D spending. When combining all data, CCS and nuclear turn out to have the largest prospects for advancement with solar following next. One take-away from this literature is that CCS seems to be important. Still, Norway is the only Nordic country that seeks to develop this technology.

Can we hope to sell these technologies to developing countries? It is a well-known fact that the Nordic countries mostly trade with each other and the rest of the EU. The United Nations Framework Convention on Climate Change has created its own body to promote technology transfer to developing countries - the UNFCCC Technology Mechanism. ${ }^{24}$ This UN organization has organized technology-need assessments in more than 80 developing countries. ${ }^{25}$ However, its main activity is to facilitate project-related clean technology deployment in developing countries. The Nordic states are already engaged in the UNFCCC Technology Mechanism. An ambitious climate policy that is more geared towards technology development for the world might imply that the Nordic countries should step up their engagement in technology transfer further. There is empirical evidence indicating that technology transfer may be spurred by state involvement. For instance, Ferguson and Forslid (2018) show that embassies can have significant effect on export promotion.

Clearly, there could be a potential conflict between developing technology for which Nordic countries have comparative advantages, and developing clean technologies for foreign markets. We tend to think that the Nordic countries can help reduce foreign GHG abatement cost without being forced to venture into technologies for which they have no (or tiny) prior knowledge. To us there seems to 
Table 1 Two climate policy views

\begin{tabular}{|c|c|}
\hline Country focus & Global focus \\
\hline $\begin{array}{l}\text { - Each Nordic country focuses on } \\
\text { their own emission targets, even } \\
\text { counting national emissions in the } \\
\text { ETS sector. }\end{array}$ & $\begin{array}{l}\text { - Acknowledge that the EU has } \\
\text { set ambitious climate policies, } \\
\text { and work together with the EU to } \\
\text { reach the EU targets. }\end{array}$ \\
\hline $\begin{array}{l}\text { - For the ESR sector, the Nordic } \\
\text { countries restrict trading with EU } \\
\text { countries to 'show a good example' } \\
\text { and consider technology mandates } \\
\text { that have dubious global effects. }\end{array}$ & $\begin{array}{l}\text { - Excess ambitions are channelled } \\
\text { to technological development in } \\
\text { the form of R\&D subsidies and } \\
\text { demonstration projects, and } \\
\text { sometimes wider roll-outs to pro- } \\
\text { mote learning. }\end{array}$ \\
\hline $\begin{array}{l}\text { - Technology policy is driven by the } \\
\text { need to reduce national emis- } \\
\text { sions, and may thus have different } \\
\text { focuses in the Nordic countries. }\end{array}$ & $\begin{array}{l}\text { - Clean technological development } \\
\text { focuses on technologies that also } \\
\text { can be applied in other countries, } \\
\text { in particular developing countries. }\end{array}$ \\
\hline
\end{tabular}

be some promising areas like CCS, floating windmills and maritime electric propulsion. We suggest a broadly composed Nordic commission should study this thoroughly before current R\&D policies are changed.

\section{Conclusions}

Based on the review of current climate policies in the Nordic countries, we propose two alternative Nordic views on climate policy: country focus or global focus. These two views are characterized in Table 1.

Our conjecture is that Nordic climate policies still have too much of a country focus:

- Emission reduction targets for the ESR sector in the Nordic countries should not be absolute with respect to the amount of emission reductions carried out at home. The Nordic countries should fully take advantage of the flexible EU mechanisms. By applying absolute targets, the Nordic countries risk promoting technologies that are dead ends. 
- Sweden aims to reduce emissions from domestic transport by 70 percent before 2030, which seems hard without a massive substitution of fossil fuels with biofuels. Finland wants to have 30 percent blending of biofuels by 2030 . We suspect both policies to be dependent on imports of first-generation bio-fuels from developing countries. Imports of biofuels could induce emissions from land use change in the exporting countries that off-set all, or more than, the emission reductions in the importing countries. ${ }^{26}$

- In Finland, Sweden and Norway, there are multiple plans for building biofuels factories based on forestry residues. The countries' motivation for subsidizing the plants seems to be the planned emission reductions in transport (see above). Nordic governments should ensure that the chosen bio-refining processes contribute to technological development for advanced biofuels, and that the chosen processes are relevant for other kinds of cellulosic feedstock.

- The Norwegian state recently supported a large Norwegian aluminium manufacturer with 1.6 billion NOK in order to develop a more energy- and GHG-efficient aluminium-melting production line. According to press statements, the company will not seek to patent the innovation, but keep the innovation secret out of fear that other firms will copy the new technological solutions. ${ }^{27}$ This conflicts with the idea that the Nordic countries should develop technologies that other countries could make use of to reduce their emissions at less costs.

There are also signs of a 'world view':

- Electricity storage and mobility solutions seem to be crucial ingredients of a low-emission society, and thus such technologies likely have a large potential for application in other countries than in the Nordics. In Sweden, there are two initiatives in this direction; two battery factories are planned in Trollhättan and in Skelleftea. ${ }^{28}$ The Norwegian electric vehicle policy and the electric ferry initiative should also be studied closer in order to uncover to what extent they have positive global effects.

\footnotetext{
${ }^{26}$ See e.g. Valin (2015) for a study of EUs biofuels policies.

${ }^{27}$ See Malkenes Hovland (2017).

${ }^{28}$ See Valle (2018).
} 
- Some renewable development may also be promising, for example, the floating windmills development project lead by the Norwegian company Equinor (former Statoil). This technology may have a large potential abroad, and draws on the offshore oil production expertise of Equinor.

- Norway has a separate carbon capture and storage (CCS) program which currently is considering two different projects: a cement factory and a waste-burning facility. The official object of this program is to promote CCS technology in the rest of the world. We believe that there is scope for much greater Nordic cooperation on CCS. According to our understanding, the planned carbon dioxide storage site on the Norwegian continental shelf has a large capacity. It can store carbon dioxide from multiple Nordic sources.

As discussed above, Kantian preferences may motivate climate policies in the Nordics. If so, we recommend Nordic politicians to refine what it implies for the Nordic countries to do their part of a sufficient climate treaty. First, Nordic governments should communicate that the EU already has an ambitious climate policy. One could argue that if the EU fulfils its Paris commitment (NDC), the Nordic countries are in fact doing their part of a sufficient climate treaty together with the EU.

The Nordic countries may still aim to be even more ambitious. In this case, the Nordic countries' choice of climate policies should take into account to what extent their climate policies constitute examples that they would want other countries to follow. In our opinion, advancing clean technologies is the key also here. The Nordic countries should also consider coordinating their technology policies better in order to maximize their global impact.

In our opinion, the major uncertainty is whether the EU will succeed to reduce emissions in the ESR sector by 30 percent by 2030 . This could require a very ambitious climate policy in the Nordic countries for the ESR sectors, even if full use is made of the flexible EU mechanisms. The centrepiece of this ambitious policy should be to price emissions sufficiently high in all sectors - also agriculture and fisheries, which are now exempted from emission pricing. We tend to think that this would set an example the Nordic countries would want other countries to follow. 


\section{References}

Acemoglu, D., Aghion, P., Bursztyn, L. and Hemous, D. (2012), The

Environment and Directed Technical Change, American Economic Review, 102(1), 131-166.

Aghion, P., Dechezleprêtre, A., Hémous, D., Martin, R. and van Reenen, J. (2016), Carbon Taxes, Path Dependency and Directed Technical Change:

Evidence from the Auto Industry, Journal of Political Economy, 124(1), 1-51.

Alger, I. and Weibull, J. (2016a), Morality - Evolutionary Foundations and Policy Implications. Manuscript prepared for the conference 'The State of Economics, The State of the World', Washington D.C.: World Bank.

Alger, I. and Weibull, J. (2016b), Evolution and Kantian Morality, Games and Economic Behavior, 98, 56-67.

Ambec, S. and Crampes, C. (2012), Electricity Provision with Intermittent Sources of Energy, Resource and Energy Economics, 34(3), 319-336.

Andreoni, J. (1990), Impure Altruism and Donations to the Public Good: A Theory of Warm Glow Giving, The Economic Journal, 100(4), 464-477.

Arrow, K. (1962), Economic Welfare and the Allocation of Resources for Invention, in Nelson, R. (ed.), The Rate of Direction of Inventive Activity, Princeton, NJ: Princeton University Press.

Aune, F. R. and Fæhn, T. (2016), Makroøkonomisk analyse for Norge av EUs og Norges klimapolitikk mot 2030 [eng: Macroeconomic Analysis for Norway of the EU's and Norway's Climate Policy Towards 2030], Report 2016/25, Statistics Norway.

Aune, F. R., Golombek R. and le Tissier, H. H. (2015), Phasing Out Nuclear Power in Europe, CREE Working Paper 5/2015, CREE Center.

Baker, E., Bosetti, V., Anadon, L. D., Henrion, M. and Reis, L. A. (2015), Future Costs of Key Low-Carbon Energy Technologies: Harmonization and Aggregation of Energy Technology Expert Elicitation Data, Energy Policy, 80, 219-232.

Barrett, S. (1994), Self-enforcing International Environmental Agreements, Oxford Economic Papers, 46, 878-894.

Beisland, C. (2013), From Targets to Timetables to Technology Investments, CREE working paper 12/2013, CREE Center.

Bijgaart, I. (2017), The Unilateral Implementation of a Sustainable Growth Path with Directed Technical Change, European Economic Review, 91, 305327. 
Bohm, P. (1993), Incomplete International Cooperation to Reduce CO2 Emissions: Alternative Policies, Journal of Environmental Economics and Management, 24(3), 258-271.

Bornstein, G. and Yaniv, I. (1998), Individual and Group Behavior in the Ultimatum Game: Are Groups More 'Rational' Players?, Experimental Economics, 1(1), 101-108.

Bosetti, V., Carraro, C., Massetti, E., Sgobbi, A. and Tavoni, M. (2009), Optimal Energy Investment and R\&D Strategies to Stabilize Atmospheric Greenhouse Gas Concentrations, Resource and Energy Economics, 31(2), 123-137.

Buchholz, W. and Konrad, K. A. (1994), Global Environmental Problems and the Strategic Choice of Technology, Journal of Economics, 60(3), 299-321.

Calmfors, L., Corsetti, G., Devereux, M. P., Saint-Paul, G., Sinn, H-W., Sturm, J-E. and Vives, X. (2008), Chapter 5: Global Warming: The Neglected Supply Side, in EEAG Report on the European Economy 2008, Munich: CESifo Group Munich.

Cason, T. N. and Mui, V. L. (1997), A Laboratory Study in Group Polarization in the Team Dictator Game, The Economic Journal, 107(444), 1465-1483.

Cox, J. C. (2002), Trust, Reciprocity, and Other Regarding Preferences: Groups vs. Individuals and Males vs. Females, in Zwick, R. and Rapoport, A. (eds.), Experimental Business Research, Boston, MA: Springer.

Croson, R. and Buchan, N. (1999), Gender and Culture: International Experimental Evidence from Trust Games, American Economic Review, 89(2), 386-391.

Danish Ministry of Energy, Utilities and Climate (2018), Energy Agreement of 29 June 2018, Retrieved December 19, 2018, from https://en.efkm.dk/ media/12307/energy-agreement-2018.pdf.

Dechezleprêtre, A., Martin, R. and Mohnen, M. (2013), Knowledge Spillovers from Clean and Dirty Technologies: A Patent Citation Analysis, Working Paper 135, Grantham Research Institute on Climate Change and the Environment.

European Commission (2018), Climate Strategies \& Targets: Economic Analysis, Retrieved December 19, 2018, from https://ec.europa.eu/clima/ policies/strategies/analysis_en.

Farrell, J. and Klemperer, P. (2007), Coordination and Lock-in: Competition with Switching Costs and Network Effects, in Armstrong, M. and Porter, R. (eds.), Handbook of Industrial Organization, Volume 3, New York City, NY: Elservier.

Fehr, E. and Schmidt, K. (1999), A Theory of Fairness, Competition, and Cooperation, Quarterly Journal of Economics, 114(3), 817-868. 
Ferguson, S. and Forslid, R. (2018), Sizing Up the Impact of Embassies on Exports, Scandinavian Journal of Economics, 121(11), 278-297.

Fischer, C., Greaker, M. and Rosendahl, K. E. (2017), Robust Policies against Emission Leakage: The Case for Upstream Subsidies, Journal of Environmental Economics and Management, 84, 44-61.

Golombek, R. and Hoel, M. (2004), Unilateral Emission Reductions and Cross-Country Technology Spillovers, Advances in Economic Analysis \& Policy, 4(2), 1-27.

Government Offices of Iceland (2018), Iceland's Climate Action Plan for 2018-2030: Summary, Retrieved December 31, 2018, from https://www. government.is/library/Files/Icelands\%20new\%20Climate\%20Action\%20 Plan\%2Ofor\%202018\%202030.pdf.

Grafton, Q. R., Kompas, T. and van Long, N. (2017), A Brave New World? Kantian-Nash Interaction and the Dynamics of Global Climate Change Mitigation, European Economic Review, 99(C), 31-42.

Greaker, M. and Rosendahl, K. E. (2008), Environmental Policy with Upstream Pollution Abatement Firms, Journal of Environmental Economics and Management, 56(3), 246-59.

Greaker, M. and Hagem, C. (2013), Strategic Investment in Climate Friendly Technologies: The Impact of Permit Trade, Environmental and Resource Economics, 59(1), 65-85.

Greaker, M. and Midttømme, K. (2016), Network effects and environmental externalities: Do clean technologies suffer from excess inertia? Journal of Public Economics, 143, 27-38.

Greaker, M., Stoknes, P. E., Alfsen, K. H. and Ericson, T. (2013), A Kantian Approach to Sustainable Development Indicators for Climate Change, Ecological Economics, 90, 10-18.

Greaker, M., Heggedal, T. R. and Rosendahl, K. E. (2018), Environmental Policy and the Direction of Technical Change, Scandinavian Journal of Economics, 120(4), 1100-1138.

Harstad, B., Lancia, F. and Russo, A. (2018), Compliance Technologies and Self-enforcing Agreements, Journal of European Economic Association, forthcoming.

Heal G. and Kunreuther, H. (2017), An Alternative Framework for Negotiating Climate Policies, Climatic Change, 144(1), 29-39.

Hoel, M. (1992), International Environmental Conventions: The Case of Uniform Reductions of Emissions, Environmental \& Resource Economics, 2(2), 141-159. 
Hoel, M. (1994), Efficient Climate Policy in the Presence of Free Riders, Journal of Environmental Economics and Management, 27(3), 259-274.

Hoel, M. and Holtsmark, B. (2012), Haavelmo on the Climate Issue, Nordic Journal of Political Economy, 37, 1-22.

Hoel, M. and de Zeeuw, A. (2014), Technology Agreements with Heterogeneous Countries, in Todd L. C., Hovi, J. and McEvoy, D. (eds.), Toward a New Climate Agreement: Conflict, Resolution and Governance, Abingdon: Routledge.

Holtsmark, K. (2019), Supply-side climate policy in Norway, Nordic Economic Policy Review (this issue).

Holtsmark, B. and Skonhoft, A. (2014), The Norwegian Support and Subsidy Policy for Electric Cars. Should it be Adopted by Other Countries?, Environmental Science \& Policy, 42, 160-168.

International Energy Agency (2000), Experience Curves for Energy Technology Policy, Paris: OECD/IEA.

International Energy Agency (2017), Energy Technology Perspectives, Paris: OECD/IEA.

IPCC (2018), Summary for Policymakers, in Masson-Delmotte, V., Zhai, P., Pörtner, H. O., Roberts, D., Skea, J., Shukla, P. R., Pirani, A., Moufouma-Okia, W., Péan, C., Pidcock, R., Connors, S., Matthews, J. B. R., Chen, Y., Zhou, X., Gomis, M. I., Lonnoy, E., Maycock, T., Tignor, M. and Waterfield, T. (eds.), Global Warming of $1.5^{\circ} \mathrm{C}$. An IPCC Special Report on the Impacts of Global Warming of $1.5^{\circ} \mathrm{C}$ above Pre-industrial Levels and Related Global Greenhouse Gas Emission Pathways, in the Context of Strengthening the Global Response to the Threat of Climate Change, Sustainable Development, and Efforts to Eradicate Poverty, Geneva: World Meteorological Organization.

Kant, I. (1785), Grounding for the Metaphysics of Morals, Introduction, page 8, translated by Ellington, J. W., Indianapolis: Hackett Publishing Company.

Lazkano, I., Nøstbakken, L. and Pelli, M. (2017), From Fossil Fuels to Renewables: The Role of Electricity Storage, European Economic Review, 99, 113-129.

Leroux, J. and Spiro, D. (2018), Leading the Unwilling: Unilateral Strategies to Prevent Arctic Oil Exploration, Resource and Energy Economics, 54, 125149.

Li, S., Tiong, L., Xing, J. and Zhou, Y. (2017), The Market for Electric Vehicles: Indirect Network Effects and Policy Design, Journal of the Association of Environmental and Resource Economists, 4(1), 89-133. 
Luderer, G., Bosetti, V., Jacob, M., Leimbach, M., Steckel, J. C., Waisman, $\mathrm{H}$. and Edenhofer, O. (2012), The Economics of Decarbonizing the Energy System - Results and Insights from the RECIPE Model Intercomparison, Climatic Change, 114(1), 9-37.

Malkenes Hovland, K. (2017, July 26), Hydro åpner milliardanlegg i august: Tør ikke patentere teknologien [eng: Hydro Opens Billion-NRK Facility in August: Do Not Dare Patent Technology], E24, Retrieved December 19, 2018, from https://e24.no/naeringsliv/norsk-hydro/hydro-aapnermilliardanlegg-i-august-toer-ikke-patentere-teknologien/24104047.

McGinty, M. (2007), International Environmental Agreements Among Asymmetric Nations, Oxford Economic Papers, 59(1), 45-62.

Mæstad, O. (2001), Efficient Climate Policy with Internationally Mobile Firms, Environmental and Resource Economics, 19(1), 267-284.

Nordhaus, W. D. (2009), The Perils of the Learning Model for Modeling Endogenous Technological Change, NBER Working Paper No. 14638, National Bureau of Economic Research.

Norwegian Environment Agency (2016), Tiltakskostnader for elbil. Samfunnsøkonomiske kostnader ved innfasing av elbiler i personbilparken [eng: Abatement cost for electrical vehicles. Economics costs of phasing in electrical vehicles in the fleet of private cars], Report M-620, Norwegian Environment Agency.

Perino, G. (2018), New EU ETS Phase 4 Rules Temporarily Puncture Waterbed, Nature Climate Change, 8, 262-264.

Romer, P. M. (1990), Endogenous Technological Change, Journal of Political Economy, 98(5), S71-S102.

Rosendahl, K. E. (2004), Cost-effective Environmental Policy: Implications of Induced Technological Change, Journal of Environmental Economics and Management, 48(3), 1099-1121.

Silbye, F. and Sørensen, P. B. (2019), Towards a more Efficient European Carbon Market, Nordic Economic Policy Review (this issue).

Stranlund, J. K. (1996), On the Strategic Potential of Technological Aid in International Environmental Relations, Journal of Economics, 64(1), 1-22.

Urpelainen, J. (2011), Can Unilateral Leadership Promote International Environmental Cooperation, International Interactions, 37(3), 320-339.

Urpelainen, J. (2013), Can Strategic Choice of Technology Development Improve Climate Cooperation? A Game Theoretic Analysis, Mitigation and Adaptation Strategies for Global Change, 18(6), 785-800.

UNFCCC (2018a), Support: Technology Mechanism, Retrieved December 19, 2018, from http://unfccc.int/ttclear/support/technology-mechanism. html. 
UNFCCC (2018b), Technology Needs Assessment: Overview, Retrieved December 19, 2018, from http://unfccc.int/ttclear/tna.

United Nations (2017), The Emission Gap Report, Retrieved December 31, 2019, from https://news.un.org/en/story/2017/10/569672-un-seesworrying-gap-between-paris-climate-pledges-and-emissions-cuts-needed.

Valin, H., Peters, D., van den Berg, M., Frank, S., Havlik, P., Forsell, N. and Hamelinck, C. (2015), The Land Use Change Impact of Biofuels Consumed in the EU - Quantification of Area and Greenhouse Gas Impacts. IIASA Report, Retrieved January 19, 2019, from https://ec.europa.eu/energy/sites/ ener/files/documents/Final\%2OReport_GLOBIOM_publication.pdf

Valle, M. (2018), Nå er det klart: En av verdens største batterifabrikker bygges i Sverige [eng: It's Clear Now: One of the Largest Battery Factories in the World to be Built in Sweden], Teknisk Ukeblad, March 15, Retrieved December 19, 2018, from https://www.tu.no/artikler/na-er-det-klart-en-avverdens-storste-batterifabrikker-bygges-i-sverige/432817.

Zhang, Y., Qian, Z., Sprei, F. and Li, B. (2016), The Impact of Car Specializations, Prices and Incentives for Battery Electric Vehicles in Norway: Choices of Heterogeneous Consumers, Transportation Research Part C, 69, 386-401. 


\section{Appendix}

\section{A.1 Industrial countries' NDCs` under the Paris treaty}

\section{Table A.1 Industrial countries NDCs}

\begin{tabular}{|l|l|}
\hline Country & NDC \\
\hline Europe & \\
EU ETS & $43 \%$ below 2005 level \\
EU Non-ETS & $30 \%$ below 2005 level \\
Denmark & $39 \%$ below 2005 level \\
Finland & $39 \%$ below 2005 level \\
Iceland & $40 \%$ below 2005 level \\
Norway & $40 \%$ below 2005 level \\
Sweden & $40 \%$ below 2005 level \\
Rest of EU & $<30 \%$ below 2005 level \\
& \\
Non-Europe & \\
Australia & $26-28 \%$ below 2005 level \\
Canada & $30 \%$ below 2005 level \\
Japan & $25.4 \%$ below 2005 level \\
New Zealand & $30 \%$ below 2005 level \\
Russia & $25 \%$ below 2005 level \\
US** & $26-28 \%$ below 2005 level \\
& \\
\hline
\end{tabular}

* GHG emission-reduction targets for 2030 reported as NDC to the UNFCCC.

** Under negotiation; probably $39 \%$ or $40 \%$.

*** The US has announced its intention to withdraw once it becomes legally possible. 


\section{A.2 Gasoline prices}

Figure A.1 Gasoline prices in OCED countries (2018 US \$/litre)

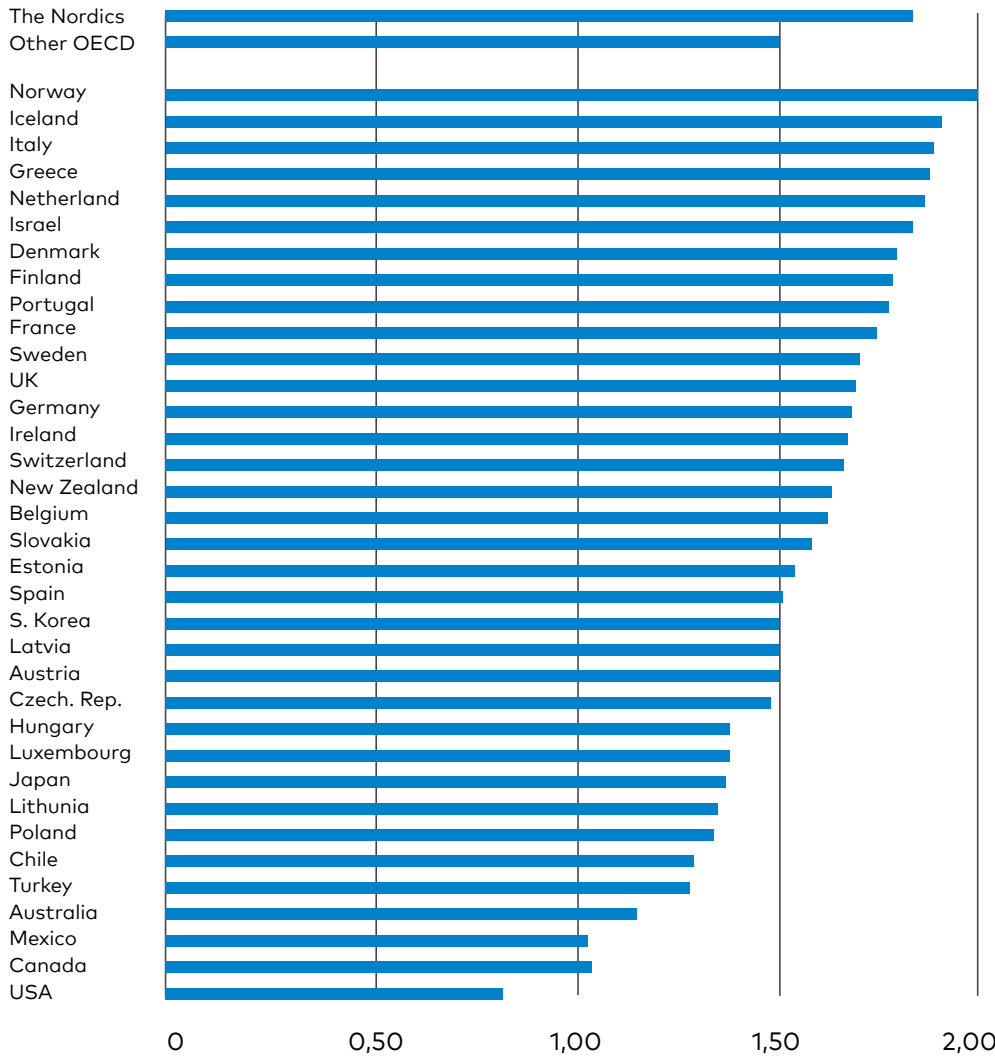

Source: The data is for an arbitrary day in November 2018, and has been retrieved from https://www.globalpetrolprices.com/gasoline_prices/. 


\section{A.3 Model with demonstration of low abatement costs}

The following model illustrates what we mean by showing 'a good example': Assume that there are two countries only, and that they have a binary choice: choose to either become a 'low-emission society' or comply with a weak international environmental agreement (IEA) at lowest possible costs. The additional cost of becoming a low-emission society is unknown to both countries. For Country 1, we assume that with probability $p_{1}$ the cost is $c^{\prime}$, and with probability $\left(1-p_{1}\right)$ the cost is $c^{h}$. For Country 2 the costs are identical, but the probability of a low cost $c^{\prime}$ is $p_{2}$ with $p_{2}<p_{1}$. Further, if both countries become low-emission societies, they will both receive a climate benefit of $B$, while if only one country makes this choice, the climate benefit is $B / 2$ to both countries. Each country $i$ also has a private benefit $b_{i}$ of becoming a low-emission society. This could for instance be less local pollution, less dependency on oil import, etc. Finally, we normalize country welfare to zero when both countries only comply with existing treaties at minimum costs.

The game has the following normal form:

\begin{tabular}{|l|c|c|}
\hline & \multicolumn{2}{|c|}{ Country 2 } \\
\hline $\begin{array}{l}\text { Low } \\
\text { emission } \\
\text { society }\end{array}$ & $\begin{array}{c}\text { Low emission society } \\
B+b_{1}-p_{1} c^{l}-\left(1-p_{1}\right) c^{h},\end{array}$ & $\begin{array}{c}\text { Comply with IEA } \\
B+b_{2}-p_{2} c^{l}-\left(1-p_{2}\right) c^{h}\end{array}$ \\
\hline Country1 & $\begin{array}{c}\text { Comply } \\
\text { with IEA }\end{array}$ & $B / 2, b_{1}-p_{1} c^{l}-\left(1-p_{1}\right) c^{h}$, \\
& $B / 2+b_{2}-p_{2} c^{l}-\left(1-p_{2}\right) c^{h}$ & 0,0 \\
\hline
\end{tabular}


The two following conditions on the parameters will then yield the classic prisoner's dilemma in the simultaneous-move game:

$$
\begin{aligned}
& B+b_{i}-p_{i} c^{l}-\left(1-p_{i}\right) c^{h}>0, i=1,2 \\
& \frac{B}{2}>B+b_{i}-p_{i} c^{l}-\left(1-p_{i}\right) c^{h}, i=1,2
\end{aligned}
$$

Although both countries would gain if both countries become a low-emission society (A1), it is privately beneficial for each country to free-ride (A2).

Consider then the following two-stage game: Country 1 chooses strategy first. If Country 1 chooses to become a low-emission society, Country 2 will update its belief about the costs of becoming a low-emission society before it chooses whether to become one. To fix ideas, assume that if Country 1 decides to become a low-emission society and the implied cost turns out to be $c^{\prime}$, Country 2 will update its probability of $c^{\prime}$ from $p_{2}$ to $p_{2}{ }^{\prime}$ with $p_{2}<p_{2}{ }^{\prime}$ (while if costs turns out to be $c^{h}$, Country 2 will update to $p_{2}{ }^{\prime \prime}$ with $\left.p_{2}>p_{2}{ }^{\prime \prime}\right)$.

The following two conditions will then make it worthwhile for Country 1 to choose to become a low emission society:

$$
\begin{aligned}
& \frac{B}{2}+b_{2}-p_{2}{ }^{\prime} c^{l}-\left(1-p_{2}{ }^{\prime}\right) c^{h}>0, \\
& \frac{B}{2}+p_{1} \frac{B}{2}+b_{1}-p_{1} c^{l}-\left(1-p_{1}\right) c^{h}>0
\end{aligned}
$$

A3 says that if Country 2 updates its probability of low costs to $p_{2}^{\prime}$ ' it would follow Country 1 and become a low-emission society. A4 denotes the expected welfare of Country 1 taking into consideration that if it successfully becomes a low-emission society - the probability of this event is $p_{1}$ - then Country 2 will follow suit.

For a large $p_{1}, A 4$ may clearly hold. On the other hand, how probable is it that $A 3$ holds? A necessary condition is of course that $\frac{B}{2}+b_{2}-c^{l}>0$, that is, 'the lowest possible abatement costs' must be 
so low that it is privately optimal to act. We suspect that the world is not yet there despite the large advances in GHG abatement costs in recent years. This reinforces our argument that more technological development is needed.

This game could be extended to $n$ countries, which were ranked by their a priori belief about the probability of becoming a low-emission society at low costs. Depending on the mechanism by which beliefs are updated, one country could set off a cascading effect. On the other hand, one may argue that the Nordic countries are 'too special' to influence other countries' beliefs about their costs of becoming a low-emission society. 


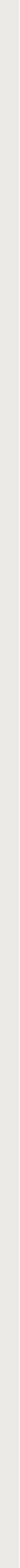


Comment on M. Greaker, R. Golombek and M. Hoel:

Global Impact of National Climate Policy in the Nordic Countries

\section{Mark Sanctuary ${ }^{1}$}

The Nordic countries are ambitious in their efforts to reduce greenhouse gas emissions. Yet the direct effect on global emissions is in fact almost negligible. As the authors point out, currently less than half a percent of greenhouse gas emissions originate from the Nordics. Moreover, some of the Nordic countries' climate policies imply abatement costs that exceed current EU ETS permit prices by a large amount. Even if the Nordics spend scarce resources to meet their ambitious domestic emission targets, there will be little direct benefit in terms of less climate change. Justification of ambitious Nordic climate policy therefore rests on the potential extra-territorial effects of these policies. The paper by Greaker et al. is a valuable contribution in mapping these potential effects and provides valuable insights on how Nordic countries should design their climate policies.

A main point of the paper is that Nordic climate policy could be deployed more effectively by supporting R\&D and technological change. Public support of clean technology is essential. Clean-tech advances are driven by public policies and industry's responses to them (Trancik 2014). There is at the same time the challenge of choosing winning technologies ex ante, and the notion that innovation support should be technology-neutral. The authors make a convincing case for challenging this view and for targeting public support for clean-technology development, and in particular focusing support on technology that can be exported. This targeted support places informational burdens on policymakers, but governments have a mixed record in picking winners and losers among technologies. Lessons learned from green industrial/infant Industry policies can be applied to help ensure that scarce support is allocated as effectively as possible (e.g. Rodrik 2014).

Another key point of the paper is that the notion of Kantian morality could help explain why Nordic climate policy is relatively ambiti-

${ }^{1}$ IVL Swedish Environmental Research Institute. Email: Mark.Sanctuary@hhs.se. 
ous. Kantian morality contrasts with an economic principle which states that if policies in one area inadequately address a problem, implementing policy in another area can have detrimental overall, societal effects. This is the theory of the second best. Interactions between domestic and foreign climate polices is an example of this economic principle. Ignoring such interactions could undo benefits of well-meaning climate policies. One key lesson from this literature is that implementing the first-best policy, when policies in other areas are second-best, can be detrimental to welfare, precisely because of the interactions. In a second-best world, the optimal second-best policy can be very different from the first-best policy.

Figure 3 in Greaker et al. exemplifies the point. Suppose Actor 1 (the Nordics) has Kantian preferences and wants her abatement efforts to reflect her moral preferences. This shifts and pivots Actor 1 's reaction curve outward to $A_{1}{ }^{\prime}$, and this Actor's abatement efforts increase fro $a_{1}$ to $a_{1}{ }^{\prime}$. However, a consequence is that Actor 2 's abatement efforts fall from $a_{2}$ to $a_{2}{ }^{\prime}$. By being moral, Actor 1's abatement effort increases in part because it has to make up for Actor 2's lower abatement effort. Kantian preferences do not get around the problem of Actor 2 free-riding on Actor 1's moral action (as in Hoel 1992). The qualitative result is essentially the same if Actor 2 is moral as well. Only when both actors are perfectly moral (with $\gamma=1$ ) there is no free-riding problem.

Notwithstanding moral considerations, ambitious climate policy in the Nordics have to be designed to contend with the fact that current global climate policies are second-best. In practice, this means 'doing the Nordic countries' share of a global effort to halt climate change' needs to be matched with efforts to gauge potential extra-territorial effects, and to design policies to manage negative, and exploit positive, spill-overs. As the authors point out, morality does not necessarily mean targeting only domestic emissions.

Understanding the drivers of cooperation is a central topic in economic research, and there is an active research agenda exploring the ramifications of notions like morality for climate policy. Greaker et al. provide a much needed normative perspective, and stimulates further research on these very important issues. 


\section{References}

Hoel, M. (1992), International Environmental Conventions: The Case of Uniform Reductions of Emissions, Environmental \& Resource Economics, 2(2), 141-159.

Trancik, J. E. (2014), Renewable Energy: Back the Renewables Boom, Nature News, 507(7492), 300-302.

Rodrik, D. (2014), Green Industrial Policy, Oxford Review of Economic Policy, 30(3), 469-491. 


\title{
Supply-Side Climate Policy in Norway
}

\section{Katinka Holtsmark ${ }^{1}$}

\begin{abstract}
To reach the Paris Agreement target - keeping global warming well below two degrees Celsius - there is a need for emission reductions on top of those already pledged. Norway has an ambitious climate policy targeting demand, while on the supply side exports of oil and gas contribute significantly to global emissions. This paper reviews the literature to assess whether a reduction in Norwegian oil extraction constitutes a cost-efficient policy to reduce global emissions. Key factors are the costs of reducing domestic supply and demand, the effect of domestic reductions on global emissions and the effect on the technological development.
\end{abstract}

Keywords: Climate policy, oil extraction, carbon leakage, technological development. JEL codes: Q30, Q50, Q54.

\footnotetext{
${ }^{1}$ Department of Economics, University of Oslo. Email: k.k.holtsmark@econ.vio.no. I am grateful to Lars Calmfors, Thorvaldur Gylfason, John Hassler, Klaus Mohn, Knut Einar Rosendahl and two anonymous referees for helpful comments and suggestions.
} 


\section{Introduction}

It can be seen as a paradox that relatively expensive measures are taken to reduce demand for fossil fuels in Norway, while at the same time an important share of Norwegian national income is from export of oil and natural gas. This lack of coherence between demand-side climate policy and the country's role as an international supplier of fossil fuels has gained attention also internationally (see for example The Economist 2017 and New York Times 2017).

This paper reviews the most relevant parts of the literature on supply-side climate policy, to assess whether a reduction in oil extraction in Norway would constitute an effective and cost-efficient policy to reduce global emissions of greenhouse gases.

In a global agreement putting a cap on aggregate greenhouse gas emissions, the distinction between demand- and supply-side climate policy would in principle not affect the resulting emission reduction. A reduction in supply would translate into the same reduction in demand and vice versa. Deep and committed international cooperation has, however, proven difficult to achieve. The Paris Agreement from 2015 has been celebrated due to its almost global participation. The agreement set an ambitious target of limiting global warming to well below two degrees Celsius above the pre-industrial level. However, according to the special report issued by the Intergovernmental Panel on Climate Change (IPCC 2018), the emission reductions implied by the participating countries' Nationally Determined Contributions (NDCs) are far from sufficient to reach this target. Moreover, the agreement does not imply a fixed future path for aggregate global emissions. Therefore, unilateral emission reductions in addition to those pledged in the Paris Agreement will not automatically be counteracted by increased emissions elsewhere. In fact, such unilateral reductions are necessary in order to prevent warming far above the target set in the agreement. In light of this, it is not clear that Norwegian policy makers should be satisfied with complying to the commitments that have already been made internationally. The need for emission reductions on top of the pledges made in the Paris Agreement is a starting point for this paper.

The policy choices already made by Norwegian policy makers suggest that the they put a positive value on global emission reductions 
in addition to the value of complying to international agreements. Norwegian policy makers have chosen to join the initiatives from the EU on climate policy: the European emission trading scheme (EU ETS), the emission reduction target for sectors not covered by EU ETS (The Effort Sharing Regulation) and the land-use change regulation (the LULUCF Regulation). In addition to these measures, which contribute to meeting the targets set together with the EU, several other measures are taken with the goal of reducing domestic and global emissions. Among these are the electrification of offshore installations and the United Nations forest conservation initiative (REDD+).

When a single country shall determine its climate policy, it must take into account potential reactions abroad to its domestic policy. Domestic policy might affect prices, technological development or even political pressure internationally, and hence the global effect on emissions is likely to differ from the domestic effect. Markusen (1975) showed how emission reductions in one country affect emission levels in other countries through changing international prices. Policy instruments - such as a carbon fee - that reduce emissions through lowering demand for fossil energy will decrease international fossil energy prices. The price decrease results in an increase in demand and consumption abroad, dampening the initial effect of the policy on global emissions. Similarly, policy instruments that reduce the supply of fossil energy - for example a fee on oil extraction - will increase the price, resulting in increased supply abroad. This counter-reaction is referred to as carbon leakage. ${ }^{2}$

The issue of carbon leakage has given rise to a literature in economics emphasizing the need for policies limiting both demand and supply when there is not full cooperation on climate policies internationally. Hoel (1994) shows that a combination of a fee on production and a fee on consumption is optimal (see also Bohm 1993). Fæhn et al. (2017) consider specifically the Norwegian setting and their results support Hoel's findings. Harstad (2012) further develops the arguments made by Hoel and shows that supply-side carbon leakage can be avoided completely if fossil energy resources can be bought internationally and conserved. Despite these findings, climate policy has mainly been focused on the demand side, both in Norway and

${ }^{2}$ See Rauscher (1997). 
internationally, with initiatives aimed at reduced deforestation as an important exception.

To determine the optimal combination of supply- and demand-side climate policy for a small country like Norway, the cost of reducing domestic emissions on either side, together with the respective effects on global emissions, must be determined. The literature reviewed in this paper suggests that the current Norwegian policy puts too little weight on supply-side climate policy, compared to an optimal combination.

The paper is structured as follows. Section 2.1 discusses the theoretical literature on the optimal combination of supply- and demand-side climate policy, while Section 2.2 moves on to the specific Norwegian case. Section 2.3 investigates how supply-side policy might affect technological development, while some aspects of optimal supply-side policy are discussed in Section 2.4. Some distributional aspects of supply-side policy are analysed in Section 2.5. Section 3 concludes the paper.

\section{Norwegian oil extraction and global emissions}

The decision to open up for exploration for oil and gas in new areas is made by the Norwegian government, while the decisions of how much to invest in exploration, and eventually how much to extract, are generally made by private firms. In the political process deciding on whether to open new areas for exploration, all expected costs and benefits, including externalities, should ideally determine the outcome. The expected future gains from possible findings should be weighed against all costs of exploration and extraction. A stylized version of the decision of how much to explore and extract is illustrated in Figure 1. The horizontal curve depicts the expected price, while the three remaining curves depict three different marginal extraction cost curves. The solid line is the private marginal cost of extraction - the only cost that will be taken into account by a profit-maximizing firm if there is no regulation or taxation. The extraction level resulting from the decision taken by a firm in this case is given by $x^{\text {private }}$. 
Figure 1 Optimal oil extraction with environmental externalities

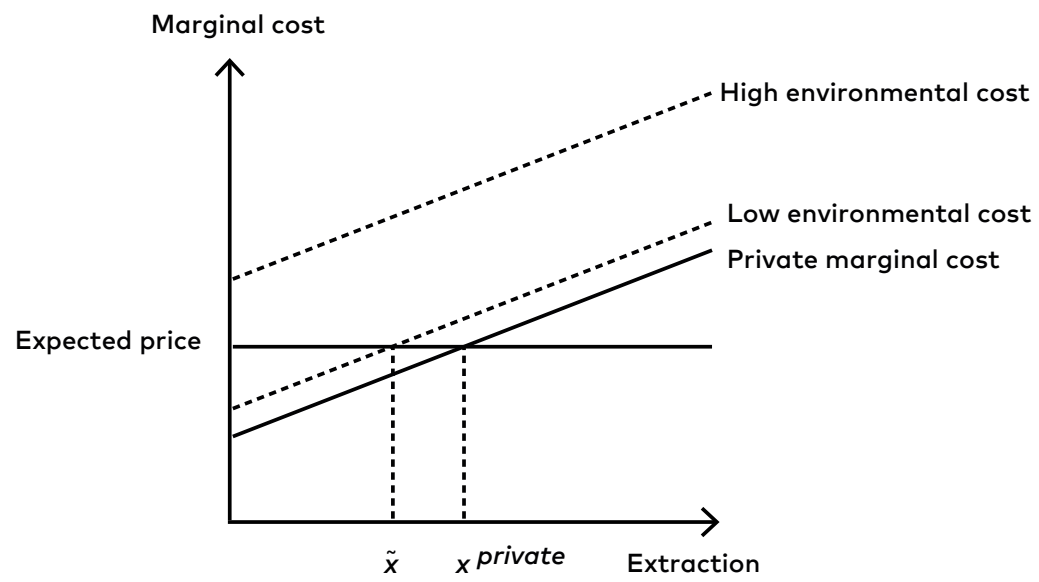

In the first-best solution, environmental costs are incorporated in the extraction decision, resulting in lower extraction. The curve denoted Low environmental costs is the social marginal cost curve given that there are relatively low environmental costs from extraction. This environmental cost implies that the socially optimal extraction level, $\tilde{x}$, is lower than $x^{\text {private }}$. Finally, the curve denoted High environmental costs represents the marginal extraction costs in a case where the environmental costs resulting from extraction are so high that there should be no extraction from this area.

There may be potentially important local environmental consequences of oil extraction in Norway, mostly connected to the potential for large oil spills and their effects on fish stocks, birds and biodiversity in general. ${ }^{3}$ For certain areas in Norway, with Lofoten, Vesterålen and Senja as the most prominent examples, it is clear that environmental-protection concerns have been consequential in postponing exploration, perhaps hindering exploration altogether.

The main focus of the paper is whether - or to what extent - reductions in Norwegian oil extraction reduce global emissions, and how the costs of these emission reductions compare to the costs of

\footnotetext{
${ }^{3}$ See for example Beyer et al. (2016) for a review of the research on environmental effects of the much-studied Deepwater Horizon oil spill in 2010.
} 
demand-side climate policy in Norway. As is clear from Figure 1, the decision of how much Norwegian oil extraction should be reduced depends crucially on how the costs associated with an increase in the atmospheric stock of greenhouse gases are evaluated. This paper considers mainly the optimal combination of supply- and demand-side climate policy and will therefore not attempt to put a number on the value of lower emissions. However, this issue is briefly discussed in Section 2.4 .

The paper focuses on supply-side policy limiting oil extraction. There is also substantial extraction of natural gas in Norway, which is left out of this analysis. There are two reasons for this choice. First, Norwegian gas exports are mainly used in the European market, and thus covered by the EU emission trading system (EU ETS). That has important implications for the effect of reduced gas extraction on global emissions and suggests that it can potentially be small or negligible. Second, the emissions from combustion of gas are relatively low compared to emissions from the main competitor, coal. However, in reality, the isolation of oil projects from natural gas can be challenging. Depending on the policy instrument chosen to implement the supply-side policy, it may or not may be possible. Section 2.4 discusses this somewhat further.

\subsection{Supply-side versus demand-side policy in theory}

In a binding global climate agreement, the difference between supply- and demand-side policies would not be relevant for the resulting emission reduction. The same emission reduction could be obtained either by reducing global extraction of fossil fuels or by lowering consumption. For an individual country, however, there can be important differences between the two approaches. Each country considering unilateral emission reductions must take into account potential changes in fossil fuel consumption outside its own boarders when the global effect of domestic policies is calculated. There is carbon leakage when emissions abroad increase as a consequence of domestic emission reductions.

Figure 2 illustrates supply-side carbon leakage - leakage resulting from reduced domestic extraction of fossil fuels - in the simplest possible way. A negative shift in oil supply in one country, shifting the global supply curve, will trigger increased oil supply in other countries, 
Figure 2 Carbon leakage following supply-side climate policy

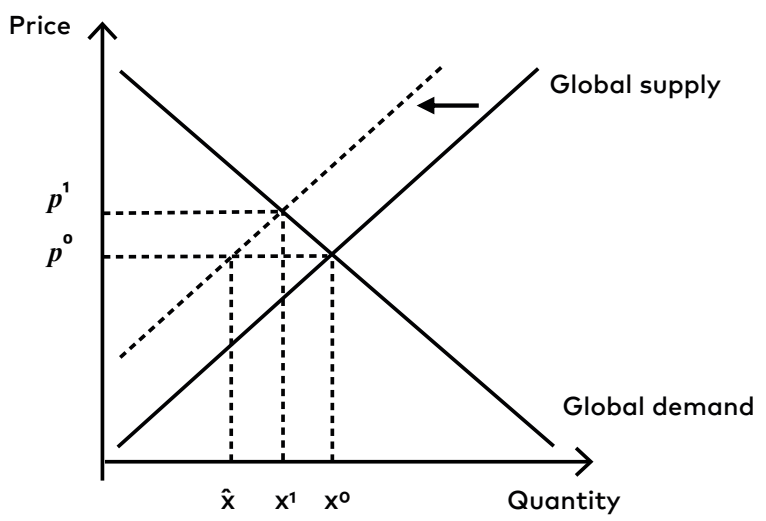

as long as the supply curve is not vertical. This happens because the domestic reduction in supply results in a price increase. The global equilibrium reduction in oil consumption will thus be smaller than the initial shift in supply. In the diagram, the initial negative shift in supply is from $x^{0}$ to $\hat{x}$, while the net reduction in the equilibrium quantity consumed is from $x^{0}$ to $x^{1}$.

The key determinants of the size of the carbon leakage are the slopes of the demand and supply curves. The steeper the global supply curve, the smaller the supply-side leakage. A very steep supply curve means that there are not many fields globally with marginal production costs close to the marginal field in the current equilibrium. Very elastic supply means that a small price increase triggers a large increase in global supply. If this is the case, the supply-side carbon leakage will be large. A steep demand curve also means large supply-side leakage because a shift in supply affects the price strongly. On the other hand, an elastic demand curve means that a negative supply shift results in a small price increase and thus weak incentives for other producers to increase supply, meaning low leakage.

In reality, the aggregate carbon leakage depends not only on the elasticity of supply and demand for oil, but also on the supply of and demand for other fossil fuels. Especially, the substitution between oil, coal and gas is important, because the three energy sources have different emission intensities. If reduced supply of oil leads consumers to increase their consumption of coal, the carbon leakage could 
be very large, and so on. These factors are taken into account by Fæhn et al. (2017) in their estimates discussed in Section 2.2.

One can also get carbon leakage through other channels, for example price changes for factors of production used in the oil industry. Moreover, firms that are subject to strict climate policy can relocate to other countries. Similar mechanisms are also in play on the demand side.

Hoel (1994) develops a theoretical framework and shows that there are three elements determining the optimal combination of supply- and demand-side climate policy. First, it is the cost of reducing demand and supply, respectively. The second element in Hoel's framework is whether the country in question is a net importer or a net exporter of fossil fuels. For a net importer, the price decrease that will follow from demand-side policy is beneficial, while the price increase following supply-side policy is costly. In contrast, for a net exporter the price change from supply-side policy is beneficial, while the effect of demand-side policy is costly. In this paper, I will not focus on this effect of the price changes generated from the different types of policy. However, it is worth keeping in mind that to the extent that these price changes are important, the channel supports supply-side policy over demand-side policy for a net exporter such as Norway.

The third element in the trade-off between supply-and demand-side policies in Hoel's framework is the size of the carbon leakage on either side. Hoel shows exactly how the carbon leakage is determined. As already discussed, it depends on the elasticity of supply and demand. If the global supply is relatively elastic compared to demand, the supply-side leakage will be more severe than the demand-side leakage. This will push the optimal combination of supply- and demand-side policy towards more reduction on the demand side.

\subsection{Supply-side versus demand-side policy in Norway}

Fæhn et al. (2017) investigate the size of the carbon leakage following both supply- and demand-side policy in Norway. They also investigate the costs of reduced extraction and compare these to the costs of reduced demand for fossil fuels. They can thus compare the costs of reducing global emissions by the same amount using demand- and supply-side policy, respectively. The theoretical frame- 
work follows Hoel (1994). Fæhn et al. consider the markets for oil, gas and coal. Consumers in all countries are assumed to be price takers, and demand is decreasing in the price in all three markets. In their main specification of the model, OPEC (Organization of the Petroleum Exporting Countries) is considered a strategic player maximizing profits, while the remaining suppliers in the oil market and the suppliers in the other two markets act competitively.

Fæhn et al. let a single country consider supply-side versus demand-side climate policy, taking the global climate policy as given. This country's government is assumed to choose policy to maximize its citizens' welfare given a target for global emission reductions that the country wants to meet. As in Hoel (1994), Fæhn et al. show that the share of the emission reduction target that should be made on the supply-side depends on three main factors: (i) the abatement cost curve for supply- and demand-side reductions, respectively; (ii) the net exports (or imports) of the country in question; and (iii) the relative carbon leakage from demand-and supply-side reductions. The second factor is disregarded in the numerical analysis because the effect is considered small.

In the numerical analysis, the authors consider the specific Norwegian case, and the purpose is to determine the abatement cost curves and the size of the carbon leakage to be able to deduce the optimal combination of supply- and demand-side climate policy. On the demand side, reduction in consumption of all fossil fuels is considered, while on the supply side the authors focus on oil extraction.

Fæhn et al. calculate the marginal abatement cost curve for demand-side policy by considering a uniform carbon price across all sectors of the economy. On the supply side, the marginal abatement cost curve is calculated by use of data on extraction costs for Norwegian fields over the period of 2009-11. The marginal costs curves are both illustrated in Figure 3. The curves show the marginal cost associated with reducing demand and supply, respectively, corresponding to a global reduction in emissions of the amount measured on the horizontal axis, without taking carbon leakage into account. The demand-side marginal abatement cost is substantially higher, for all abatement levels. Seen in isolation, these estimates suggest that the marginal cost of reducing emissions can be substantially lowered by including supply-side policy. 
Figure 3 Marginal abatement cost curves for supply- and demand-side climate policy for Norway, without accounting for carbon leakage

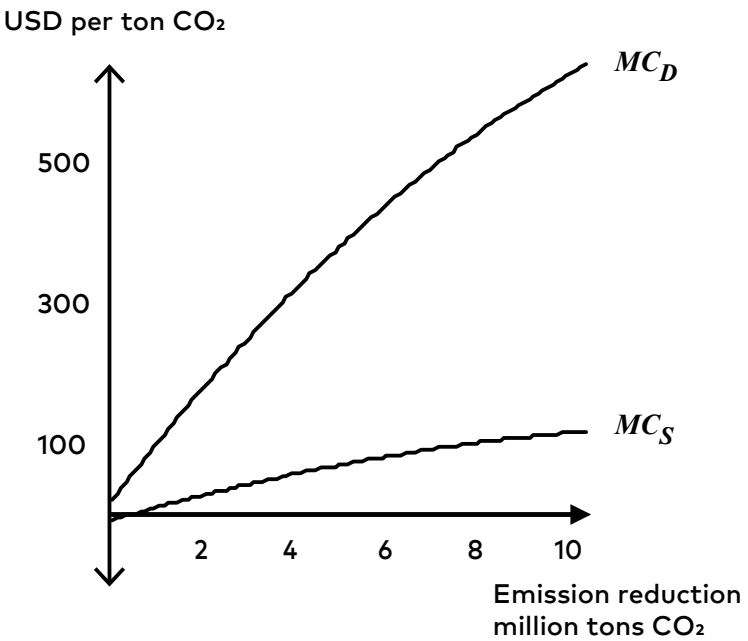

Source: Fæhn et al. (2017).

Next, Fæhn et al. consider the effect on global emissions of cuts in consumption or in oil extraction. The main drivers of their results are the assumed elasticities of supply and demand for each fuel. In the main simulation, the price elasticity of oil demand is assumed to be -0.5 , while the cross-price elasticities to gas and coal are assumed to be 0.08 . The supply elasticity for non-OPEC suppliers is set at 0.5. As OPEC optimizes profits, the central parameter is the marginal production cost, which is set at $45 \%$ of the oil price. Table 1 summarizes the findings on carbon leakage. The Net emission reduction gives the global emission reduction following a reduction in supply or demand in Norway corresponding to a one unit reduction of $\mathrm{CO}_{2}$. The table shows that the carbon leakage is substantially higher on the supply side than on the demand side. The differences in the carbon leakage arise despite the fact that the supply-and demand-side elasticities are the same. This is due to the different effects of supply- and demand-side policy in the markets for coal and gas, to the relatively low emissions in the Norwegian oil production process and to the behaviour of OPEC in the oil market. 
Table $1 \mathrm{Global}$ emission reductions following domestic cuts

\begin{tabular}{|l|l|l|}
\hline & Supply side & Demand side \\
\hline Gross emission reduction & 1 & 1 \\
\hline Net emission reduction & 0.35 & 0.68 \\
\hline
\end{tabular}

Source: Fæhn et al. (2017).

To summarize, Fæhn et al. (2017) find that the carbon leakage is substantially higher on the supply side than on the demand side. However, they also find that the marginal abatement cost is much lower - for a given abatement level - on the supply side than on the demand side. In sum, they find that reduction in oil extraction constitutes an important part in the optimal combination of supply- and demand-side climate policy in Norway. It is the increasing marginal abatement cost both on the supply side and on the demand side that implies that a combination of the two is optimal. In the Fæhn et al. paper, the result is summarized by the following example: Say Norway were to reduce emissions globally by 5 million tons of $\mathrm{CO}_{2}$ by 2020 , corresponding to about $10 \%$ of Norway's current domestic greenhouse gas emissions. Then the cost-effective combination of supply- and demand-side reduction would be $2 / 3$ on the supply-side (lower oil extraction) and 1/3 on the demand side (carbon pricing). Hence, the analysis suggests that supply-side policy should play a significant role in a cost-effective Norwegian climate policy. It is, however, important to note that there is considerable uncertainty regarding the size of all the effects and hence regarding the overall conclusion.

A few other papers also look at the effect on global emissions of unilateral supply-side policy. Metcalf (2016), and Erickson and Lazarus (2018) both consider reduction in the US oil production. Their findings are in line with those of Fæhn et al. (2017). ${ }^{4}$ It is clear, however, that the cost of both supply- and demand-side climate policy depend heavily on the choice of policy instrument. If the Norwegian government should consider changing its current policy, an

${ }^{4}$ See also Lazarus et al. (2015). 
assessment using new data and including the choice of policy instruments would provide useful information.

The main conclusion in Fæhn et al. (2017) does not change depending on whether they consider OPEC to behave competitively or not. This is partly contrasted by the findings of Böhringer et al. (2014, 2018). These papers both consider carbon leakage from demand-side climate policy, taking into account the strategic behaviour of OPEC in the oil market. They show that OPEC's response to EU's climate policy can be large, and hence including these responses can be important for the results. It is shown that if OPEC believes the EU is pursuing a quantity target, it will counteract a European carbon price reduction by reducing production. By doing this, the producers shift the rents from taxation from the EU to themselves. The authors show that the response might be sufficiently strong for the carbon leakage to be negative. Böhringer et al. (2018) show that these results do not necessarily hold when the size of the group of countries pursuing the climate policy changes. Moreover, it is demonstrated that the results depend on the composition of the group, and on the share of emission cuts that are done by reducing use of coal versus that of oil.

Although these results suggest that taking the strategic behaviour of OPEC into account is important, the findings rest on specific assumptions regarding the beliefs that OPEC have about other countries' policies. Moreover, the findings do not suggest that OPEC will counteract supply-side policies in a similar way. These policies raise the price, and although that can give OPEC a somewhat stronger incentive to increase production, it does not provide the strategic incentive to change the volume in order to seize rents.

There is a large literature in economics on the so-called green paradox, which is the situation that arises when policies aimed at reducing emissions result in earlier - and potentially higher - extraction. The term was originally used by Sinn (2008), who argued that an increase in the carbon fee over time gives owners of a non-renewable fossil resource an incentive to increase extraction. The model of Fæhn et al. (2017) is static and therefore would not pick up changes in emissions due to this paradox. Hagem and Storrøsten (2018) consider carbon leakage in a dynamic framework and show that when intertemporal carbon leakage is taken into account, the case for 
supply-side policy is strengthened. The reason is that commitment to future reductions in extraction by one country provides incentives for producers in other countries to delay extraction to increase overall profits. For similar reasons, both Hoel (2013) and Jensen et al. (2015) argue that supply-side policies are less likely to create the socalled green paradox that can result from demand-side policies.

Finally, Fæhn et al. (2017) do not consider potential effects of demand-and supply-side climate policy on the technological development. The next section looks more closely into this issue.

\subsection{Can supply-side policy change the technological development?}

This section discusses some important insights from the economics literature that are relevant for understanding how a shift from demand-side to supply-side climate policy can potentially affect technological development. If the development of either renewable or fossil technologies are affected by changes in the global demand or supply of fossil fuels, the long-run consequences of demand- and supply-side climate policy will be different from the short-run consequences discussed so far.

The term carbon lock-in refers to the possibility that technological, institutional and economic factors prevent shifts from carbon-intensive to low-carbon systems. Such a lock-in can be created if production methods require large up-front investments, for example in infrastructure, while production subsequently becomes very cheap. If the required up-front investments are large enough, or if investments are required from several different actors at the same time, the investments may not be made and that may prevent the shift to a low-carbon system. ${ }^{5}$ A potential contribution to carbon lock-in could be that there is learning by doing in exploration and extraction of oil. The concept of learning by doing has been used and discussed in economics for many decades. ${ }^{6}$ If a larger fossil energy sector results in more rapid development of knowledge and technology in this sector, higher global extraction of fossil fuels could over time make the shift to renewable energy more and more costly.

${ }^{5}$ See for example Erickson et al. (2015) or Unruh (2000) for discussion of carbon lock-in.

${ }^{6}$ Arrow (1962) and Lucas (1988) are important early contributions. 
It is possible that the development of technology in Norway for keeping emissions low in the extraction process of oil and gas have been strengthened by learning-by-doing processes. These emissions have been subject to carbon pricing since 1991, and the aggregate price on emissions from this sector is today approximately 75 USD per ton $\mathrm{CO}_{2}$ according to Nasjonalbudsjettet 2019. When looking into the emission intensities in extraction for different oil producing countries, Fæhn et al. (2017) find that the emission intensity in Norway is below a third of the average for other non-OPEC producers. Similar conclusions are drawn by Masnadi et al. (2018). They compare emissions from extraction and transportation of crude oil in different producer countries. According to their estimates, Norway is in the bottom six countries when measuring the volume-weighted average crude oil upstream greenhouse-gas intensities, with an intensity below one third of the countries at the top of the list (Algeria and Venezuela). ${ }^{7}$

Similar learning-by-doing processes might be in play in sectors where fossil energy is used as a factor of production and might hence affect the demand for and use of fossil energy. However, it is not obvious whether more rapid technological development in sectors with high fossil energy use leads to more or less overall dependence on fossil fuels. On the one hand, better or more efficient technologies for using fossil fuels may result in fossil energy being used for new purposes, used in new sectors of the economy etc., because fossil energy becomes a more competitive factor of production. Higher fossil fuel prices resulting from this process will increase global extraction, and the technological development results in higher emissions. On the other hand, the result of the technological development may as well be that fossil fuels become more redundant, prices fall, and extraction and emissions go down, due to increased efficiency in energy use.

An important contribution to the understanding of how the development of green technology is determined - and how it can affect the shift from fossil to renewable energy - is presented by Acemoglu (2002). The framework is further developed by Acemoglu and co-authors in more recent papers (Acemoglu et al. 2012 and Acemoglu et

\footnotetext{
7 See also Gavenas et al. (2015) for a detailed account of emissions resulting from extraction of oil and gas in Norwegian fields.
} 
al. 2016). These papers can also shed light on potential differences between supply- and demand-side climate policy.

Acemoglu (2002) shows that one key to understanding how technological development affects the demand for a given factor of production, is the potential for this factor to replace other factors of production in the economy. If a factor in production can be used more efficiently due to technological development, demand for this factor will drop if the excess supply cannot easily be used in alternative ways. On the contrary, more efficient technologies can lead to an increase in the demand for this factor if the substitutability between this factor and others is high, because the factor can then be used in new sectors of production.

Acemoglu also considers the determinants of directed technical change. In a stylized model with two production factors he defines the complementary technology for each of the two factors as technology that is used in combination with this factor and increases its marginal productivity. He finds that both the price of a factor and the market share of this factor determine how rapidly its complementary technology is developed. A high factor price means that the willingness to pay for a technology that saves the use of the factor increases. More widespread use of the factor in the economy also implies higher demand for complementary technology. Which of these channels that is most important in determining the direction of the technological development depends on how easily the two factors of production can substitute each other in the economy.

The hypothesis of a causal relationship between energy prices and the development of energy-saving technology is supported by several empirical findings, for example by Newell et al. (1999). They find that when energy prices are high, there is a more rapid development in energy-saving technology. Similarly, Popp (2002) uses US patent data from 1979-94 and shows that there is more innovation in energy efficiency in periods with high energy prices. These studies support Acemoglu's hypothesis that a higher fossil fuel price will, in isolation, trigger quicker technological development in the fossil energy sector. However, they do not provide sufficient information to 
conclude whether the price channel is more or less important than the market size channel for fossil fuels. ${ }^{8}$

The mechanisms identified by Acemoglu (2002) and developed in Acemoglu et al. $(2012,2016)$ can help our understanding of how supply- and demand-side climate policy may affect the technological development and over time the value of fossil energy relative to other factors in the economy. Reduced global supply of fossil energy will mechanically reduce the use of fossil energy globally. This implies, all else equal, less investment in development of fossil energy complementary technology. However, reduced supply increases fossil energy prices, which implies larger investments in these technologies. If fossil energy can easily be substituted by other factors of production in the economy, the market size effect dominates, and supply-side climate policy will shift the technological development away from the fossil energy sector. In this case, the technological development will over time contribute to lower demand for fossil energy because other factors of production - with more efficient technologies - will gradually replace it in the production process. If fossil energy, on the other hand, cannot easily be substituted, the price effect will dominate, and the technological development will be shifted towards the fossil energy sector. However, in this case, the more rapid technological development will make fossil energy redundant over time. Hence in both cases, supply-side climate policy will change the technological development in a way that contributes to lower long-term carbon leakage through decreasing the price and value of fossil fuels.

Reduced global demand for fossil energy will affect the global use in the same way as the supply-side reduction discussed above. This implies lower investment in fossil energy complementary technology. At the same time, at least outside the country or region considered, reduced demand lowers fossil energy prices, which affects investment in the same way. Hence, demand-side climate policy will direct the technological development towards other sectors of the economy independently of whether fossil energy can easily be replaced by other factors. If fossil energy can be easily replaced, this technological development will lead to decreased fossil energy demand over time, and the short-run effect of demand-side climate policy

${ }^{8}$ For more recent empirical studies, see also Hassler et al. (2012) and Aghion et al. (2016). 
is strengthened over time. Because the price effect and the market-size effect work in the same direction, the effect is potentially larger than the similar long-run effect of supply-side policy. However, if fossil energy cannot easily be replaced, the relatively slow technological development in the fossil energy sector will contribute to keeping the demand for fossil energy high, counteracting the shortrun effect of the policy.

Given the mechanisms identified by Acemoglu and coauthors, sup-

ply-and demand-side policy can thus be expected to affect the technological development in different ways. Moreover, the technological development can contribute to a higher or a lower long-run carbon leakage, depending on how easily fossil energy can be substituted by other factors of production in the economy. The above discussion may suggest that the long-run effect of supply-side policy is strengthened by the technological development both in the case where fossil fuel can be easily substituted and when it cannot. For demand-side policy, it is only in the case of high substitutability that the long-run effect on emissions is strengthened. In the case where fossil energy cannot easily be replaced by other factors of production, the long-run effect of demand-side policy may be smaller than the short-run effect.

All else equal, the above discussion thus suggests a stronger weight on supply-side climate policy if the global production technology is such that there are no close substitutes to fossil energy. Whether or not this is the case differs across sectors, countries and fossil energy sources, and it is ultimately an empirical question that the economics literature does not yet give a clear answer to.

\subsection{Optimal supply-side climate policy in Norway}

So far, the paper has mainly focused on the optimal combination of supply-and demand-side climate policy. This section will briefly discuss some important trade-offs that must be made in order to determine how large the overall emission reductions made by use of supply-side policy should be. Furthermore, the section will discuss some of the policy instruments that can be used to implement supplyside climate policy. 
Ideally, the total cost of reducing oil extraction should be weighed against the value of reducing global emissions, of reducing other environmental effects of extraction and of reducing other externalities, if any. Both the short- and the long-run effect on global emissions of a domestic reduction in extraction should be taken into account. According to the findings of Fæhn et al. (2017), the marginal cost of reducing extraction in Norway should reflect policy makers' willingness to pay for a reduction of global emissions. Here, however, none of the potential local environmental externalities from extraction are taken into account, neither are the potential long-run effects of reduced extraction discussed in Section 2.3.

It is not obvious how Norwegian policy makers' willingness to pay for a reduction in global emissions should be evaluated. However, it is clear that shifting Norwegian governments to some extent value reductions in greenhouse gas emissions globally. As a starting point for measuring this value, one could look at the carbon prices that are implemented on the demand side in the Norwegian economy. ${ }^{9}$ The carbon prices used in the different sectors in the Norwegian economy range from 0-700 NOK per ton carbon dioxide (including the EU ETS permit price). This is equivalent to about USD 0-85. The highest prices are faced by domestic air traffic, and offshore oil and gas installations (Norwegian Government 2018). But, as is clearly illustrated by Fæhn et al. (2017), there is carbon leakage also on the demand side. For a uniform fee on all sectors outside the EU ETS, they estimate the global emission reduction to be about $2 / 3$ of the domestic reduction. If the policy makers take into account the demand-side carbon leakage the implemented carbon prices indicate the willingness to pay for only $2 / 3$ of a ton, in terms of global emission reductions. Moreover, a number of climate policy measures taken on the demand side in the Norwegian economy have costs that are estimated to be far above the highest implemented carbon prices. As one example, the cost of emission reductions as a consequence of the subsidies to electrical cars is calculated to be

\footnotetext{
9 Norway faces commitments on domestic emission reductions both towards the EU and according to the Paris Agreement. The demand-side measures that are taken can in principle be the result only of these commitments. Supply-side policies will not - given the current system of calculating emission reductions - contribute to the fulfilment of these commitments. However, as Norway is already taking on costs to reduce global emissions in addition to these commitments, for example through the REDD+ initiative (initiative for reducing emissions from deforestation and forest degradation in developing countries), it can be argued that international commitments do not seem to be the only reason for the measures.
} 
almost 600 USD according to a Norwegian expert panel (NOU 2015:15).

In sum, the demand-side measures that are implemented by Norwegian policy makers imply a substantial willingness to pay for global emission reductions. Moreover, Greaker and Rosendahl (2017) suggest that there are non-negligible amounts of oil to be extracted in Norway in the coming years with relatively low profits. They investigate the Impact Assessment that was made before the Licensing Decision in 2016 for exploration in Barents Sea South-East and find that the economic profitability of exploration can turn out to be low. A fee on emissions reflecting the actual willingness to pay for emission reductions could therefore potentially mean a substantial reduction in extraction of Norwegian oil.

The parts of the Norwegian Continental Shelf (NCS) where there is currently oil and gas extraction activity consist of the Barents Sea in the North, the Norwegian Sea and the North Sea. In the north, the NCS reaches into the Arctic Ocean. According to the Norwegian Ministry of Petroleum and Energy, $45 \%$ of the estimated resources on the NCS have already been extracted. In the Northern part of the NCS there are large areas that are yet unexplored. For obvious reasons, there is considerable uncertainty regarding the remaining resources. But they are unlikely to be negligible..$^{10}$ Norwegian supply-side climate policy must in some way target these resources that are not yet extracted.

There are two main approaches to reducing exploration and extraction on the NCS. The first approach is to reduce the number and size of new areas that are opened for exploration. The second approach is to make changes to the tax system in order to weaken the incentives for exploration and extraction facing private firms, for example by putting a fee on each ton of oil extracted. In the following, I will briefly discuss some benefits and challenges with each of these approaches. $^{11}$

The decision of opening up a new area on the NCS for exploration for petroleum resources is made by the Norwegian government. The

\footnotetext{
${ }^{10}$ See Norwegian Petroleum (2018).

${ }^{11}$ See also Lazarus et al. (2015) and Fæhn et al. (2018) for further discussion on implementation of supply-side climate policy. 
political resistance towards reducing the pace at which new areas are opened for exploration - and eventually starting extraction from fewer new fields - can potentially be lower than that towards large changes to the tax system in the oil and gas sector. In the political process of opening up new areas for exploration, the decision makers will also be able to include local environmental externalities in the equation. These externalities will typically not be accounted for if a fee on extraction is included.

Both the environmental externalities, the extraction cost levels and public opinion suggest that the Northern areas of the NCS are the best candidates for being left unopened. Reserves in the Arctic can be especially well-suited. In the Arctic, extreme conditions require new and better technology. The effect of extraction on the technological development discussed in Section 2.3 can therefore be more important in the Arctic than in other areas. ${ }^{12}$

A fee on extraction could be an effective instrument to reduce oil extraction. Such a fee could in principle be implemented at any point in time. In fields that are already open, the fee would influence the extraction level, especially for late-life fields with relatively high extraction costs. For fields in earlier stages the fee would also affect the investment decisions, including the exploration decisions for fields that are not yet found. In addition to the cost-effectiveness in the extraction reduction that would result from implementing a fee on extraction, an advantage of this approach would be the possibility to differentiate between extraction of oil and natural gas.

However, there could be other types of costs connected to implementing a fee on extraction. The tax system in the Norwegian petroleum sector is designed to be neutral in the sense that the tax system itself should not distort the investment decisions made by firms. ${ }^{13}$ The tax system has served the Norwegian economy well. The high profit tax rate facing firms extracting Norwegian oil and gas (78\% in total) makes sure that a large share of the revenues from

\footnotetext{
${ }^{12}$ Similar mechanisms, and the consequences for exploration for fossil fuels in the Arctic, are discussed by Leroux and Spiro (2018).

${ }^{13}$ Note that according to the Norwegian Ministry of Finance the current system is not fully neutral and encourages too high investments in the oil and gas extraction sector (see e.g. note 7, page 135 in the National Budget 2019. Changing the system to achieve full neutrality will therefore decrease extraction and thus also global emissions.
} 
these natural resources goes to the Norwegian population. Furthermore, a neutral tax system ensures that the investment level is not affected by the high tax rate, and therefore that socially desirable investments are not prevented from being carried out. If changes to the tax system can undermine the support for the system itself, this may be an additional cost that the policy makers must take into account.

There are also other possible approaches to reduction in global supply of fossil fuels than those that have been the main focus of this paper. One of them is the possibility of leasing or buying fossil fuel reserves abroad to conserve them (see Harstad 2012, and Eichner and Pethig 2017). There are at least two benefits to this approach. Firstly, because the total number of reserves that can be preserved is larger than the number of domestic reserves alone, the abatement cost curve on the supply side will be less steep. Secondly, as is demonstrated by Harstad (2012), by removing the right segment of reserves from the global supply curve, the problem of carbon leakage on the supply side can be eliminated. If the global supply curve for fossil fuels is partly vertical due to preservation of all reserves with costs within a given range, changes in domestic emissions will not result in increased supply even if the price increases. ${ }^{14}$

The benefits and challenges of the different policy instruments must be evaluated carefully by policy makers considering implementing supply-side climate policy. The chosen policy instruments will also affect the optimal combination of supply- and demand-side climate policy.

\subsection{Distributional effects of supply-side climate policy}

Distributional aspects of different climate policies can be considered at least along two dimensions - across individuals or groups at one point in time and across generations. Furthermore, there will be distributional impacts of supply-side climate policy both within Norway and in the rest of the world. There might also be links between distributional consequences - or perceived distributional consequences - of different policies and the political feasibility of these policies. More generally, there are ethical aspects to climate

\footnotetext{
14 Some important challenges to international trade in conservation of fossil fuels are discussed by Harstad (2016).
} 
policy that have not been discussed above. This section first briefly discusses the distributional aspects of supply-side climate policy. Then, it investigates how a stronger focus on supply-side policy can potentially strengthen international cooperation on climate policy, and finally mentions some ethical aspects to supply-side policy in Norway.

Demand-side climate policy will lower global fossil fuel prices, benefiting countries that import fossil fuels, or more generally, consumers of fossil fuels. Lowered Norwegian oil extraction, on the other hand, will increase the global oil price, and to some extent also the prices of gas and coal. These price changes benefit oil-exporting countries and harm consumers. It can be argued that the global distributional effects are more favourable for demand-side climate policy.

However, if a larger weight on supply-side climate policy can lower the overall cost of emission reductions and therefore result in a larger and more rapid decline in emissions, the overall distributional effect can be quite different. The most dramatic consequences of climate change are likely to be faced by poor countries with weak ability to adapt to the changes; hence these countries will benefit the most from larger emission reductions.

Within Norway, there will also be differences between the distributional consequences of supply- and demand-side policy. Through the tax system, a large share of the profits from the oil sector would go to the Norwegian state. Thus, the distribution of costs in terms of lower profits cannot be expected to be very different from that of other climate policy instruments that are paid over the state budget, such as green technology subsidies. However, lower extraction will to a larger extent than demand-side policies hit a specific group, namely those employed in the oil sector. At the same time, a larger share of the burden of supply-side policies is put on firms, relative to consumers.

The differences in distributional consequences, or even the mere perception of the distributional consequences of the different policies, might in some countries act in favour of supply-side policy in terms of political feasibility. Green and Denniss (2018) argue that supply-side climate policy will be more politically feasible, and hence applied to a larger extent, than demand-side policy. Firstly, they argue 
that the benefits from supply-side policies are more easily seen and accepted by voters, partly because there are clear co-benefits such as less local air pollution, in addition to the climate benefit. The benefit from less climate change can be difficult to apprehend because it is spread out both geographically and across generations. Secondly, the authors argue that the costs of supply-side policy are likely to be perceived as both smaller and more fairly distributed than the costs from demand-side policy. The argument is that voters believe the fossil fuel firms themselves are taking a larger part of the total cost. In Norway, however, supply-side climate policy seems to have very low support in the population, and the arguments of Green and Denniss (2018) are perhaps not very relevant. An important explanation for this might be the redistribution of income from oil and gas extraction through the tax system.

It can also be argued that a stronger focus on supply-side climate policy could improve on the current situation in international cooperation on climate policy. Collier and Venables (2014) argue that a planned and sequenced closing of global coal industry, where the richest countries move first, could create sufficient moral pressure on countries and governments to induce much more stringent climate policy worldwide. They argue that for countries to be affected by such moral pressure, there must be a mechanism in play that puts the moral responsibility on only one or a few countries at any point in time. As soon as these countries comply with the closing scheme, the responsibility is moved. The sequence must be perceived as fair, and it could be important that rich countries are first on the list. Although these authors consider closing of the coal industry, the same argument could potentially be made for oil.

A somewhat similar argument is put forward by Green (2018) who argues that reduced extraction in some countries can contribute to the strengthening of global moral norms that can in turn induce other countries to strengthen their climate policies. Finally, if a rich and well-functioning state like Norway is not willing to bear the cost of reducing its oil extraction, it would clearly to some extent weaken the existing moral pressure - if any - on other countries to do so. Moreover, it seems intuitively clear that it will be especially difficult to raise the necessary political support to implement large and disruptive changes in energy use globally if the international distribution of costs is perceived as very unfair by many. Rich countries - such 
as Norway - taking on higher costs, for example through strong supply-side measures can potentially reduce this unfairness. ${ }^{15}$

\section{Conclusions}

The Paris Agreement from 2015 set an ambitious target for the world's climate policy: To keep global warming well below 2 degrees Celsius above the pre-industrial level. However, the contributions to the necessary emission reductions pledged by the participating countries are far from sufficient to reach the target. In light of this, all countries should consider additional measures to reduce global emissions. Norway has an ambitious climate policy targeting the demand side, in terms of carbon pricing and alternative energy subsidies. On the supply side, however, Norwegian exports of oil and gas contribute significantly to global carbon emissions.

This paper has reviewed relevant parts of the economics literature and discussed the effects of a shift in Norwegian climate policy towards reduced oil extraction. Both the theoretical and the empirical literature suggest that the optimal combination of supply- and demand-side policy in Norway would include reduced extraction as an important component. In the short run, the optimal combination of supply- and demand-side policy is determined by the costs of domestic emission reductions on either side together with the respective degrees of carbon leakage. In the long run, the effect of the different policies on technological development, international institutions and political processes are among the factors that should also be taken into account. Furthermore, there are different distributional aspects of the different policies.

\section{References}

Acemoglu, D. (2002), Directed Technical Change, Review of Economic Studies, 69(4), 781-809.

Acemoglu, D., Aghion, P., Bursztyn, L. and Hemous, D. (2012), The Environment and Directed Technical Change, American Economic Review, 102(1), 131-66.

${ }^{15}$ See also Kartha et al. (2018) for further discussion. 
Acemoglu, D., Akcigit U., Hanley, D. and Kerr, W. (2016), Transition to Clean Technology, Journal of Political Economy, 124(1), 52-104.

Aghion, P., Dechezleprêtre, A., Hémous, D., Martin, R. and Van Reenen, J. (2016), Carbon Taxes, Path Dependency, and Directed Technical Change: Evidence from the Auto Industry, Journal of Political Economy, 124(1), 1-51.

Arrow, K. (1962), The Economic Implications of Learning by Doing, Review of Economic Studies, 29(3), 155-173.

Beyer, J., Trannum H. C., Bakke, T., Hodson, P. V. and Collier, T. K. (2016), Environmental Effects of the Deepwater Horizon Oil Spill: A Review, Marine Pollution Bulletin, 110(1), 28-51.

Bohm, P. (1993), Incomplete International Cooperation to Reduce $\mathrm{CO}_{2}$ Emissions: Alternative Policies, Journal of Environmental Economics and Management, 24(3), 258-271.

Böhringer, C., Rosendal, K. E. and Schneider, J. (2018), Unilateral Emission Pricing and OPEC's Behaviour, Strategic Behavior and the Environment, 7, 225-280.

Böhringer, C., Rosendahl, K. E. and Schneider, J. (2014), Unilateral Climate Policy: Can OPEC Resolve the Leakage Problem?, The Energy Journal, 35(4), 79-100.

Collier, P. and Venables, A. J. (2014), Closing Coal: Economic and Moral Incentives, Oxford Review of Economic Policy, 30(3), 492-512.

Eichner, T. and Pethig, R. (2017), Trade in Fossil Fuel Deposits for Preservation and Strategic Action, Journal of Public Economics, 147, 50-61.

Erickson, P., and Lazarus, M. (2018), Would Constraining US Fossil Fuel Production Affect Global $\mathrm{CO}_{2}$ Emissions? A Case Study of US Leasing Policy, Climatic Change, 150, 29-42.

Erickson, P., Kartha, S., Lazarus, M. and Tempest, K. (2015), Assessing Carbon Lock-in, Environmental Research Letters, 10(8), 084023.

Fæhn, T., Hagem, C., Lindholt, L., Mæland, S. and Rosendahl, K. E. (2017), Climate Policies in a Fossil Fuel Producing Country Demand Versus Supply Side Policies, The Energy Journal, 38(1), 77-102.

Fæhn, T., Asheim, G., Greaker, M., Hagem, C., Harstad, B., Hoel, M., Lund, D., Nyborg, C., Rosendahl, K. E. and Storrøsten, H. (2018), Parisavtalen og oljeeksporten, Samfunnsøkonomen, 3, 39-50.

Gavenas, E., Rosendahl K. E. and Skjerpen T. (2015), CO2-emissions from Norwegian Oil and Gas Extraction, Energy, 90, 1956-1966.

Greaker, M. and Rosendahl K. E. (2017), Petroleum Activity in Barents Sea South-East - Climate, Economics and Employment, Retrieved January 3, 2019, from http://www.greenpeace.org. 
Green, F. (2018), Anti-fossil Fuel Norms, Climatic Change, 150(1), 103-116.

Green, F., and Denniss, R. (2018), Cutting with Both Arms of the Scissors: The Economic and Political Case for Restrictive Supply-side Climate Policies, Climatic Change, 150(1), 73-87.

Hagem, C., and Storrøsten, H. B. (2018), Supply- versus Demand-side Policies in the Presence of Carbon Leakage and the Green Paradox, The Scandinavian Journal of Economics, 121(1), 379-406.

Harstad, B. (2012), Buy Coal! A Case for Supply-side Environmental Policy, Journal of Political Economy, 120(1), 77-115.

Harstad, B. (2016), The Market for Conservation and Other Hostages, Journal of Economic Theory, 166, 124-151.

Hassler, J., Krusell, P. and Olovsson, C. (2012), Energy-saving Technical Change, NBER Working Paper No. 18456, National Bureau of Economic Research.

Hoel, M. (1994), Efficient Climate Policy in the Presence of Free Riders, Journal of Environmental Economics and Management, 27(3), 259-274.

Hoel, M. (2013), Supply Side Climate Policy and the Green Paradox, CESifo Working Paper Series No. 4094, CESifo Group Munich.

Intergovernmental Panel on Climate Change (IPCC) (2018), Global Warming of $1.5^{\circ} \mathrm{C}$, Retrieved January 3, 2019, from https://www.ipcc.ch/ sr15/.

Jensen, S., Mohlin, K., Pittel, K. and Sterner, T. (2015), An Introduction to the Green Paradox: The Unintended Consequences of Climate Policies, Review of Environmental Economics and Policy, 9, 246-265.

Kartha, S., Caney, S., Dubash, N. K. and Muttitt, G. (2018), Whose Carbon is Burnable? Equity Considerations in the Allocation of a 'Right to Extract', Climatic Change, 150(1), 117-129.

Lazarus, M., Erickson, P. and Tempest, K. (2015), Supply-side Climate Policy: The Road Less Taken, SEI Working Paper No. 2015-13, Stockholm Environment Institute.

Leroux, J., and Spiro, D. (2018), Leading the Unwilling: Unilateral Strategies to Prevent Arctic Oil Exploration, Resource and Energy Economics, 54, 125-149.

Lucas, R., Jr. (1988), On the Mechanics of Economic Development, Journal of Monetary Economics, 22(1), 3-42.

Markusen, J. R. (1975), International Externalities and Optimal Tax Structures, Journal of International Economics, 5(1), 15-29. 
Masnadi, M. S., El-Houjeiri, H. M., Schunack, D., Li, Y., Englander, J. G., Badahdah, A., Monfort, J., Anderson, J. E., Wallington, T. J., Bergerson, J. A., Gordon, D., Koomey, J., Przesmitzki, S., Azevedo, I. L., Bi, X. T., Duffy, J. E., Heath, G. A., Keoleian, G. A., McGlade, C., Meehan, D. N., Yeh, S., You, F., Wang, M. and Brandt, A. R. (2018), Global Carbon Intensity of Crude Oil Production, Science, 361(6405), 851-853.

Metcalf, G. (2016), The Impact of Removing Tax Preferences for U.S. Oil and Gas Production: Measuring Tax Subsidies by an Equivalent Price Impact Approach, NBER Working Paper No. 22537, The National Bureau of Economic Research.

Nasjonalbudsjettet 2019 Meld. St. 1 (2018-2019), Norwegian government

Newell, R. G., Jaffe, A.B. and Stavins, R. N. (1999), The Induced Innovation Hypothesis and Energy-saving Technological Change, Quarterly Journal of Economics, 114(3), 941-975.

New York Times (2017), Both Climate Leader and Oil Giant? A Norwegian Paradox, by Somini Sengupta, June 17.

Norwegian Petroleum (2018), The Petroleum Resources, Retrieved December 3, 2018, from https://www.norskpetroleum.no/petroleumsressursene/ ressurser-per-havomrade/.

NOU 2015:15, Sett pris på miljøet - Rapport fra grønn skattekommisjon, Norwegian Government.

Popp, D. (2002), Induced Innovation and Energy Prices, American Economic Review, 92(1), 160-180.

Rauscher, M. (1997), International Trade, Factor Movements, and the Environment, Oxford: Oxford University Press.

Sinn, H. (2008), Public Policies Against Global Warming: A Supply Side Approach, International Tax and Public Finance, 15(4), 360-394.

The Economist (2017), The Economist explains: Why Norway may leave $\$ 65 \mathrm{bn}$ worth of oil in the ground, August 29.

Unruh, G. C. (2000), Understanding Carbon Lock-in, Energy Policy, 28(12), 817-830. 


\section{Comment on K. Holtsmark: \\ Supply-Side Climate Policy in Norway}

\section{Thorvaldur Gylfason ${ }^{1}$}

I am particularly pleased to see the author of this excellent paper distinguish so clearly between user fees and taxes, a distinction that is too often ignored in economic discourse with deleterious policy consequences. Too often, economists talk carelessly about easing congestion by taxing traffic, thereby weakening their own argument for efficient and fair market-based environmental policy by unnecessarily empowering those who, for ideological or other reasons, oppose taxes in any shape or form. The councils of London, Oslo, Singapore, Stockholm, and other cities do not tax traffic. They levy fees on vehicles in motion to ease traffic congestion just as they have for a long time, without fanfare, levied parking fees on stationary vehicles.

In the context of environmental policy, fees and charges are more appropriate terms than taxes because, like rents, fees and charges are typically levied in exchange for the provision of specific services - such as the permission to utilize public roads and parking spaces. In the same way, what many economists continue to call resource taxes should rather be referred to as user fees or resource depletion charges (Gylfason and Weitzman 2003). Some opponents of fees still insist on calling them taxes precisely to incite opposition to regulation by price.

The common failure to accept correct word usage has strengthened the position of those who oppose fishing fees in Iceland, for example. The result is that still, after 35 years of fisheries regulation by quantity rather than by price, only ten percent of Iceland's fishing rent accrues to the right owner, the Icelandic nation, while 90 percent of the rent accrues to vessel owners who, in return, finance political parties, newspapers, and more (Gylfason 2018). It was not until after the financial collapse of 2008 that the International Monetary Fund announced publicly its support for fishing fees in Iceland. Thereafter, the IMF and the World Bank jointly

1 University of Iceland. 
announced their advocacy of carbon pricing as the correct reaction to climate change (Lagarde and Kim 2015). Pigou would be pleased.

This having been said, the paper offers a useful review of the literature on supply-side climate policy in Norway, emphasizing that demand-side regulation of carbon dioxide emissions needs to be supported by appropriate policy action on the supply side, that is, by reduced oil extraction. Specifically, the paper shows how simple demand-and-supply analysis can be applied to suggest optimal geographical patterns of pollution abatement where different estimates of demand and supply elasticities lead to different patterns of abatement. Suggestive as they are, such economic calculations can only provide partial answers, however. Developing countries, including China and India, can with considerable justification say to the rest of us: Elasticities are not enough. You have been polluting the world's climate much longer than we have so you have to carry a correspondingly heavy share of the load. Economic and political considerations need to be balanced. The paper clearly helps to inform on the economic part of the policy challenge.

This is important because climate change has become one of the most pressing political and moral issues of our time. The evidence suggests overwhelmingly that we have little time left to lose. Norway is a small country and hence a price taker in world markets, accounting for only two percent of the world's oil production and 0.1 percent of the world's carbon dioxide emissions. Stronger climate policy in Norway, therefore, can have only small direct effects on world climate. Even so, indirectly, due to its singularly impressive record of oil management, including the world's largest Sovereign Wealth Fund, and one of the largest shares of electric vehicles ${ }^{2}$, Norway can lead by example, exercising welcome and well-earned moral authority in the field of environmental policy.

230 percent of all new cars in Norway are now electric compared with two percent in Europe and one to two percent in the United States. 


\section{References}

Gylfason, T. and Weitzman, M. L. (2003), Icelandic Fisheries Management: Fees versus Quotas, CEPR Discussion Paper No. 3849, Center for Economic Policy Research.

Gylfason, T. (2018), From Natural Resources to Human Rights, in Ems, E. and Gylfason, T. (eds.), Prosperity Through Trade and Structural Reform, Festschrift in honour of Per Magnus Wijkman, Stockholm: Dialogos,.

Lagarde, C. and Yong Kim, J. (2015), The Path to Carbon Pricing, Project Syndicate, 19 October. 


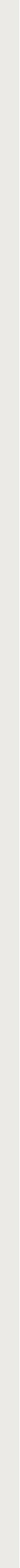




\section{Comment on K. Holtsmark: \\ Supply-Side Climate Policy in Norway}

Klaus Mohn ${ }^{1}$

Although the consensus of climate policies remains dominated by a demand-side perspective, supply-side policies have gained increasing interest and attraction among academic researchers over the last years. Nevertheless, a breakthrough for supply-side climate policies among politicians and policy-makers is still pending (Lazarus and van Asselt 2018). A summary of findings and potential applications is therefore highly relevant for policy design of oil-exporting countries, and in particular for countries where the ambitions for climate policies go beyond domestic emissions.

For a reasonable set of supply and demand elasticities, research so far has established that unilateral supply-side policies are likely to contribute to reduced emissions of greenhouse gases on a global scale (e.g., Fæhn et al. 2017), in particular if coalitions of cooperating producers of fossil fuels can be formed (Harstad 2012). Supply-side policies also have the advantage of addressing the issue of fossil fuels directly at the core, thereby reducing the risk of compensating behavior among producing companies and countries, as exemplified by the so-called green paradox (e.g., Sinn 2015). Finally, a supply-side approach to climate policies can also be justified by recent research on readjustment and strategic industrial policy (e.g., Acemoglu et al. 2018).

Holtsmark's paper provides a good review of these branches of economic research, with reflections of the academic discussion of world market elasticities of supply and demand, carbon leakage in space and time, and path dependence in policies and technological development. For a policy journal, however, the question is how such an update could help in actual formation of policies for oil-exporting countries. On the one hand, the justification for supply-side policies is increasingly well established in the economic literature. On the other hand, this is not the case when it comes to implications of theoretical insights for actual design of climate policies in

\footnotetext{
${ }^{1}$ University of Stavanger Business School. Email: klaus.mohn@mhh.no.
} 
oil-exporting countries. For a policy journal, the time has therefore come for the research question of supply-side climate policies to shift from why to how. This call is also the main motivation for my comment to Holtsmark's paper, and the exposition below is developed accordingly.

My point of departure is a brief review of the licensing and decision system of Norwegian oil and gas fields, to initiate a discussion on the specific points of interference for supply-side policies. I go on to review the current outlook for Norwegian oil and gas production, and discuss how current and expected production might respond to climate-related policy measures. I then briefly discuss how adjustments to the tax system might potentially serve the purpose of climate policy ambitions, keeping distortions at a minimum. Finally, I present some concluding remarks.

Academic research on supply-side climate policies often leave the impression that policy makers of oil-producing countries have tools at their hand that enable them to fine-tune the volumes of oil and gas extraction on a continuous basis. Obviously, this is not the case, and least of all for Norway, where oil exploration, development and production is subject to long-term profit maximization by competitive oil companies in a stable and market-based regulatory environment (Mohn 2008, Norwegian Petroleum Directorate 2014). Licensing policies form the point of departure not only for oil resource management in Norway, but also for the decision process of oil companies. Once the exploration licenses are awarded in regular licensing rounds, oil companies are basically left on their own, with a sequence of investment decisions to consider (see Figure 1), and without further direct government involvement. Large field developments do require approval by the Norwegian parliament. However, this milestone for field project progress is currently more of a formality, and no project plans have been rejected over the last couple of decades. With substantial uncertainty around exploration results, development lags, cost and prices, this means that the control by government over ultimate extraction rates is very limited. 


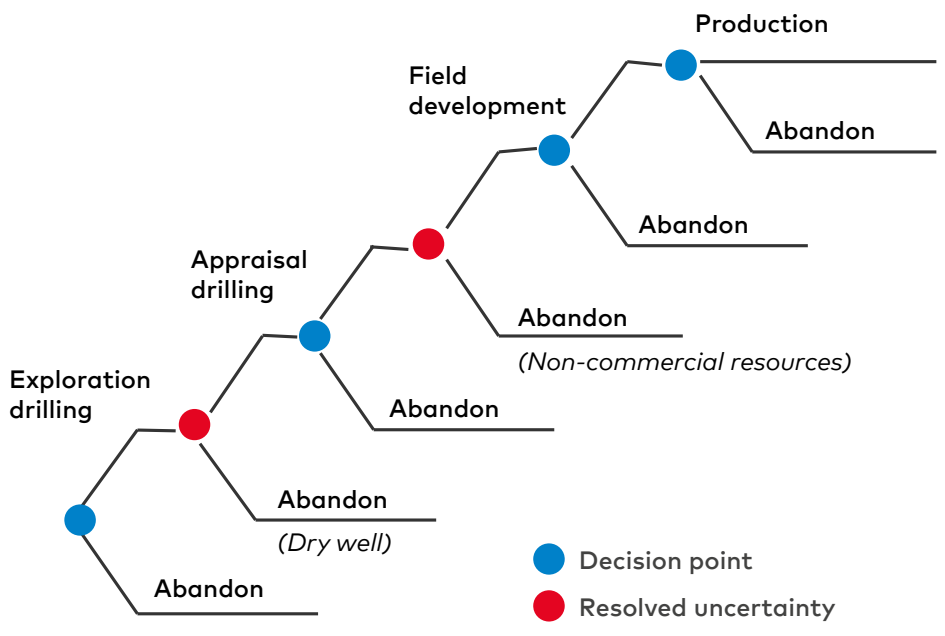

Once oil companies have engaged in exploration and development activities, their interest is to recover their capital expenditures as fast as possible, and to maximise cash flows to enhance investment returns. Cost of exploration and development play an important part in the optimization process among the companies. However, project design in terms of scale, and not least the pace of development and production is as important. The reason is that capital recovery is closely connected to the ramp-up and pace of production. Once the production capacity is determined, front-loading of production will enhance the net present value of the field project. This also means that any interference to delay development or production will imply a reduction in net present values and investment returns. Any attempts by politicians to intervene in oil company decisions, through direct intervention or adjustments to the taxation system, will leave shareholder value at risk and potentially also put the stability of the regulatory environment in jeopardy.

At any point in time, it should also be noted that oil and gas production is the output from a portfolio of field projects, involving fields at all stages of development. As illustrated in Figure 2, this means that a significant part of the outlook for oil and gas production is 
Figure 2 Oil and gas production in Norway

Oil and gas production

Million boe per day

5

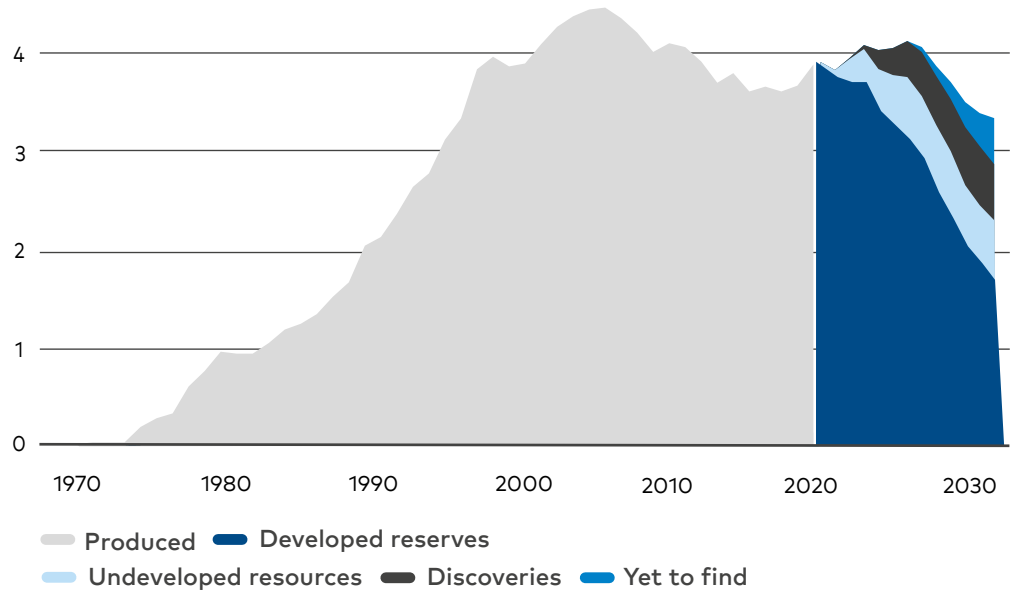

Source: Norwegian Petroleum Directorate.

based on investments that already are sunk. This begs the question which of these categories is the most relevant for supply-side climate policies? Policies to reduce oil production from oil fields in the early phase of production, where the initial investment is yet to be recovered, is particularly costly - and controversial. The same goes for oil fields that are currently under development. That leaves us with oil discoveries where the final investment decision is still pending, as well as exploration activities. Policies directed at these oil fields are less costly, as the bulk of capital expenditures are yet to be sunk, and less controversial, because their revenues are more distant. The implication is that supply-side climate policies will be costly and controversial for a large majority of current production volumes, and therefore more viable for production in the more distant future, i.e., exploration activities and field projects with marginal profitability.

A tax on extraction could potentially have an effect even on fields that are currently producing, as some of these would possibly have 
to close down earlier if their revenues were subject to an extra volume tax. Some marginal late-life projects to increase oil recovery could potentially also be stopped by an extraction tax. However, unless the tax was substantial, the total impact on production rates would be very modest. An additional tax on extraction would also interfere with an already complex system of petroleum taxation. Specifically, an extraction tax motivated by climate policy ambitions would threaten attractive qualities of symmetry and neutrality of the Norwegian system of petroleum taxation. Still, as the Norwegian petroleum sector is ageing rapidly and climate concerns are looming, there could be reasons for a review of the Norwegian system of petroleum taxation in light of contemporary challenges of resource scarcity and climate change. ${ }^{2}$

The current consensus for a concentration of climate policies on the demand side of the market for fossil fuels is challenged by recent economic research, calling for a closer consideration also of supply-side measures to reduce global carbon dioxide emissions. Textbook theory clearly suggests that withdrawal of production will have an effect on the oil price. The ultimate impact on demand and emissions is an empirical question. Supply-side climate policies also have the advantage that compensating behavior among oil producers might be avoided, thereby arresting the so-called green paradox. Finally, the transition to a low-carbon society will involve readjustment and restructuring in oil-producing countries, which can be supported by a supply-side perspective on climate policies.

At the end of the day, the combination of demand-and supply-side approaches should be determined by comparisons of their marginal costs, taking the full spectrum of side effects into consideration. In the meantime, resistance prevails against measures to limit oil and gas production, in particular from countries and companies who already invested heavily in this industry. These controversies imply that any interference with the timing and pace of extraction in a market-based industry environment will have to be evaluated carefully before implementation. Restraining production from field projects where capital has just been sunk has a high cost, both to

\footnotetext{
2 See Osmundsen et al. (2015), Berg et al. (2018), and Davis and Lund (2018) for recent discussions of the Norwegian system of petroleum taxation.
} 
companies and society. Minor adaptations of the taxation system and adjustments to restrain exploration activities therefore stand out as the most interesting candidates for further examination if a supply-side approach to climate policies were to gain additional ground.

\section{References}

Acemoglu, D., Akcigit, U., Alp, H., Bloom, N. and Kerr, W. (2018), Innovation, Reallocation, and Growth, American Economic Review, 108(11), 3450-3491.

Berg, M., Bøhren, Ø., and Vassnes, E. (2018), Modelling the Response to Exogenous Shocks: The Capital Uplift Rate in Petroleum Taxation, Energy Economics, 69, 442-455.

Davis, G. A. and Lund, D. (2018), Taxation and Investment Decisions in Petroleum, The Energy Journal, 39(6), 189-208.

Fæhn, T., Hagem, C., Lindholt, L., Mæland, S., and Rosendahl, K. E. (2017), Climate Policies in a Fossil Fuel Producing Country, The Energy Journal, 38(1), 77-102.

Harstad, B. (2012), Buy coal! A Case for Supply-side Environmental Policy, Journal of Political Economy, 120(1), 77-115.

Lazarus, M., and van Asselt, H. (2018), Fossil Fuel Supply and Climate Policy: Exploring the Road Less Taken, Climatic Change, 150(1-2), 1-13.

Mohn, K. (2008), Efforts and Efficiency in Oil Exploration: A Vector Error-Correction Approach, The Energy Journal, 30(4), 53-78.

Norwegian Petroleum Directorate (2014), Facts 2014: The Norwegian Petroleum Sector, Norwegian Ministry of Petroleum and Energy.

Osmundsen, P., Emhjellen, M., Johnsen, T., Kemp, A. and Riis, C. (2015), Petroleum Taxation Contingent on Counter-factual Investment Behavior, The Energy Journal, 36(SI1), 195-213.

Sinn, H. W. (2015), The Green Paradox: A Supply-side View of the Climate Problem, Review of Environmental Economics and Policy, 9(2), 239-245. 
Nordic Council of Ministers

Nordens Hus

Ved Stranden 18

DK-1061 Copenhagen K

www.norden.org

CLIMATE POLICIES IN THE NORDICS

Nordic Economic Policy Review 2019

Climate Policies in the Nordics

Lars Calmfors and John Hassler

International Climate Policy

in the Post-Paris Era

Naghmeh Nasiritousi and

Karin Bäckstrand

Comment by Torben Mideksa

Comment by Åsa Romson

National Climate Policies and the

European Emissions Trading System

Frederik Silbye and

Peter Birch Sørensen

Comment by Svante Mandell

Comment by Saara Tamminen
Are Climate Policies in the Nordic

Countries Cost-Effective?

Björn Carlén and Bengt Kriström

Comment by Peter K. Kruse-Andersen

Comment by Åsa Löfgren

Global Impact of National Climate

Policy in the Nordic Countries

Mads Greaker, Rolf Golombek

and Michael Hoel

Comment by Mark Sanctuary

Supply-Side Climate

Policy in Norway

Katinka Holtsmark

Comment by Thorvaldur Gylfason

Comment by Klaus Mohn 